\title{
NBSIR 76-1058
}

\section{Performance of Mobile Homes - Summary Report}

\author{
J. H. Pielert \\ W. E. Greene, Jr. \\ L. F. Skoda \\ W. G. Street
}

Office of Building Standards and Codes Services

Center for Building Technology

Institute for Applied Technology

National Bureau of Standards

Washington, D. C. 20234

April 1976

Final Report

\section{Prepared for}

Office of Policy Development and Research

Division of Energy, Building Technology and Standards

U.S. Department of Housing and Urban Development

Washington, D. C. 20410 



\section{PERFORMANCE OF MOBILE HOMES - SUMMARY REPORT}
J. H. Pielert
W. E. Greene, Jr.
L. F. Skoda
W. G. Street

Office of Building Standards and Codes Services Center for Building Technology Institute for Applied Technology National Bureau of Standards

Washington, D. C. 20234

April 1976

Final Report

Prepared for

Office of Policy Development and Research

Division of Energy, Building Technology and Standards U.S. Department of Housing and urban Development Washington, D. C. 20410

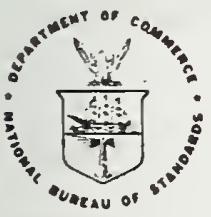

\section{U.S. DEPARTMENT OF COMMERCE, Elliot L. Richardson, Secrotary James A. Baker, III, Under Secretary Dr. Betsy Ancker-Johnson, Assistant Secretery for Scionce and Technology} NATIONAL BUREAU OF STANDARDS, Emeot Ambler, Acting Diroctor 



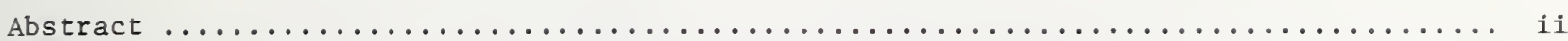

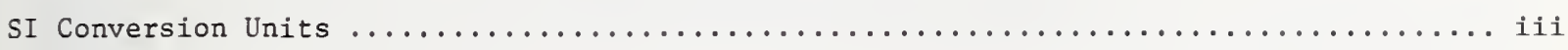

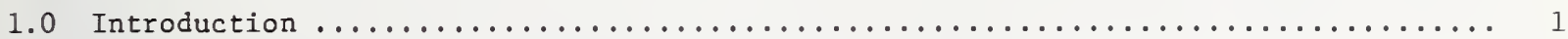

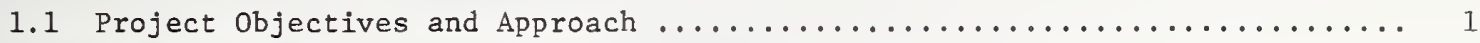

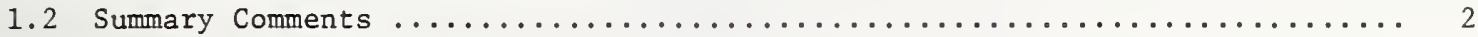

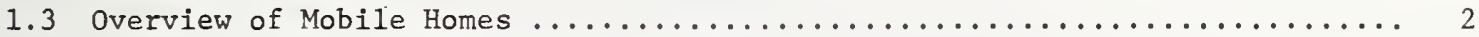

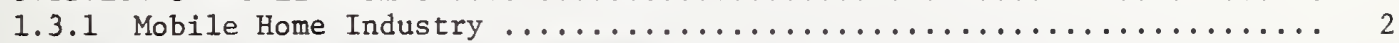

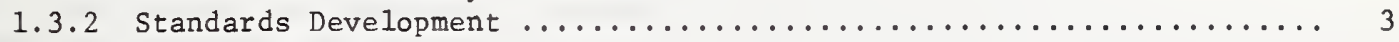

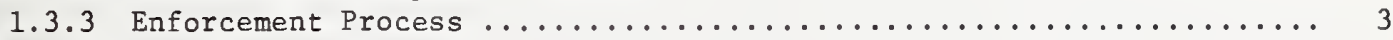

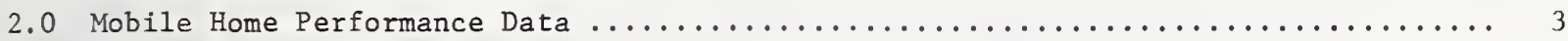

2.1 Mobile Home Performance Data Acquisition .......................

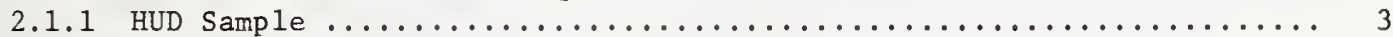

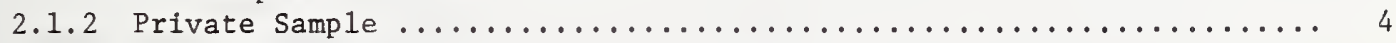

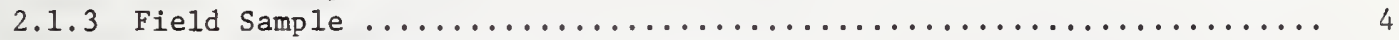

2.2 Mobile Home Performance Data Characteristics ...................... 4

2.2.1 Problem Data Characteristics ............................ 5

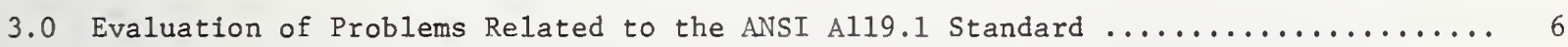

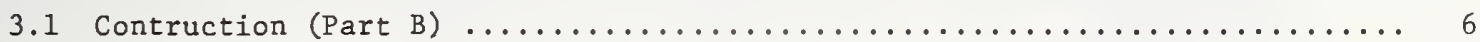

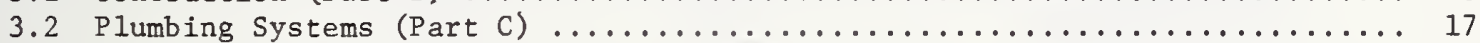

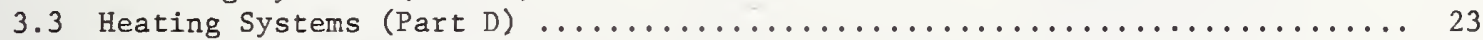

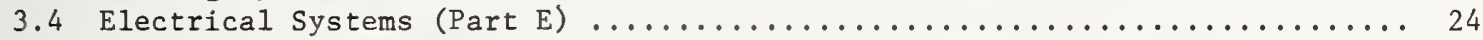

4.0 Evaluation of Problems Related to the Mobile Home Enforcement Process .......... 26

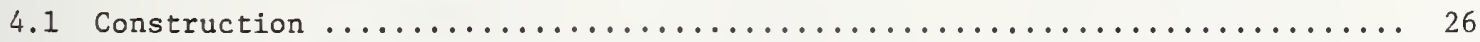

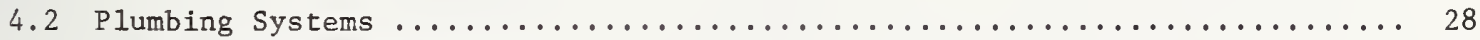

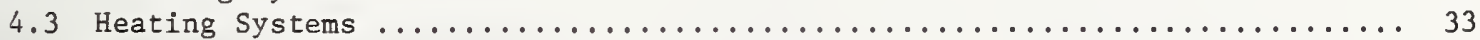

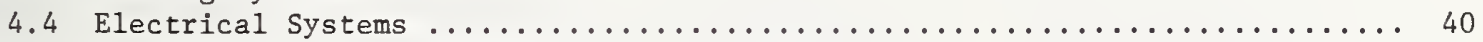

5.0 Durability Related Problems ................................... 50

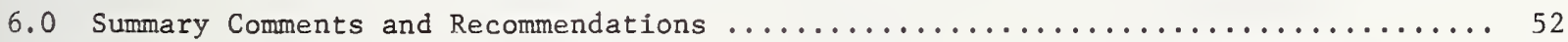

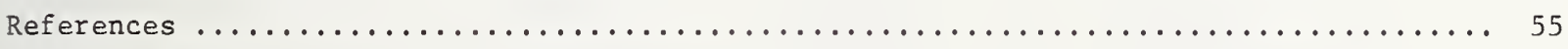

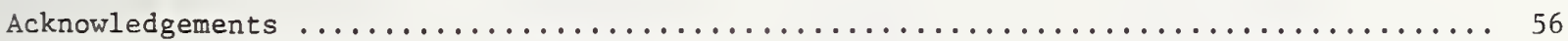

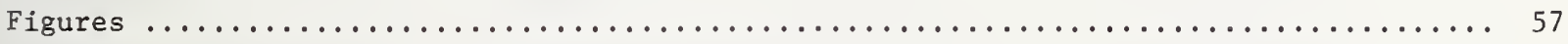

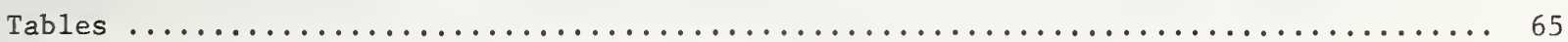

Appendix A - Organization and Use of the Problem Summation Tables ................ 89

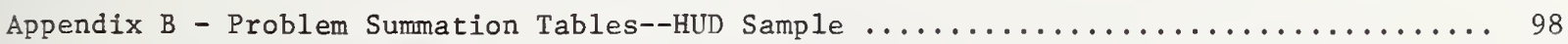

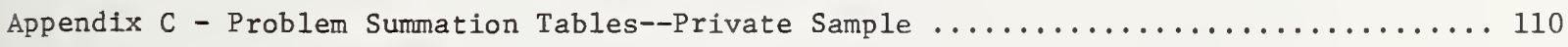

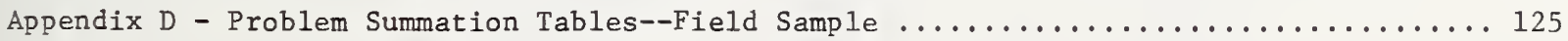




\begin{abstract}
This project was sponsored at the National Bureau of Standards by the Department of Housing and Urban Development, Office of Policy Development and Research, Division of Energy, Building Technology and Standards, with the objective of documenting mobile home performance problems and relating them to possible inadequacies in the AisI Al19.1 Standard for Mobile Homes and the mobile home enforcement process. Additionally, the durability of mobile home components was a study objective for potential use in mortgage insurance evaluation. The mobile home performance data were obtained for 4,105 mobile homes, categorized and related to the project objectives. This summary report is the last of a series of four project reports. It documents the project approach, results of the various tasks, and presents conclusions and recommendations. This was a problem-oriented study and did not attempt to document the many areas of satisfactory mobile home performance.

Key Words: Computer Techniques; Construction; Enforcement Process; Housing; Hurricane Agnes; Mobile Homes; Mobile Home Parks; Performance Data; Regulatory Process; Standards
\end{abstract}




\section{SI CONVERSION UNITS}

In view of the present accepted practice in this country for building technology, common U.S. units of measurement have been used throughout this publication. In recognition of the position of the United States as a signatory to the General Conference on Weights and Measures, which gave official status to the metric SI system of units in 1960, appropriate conversion factors have been provided in the table below. The reader interested in making further use of the coherent system of SI units is refered to:

NBS SP330, 1972 Edition, "The International System of Units"

E380-72 ASTM Metric Practice Guide (American National Standard Z210.1)

Table of Conversion Factors to Metric (S.I.) Units

\begin{tabular}{|c|c|c|c|}
\hline $\begin{array}{l}\text { Physical } \\
\text { Quantity }\end{array}$ & $\begin{array}{l}\text { To Convert } \\
\text { From }\end{array}$ & To & Multiply By \\
\hline Length & $\begin{array}{l}\text { inch } \\
\text { foot }\end{array}$ & $\begin{array}{l}\text { meter } \\
\mathrm{m}\end{array}$ & $\begin{array}{l}2.54 * \times 10^{-2} \\
3.048 * \times 10^{-1}\end{array}$ \\
\hline Area & $\begin{array}{l}\text { inch }^{2} \\
\text { foot }^{2}\end{array}$ & $\begin{array}{l}\mathrm{m}^{2} \\
\mathrm{~m}^{2}\end{array}$ & $\begin{array}{l}6.4516 * \times 10^{-4} \\
9.290 \times 10^{-2}\end{array}$ \\
\hline Volume & $\begin{array}{l}\text { inch }_{3}^{3} \\
\text { foot }\end{array}$ & $\mathrm{m}^{3}$ & $\begin{array}{l}1.639 \times 10^{-5} \\
2.832 \times 10^{-2}\end{array}$ \\
\hline Temperature & Fahrenheit & Celsius & $t_{c}=\left(t_{0} F^{-32) / 1.8}\right.$ \\
\hline Temperature difference & Fahrenheit & Kelvin & $\Delta t^{\circ} \mathrm{K}=\left(\Delta t_{{ }_{\mathrm{F}}}\right) / 1.8$ \\
\hline Pressure & Inch $\mathrm{Hg}\left(60^{\circ} \mathrm{F}\right)$ & newton $/ \mathrm{m}^{2}$ & $3.377 \times 10^{3}$ \\
\hline Mass & $1 \mathrm{bm}$ & $\mathrm{kg}$ & $4.536 \times 10^{-1}$ \\
\hline Mass/unit area & $1 \mathrm{bm} / \mathrm{ft}^{2}$ & $\mathrm{~kg} / \mathrm{m}^{2}$ & 4.882 \\
\hline Moisture content rate & $1 \mathrm{bm} / \mathrm{ft}{ }^{2}$ week & $\mathrm{kg} / \mathrm{m}^{2} \mathrm{~s}$ & $8.073 \times 10^{-6}$ \\
\hline Density & $1 \mathrm{bm} / \mathrm{ft} \mathrm{t}^{3}$ & $\mathrm{~kg} / \mathrm{m}^{3}$ & $1.602 \times 10^{1}$ \\
\hline Thermal conductivity & $\mathrm{Btu} / \mathrm{hr} \mathrm{ft}^{2}\left({ }^{\circ} \mathrm{F} / \mathrm{in}\right)$ & $\frac{\mathrm{W}}{\mathrm{mK}}$ & $1.442 \times 10^{-1}$ \\
\hline U-value & $\mathrm{Btu} / \mathrm{hr} \mathrm{ft}^{2 \circ} \mathrm{F}$ & $\frac{W}{m^{2} K}$ & 5.678 \\
\hline Thermal resistance & ${ }^{\circ} \mathrm{F} /\left(\mathrm{Btu} / \mathrm{hr} \mathrm{ft}{ }^{2}\right)$ & $\mathrm{K} /\left(\mathrm{W} / \mathrm{m}^{2}\right)$ & $1.761 \times 10^{-1}$ \\
\hline Heat Flow & $\mathrm{Btu} / \mathrm{hr} \mathrm{ft}^{2}$ & $\mathrm{~W} / \mathrm{m}^{2}$ & 3.155 \\
\hline
\end{tabular}

*Exact value; others are rounded to fourth place. 


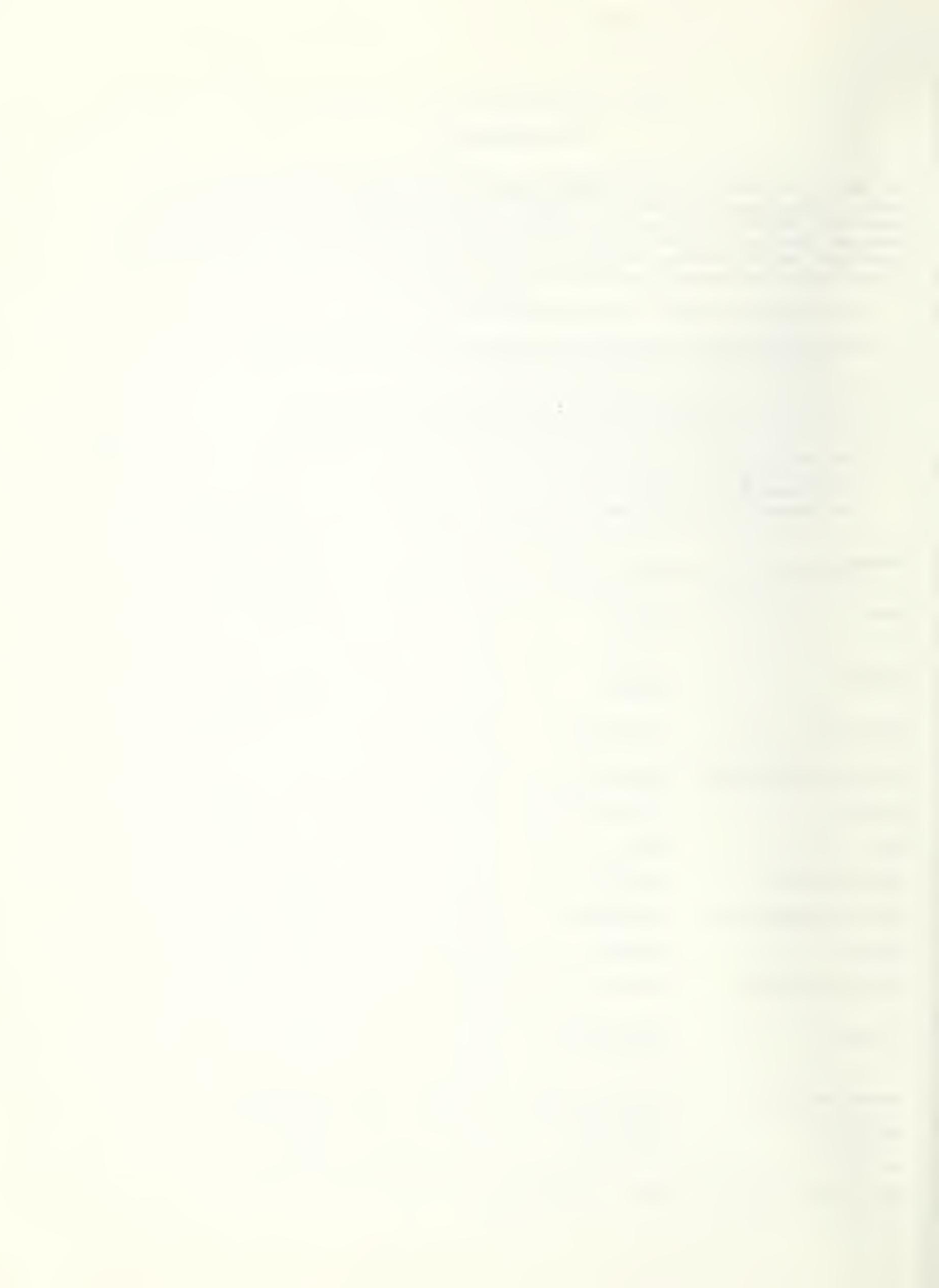


1.1 PROJECT OBJECTIVES AND APPROACH. Recently, many individuals and groups have questioned the effectiveness of mobile homes in providing safe, adequate and low-cost shelter. Although life-safety aspects such as fire safety and susceptiblity to wind damage receive the most publicity, functional characteristics appear to be of broader concern to mobile home owners. It is recognized that the mobile homes supply process (manufacturing, transportation, sitingl/) differs greatly from conventional site-built housing and is partly responsible for some of their unique performance problems. Unfortunately, there is a limited amount of organized documentation of these performance problems, making it difficult to pinpoint what aspect of the mobile home supply process may be in need of change or improvement.

To respond to this recognized deficiency of information, a project funded at the National Bureau of Standards (NBS) by the Office of Policy Development and Research of the Department of Housing and Urban Development (HUD) was structured around the following objectives:

1. Identification and documentation of significant mobile home performance problems.

2. Determine the relationship of these problems to provisions of the ANSI Al19.1 Standard for Mobile Homes [1] 2 .

3. Determine the relationship of these problems to the mobile home enforcement process (plan review, design certification, plant inspection.)

4. Relate problem data to the durablitity of mobile home components (mortgage insurance concern.)

5. Identification of needed areas of research relative to the mobile home supply process.

The project scope and the unique data acquisition and analysis methodology developed to accomplish the objectives are presented in reference [2]. The project was organized into two principal tasks. Task I was designed to collect and analyze existing mobile home performance data relative to the structural, electrical, heating and plumbing systems. These data, presented in reference [3], were obtained from Federal and state agencies responsible for the regulation of mobile homes, consumer groups, and owner of mobile homes. Task II involved the field inspection of mobile homes to determine the causes and consequences of the performance problems found during Task I. The results of Task II are documented in reference [4].

This report summarizes the results of the project where the data obtained in Tasks I and II are synthesized to determine if a relationship exists between the identified problems, the ANSI Al19.1 Standard, and the mobile home enforcement process. The mobile home problems documented can be generally related to (1) malfunctioning components (structural, electrical, mechanical and plumbing) resulting in conditions affecting health and safety and adversely impacting on the longevity of the unit, (2) inadequate durability of components, and (3) poor design and construction practice. Routine maintenance concerns are also included but are tabulated separately.

This is a problem oriented study which does not reflect the many mobile home owners who are happy with the performance of their units. The number of mobile homes included is small when compared to the total number of mobile homes in use in the United States. While the results of this study may not be statistically applicable to mobile homes in general, it is believed that the problems documented are representative of those encountered with mobile homes in this country.

1/ Siting encompasses placement and leveling the mobile home on its foundation, installation, steps, skirting and connection of utilities.

2/ References are listed at end of paper. 
1.2 SUMMARY COMMENTS. The data presented in this report and in references [2], [3] and [4] represent a significant base of information from which the project objectives can be addressed. While the study does include data on 4105 mobile homes, this number is small when compared to the total number of units now occupied in the United States. It is felt that the problems identified in the study are typical of mobile homes now in use; however, it is not intended that the data can be statistically extrapolated to the total mobile home population in the United States.

Problem data were separated into five different categories; (1) inadequacies or omissions in the ANSI Al19.1 Standard for Mobile Homes, (2) deficiencies in the mobile home enforcement process, (3) routine maintenance problems, (4) mechanical/electrical appliance problems, and (5) miscellaneous or undefined problems. Sections $3.0,4.0$ and 5.0 present detailed discussion of the various problems in these categories.

Problems in the ANSI Al19.1 category are organized within the construction, plumbing, heating and electrical systems. The major problem areas in the construction system were rain leaks, failure of interior paneling attachment, inadequate bottomboard durability, corrosion of exterior fasteners, and excessive metal roof membrance flexibility (roof rumble.) Plumbing problems included questionable quality of fixtures, loose fixture connections, watertightness of shower enclosures, and freezing of piping. Heating and electrical problems consisted of questionable location of furnace thermostat and inadequate fastening of electrical boxes.

The mobile home enforcement category included problems which indicated deficiencies in the mobile home regulatory process (plan and specification review, certification, and in-plant inspection). In the construction area, this included instances where thermal insulation in the walls and roof were found missing or improperly installed. Typical problems in the plumbing area included piping water leaks, inadequate grade (slope) of drain pipe, water heater relief valve drain problems, and corrosion of piping. Heating system problems included use of unlisted or inadequately installed components, inadequate accessibility of appliances, joints of supply and vent systems not airtight, inadequate separation of combustion air system, inadequate marking of appliances and improper flexible gas connector usage. Electrical problems included lack of durability and long-term performance of devices, improper location of receptacles and devices, inadequate number of branch circuits, and problems related to workmanship such as insufficient cable support, inadequate cable protection, etc.

Problems related to durability of mobile home components are discussed in Section 5.0 which includes most of the items in the Mechanical/Electrical Appliance category.

Many specific recommendations are made in the body of the report for revisions to the ANSI A119.1 Standard and improvements in the mobile home enforcement process. The following areas were identified for additional mobile home work.

A. The effect of transportation and site set-up.

B. The effect of wind forces both during transportation and on site.

C. Durability of mobile home components.

D. Application of the performance approach to the development of mobile home standards.

E. Pre-occupancy inspection of mobile home after set-up.

\subsection{OVERVIEW OF MOBILE HOMES}

1.3.1 Mobile Home Industry. Mobile homes have risen to a position of importance in housing in the United States representing approximately one-fifth of all new housing starts in each of the past five years - 1970 through 1974 (Figure 1). Considering only the single family housing classification, mobile homes have provided 30 percent of the total during the same period (Figure 2). The production of mobile homes increased dramatically from 103,700 units in 1960 to 566,920 in 1973; however, consistent with trends in conventional housing, production fell to 329,300 units in 1974 (Figure 3). Mobile homes represented $94 \%$ of the houses produced in 1974 in the under $\$ 20,000$ new housing market as shown in Figure 4. 
1.3.2 Standards Development. The mobile home industry is unique within the building industry in that there is a single model standard, ANSI A119.1 Standard for Mobile Homes [1], which covers the mafor aspects of the mobile home building process; i.e., construction, plumbing, heating and electrical. Park considerations are included in ANSI Al19.3 Standard for Mobile Home Parks [5]. These standards are developed using the concensus process by ANSI Comittee A119 on Mobile Homes and Recreational Vehicles.

States that have legislated mobile home construction requirements have most frequently adopted ANSI A119.1 as a whole or have used 1 t as a model upon which to base their standards. As of June 1, 1974, 45 States had adopted or were in the process of adopting ANSI A119.1 or portions thereof. An NBS publication by Cooke, Zelenka, and Tejuja [6] presents deviations various States have made in the ANSI Al19.1 Standard when modifying it for use in their regulatory programs.

1.3.3 Enforcement Process. Enforcement of a mobile home standard is primarily the responsibility of the State in which the mobile home is manufactured and generally includes certification of the design by that State's regulatory agency and in-plant inspection to insure compliance to the approved design. Generally, when a mobile home is transported and sold in a State other than in which it was manufactured, standard compliance becomes the responsibility of the State in which it is sold and is subject to that State's regulatory process.

There are two basic enforcement programs which are used separately or in combination by the States. Some States set up mobile home agencies to enforce mobile home regulations while others utilize independent third-party organizations to perform such services in their behalf. A typical combination would be for the State to set up an in-house agency for plan certification while employing a third party to perform in-plant inspection. An NBS publication by Cooke, Tejuja, Dikkers and Zelenka [7] outlines the various programs in use by the 50 states as of early 1974.

\subsection{MOBILE HOME PERFORMANCE DATA}

2.1 MOBILE HOME PERFORMANCE DATA ACQUISITION. The three major mobile home performance data sources were: (1) data accumulated by HUD as a result of using mobile homes as temporary housing following Hurricane Agnes, (2) data collected from State regulatory agencies and federal sources, and (3) data resulting from the field inspection of Hurricane Agnes units, private sector units and units being used by other government agencies. These data bases are referred to as the HUD Sample, Private Sample and Field Sample.

2.1.1 HUD Sample. The Department of Housing and Urban Development purchased approximately 18,000 mobile homes that were used as temporary housing for victims of the Hurricane Agnes disaster which occurred in June 1972. The largest concentration of these mobile homes was in the Wilkes-Barre, Pennsylvania area and totaled approximately 12,500 units. The urgent need for mobile homes following the hurricane was such that units were purchased from manufacturers and dealers from as far away as Texas and Florida and shipped to Wilkes-Barre. In many instances, the exigencies of time precluded specifying that the mobile homes meet the requirements of standards such as ANSI Al19.1 or the code of the state in which the home was purchased.

A large maintenance operation was established in Wilkes-Barre to make the units ready for occupancy and to maintain the units when occupied. The maintenance crews also refurbished homes between occupancies or prior to shipment to storage sites around the country.

Data for approximately 10,000 of the 12,500 units were brought to NBS from Wilkes-Barre on loan from HUD. Since it was not possible to evaluate data for the entire 10,000 units, a method of selecting a representative sample without bias was devised by the Statistical Engineering Section of the NBS Institute for Basic Standards. The resulting HUD Sample consisted of 2,881 randomly selected units chosen without regard to performance problems or attributes such as manufacturer, size, etc. Maintenance and refurbishment data were accumulated for these units. 
This sample is unique since all the units were manufactured at approximately the same time (1971-1972) and were put into use under emergency conditions. The temporary nature of the mobile home parks and private site placements created problems that would not have been encountered under normal circumstances. The conditions were further complicated by the fact that the occupants were living in mobile homes by necessity and not by choice. In general, the mobile homes were treated as rental units with the HUD Maintenance Staff being called upon to perform all maintenance services. The mobile home performance data in the HuD Sample reflects a wide range of problems from routine maintenance to major component failures.

2.1.2 Private Sample. Acquisition of performance data on mobile homes from sources other than HUD was established as a basic requirement of the project.

States with large mobile home populations were selected to gain access to a quantity of mobile home performance data in an efficient manner. These agencies regulating mobile homes varied widely from State-to-State and were attached to building code, consumer affalrs, community development, labor and motor vehicle organizations, etc. In addition to the State organizations, Federal agencies such as the Veterans Administration and Department of Defense, mobile home owners' organizations, privately owned mobile home parks with rental units, and various consumer groups were contacted. There were no attempts made to interview private mobile home owners on an individual basis. After a preliminary review of performance data available around the country, data from 14 sources 1 isted in Table 1 were selected for detailed evaluation. Problem files for a total of 967 mobile home units were obtained from these sources making up the Private Sample.

2.1.3 Field Sample. Since the degree of problem detail obtained in Task I varied consider$a b 1 y$, the field inspection of mobile homes was necessary to determine specific causes and consequence of the identified performance problems. A total of 257 units were inspected in the Field Sample and included mainly those used by HUD for temporary housing following the Hurricane Agnes disaster in addition to a small number of units from the private sector.

2.2 MOBILE HOME PERFORMANCE DATA CHARACTERISTICS. An attempt was made to gather all 1 dentifying attributes possible for each mobile home included in the three samples. Tables 2 through 5 summarize the State of manufacture, the year of manufacture, unit width data, and agency certifying seals for the units in the total combined sample.

With regard to the performance problems identified in the study, four major categories listed below were established to classify the problems. An additional miscellaneous category was used to tabulate a small number of problems of an undefined nature.

A. Problems Related to deficiencies and inadequacies of the ANSI Al19.1 Standard for Mobile Homes

B. Problems Related to Mobile Home Enforcement Process

C. Routine Maintenance Problems

D. Mechanical Electrical Appliance Problems

E. Miscellaneous Problems

This categorization of problems permits documentation of all mobile home performance problems obtained from the data sources or observed during the field inspections. Computer techniques are used to organize the data into tables (See Appendix A). Computer printouts showing the performance problem distribution are in Appendix B (HUD Sample), Appendix C (Private Sample), and Appendix D (Field Sample). The problem distribution in these four major categories for all data samples in percent of total problems is summarized in Table 6 .

Table 7 shows the rank ordered distribution of problems relative to the five categories for the Private Sample data. The rank ordered problem distribution within each of the four major categories are shown in Tables 8 through 11.

Table 12 shows the rank ordered distribution of problems relative to the five categories for the Field Sample data. The rank ordered problem distribution within each of the four 
major categorles are shown in Tables 13 through 16.

Table 17 shows the rank ordered distribution of problems relative to the five categories for the HUD Sample data. The rank ordered problem distribution within each of the four major categories are shown in Tables 18 through 21.

2.2.1 Problem Data Characteristics. Since each of the three data samples exhibit unique problem distributions, as seen in Tables 6 through 21, it is necessary to consider the characteristics of the data in each sample in evaluating the severity of the various problems.

Since the mobile homes in the HUD Sample were generally treated as rental units by the occupants, a large portion of the problems were routine maintenance in nature of the type that a home owner would normally repalr on his own rather than seeking professional assistance.

Private Sample data generally consisted of consumer complaints and the resulting on-site inspection reports of enforcement officials. The data would tend to be of a more severe nature than the HUD Sample since the mobile home owner would generally not go to the enforcement agency for assistance with problems of a routine maintenance nature. Also, enforcement official inspections generally concentrated on problems associated with code violations and enforcement program inadequacies.

The inspection procedures used in accumulating the Field Sample data were structured to concentrate on problems related to Standard violations and enforcement program inadequacies. Since most of the mobile homes were unoccupied at the time of the inspections, problems with appliances of a routine maintenance nature were less prominent.

The various characteristics of the three data samples should be considered in evaluating the problems discussed in Sections $3.0,4.0$ and 5.0 of this report. 


\section{3,0 EVALUATION OF PROBLEMS RELATED TO THE \\ ANSI AII9. I STANDARD}

3.1 CONSTRUCTION (PART B) - The following problems are taken from the data presented in Appendices $B, C$ and $D$. The percentage of mobile homes in each sample which have the problem is tabulated along with the pertinent paragraphs of the 1974 and 1975 editions of the ANSI A119.1 Standard for Mobile Homes (NFPA $501 B-1973$ and 1974 editions). A discussion of the problem is included with recommendations for changes in the Standard and other phases of the mobile home supply process where appropriate.

\section{1 .1 ROOF SYSTEM-RAIN LENKS (RLWR) 3/}

\begin{tabular}{|l|c|}
\hline Sample & $\begin{array}{l}\text { \% of Mcbile Homes in } \\
\text { Sample with Problem }\end{array}$ \\
\hline HUD & 17.4 \\
Private & 27.9 \\
Field & 40.1 \\
\hline
\end{tabular}

Pertinent ANSI A119.1 References (1974 and 1975)4/

Principle No. 7. To provide against the entrance of water and winds at all joints, connections, and openings in exterior surfaces.

B7.1 Weather Resistance. Exterior covering shall be of moisture and weather resistive materials attached with corrosion resistant fasteners to resist wind and rain. Metal coverings shall be of corrosion resistant materials.

Discussion - Roof membrane rain leaks were generally evidenced by staining of ceiling panels. The leaks appeared to be caused by one or more of the following factors:

a. Flexibility of the metal roofing membrane.

b. Lack of effective sealants.

c. Inadequate joint constructions in the metal roofing.

d. Flashing procedures at roof penetrations.

e. Ineffective joint design details of roof-exterior wall interface.

Other factors impacting the severity of this problem include transportation induced forces and deflections, and improper site set-up and leveling procedures. Also, the roof leak problem can be aggravated by persons walking on the roof for purposes of repair or maintenance which can affect the integrity of the roof membrane joints. The ANSI Al19.1 Standard states, in general performance terms, that the mobile home shall be moisture resistant. However, there is no way for enforcement officials to completely evaluate a mobile home design to determine the expected performance in this area.

3/ Symbol refers to computer code used to identify the problem (Appendices B, C and D).

4/ Excerpted and reprinted with permission from NFPA 501B, Standard for Mobile Homes, Copyright 1973 and 1974, National Fire Protection Association, Boston, Massachusetts. 


\section{Recommendations}

1. A method of evaluation should be developed and included in the Standard if enforcement officials are to determine if the moisture resistant performance specified in B7.1 is provided by the manufacturer.

2. Manufacturers should provide the mobile home owner with instructions for routine preventative maintenance of the roof. This could include coating of all roof membrane joints at specified intervals.

3. There should be provided at least a one-year warranty on roof leakage.

4. Inspection for rain leaks should be part of a pre-occupancy inspection program and the area of any leaks should be repaired before occupancy of the unit is authorized.

3.1 .2 PARTITION WALLS AND SIDEWALLS - FAILURE OF ATTACHMENT OF INTERIOR PANELING TO WALL FRAMING (INSSI.)

The higher percentage of this problem in the Field Sample may have been due to the frequent occurrence of water leaks causing wood panel buckling.

\begin{tabular}{|l|c|}
\hline Sample & $\begin{array}{c}\text { \% of Mobile Homes in } \\
\text { Sample with Problem }\end{array}$ \\
\hline HUD & 15.2 \\
Private & 25.4 \\
Field & 38.1 \\
\hline
\end{tabular}

\section{Pertinent ANSI A119.1 References}

1974

B6.7 Interior Partition. Whenever an interior partition is designed to serve as a secondary structural member, it shall be constructed with adequate strength for the purpose intended.

B6.10 Design Load Deflections. When a structural assembly is subjected to total design live loads, the deflection shall not exceed the following:

Floon ......................... L/240

Roof and Ceiling .............. L/180 (see Appendix II)

Sidewalls .................... L/180

Where $L=$ the clear span between supports or two times the length of a cantilever. 1975

B6.7 Interior walls. Interior walls shall be constructed with structural capacity adequate for the intended purpose and shall be capable of resisting a horizontal load of not less than five pounds per square foot. 
B6.10 Design Load Deflection. When a structural assembly is subjected to total design live loads, the deflection for structural framing members shall not exceed the following:

Floor ........................ L/240

Roof and Ceiling .............. L/180 (See Appendix, Part B)

Headers, Beams, Girders ......... L/180 (Vertical Loads Only)

Where $L=$ the clear span between supports or two times the length of a cantilever.

Discussion - This problem represents a failure of the attachment of the wood wall paneling to wall framing. Field inspection revealed that paneling is often attached with smooth staples which appear to provide inadequate fastening strength. The use of adhesive attachment in conjunction with staples was seldom found in the fleld investigation, and when it was encountered, continuous glue lines between the paneling and studs were rarely observed. The use of $1 / 8$ inch and $3 / 16$ inch thickness interior wood paneling provides questionable flexural rigidity between wall studs. Field observations indicated that some of the pane1ing appeared susceptible to dimensional changes due to molsture which could account for the buckling observed in conjunction with rain leaks.

The structural function of interior wall paneling is to ald in resisting forces due to transportation, site set-up, wind, and occupancy. These data bring into question the adequacy of the wall construction in resisting these forces; especlally since the ANSI Al19.1 Standard does not provide specific design criterla for transportation and site set-up.

The ANSI Al19.1 Standard does not adequately define performance criteria that would insure successful attachment of paneling to the framing members. The ANSI A119.1-1975 was improved to require interior walls to be designed for 5 psf horizontal load; however, the sidewall deflection limit of L/180 in the 1974 edition (B6.10) was deleted in 1975.

\section{Recommendations}

1. B6.10 should be modified to again incorporate a deflection limit on walls subfected to design loads. Consideration should be given to reimposing the L/180 limit as in ANSI Al19.1-1974 or adopting L/240 as required in paragraph 601-1le of FHA Minimum Property Standards [8].

2. The effects of wind loads and forces resulting from transportation and site set-up should be studied to develop additional design criteria for wall design.

3. Adhesive bonding should be used with mechanical fasteners in attaching wood paneling to the wall framing.

\subsubsection{EXTERIOR WALLS - RAIN LEAKS (EXWR)}

The high occurence of window leaks (paragraph 3.1.5) and door leaks (paragraph 3.1.6) in the Private Sample should also be considered in evaluating these data.

\begin{tabular}{|l|r|}
\hline Sample & $\begin{array}{c}\text { \% of Mobile Homes in } \\
\text { Sample with Problem }\end{array}$ \\
\hline HUD & 15.9 \\
Private & 6.4 \\
Field & 14.4 \\
\hline
\end{tabular}


B7.1 Weather Resistance. Exterior covering shall be of moisture and weather resistive materiats attached with corrosion resistant fasteners to resist wind and rain. Metal coverings shall be of corrosion resistant materials.

Discussion - Penetration of rain water is the predominate problem with exterior walls. These leaks occurred through the exterior siding and at windows, doors, and other penetrations. The rain leaks at windows and doors occurred at the juncture with the exterior wall. Rain leaks through windows and doors are discussed in paragraphs 3.1 .5 and 3.1.6. The usual manufacturing procedure is to attach the siding material to the wall framing, cut out openings for windows and doors and install windows and doors over the exterior siding. Caulking must be used where the frame of these components mate with the siding in order to prevent rain water penetration.

Lack of effective sealing of joints in exterior walls can be caused by:

1. Excessive distortion of the walls due to transportation and set-up. The resulting differential movement between the window/door frame and exterior wall covering can disturb the caulking seal applied in the factory.

2. Manufacturing procedures of installing window and door frames over exterior siding which is not good flashing practice.

3. Poor workmanship characterized by improper application of sealant, the omission of sealant in some areas around frames, etc.

4. Inferior caulking that becomes brittle and cracks in a relatively short time.

$\underline{\text { Recommendations }}$

1. A water penetration test procedure should be established for exterior wall assemblies similar to that adopted for windows (MHMA Specification 1-71-Rev. 1973). The test should include simulation of the effects of transportation.

2. The use of sealants between components of wall assemblies should be required to meet one or more of the following Federal Specifications:

TT-S-00230

TT-S-001657

TT-S-001543A

TT-S-00227E

3. Paragraph B7.1 of ANSI A119.1 should be revised as follows:

B7.1 Exterior covering and component joints sha11 be of moisture and weather resistive materials attached with corrosion resistant fasteners to resist wind and rain. Metal coverings shall be of corrosion resistant materials.

3.1.4 EXTERIOR WALL SYSTEM - FAILURE OF ATTACHMENT OF EXTERIOR COVERING TO WALL FRAMING (EXSS1.)

\begin{tabular}{|l|c|}
\hline Sample & $\begin{array}{l}\text { \% of Mobile Homes in } \\
\text { Sample with Problem }\end{array}$ \\
\hline HUD & 6.9 \\
Private & 12.0 \\
Field & 17.1 \\
\hline
\end{tabular}

Pertinent ANSI A119.1 Reference (1974 and 1975)

B6.6 walls. The walls shall be of sufficient strength to withstand the load requirements as defined in 6.3.1, 6.3.2 and 6.4 of this Part, without exceeding the deflections as 
specified in 6.10. The connections between the bearing walls, floor, and roof framework members shall be fabricated in such a manner as to provide support for the material used to enclose the mobile home and to provide for transfer of all lateral and vertical loads

to the floor and chassis.

Discussion - Typical of these problems was pulling of the fastener head through the metal siding and loosening of the fasteners. These problems could be related to excessive vibration and racking during transportation and site set-up of the unit. Wind induced forces could also cause connection loosening and fastener pull through problems.

Recommendation - A research study should be initiated to investigate the acceleration forces and stresses induced by transportation and site set-up in mobile homes. A study of wind effects on exterior wall connections, over an extended period of time, should also be initiated. The results of these studies would form the basis for the development of more realistic design criteria for incorporation into the current Standard.

\section{1 .5 WINDOWS - RAIN LEAKS (WNNR)}

\begin{tabular}{|l|r|}
\hline Sample & $\begin{array}{c}\text { \% of Mobile Homes in } \\
\text { Sample with Problem }\end{array}$ \\
\hline Hun & 2.7 \\
Private & 13.9 \\
Field & 3.9 \\
\hline
\end{tabular}

Pertinent ANSI Al19.1 References

$\underline{1974}$

B7.1 Weather Resistance. Exterior covering shall be of moisture and weather resistive materials attached with corrosion resistant fasteners to resist wind and rain. Metal coverings shall be of corrosion resistant materials.

B8.5.1 Windows. All windows shall comply with requirements set forth in Table B-2 and, in addition, shall meet the reqirements for windows as detailed in the "Window Specifications for Utilization in Mobile and Factory-Built Homes (MHMA Spec. No. 1-71-Rev. 1972).

$\underline{1975}$

\section{B7.1 Same as 1974.}

B8.5.1 Windows. All windows shall meet the requirements for windows as detailed in the Window Specifications for Utilization in Mobile and Factory-Built Housing, (MHMA Spec. No. 1-71-Rev. 19731.

Discussion - These problems are concerned with the penetration of rain water through windows. Rain leaks at the juncture of the window frame and the wall are discussed in 3.1.3. The referenced Mobile Home Manufacturers Association (MHMA) Spec No. 1-71 includes a winddriven rain test which appears adequate in evaluating window performance. This specification was first included in the 1973 edition of ANSI Al19.1. A large majority of the mobile homes in this study were 1972 models, or older, and may have used windows which did not meet the MHMA Specification.

Recommendation - Use of windows which meet the latest revision of MHMA Spec. No. 1-71 may alleviate the rain leak problem.

\subsubsection{EXTERIOR DOORS - RAIN LEAKS (DEIVR)}

\begin{tabular}{|l|c|}
\hline Sample & $\begin{array}{l}\text { \% of Mobile Homes in } \\
\text { Sample with Problem }\end{array}$ \\
\hline HUD & 3.2 \\
Private & 13.0 \\
Field & 3.1 \\
\hline
\end{tabular}


B7.1 Weather Resistance. Exterior covering shall be of moisture and weather resistive. materials attached with corrosion resistant fasteners to resist wind and rain. Metal coverings shall be of corrosion resistant materials.

Discussion - This problem concerns the penetration of rain water through exterior doors. Rain leaks at the juncture of the door frame and the exterior wall are discussed in 3.1.3. ANSI Al19.1-1975 does not include a wind-driven rain test for exterior doors. MHMA Spec. 3-74 "Exterior Passage Door Specifications for Utilization in Mobile and Factory Built Housing" is weak in the area of water penetration as indicated by the following from paragraph 1.4.4:

"No leakage shall pass interior face of the test specimen at a test pressure of 9 psf when tested in accordance with ASTM E-331. Note: The development of this standard was primarily instituted to answer energy conservation requirements. Insufficient time to establish further water penetration criteria was allowed; therefore, the MHMA Door Subcommittee is presently effecting further testing and criteria for revision to this standard at a later date."

Recommendation - MHMA Spec. 3-74 appears to be a step in the right direction. Work on the development of additional water penetration criteria to augment this specification should be undertaken.

3.1.7 FLOOR SYSTEM - INADEQUATE BOTTOMBOARD WEATHER AND RODENT RESISTANCE (FLWR, FLRR, PREQ5., HGPG1.)

\begin{tabular}{|l|c|}
\hline Sample & No. of Problems* \\
\hline HUD & 129 \\
Private & 290 \\
Field & 127 \\
\hline
\end{tabular}

*Table represents a summation of problems in the Construction, Plumbing and Heating Parts of Al19.1 relative to bottomboard durability.

Pertinent ANSI Al19.1 References (1974 and 1975)

B7.1 Weather Resistance. Exterior covering shall be of moisture and weather resistive materials attached with corrosion resistant fasteners to resist wind and rain. Metal coverings shall be of corrosion resistant materials.

B7.4 Rodent Resistance. Exterior surfaces shall be sealed to resist the entrance of rodents.

C5.2.5 Rodent Resistance. All exterior openings around piping and equipment shall be sealed to resist the entrance of rodents.

D5.1.1.1 Rodent Resistance. All exterior openings around piping, ducts, plenums or vents shall be sealed to resist the entrance of rodents.

Discussion - The problems grouped in this category concern penetrations in the bottomboard material (underside covering material) which affects the weather and rodent resistance of the mobile home. As illustrated in the referenced paragraphs of the ANSI Al19.1 Standard, Part B (Construction), Part C (Plumbing) and Part D (Heating) contain essentially the same requirement against rodent penetration. A summation of these problems for the three samples represents $7.2 \%$ of all ANSI Al19.1 related problems.

The failure of the bottomboard barrier could lead to penetration of the underside of the home by wind, rain, rodents, insects and dust. The low tear and puncture strength characteristics of most bottomboard materials presently being used allows them to be easily damaged. In many 
cases, the attachment of the bottomboard material to the main floor frame failed, possibly as a result of low "wet strength" or due to forces imposed during transportation and site set-up.

The referenced ANSI Al19.1 Standard paragraphs give the required performance of the bottomboard in general terms without specifying methods for enforcement officials to determine if the performance of a material is acceptable. This problem can be attributed to the Standard which does not provide specific performance requirements for the strength and durability of the bottomboard along with methods to evaluate the adequacy of the barrier.

$\underline{\text { Recommendations }}$

1. The bottomboard construction of mobile homes should be upgraded.

2. Performance requirements for mobile home bottomboard materials and attachment methods should be developed and incorporated in the ANSI A119.1 Standard. These requirements should include tear resistance, puncture resistance, wet strength and water penetration resistance.

\subsubsection{EXTERIOR WALLS - CORROSION OF EXTERIOR FASTENERS (EXOR)}

Exterior fasteners were routinely inspected in the Field Sample Survey. Mobile home occupants (HUD and Private Samples) did not generally consider this a major problem.

\begin{tabular}{|l|c|}
\hline Sample & $\begin{array}{l}\text { \% of Mobile Homes in } \\
\text { Sample with Problem }\end{array}$ \\
\hline HUD & -- \\
Private & 1.3 \\
Field & 49.4 \\
\hline
\end{tabular}

\section{Pertinent ANSI A119.1 Reference (1974 and 1975)}

B7.1 Weather Resistance. Exterior covering shall be of moisture and weather resistive materials attached with corrosion resistant fasteners to resist wind and rain. Metal coverings shall be of corrosion resistant materials.

Discussion - In many cases, corrosion of exterior fasteners were noted on mobile homes less than two years old. While this initially may be only an aesthetic problem, it could eventually lead to a loss of the structural attachment of the exterior covering. The ANSI Al19.1 Standard specifies "corrosion resistant fasteners;" however, it gives no level of performance for enforcement officials to evaluate the adequacy of a proposed fastener.

\section{Recommendations}

1. The ANSI A119.1 Standard should include performance specifications that would insure long-term durability of exterior fasteners.

2. The specification should be such that hot-dip galvanized, electro-galvanized, aluminized steel, stainless steel, double cadmium plated, aluminum screws, or any other corrosion-resistant fastener type could be considered for use by the manufacturers. 


\subsubsection{ROOF SYSTEM - FAILURE OF ATTACIMENT OF CEILING MATERIAL TO TRUSS (RFSS4.)}

\begin{tabular}{|l|c|}
\hline Sample & $\begin{array}{c}\text { \% of Mobile Homes in } \\
\text { Sample with Problem }\end{array}$ \\
\hline HUD & 0.1 \\
Private & 6.3 \\
Field & -- \\
\hline
\end{tabular}

Pertinent ANSI A119.1 References (1974 and 1975)

Principle No. 3. To provide structural strength and rigidity sufficient for design loads, both in transit and on site.

B5.3 Structural Analysis. The strength and rigidity of the component parts and/or the integrated structure shall be determined by engineering analysis or by suitable load tests to simulate the actual loads and conditions of application that occur on site.

Discussion - The loss of attachment between ceiling material and roof trusses occurred almost totally in the Private Sample. This problem can be related to transportation forces, site set-up and occupancy. Another contributing factor would be the excessive occurrence of roof rain leaks and the resulting water damage to ceiling material which generally exhibits a lack of wet strength. Except for the referenced paragraphs which call for good engineering design, ANSI Al19.1 does not give specific design criteria for the attachment.

\section{Recommendations}

1. The susceptibility of mobile home roofs to rain leaks should be reduced which would help alleviate the incidence of ceiling material attachment failure.

2. Results from a study of the effects of transportation and site set-up on mobile homes could be used to develop design criteria for the ceiling system.

3.1.10 ROOF SYSTEM - EXCESSIVE METAL MEMBRANE DEFLECTION AND ROOF RUMBLE (RDEF)

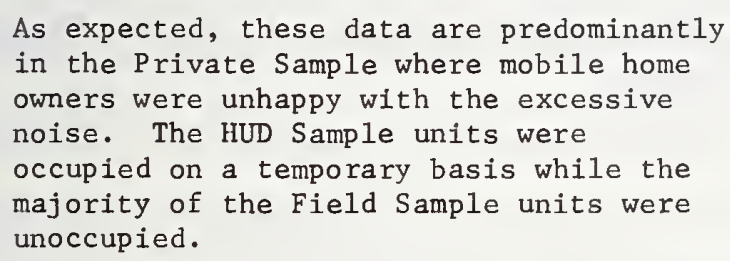

\begin{tabular}{|l|c|}
\hline Sample & $\begin{array}{c}\text { \% of Mobile Homes in } \\
\text { Sample with Problem }\end{array}$ \\
\hline HUD & -- \\
Private & 4.7 \\
Field & 0.4 \\
\hline
\end{tabular}

Pertinent ANSI A119.1 References (1974 and 1975)

Principal No. 3. To provide structural strength and rigidity sufficient for design loads, both in transit and on site.

B5.3. Structural Analysis. The strength and rigidity of the component parts and/or the integrated structure shall be determined by engineering analysis or by suitable load tests to simulate the actual loads and conditions of application that occur on site. 
Discussion - This problem primarily consisted of excessive noise or "roof rumble" during windy weather conditions. The basic cause of the problem is the lack of rigidity of the metal roof membrane. Typical roof construction consists of a sheet metal installed over the wood trusses attached only around the outside perimeter edges of the mobile home. This method of attachment allows deflection of the roof membrane between trusses under the oscillating wind conditions. A sheathing material and/or insulation is sometimes placed between the metal membrane and the roof trusses. Roof rumble occurs when the metal roofing "slaps" against the roof trusses or sheathing material or the metal itself "oil cans" under wind loading. While walking on the roof is not recommended, it may be necessary to do so when performing routine maintenance. This could damage the metal membrane because of its lack of rigidity between roof trusses.

Recommendations

1. Establish criteria to limit the deflection of metal roofing membrane between trusses. This would impart rigidity to the membrane and greatly reduce the occurrence of "roof rumble."

2. The manufacturer should alert the mobile home owner to the fact that "roof rumble" may occur and caution against walking on the roof.

\subsubsection{FLOOR SYSTEN - FAILURE OF ATTACHMIVNT OF DECKING TO FLOOR JOISTS (FASS1.)}

\begin{tabular}{l|c|}
\hline Sample & $\begin{array}{c}\% \text { of Mobile Homes in } \\
\text { Sample with Problem }\end{array}$ \\
\hline HUD & 0.1 \\
Private & 3.8 \\
Field & -- \\
\hline
\end{tabular}

Pertinent ANSI A119.1 References

1974

B6.9 Floors. Floor assemblies shall be designed in accordance with accepted engineering practice to support a uniform live load of $40 \mathrm{lb} / \mathrm{ft2}$, plus the dead load of the materials. In addition (but not simultaneously), floors shall be able to support a 200-pound concentrated load on a 2-inch diameter disc at the most critical location with a maximum deflection not to exceed $1 / 8$ inch relative to floor framing.

1975

\section{B6. 9 Floors}

(a) Floor assemblies shall be designed in accordance with accepted engineering practice standards to support a minumum uniform live load of $40 \mathrm{lb} / 6 \mathrm{t} 2$ plus the dead load of the materials. In addition (but not simultaneously), floors shall be able to suppr:t a 200-pound concentrated load on a two-inch diameter disc at the most critical lucation with the maximum deflection not to exceed 1/8 inch relative to floor framina. Perimeter joists of more than six inches depth shall be stabilized against over urning from superimposed loads as follows: at ends by solid blocking not less than two-inch thickness by full depth of joists, or by connecting to a continuous header not iejs than two inch thiciness and not less than the depth of the joist with connecting device; at eight feet maximum intermediate spacing by solid blocking or by wood cross-bridging of not less thean one inch by three inches, metal cross-bridging of equal strength, or by other approved methods. 
(b) Wood floors or subfloors in kitchens, bathrooms (including toilet compartments), laundry rooms, water heater compartments, and any other areas subject to excessive moisture shall be moisture resistant or shall be made moisture resistant by sealing or by an overlay of nonabsorbent material applied with water-resistant adhesive.

Discussion - This problem is concerned with inadequate attachment of the decking to the floor joists. Attachment is generally by staples or nails and adhesive bonding. The fasteners often pull through particle board floor decking commonly used in mobile homes, especially if it should become water soaked from plumbing or rain leaks. The requirements as presented for floors in the referenced ANSI Al19.1 Standard paragraphs are consistent with most codes and standards that exist for conventional housing. However, conventional housing is not subject to the dynamic forces of transportation and site set-up that are imposed on mobile homes. Therefore, consideration for these special conditions should be made during the design process. As presently written, the Standard does not provide design criteria for these special load conditions.

\section{Recommendations}

1. Develop design criteria for floors which take into account the effects of transportation and site set-up. This could result from a program to determine the magnitude of dynamic forces to which mobile homes are subjected during transit and set-up.

2. A performance criteria should be developed using these measured dynamic loads to assure adequate attachment strength for floor decking to floor joists.

3. A test procedure could be developed and specified so that regulating agencies can evaluate compliance with the criteria.

\section{1 .12 DOUBLEWIDE MISALIGNENT (RFSS5.)}

There were no doublewide units in the HUD and Field Sample Data.

\begin{tabular}{|l|c|}
\hline Sample & $\begin{array}{c}\text { \% of Mobile Homes in } \\
\text { Sample with Problem }\end{array}$ \\
\hline HuD & -- \\
$\begin{array}{l}\text { Private } \\
\text { Field }\end{array}$ & 2.9 \\
\hline
\end{tabular}

Pertinent ANSI A119.1 Reference (1974 and 1975)

Principle No. 7 (Part B). To provide against the entrance of water and wind at all joints, connections, and openings in exterior surfaces.

Discussion - Misalignment of the two sections forming a doublewide mobile home generally resulted in a rain water leak.

This problem can be attributed primarily to two causes: (1) failure of the manufacturer to hold dimensional tolerances during the fabrication phase, and (2) improper leveling and blocking of the two halves during site set-up. Except for general requirements of Principle No. 7, the ANSI Al19.1 Standard does not include guidance for dimensional tolerance requirements to be used by the manufacturer in the production of doublewide units. ANSI Al19.3 Standard for Mobile Home Parks [5] does not include dimensional tolerance requirements for mobile home set-up. 


\section{Recommendations}

1. The ANSI Al19.1 Standard should include a section on dimensional tolerances of mobile home construction with particular attention given to doublewide units.

2. A mobile home installation guide should be supplied with each mobile home by the manufacturer.

3. The ANSI Al19 Committee on Mobile Homes should undertake further study of the installation problems.

Note: In response to this need, ANSI Committee All9 has established a new Sectional Committee on Mobile Home Installation with the following scope, "to develop standards or recommend practices for the proper placement of mobile homes on any lot, covering such items as piers, skirting, removal of running gear and any additional provisions for tiedowns and connections to utilities not covered in either the ANSI A119.1 Standard for Mobile Homes or the ANSI Al19.3 Standard for Mobile Home Parks." The successful completion of this effort should help alleviate this problem with doublewides which are providing an ever increasing share of the mobile home market.

\subsubsection{ROOF SYSTEM - CUTTING STRUCIURAL ROOF COMPONENTS TO ALLOW FOR INSTALLATION OF VENT} PIPES OR STACKS (RLCC)

Where possible, roof trusses over the furnace were inspected in the field study. The mobile home occupant would not generally know of this problem as evidenced by the low frequency of occurrence in the HUD and Private Samples.

\begin{tabular}{|l|c|}
\hline Sample & $\begin{array}{l}\text { \% of Mobile Homes in } \\
\text { Sample with Problem }\end{array}$ \\
\hline HUD & -- \\
Private & 0.3 \\
Field & 1.9 \\
\hline
\end{tabular}

Pertinent ANSI A119.1 References (1974 and 1975)

B5.2 Construction. All construction methods shall be in conformance with accepted engineering practices to insure durable, livable, and safe housing. Exposed metal structural members shall be protected to resist corrosion.

B5.3 Structural Analysis. The strength and rigidity of the component parts and/or the integrated structure shall be determined by engineering analysis or by suitable load tests to simulate the actual loads and conditions of application that occur on site.

Discussion - This problem was observed over furnace compartments where roof trusses were cut to allow for installation of roof jacks. Even though there were a small number of instances, it is serious enough to warrant a revision in the Standard. The basic cause of this problem was a result of poor design of the mobile home and/or inadequate plant inspection. Although the referenced ANSI Al19.1 paragraphs cover this type of violation in a general sense, it is believed that there should be specific wording in the Standard that would prevent the cutting of major structural roof components without justification by engineering analysis.

Recommendation - Add the following requirement to ANSI Al19.1:

"Cutting of roof truss components for passage of electrical, plumbing or mechanical systems are not permitted without justification by engineering analysis." 
3.1 .14 TIEDOMNS - MPROPERLY LOCATED BETHEEN RDOF TRUSSES (TIDN2.)

Inspection for this problem was possible only in the field inspection. study.

\begin{tabular}{|l|c|}
\hline Sample & $\begin{array}{c}\text { \% of Mobile Homes in } \\
\text { Sample with Problem }\end{array}$ \\
\hline & -- \\
HUD & - \\
Private & 1.0 \\
\hline Field & \\
\hline
\end{tabular}

Pertinent ANSI A119.1 Reference (1974 and 1975)

B5.5.1 Tiedowrs. All mobile homes shall have tiedowns with provisions for distributing the load of these tiedouns and provisions for the attachment to ground anchors so as to esist wind overturning and sliding as imposed by the respective design loads of this part.

Discussion - It was noted in the fleld inspection task that over-the-roof hurricane straps were somezines located between roof trusses and not at a truss where a path of load transfer froz wall to wall is provided.

ANS A119.1-1975 does not specifically address this point other than calling for good design. The proposed Tentative Interim Admendment (TIA) on Windstorm Protection for the ANSI Al19.1 Standard has the Eollowing requirement:

"6.6.1.2(c) When continuous straps are provided as vertical ties, such ties shall by positioned at rafters and studs."

Recomendation - Adoption of hindstorm Protection IIA should alleviate this problem.

5.2 PLUMBING SISTEMS (P.ART C) - The following problems are taken from the data presented in Appendices $B, C$ and $D$. The percentage of zobile homes in each sample with the problem is tabulated along with the pertinent paragraphs of the 1974 and 1975 editions of the ANSI Al19.1 Standard for Mobile Homes (IFPA 501B-1973 and 1974 editions). A discussion of the problem is included with recomendations for changes in the Standard and other phases of the mobile home supply process where appropriate.

3.2.1 QUALITY OF FIXTURES - DURABILITY OF FAUCEI ASSEMBIES (PFGRI.)

\begin{tabular}{|l|c|}
\hline Sample & $\begin{array}{c}\text { \% of Mobile Homes in } \\
\text { Sample with Problem }\end{array}$ \\
\hline HUD & 15.6 \\
Private & 11.1 \\
Field & 13.6 \\
\hline
\end{tabular}

Pertinent ANSI A119.1 References

1974

C6.1 Minimum Standards. Materials, fixtures, or devises used or entering into the construction of plumbing systems in any mobile home shall be free from defects and shall conform to approved standards or the applicable standards listed in the Appendix of this Part, Table C-1.

1975

C6.1 Minimum Standards. Materials, fixtures, or devices used or entering into the construction of peumbeng systems in any mobile home shall be free from defects and shall conform to approved standards.

Note: See Appendix for Reference Table for Standards on Plumbing System Components. 
Discussion - The majority of these problems concerned early faucet failures requiring replacement. The replacement of faucet washers (routine maintenance) is not included in these data. The ANSI A119.1 Standard is deficient with regards to specifying a minimum quality of faucet; therefore, a large percentage of faucet assemblies did not perform adequately.

\section{Recommendations}

1. The ANSI A119.1 Standard should include performance criteria on faucet assemblies that would insure the owner of some useful life (in years).

2. The Appendix to Part $C$ of ANSI Al19.1 should include acceptable durability standards for faucet assemblies.

3. A requirement for permanently marking the faucet assemblies with the manufacturers' name and model number should be adopted to enable enforcement officials to check for compliance.

\subsubsection{TOILET FLUSHING DEVICES - REPAIR OR REPLACE MENT OF TOILET FLUSIING DEVICES (TØIL2.)}

\begin{tabular}{|l|c|}
\hline Sample & $\begin{array}{c}\text { \% of Mobile Homes in } \\
\text { Sample with Problem }\end{array}$ \\
\hline HUD & 5.9 \\
Private & 5.6 \\
Field & 5.4 \\
\hline
\end{tabular}

\section{Pertinent ANSI A119.i Reference (1974 and 1975)}

C9.2.1.2 Toilet flushing devices shall be designed to replace the water seal in the bowl after each operation. Flush valves, flushometer valves, and ball cocks shall operate automatically to shut off at the end of each flush or when the tank is filled to operating capacity.

Discussion - The general quality of toilet assemblies installed by mobile home manufacturers appears to be equivalent to those used in conventional housing. When the effects of transportation are considered, however, these data indicate that the toilet flushing device may not be adequate for the forces and vibrations encountered.

\section{Recommendations}

1. The effect of transport induced forces on plumbing fixtures including toilet flushing devices should be examined in an overall study of transportation induced forces on mobile homes.

2. From these studies, performance criteria could be developed for plumbing fixtures (including toilet flushing devices) that would insure the owner of the mobile home reduced maintenance costs and extended life for these devices. 


\subsubsection{TOILET - LOOSE TOILET TO FLOOR CONNECTIONS (TøIL5.)}

\begin{tabular}{|l|c|}
\hline Sample & $\begin{array}{c}\text { \% of Mobile Homes in } \\
\text { Sample with Problem }\end{array}$ \\
\hline HUD & 4.1 \\
Private & 8.2 \\
Field & 9.3 \\
\hline
\end{tabular}

Pertinent ANSI A119.1 References

1974

99.2.1.5 Floor Connection. Toilets shall be securely bolted to the floor by means of an approved flange or other approved fitting. Bolts and screws, when used, shall be of solid brass or other corrosive-resistant material and shall be not less than $1 / 4$ inch in diameter. A watertight seal shall be made between the toilet and flange or other approved fitting by use of a gasket or sealing compound.

1975

99.2.1.5 Floor Connection. Toilets shall be securely bolted to an approved flange or other approved fitting which is secured to the floor by means of corrosion-resistant plated screws. The bolts shall be of solid brass or other corrosion-resistant material and shall be not less than $1 / 4$ inch in diameter. A watertight seal shall be made between the toilet and flange or other approved fitting by use of a gasket or sealing compound. (See also Paragraph 6.9(b) of Part B.)

Discussion - This problem concerns the connection of the toilet assembly to the floor of the mobile home. The toilets frequently become loose and require tightening or seal replacement. In some cases, this looseness resulted in waste water leakage (which can cause deterioration of the bathroom floor) and the release of sewer gases and odors into the home. Since toilets are normally tightened down on the seal in the factory, it is likely that the vibrations due to transportation and set-up account for the loosening of many connections. This toilet connection method is the same as that used in conventional housing; however, mobile homes are subjected to these additional transit induced forces which do not appear to be adequately taken into consideration during the design and fabrication process.

Recommendations

1. The effect of transport induced forces on the floor connection of the toilet should be included in an overall study of transportation forces on mobile homes.

2. The feasibility of transporting the mobile home with the toilet loose and temporarily shimmed to be tightened after set-up should be considered.

3. Tightening of all plumbing fixtures should be part of a pre-occupancy inspection.

4. The following clarifying statement should be added to the Standard:

"Attachment to Structure. Plumbing fixtures shall be securely attached to the mobile home to resist transportation, set-up and normal use forces. Piping shall not be used to support the weight of the fixtures." 


\subsubsection{WATERTIGHTNESS OF TUB/SHOWER ENCLOSURES - WATER LEAKAGE AT JOINI'S OF SHOWEK ENCLUSURES}

(SHRR3.)

This problem could not readily be evaluated in the field study since unoccupied mobile homes were generally inspected.

\begin{tabular}{|l|c|}
\hline Sample & $\begin{array}{l}\text { \% of Mobile Homes in } \\
\text { Sample with Problem }\end{array}$ \\
\hline HUD & 1.7 \\
Private & 13.8 \\
Field & 2.3 \\
\hline
\end{tabular}

Pertinent ANSI A119.1 Reference

1974

9.2.2.1 - Each shower stall shall be provided with an approved watertight receptor with sides and back extending 1 inch above the finished dam or threshold. In no case shall the depth of a shower receptor be less than 2 inches or more than 9 inches measured from the top of the finished dam or threshold to the top of the drain. The wall area in shower compartments shall be constructed of smooth, noncorrosive, and nonabsorbent waterproof materials to a height not less than 6 feet above the floor level. Such walls shall form a watertight joint with each other and with the receptor or shower floor. The floor shall slope uniformly to the drain at not less than one-fourth nor more than one-half inch per foot.

1975

9.2.2.1 - Each compartment stall shall be provided with an approved watertight receptor with sides and back extending 1 inch above the finished dam or threshold. In no case shall the depth of a shower receptor be less than 2 inches or more than 9 inches measured from the top of the finished dam or threshold to the top of the drain. The wall area shall be constructed of smooth, noncorrosive, and nonabsorbent waterproof materials to a height not less than 6 feet above the compartment floor level. Such walls shall form a watertight joint with each other and with the receptor or shower floor. The floor of the compartment shall slope uniformly to the drain at not less than one-fourth nor more than one-half inch per foot.

Note: See also Appendix to Part B on Selection of Material and Installation of wood Product Based Wall Surfacing for Tub and Shower Enclosures.

Discussion - The problem of leaking shower enclosures can be attributed primarily to the breakdown of the moisture seal at corners, edges and joints of the enclosure material. The 1975 edition of the ANSI Al19.1 Standard includes a new appendix that specifies material and installation requirements for wood product based wall surfacing materials for tub and shower enclosures. However, this new appendix does not include specific requirements relative to the materials to use when caulking and sealing corners and edges to prevent water leakage. Even if shower enclosure joints are sealed against moisture in the factory, transportation and set-up forces can damage the joints causing leakage. Aging of sealants is also a concern. 


\section{Recommendations}

1. The ANSI Al19.1 Standard should be amended to include the use of the sealants meeting Federal Specification Nos. TT-S-00230, TT-S-001543A, and TT-S-00227E when the design of of a shower stall enclosure requires sealing.

2. A pre-occupancy check should include an evaluation of the seals of shower enclosure joints.

\subsubsection{WATERTIGHTNESS OF JOINT AT DRAIN - SHOWER DRAIN LEAKAGE (SHRS2.)}

\begin{tabular}{|l|c|}
\hline Sample & $\begin{array}{c}\% \text { of Mobile Homes in } \\
\text { Sample with Problem }\end{array}$ \\
\hline HUD & 4.2 \\
Private & 3.7 \\
Field & 3.5 \\
\hline
\end{tabular}

\section{Pertinent ANSI Al19.1 References}

1974

99.2.2.2 The joint around the drain connection and around the toilet outlet in combination compartments shall be made watertight by a flange, clamping ring, or other approved or listed means.

C14.4 Shower Stalls. Nonmetallic shower stalls and receptors shall be tested for leaks prior to being covered by finish material. Each pan shall be filled with water to the top of the dam for not less than 15 minutes.

1975

C9.2.2.2 The joint around the drain connection shall be made watertight by a flange, clamping ring, or other approved listed means.

C14.4 Shower Compartments. Nonmetallic shower compartments and receptors shall be tested for leaks prior to being covered by finish material. Each pan shall be filled with water to the top of the dam for not less than 15 minutes.

Discussion - This general problem may be related to forces or vibrations induced as a result of transportation and set-up. The connections used are similar to those used in conventional housing.

Recommendations

1. The effect of dynamic loads on plumbing piping connections should be included in an overall study of transportation and set-up forces on mobile homes.

2. A pre-occupancy check should include an evaluation of the tightness of the plumbing piping system. 
3.2.6 PROTECTIVE REQUIREMENT: FREEZING OF WATER SUPPLY PIPING (PREQ4.)

Most of these problems occurred in HUD Agnes units (HUD and Field Samples).

\begin{tabular}{|l|c|}
\hline Sample & $\begin{array}{c}\text { \% of Mobile Homes in } \\
\text { Sample with Problem }\end{array}$ \\
\hline HUD & 3.3 \\
Private & 0.1 \\
Field & 4.7 \\
\hline
\end{tabular}

Pertinent ANSI A119.1 Reference (1974 and 1975)

C5.2.4 Freezing. All piping and fixtures subject to freezing temperatures shall be insulated or protected to prevent freezing under normal occupancy.

Discussion - The predominance of these data in the HUD and Field Samples indicated that conditions unique to the HUD Wilkes-Barre operation may be responsible for many of these problems. In many cases, it is known that due to the emergency conditions following the Agnes disaster, some mobile homes awaiting occupancy were unheated resulting in freezing of pipes. A contributing factor was the difficulty in draining the water supply and drain systems. Also, there were malfunctions of heat tape which allowed piping within the floor cavity to freeze. Cases of inadequate insulation were noted but the HUD procured mobile homes may have been manufactured for southern climates and not for Central Pennsylvania.

\section{Recommendations}

1. The following sentence should be added to Section C5.2.4:

"The plumbing system shall be designed for convenient drainage of both the water supply and drain systems."

2. The plan review and plant inspection aspects of the enforcement process should be tightened to insure that plumbing piping is adequately insulated for the intended climate.

3. There is a potential weakness in the mobile home design where reliance is place on heat tape to prevent freezing of plumbing pipe. Heat tapes wear out requiring periodic replacement and the typical mobile home occupant normally will not be alerted to the failure until pipes are frozen.

\subsubsection{VENT TERMINAL - VENT CAPS - REMOVAL POTENTIAL (VVTL3.)}

Vent pipe terminations on roofs were routinely inspected during the field study. Mobile home occupants would not normally be aware of the problem.

\begin{tabular}{|l|c|}
\hline Sample & $\begin{array}{c}\text { \% of Mobile Homes in } \\
\text { Sample with Problem }\end{array}$ \\
\hline HUD & -- \\
Private & 0.1 \\
Field & 7.4 \\
\hline
\end{tabular}


1974

C13.5.3 Vent Caps. All vent caps shall be of a removable type to permit testing under Paragraph 74.2.

1975

C13.1 Vent Caps. Vent caps, if provided, shall be of the semovable type luithout removing the flashing focm the roofl) where required to perform the tests under Paragraph 14.2. I and 14.2 .2 or when the vent is used as a clean out.

Discussion - These data are related to the necessity of removing permanent flashing from around roof penetrations in order to test or maintain plumbing vent systens as required in C14.2. The 1975 revision requires that vent caps be the removable type "without removing the flashing from the roof" which is an improvement.

Recomendation - For testing and maintenance of the mobile home plumbing systens (accorcing to C14), it is important that plumbing vents be identified. The following adcition to Section C13.7 should be considerec:

"When vent caps used for roof space ventilation are identical to the vent caps used for the plubing system, plumbing system caps shall be identified with permanent markings."

3.3 HEATING SYSTEIS (PART D) - The following problems are taken from the data presented in Appendicas B, C and D. The percentage of mobile homes in each sample with the problen is tabulated along with the pertinent paragraphs of the 1974 and 1975 ecitions of the ANSI A119.1 Standard for Mobile Homes (NFPA 5013-1973 and 1974 editions). A discussion of the problen is included with recommencations for changes in the Standard and other phases of the mobile hore supply process where appropriate.

\subsubsection{APPLIANCES - QUESTIONHBLE LOCATION OF FURNACE THFR'OSTAT (HAINI.)}

The location of the therrostat was

routinely checked in the field study.

Mobile home occupants generally did

not recognize this as a problem.

Pertinent AVSI A119.1 Reference (1974 and 1975)

\begin{tabular}{|l|c|}
\hline Sample & $\begin{array}{c}\text { \% of Mobile Homes in } \\
\text { Sample with Problem }\end{array}$ \\
\hline HUD & -- \\
Private & 0.4 \\
Field & 8.6 \\
\hline
\end{tabular}

Not covered in ANSI A119.1-1974 or 1975.

Discussion - This category involved the location of furnace thermostats on walls acjacent to the furnace. In some cases, the thermostat was attached to a wall common to the furnace compartment or on an exterior wall. This proximity to the furnace or to a cold exterior wall has an adverse effect on the operation of the thermostatic control. 
Recommendation - Add the following requirement to ANSI A119.1:

"The furnace thermostat shall be placed a minimum of three (3) feet from the vertical edge of the furnace compartment door. It shall not be located on an exterior wall or on a wall separating the furnace compartment from a habitable room."

3.4 ELECTRICAL SYSTEMS (PART E) - The following problems are taken from the data presented in Appendices B, C and D. The percentage of mobile homes in each sample with the problem is listed along with the pertinent paragraphs of the 1974 and 1975 editions of the ANSI A119.1 Standard for Mobile Homes (NFPA 501B - 1973 and 1974 editions). A discussion of the problem is included with recommendations for changes in the Standard and other phases of the mobile home supply process where appropriate.

\subsubsection{WIRING METHIODS - FASTENING BOXISS, FITTINGS, CABINETS (EIVFB)}

Boxes were routinely inspected for tightness in the field study. Mobile home occupants would not generally recognize this as a problem (Private and HUD Samples).

\begin{tabular}{|l|c|}
\hline Sample & $\begin{array}{c}\text { \% of Mobile Homes in } \\
\text { Sample with Problem }\end{array}$ \\
\hline HUD & - \\
Private & 5.6 \\
Field & 26.8 \\
\hline
\end{tabular}

Pertinent ANSI Al19.1 Reference (1974 and 1975)

E8.13 - Boxes, fittings and cabinets shall be securely fastened in place. Exception: Snapin type boxes or boxes provided with special wall or ceiling brackets that securely fasten boxes in walls and ceilings may be used (E11.5 in 1974).

Discussion - The basic problem was that switch boxes, duplex outlet boxes and boxes that serviced ceiling fixtures were not adequately attached to their surroundings. Where mechanical fastenings of boxes to wall paneling was used (screws, nails, or staples) and the wall paneling was less than $1 / 4$ inch thick, the paneling did not offer a sufficient thickness of material to adequately anchor the boxes. Where snap-in boxes were used, the clearance between box and paneling becomes critical and in the majority of cases these clearances were excessive resulting in inadequately anchored boxes.

Loose ceiling fixtures were noted where snap-in type boxes were used in vegetable fiberboard ceiling materials. Some of these ceiling materials do not have the necessary degree of structural integrity to provide proper anchorage for snap-in type boxes or mechanically fastened boxes. As in the case of snap-in boxes anchored to wall paneling, the dimensions of the cutouts into which the box fits are critical. The cutout dimensions are specially critical when vegetable fiberboard ceiling materials are used.

Another possible cause for the loosening of the mechanical fasteners used to attach boxes and fittings are the vibrations induced during transportation of the mobile home.

These observed problems can be related to an inadequacy in the ANSI Al19.1 Standard that simply states that "boxes, fittings and cabinets shall be securely fastened in place," and does not define "securely fastened in place" or indicate how it can be evaluated in the enforcement process. 
Recommendations

1. A solution to this problem could be to adopt the National Electrical Code (N.E.C.) requirements for support of boxes that require attachment to structural members directly, or to approved metal or wooden braces that are attached to structural members. The pertinent paragraph in N.E.C. is 370-13 "Supports" which states that:

"Boxes shall be securely and rigidly fastened to the surface upon which they are mounted, or securely and rigidly embedded in concrete or masonry. Boxes shall be supported from a structural member of the building either directly or by using a substantial and approved metal or wooden brace, or shall be supported as is otherwise provided in this Section. If of wood, the brace shall not be less than one-inch thickness. If of metal, it shall be corrosionresistant and shall not be less than No. 24 MSG.

Where mounted in new walls in which no structural members are provided or in existing walls in previously occupied buildings, boxes not over 100 cubic inches in size, specifically approved for the purpose, shall be affixed with approved anchors or clamps so as to provide a rigid and secure installation."

2. An alternative to adoption of the N.E.C. prescriptive requirement would be to develop a performance specification giving strength and rigidity requirements for box and fitting attachments to ceiling and wall components.

\subsubsection{LIGHTING FIXTURES - DURABILITY OF LIGHTING FIXTURES (EXUR)}

\begin{tabular}{|l|c|}
\hline Sample & $\begin{array}{c}\text { \% of Mobile Homes in } \\
\text { Sample with Problem }\end{array}$ \\
\hline HUD & 3.5 \\
Private & 5.5 \\
Field & 4.7 \\
\hline
\end{tabular}

Pertinent ANSI A119.1 References

1974

E5.1 - Electrical materials, devices, appliances, fittings and other equipment installed, intended for use in, or attached to the mobile home shall be listed by a nationally recognized testing agency and shall be connected in an approved manner when in service. Facilities shall be provided to securely fasten appliances when the mobile home is in transit (see Section 23 for provisons on grounding).

1975

E7.1 - Electrical materials, devices, appliances, fittings and other equipment installed, intended for use in, or attached to the mobile home shall be approved for the application and shall be connected in an approved manner when in service. Facilities shall be provided to securely fasten appliances when the mobile home is in transit / see Section 9 for provisions on grounding). 
Discussion - Poor durability performance of lighting fixtures was a general problem found in the study. Although the fixtures had been approved for use "by nationally recognized testing agencies" many were of a low quality and required frequent repair or replacement. It is difficult for the enforcement officials to require some useful life of the fixtures since the ANSI Al19.1 Standard (like most of the housing standards) does not address durability other than in general terms.

Recommendation - A study of durability of electrical devices, including lighting fixtures, should be initiated for all types of housing.

\subsubsection{OUTDOOR OUTLETS, FIXTURES, ETC. - LACK OF WATERPROOFING (EBTF)}

\begin{tabular}{|l|c|}
\hline Sample & $\begin{array}{c}\% \text { of Mobile Homes in } \\
\text { Sample with Problem }\end{array}$ \\
\hline HUD & 1.3 \\
Private & 1.9 \\
Field & 2.7 \\
\hline
\end{tabular}

Pertinent ANSI Al19.1 References

\section{4}

E22.1 - Outdoon fixtures and equipment shall be recognized for outdoor use. outdoon receptacles or convenience outlets shall be of gasketed-cover type.

1975

E13.1 - Same as E22.1 - 1974 .

Discussion - The majority of problems were caused by convenience outlets that did not remain waterproof or by the use of non-waterproof outlets in exterior applications. The Standard does not require mobile homes to have exterior convenience outlets but does state that if they are provided, they must be waterproof.

The mobile home manufacturers cannot be held responsible in the many instances where mobile homes delivered to the Wilkes-Barre area in the aftermath of Hurricane Agnes had to be equipped with outside outlets for heat tape connections and weatherproof fixtures were not available for instaliation; non-waterproof outlets were used in these cases. This does point out a problem if the mobile home occupant should require use of heat tape and an exterior outlet is not available on the unit.

Recommendation - The ANSI Standard should be amended to require at least one weatherproof outlet on a separate fused circuit in the vicinity of the water inlet pipe for heat tape use.

\subsection{EVALUATION OF PROBLEMS RELATED TO THE MOBILE HOME ENFORCEMENT PROCESS}

4.1 CONSTRUCTION - The following problems are taken from the data presented in Appendices $B, C$ and $D$. The percentage of mobile homes which have the problem is listed along with the pertinent paragraphs of the 1974 and 1975 editions of the ANSI All9.1 Standard for Mobile Homes (NFPA 501B - 1973 and 1974 editions). A discussion of the problem is included with recommendations for changes in the enforcement process or other phases of the mobile home supply process where appropriate. 


\subsubsection{EXTERIOR WALLS - EXCESSIVE HEAT LOSS (EXHL)}

Wall cavities of mobile homes in the Field Study were generally not inspected for sufficient amounts of insulation since it would require removal of permanent construction. Data in the HUD and Private Samples resulted from occupant complaints.

\begin{tabular}{|l|c|}
\hline Sample & $\begin{array}{c}\text { \% of Mobile Homes in } \\
\text { Sample with Problem }\end{array}$ \\
\hline HUD & 5.5 \\
Private & 1.7 \\
Field & 0.4 \\
\hline
\end{tabular}

\section{Pertinent ANSI A119.1 Reference (1974 and 1975)}

B7.5 Heat Loss. The total calculated heat loss of the living unit at the outdoor design temperature as certified in 7.5 .1 of this Part shall not exceed 40 Btu/hr/6t ${ }^{2}$ of the total floor area or $275 \mathrm{Btu} / \mathrm{hr}$ lineal ft. of the perimeter of the space to be heated to $70^{\circ} \mathrm{F}$, whichever is greater. The minimum total resistance value $(R)$, excluding framing, of the wall (less windows and doors), ceiling and floor shall not be less than:

$$
\begin{aligned}
& \text { wall } \ldots \ldots \ldots \ldots \ldots \ldots \ldots \ldots \ldots .6 .0 \\
& \text { Ceiling ................... } 16.0 \\
& \text { Floor ........................ 10.0 }
\end{aligned}
$$

Discussion - Problems recorded in this category were generally indications of missing or inadequate amounts of thermal insulation in portions of exterior walls including hot water heater compartment doors. The frequent problem of insufficient insulation in the HuD mobile homes may be explained in part, at least, by the fact that some probably were not insulated for the Central Pennsylvania climate. Missing insulation is an indication of an inadequate enforcement program ( $p l a n t$ inspection).

\section{Recommendations}

1. In-plant monitoring of the construction process must be improved to eliminate the possibility of insufficient or missing insulation or the application of insulation that is cut too short for the intended purpose or not properly fitted.

2. Adoption of the Tentative Interim Admendment on Energy Conservation being developed by the ANSI Al19.1 Committee is recommended.

\subsubsection{ROOF SYSTEM - EXCESSIVE HEAT LOSS (RHLS)}

The Field Sample data are quite significant since of the 20 units inspected in the roof cavity for missing insulation or insulation cut short, three (1.2\% of Field Sample) were found to have insulation deficiences.

\begin{tabular}{|l|c|}
\hline Sample & $\begin{array}{l}\% \text { of Mobile Homes in } \\
\text { Sample with Problems }\end{array}$ \\
\hline HUD & 0.1 \\
Private & 0.9 \\
Field & 1.2 \\
\hline
\end{tabular}

Pertinent ANSI Al19.1 Reference (1974 and 1975)

B7.5 Heat Loss. The total calculated heat loss of the living unit at the oytdoor design temperature as certified in 7.5 .1 of this Part shall not exceed $40 \mathrm{Btu} / \mathrm{hr} / \mathrm{ft} \mathrm{t}^{2}$ of the to tal floor area or $275 \mathrm{Btu} / \mathrm{hr}$ lineal $6 t$. of the perimeter of the space to be heated to $70^{\circ} \mathrm{F}$, whichever is greater. The minimum total resistance value $(R)$, excluding framing, of the wall (less windows and doors), ceiling and floor shall not be less than: 


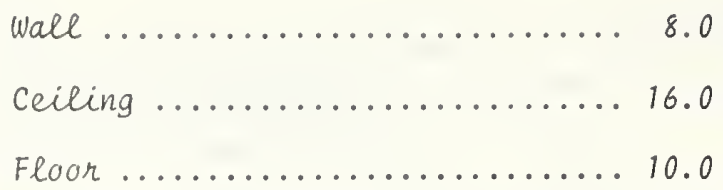

Discussion - Thermal insulation between roof trusses were found to be missing or cut short of the wall resulting in the potential for excessive heat loss. Inadequate in-plant inspection probably accounted for most of these construction deficiencies.

Recommendation - Improved in-plant inspection during the manufacturing process is needed to insure that the required thermal insulation is used.

4.2 PLUMBING SYSTEMS - The following problems are taken from the data presented in Appendices B, C and D. The percentage of mobile homes which have the problem 1s 1 isted along with the pertinent paragraphs of the 1974 and 1975 editions of the ANSI Al19.1 Standard for Mobile Homes (NFPA 501B - 1973 and 1974 editions). A discussion of the problem is included with the recommendations for changes in the enforcement process or other phases of the mobile home supply process where appropriate.

\subsubsection{PLUMBING PIPING - WATER LEAKS (JCT1.)}

\begin{tabular}{|l|c|}
\hline Sample & $\begin{array}{c}\% \text { of Mobile Homes in } \\
\text { Sample with Problem }\end{array}$ \\
\hline HUD & 23.3 \\
Private & 17.7 \\
Field & 22.6 \\
\hline
\end{tabular}

Pertinent ANSI A119.1 Reference (1974 and 1975)

C7.1 Tightness. Joints and connections in the plumbing system shall be gastight and watertight for the pressures required under testing procedures.

Discussion - These problems include plumbing piping joint leaks of supply, drain and vent systems. This category includes all piping problems not related to freezing, material defects or corrosion. Possible reasons for approximately one-fifth of the mobile homes in the study exhibiting plumbing leaks are: (1) poor workmanship, (2) inadequate in-plant inspection, and (3) inadequate design for forces induced during transit and site set-up.

\section{Recommendations}

1. Improved in-plant inspection of the manufacturing process is needed to insure that workmanship standards are maintained.

2. An evaluation of the dynamic loading effects of transportation and site set-up on joints and piping should be conducted.

\subsubsection{DRAINAGE SYSTEM - INADEQUATE GRADE OF HORIZONTAL PIPING (DSGR)}

\begin{tabular}{|l|c|}
\hline Sample & $\begin{array}{l}\text { \% of Mobile Homes in } \\
\text { Sample with Problem }\end{array}$ \\
\hline HUD & 0.1 \\
Private & 5.7 \\
Field & 0.4 \\
\hline
\end{tabular}


Same as 1975 except the phrase "Except for fixture connections on the inlet side of the trap," is deleted.

C12.7 Grade of Horizontal Drainage Piping. Except for fixture connections on the inlet side of the trap, horizontal drainage piping shall be run in practical alignment and have a uniform grade of not less than $1 / 4$ inch per foot toward the mobile home drain outlet. Where it is impractical, due to the structural features or arrangement of any mobile home, to obtain a grade of $1 / 4$ inch per foot, the pipe or piping may have a grade of not less than $1 / 8$ inch per foot, when a full size cleanout is installed at the upper end.

Discussion - The inadequate slope of horizontal drain piping is an enforcement problem in that the ANSI Al19.1 Standard is very specific as to minimum slope requirements.

Recommendation - The in-plant inspection process should be improved in the area of plumbing piping for Standard compliance.

\subsubsection{WATER DISTRIBUTION SYSTEM - PROBLEMS WITH WATER HEATER RELIEF VALVE DRAINS (WIRV3.)}

Hot water heater relief valve drains were routinely inspected during the field study. Occupants of units included in the HUD and Private Samples would not generally consider this a problem.

\begin{tabular}{l|c}
\hline \multicolumn{1}{|c|}{ Sample } & $\begin{array}{l}\text { \% of Mobile Homes in } \\
\text { Sample with Problem }\end{array}$ \\
\hline HUD & 0.1 \\
Private & 0.8 \\
Field & 15.6
\end{tabular}

Pertinent ANSI A119.1 References (1974 and 1975)

1974

111.3.1.3 - Relief valves shall be provided with full-sized drains which shall extend outside directed downward and terminate beneath the mobile home. Drain lines shall be of a material listed for hot water distribution and shall drain fully by gravity, shall not be trapped and shall not have their outlets threaded.

\section{5}

C11.3.1.3 - Relief valves shall be provided with full-size drains which shall be directed downward and discharged beneath the mobile home. Drain lines shall be of a material listed for hot water distribution and shall drain fully by gravity, shall not be trapped, and shall not have their outlets threaded.

Discussion - Most of these data occurred in HUD Agnes units and could have resulted from field replacement or repair of hot water heaters. The problems are of three general types which are violations of $\mathrm{Cll} .3 .1 .3$; (1) relief valve terminates above the floor or in the floor and does not directly "discharge beneath the mobile homes," (2) relief valve drain end threaded, and (3) relief valve drain undersize as compared to the relief valve outlet. These observed violations would only result in a problem if a water heater malfunction occurred requiring the relief valve drain to function. Violation (1) would result in water discharge into the mobile home damaging flooring, carpeting, floor insulation, etc. Violations (2) and (3) could result in a life-safety hazard, such as pressure build-up and explosion of the hot water heater, if a threaded-end drain were capped or an undersized drain installed.

Recommendations

1. Excluding hot water heater problems caused by modifications in the field, the standard violations indicate an inadequate enforcement program (in-plant inspection). 
2. As a clarification, revise Cll.3.1.3 as follows (revised portion underlined):

"Relief valves shall be provided with drains of cross sectional area equivalent to that of the relief valve outlet and be directed downward and discharge beneath the mobile home. Drain lines shall be of a material listed for hot water distribution and shall drain fully by gravity, shall not be trapped, shall not have their outlets threaded, and the end of the drain shall be visible for inspection."

\subsubsection{PLUMBING PIPING - INADEQUATE HANGERS AND SUPPORTS (PHAS)}

\begin{tabular}{|l|c|}
\hline Sample & $\begin{array}{c}\text { \% of Mobile Homes in } \\
\text { Sample with Problem }\end{array}$ \\
\hline HUD & 2.1 \\
Private & 2.8 \\
Field & 0.8 \\
\hline
\end{tabular}

Pertinent ANSI Al19.1 References (i974 and 1975)

C.10. Hangers and Supports

C10.1 Strains and Stresses. Piping in a plumbing system shall be installed without undue strains and stresses, and provision shall be made for expansion, contraction, and structural settlement.

C10.2 Piping Supports. Piping shall be secured at sufficiently close intervals to keep the pipe in alignment and carry the weight of the pipe and contents.

\section{C10.3 Hangers and Anchors}

C10.3.1 Hangers and anchors shall be of sufficient strength to support their proportional share of the pipe alignments and prevent rattling.

C10.3.2 Piping shall be securely attached to the structure by proper hangers, clamps or brackets which provide protection against motion, vibration, road shock, torque in the chassis, or other unusual conditions.

Discussion - Plumbing piping support criteria in ANSI Al19.1 are presented in a performance format with requirements such as "secured at sufficiently close intervals," "sufficient strength," and "securely fastened." C10.3.2 specifically requires design for the antic1pated forces of transportation and site set-up. This would appear to be adequate as long as the enforcement agency requires the manufacturer to provide documentation showing such compliance.

\section{Recommendations}

1. The enforcement process (plan review and in-plant inspection) should be improved to insure adequate support of the plumbing piping.

2. A study of the effects of transportation on mobile homes should include its impact on the plumbing system.

\subsubsection{FITTINGS - CORROSION OF WATER SUPPLY PIPING (WDM)}

Water piping was routinely inspected during the field study. Corrosion of piping would generally not be reported as a problem by mobile home occupants (HUD and Private Samples) unless it resulted in a water leak.

\begin{tabular}{|l|c|}
\hline Sample & $\begin{array}{l}\text { \% of Mobile Homes in } \\
\text { Sample with Problem }\end{array}$ \\
\hline HUD & -- \\
Private & 0.3 \\
Field & 8.6 \\
\hline
\end{tabular}


011.4.2 Fittings. Appropriate fittings shall be used for all changes in direction or size and where pipes are joined. The material and design of fittings shall conform to the type of piping used.

1975

C11.4.2 Fittings. Appropriate fittings shall be used for all changes in size and where pipes are joined. The material and design of fittings shall conform to the type of piping used.

Discussion - Corrosion of water distribution piping was observed with systems composed of similar metals as well as those of dissimilar metals (copper to galvanized steel). The A119.1 Standard requires special consideration for the design of fittings when piping materials are joined.

\section{$\underline{\text { Recommendations }}$}

1. The enforcement process should be improved at the plan review stage to insure that necessary precautions are taken to prevent corrosion of piping at fittings.

2. In-plant inspection procedures should verify that these precautions are implemented in the manufacturing process.

3. As a clarification of good practice, Cll.4.2 should be modified as follows:

"Fittings - Appropriate fittings shall be used for all changes in size and where pipes are joined. The material and design of fittings shall conform to the type of piping used. Special consideration shall be given to prevent corrosion when dissimilar metals are joined."

\subsubsection{PLUMBING FIXTURE MALFUNCTIONS (VVGL)}

\begin{tabular}{|l|c|}
\hline Sample & $\begin{array}{l}\text { \% of Mobile Homes in } \\
\text { Sample with Problem }\end{array}$ \\
\hline HUD & -- \\
Private & 1.2 \\
Field & 0.1 \\
\hline
\end{tabular}

Pertinent ANSI A119.1 Reference (1974 and 1975)

C13.1 General. Each plumbing fixture trap shall be protected against siphonage and back pressure, and air circulation shall be insured throughout all parts of the drainage system by means of vents installed in accordance with the requirements of this section and as othervise required by this standard.

Discussion - These problems are related to poorly functioning plumbing fixtures or reported sewer gas odors in the mobile home. Even though the amount of data is small with most occurring in the Private Sample, it is significant because of the potential life-safety hazard if sewer gas should back up into the mobile home. Plumbing systems which were inadequately sealed or vents which were plugged oould have caused this problem. Even if the plumbing piping is sealed correctly in the factory, joints could become loose during transportation and site set-up. 
1. Adequate plant workmanship and conformance with the ANSI A119.1 Standard should be verified by improved in-plant inspections as part of the enforcement process.

2. The drainage system, vent system and plumbing fixtures should be tested prior to occupancy to insure tightness of the system which may have been affected by transportation and set-up.

\subsubsection{TOILET FLUSH TANKS - USE OF NONAPPROVED FLUSHING DEVICES (WøSC6.)}

The ball cock was routinely inspected in the field study. Mobile home occupants (HUD and Private Samples) would not report this as a problem unless a malfunction occurred.

\begin{tabular}{|l|c|}
\hline Sample & $\begin{array}{l}\text { \% of Mobile Homes in } \\
\text { Sample with Problem }\end{array}$ \\
\hline HUD & -- \\
Private & -- \\
Field & 3.9 \\
\hline
\end{tabular}

Pertinent ANSI A119.1 Reference (1974 and 1975)

11.2.6 Flush Tanks. Toilet flush tanks shall be equipped with an approved anti-siphon ball cock which shall be installed and maintained with its outlet or critical level mark not less than 1 inch above the full opening of the overflow pipe.

Discussion - These problems concern the use of a submerged ball cock flushing devices in violation of C11.2.6. These devices could allow flushing tank water to back flow into the potable water supply.

Recommendation - Improved plan review and in-plant inspection is required.

\subsubsection{VENT PIPE PENETRATION PROBLEM (NVTL1.)}

Although only a limited number of roof vents were inspected during the field study, this problem was observed with sufficient frequency to warrant discussion here.

\begin{tabular}{|l|c|}
\hline Sample & $\begin{array}{c}\text { \% of Mobile Homes in } \\
\text { Sample with Problem }\end{array}$ \\
\hline HUD & -- \\
Private & 0.5 \\
Field & 0.8 \\
\hline
\end{tabular}

Pertinent ANSI A119.1 Reference (1974 and 1975)

C13.6.1 Roof Extension. Each vent pipe shall extend through its flashing and terminate vertically, undiminished in size, not less than 2 inches above the roof. Vent openings shall not be less than 3 feet, 0 inches away from any motor-driven air intake that opens into habitable areas.

Discussion - These problems are concerned with extension of the vent pipe 2 inches above the roof as required by C13.6.1. Vents were observed which terminated within the roof cavity, at the roof level or the vent opening was blocked by insulation which could cause trap seal failure.

Recommendation - The required extension of vents above the roof is quite specific in C13.6.1 and the violations would indicate a problem with the enforcement process (in-plant inspection). 
4.3 HEATING SYSTEMS - The following problems are taken from the data presented in Appendices $B, C$ and D. The percentage of mobile homes in each sample with the problem is listed along with the pertinent paragraphs of the 1974 and 1975 editions of the ANSI Al19.1 Standard for Mobile Homes (NFPA 501B - 1973 and 1974 editions). A discussion of the problem is included with recommendations for changes in the Enforcement Process or other phases of the mobile home supply process where appropriate.

\subsubsection{VENT SYSTEM - USE OF UNLISTED APPLIANCE COR.PONENTS OR INLDEQUATELY INSTALLED COM-} PONENTS (HAVE)

\begin{tabular}{|c|c|}
\hline Sample & $\begin{array}{l}\% \text { of Mobile Homes in } \\
\text { Sample with Problem }\end{array}$ \\
\hline HUD & 2.5 \\
\hline Private & 14.6 \\
\hline Field & 12.5 \\
\hline
\end{tabular}

Pertinent ANSI Al19.1 Reference (1974 and 1975)

06.4.1 - The venting as required by 6.1 .2 shall be accomplished by one or more of the methods given in $(a)$ and $(b)$ below:

(a) An integral vent system listed or certified as part of the appliance.

(b) A venting system consisting entirely of listed components, including roof jack, installed in accordance with the terms of the appliance listing and appliance manufacturer's instructions (see 6.3.2).

Discussion - These problems concern the vent systems of heating appliances (furnace and hot water heater) which do not consist entirely of listed components or were not installed in accordance with the terms of the appliance listing or the manufacturer's instructions. The cause of this problem appears to be regulatory in nature with the inspection process allowing the installation of venting systems which do not conform to D6.4.1.

Recommendation - The plan and specification review and plant inspection phases of the enforcement process should be improved to insure that vent systems conform to D6.4.1.

\subsubsection{APPLIANCES - INADEQUATE ACCESSIBILITY FOR REPAIR AND REPLACEMENT (HAAC)}

Appliance accessibility was routinely

inspected during the field study.

Mobile Home occupants (HUD and Pri-

vate Samples) would not generally

recognize this as a problem.

\begin{tabular}{l|c}
\hline Sample & $\begin{array}{c}\text { \% of Mobile Homes in } \\
\text { Sample with Problem }\end{array}$ \\
\hline HUD & 3.5 \\
Private & 1.3 \\
Field & 19.5 \\
\hline
\end{tabular}

Pertinent ANSI A119.1 Reference (1974 and 1975)

06.7 Accessibility. Every appliance shall be accessible for inspection, service, repair, and replacement without removing permanent construction. Sufficient room shall be available to enable the operator to observe the burner, control, and ignition means while starting the appliance.

Discussion - Accessibility to hot water heaters for replacement or repair was quite limited in many cases. D6.7 is quite specific in requiring "accessibility for inspection, service, repair and replacement without removing permanent construction." The placement within permanent kitchen cabinet construction makes it difficult to repair and impossible to replace without removing permanent construction. The location adjacent to living areas or closets often requires the removal of wall paneling for access. 
Recommendation - The enforcement process (plan review and 1n-plant inspection) should be Improved to insure accessibility to appliances as required by D6.7.

\subsubsection{VENT SYSTE1 - LOOSE VENT PIPING (IAVE3.)}

\begin{tabular}{|l|r|}
\hline Sample & $\begin{array}{l}\text { \% of Mobile Homes in } \\
\text { Sample with Problem }\end{array}$ \\
\hline HUD & 0.8 \\
Private & 9.1 \\
Field & 10.5 \\
\hline
\end{tabular}

Pertinent ANSI A119.1 Reference (1974 and 1975)

D6.4.2 - Venting and combustion air systems shall be installed in accordance with the following:

(a) Components shall be securely assembled and properly aligned using the method shown in the appliance manufacturer's instructions.

(b) Draft hood connectors shall be firmly attached to draft hood outlets on jlue collars by sheet metal screws or by an equivalent means.

(c) Every joint of a vent, vent connector, exhaust duct and combustion air intake shall be secure and in alignment.

Discussion - Problems listed in this category are related to loose piping in the venting and combustion air systems for gas and oil furnaces and gas hot water heaters. This could be a life-safety hazard if flue gases should discharge into an appliance compartment which shares a common atmosphere with the living area. In describing the type of vent connections required, D6.4.2 (b) specifies required performance attributes such as "firmly attached" and "by an equivalent means" which could present difficulties in obtaining uniform enforcement. It is also possible that the vent system attachment may meet the requirements of the Standard as the mobile home leaves the plant but forces induced during transportation and site set-up could have a deteriorating effect on the attachments.

\section{Recommendations}

1. Because of the life-safety implications, the enforcement process (plan review and in-plant inspection) should provide thorough evaluation of the joints of the fuel burning vent system.

2. A pre-occupancy check should be required including an inspection of the venting and combustion air system.

3. A study of the dynamic effects of transportation and set-up on mob1le homes should include an evaluation of these effects on venting and combustion air system joints.

4. Clarify the intent of D6.4.2(b) as follows:

"D6.4.2(b) - Draft hood connectors sha11 be firmly attached to draft hood outlets or flue collars by sheet metal screws or by equivalent effective mechanical fasteners."

\subsubsection{SUPPLY AIR SYSTEM - JOINTS AND SEAMS NOT AIRTIGHT (HARG)}

Duct risers to floor registers were routinely inspected during the field study.

\begin{tabular}{|l|c|}
\hline Sample & $\begin{array}{l}\text { \% of Mobile Homes in } \\
\text { Sample with Problem }\end{array}$ \\
\hline HUD & - \\
Private & 6.5 \\
Field & 19.5 \\
\hline
\end{tabular}


1974

06.10.3 Joints and Seams. Joints and seams of ducts shall be securely fastened and made substantially airtight. Slip joints shall have a lap of at least 1 inch and shall be individually fastened. Tape or caulking compound may be used for sealing mechanically secure joints. Where used, tape or caulking compound shall not be subject to deterioration under long exposures to temperatures up to $200^{\circ} \mathrm{F}$ and to conditions of high humidity, excessive moisture, or mildew.

06.10.5 Registers. Fittings connecting the registers to the duct system shall be constructed of metal or material which complies with the requirements of class 1 or 2 ducts under UL Standard 181. Registers shall be constructed of metal or conform with the following:

06.10.5.1 - Be made of a material classified SE-O or SE-1 when tested as described in Underwriters' Laboratories, Inc. Standard for Tests of Flammability of Plastic Materials, UL94-1972.

1975

06.10 .3 Same as 1974 .

06.10.5 Registers or Grills. Fittings connecting the registers or grills to the duct system shall be constructed of metal or material which complies with the requirements of Class 1 or 2 ducts under Underwriters' Laboratories. Inc. Standard for Air Ducts, UL181-1972. Registers or grills shall be constructed of metal or conform with the following:

06.10.5.1 Same as 1974 except SE-0 changed to 94VE-0 and SE-1 changed to 94VE-1.

Discussion - The problems grouped in this category are of three distinct types: (1) riser from the horizontal air supply duct to the floor register is either missing or constructed of duct tape, (2) debris in the duct such as trash, flooring covering, etc., and (3) restriction of air flow through the floor register. The use of duct tape risers is a violation of D6.10.5 where the riser material must meet the requirements of UL 181-1972. The absence of a riser and the presence of construction debris in the duct are workmanship problems reflecting on the in-plant inspection process. The restriction of air flow from the duct to the floor register can be caused by undersize floor openings, sheet metal bent into the air flow of the duct, or improper workmanship associated with the installation of floor covering.

Recommendation - In-plant inspection should be improved to eliminate obvious violations of the Standard.

4.3.5 FUEL-BURNING APPLIANCES - INADEQUATE SEPARATION OF COMBUSTION AIR SYSTEM FROM ATMOSPHERE OF MOBILE HOME (HAMS)

The major portion of these data resulted from the mobile home inspections by state enforcement officials (Private Sample).

\begin{tabular}{l|c}
\hline Sample & $\begin{array}{c}\% \text { of Mobile Homes in } \\
\text { Sample with Problem }\end{array}$ \\
\hline HUD & -- \\
Private & 5.8 \\
Field & 0.4 \\
\hline
\end{tabular}




\section{4}

D6.3.2 - All fuel-burning appliances, except ranges, ovens, illuminating appliances and clothes dryers, shall be installed to provide for the complete separation of the combustion system from the interior atmosphere of the mobile home. Combustion air inlets and flue gas outlets shall be listed or certified as components of the appliance. The required separation may be obtained by:

(a) The installation of direct vent system (sealed combustion system) appliances, or

(b) The installation of appliances within enclosures so as to separate the appliance combustion system and venting system from the interior atmosphere of the mobile home. There shall not be any door, removable access panel, or other opening into the enclosure from the inside of the mobile home. Any opening for ducts, piping, wiring, etc., shall be sealed.

1975

06.3.2 - All fuel-burning appliances, except ranges, ovens, illuminating appliances, clothes dryers, solid fuel-burning fireplaces and solid fuel-burning fireplace stoves, shall be installed to provide for the complete separation of the combustion system from the interior atmosphere of the mobile home. Combustion air inlets and flue gas outlets shall be listed or certified as components of the appliance. The required separation may be obtained by:

(a) Same as 1974 .

(b) Same as 1974 .

Discussion - Some of these problems were violations of D6.3.2(b) where the furnace and water heater compartments were not adequately sealed from the atmosphere of the mobile home. Others resulted when the direct vent systems of sealed combustion system appliances [D6.3.2 (a)] were not sealed adequately due to manufacturing problems or separation caused by transit and set-up. This could be a life-safety problem if combustion air was taken from the interior atmosphere of the mobile home depleting oxygen available to the occupants.

\section{Recommendations}

1. Because of safety-related concerns, the in-plant inspection of sealed combustion systems for appliances listed in D6.3.2 should be more thorough.

2. A check of the sealed combustion system for these appliances should be part of a preoccupancy inspection to insure that a dangerous condition does not exist.

\subsubsection{GAS SUPPLY CONNECTION - INADEQUATE PERMANENT MARKING (HGID)}

The presence of a gas identification tag was routinely checked in the field study. Mobile home occupants (HUD and Private Samples) would not generally recognize this as a problem.

\begin{tabular}{lc}
\hline Sample & $\begin{array}{c}\text { \% of Mobile Homes in } \\
\text { Sample with Problem }\end{array}$ \\
\hline HUD & $-\overline{7}$ \\
Private & 0.7 \\
Field & 17.9 \\
\hline
\end{tabular}


05.1.11 Identification of Gas Supply Connections. Each mobile home shall have permanently affixed to the exterior skin at or near each gas supply connection or the end of the pipe, a tag of 3 inches by 1-3/4 inches minimum size, made of etched, metal-stamped or embossed brass, stainless steel, anodized or alclad aluminum not less than 0.020 inch thick, or other approved material (e.g., 0.005 inch plastic laminates), which reads (as appropriate) either:

\section{$\underline{1975}$}

D5.1.11 Identification of Gas Supply Connections. Each mobile home shall have permanently affixed to the exterior skin at or near each gas supply connection or the end of the pipe, a tag of 3 inches by 1-3/4 inches minimum size, made of etched, metal-stamped or embossed brass, stainless steel, anodized or alclad aluminum not less than 0.020 inch thick, or other approved material (e.9., 0.005 inch plastic laminates), which reads (as appropriate) in accordance with one of the following label designs depending upon the fuel used. The connector capacity indicated on this tag shall be equal to or greater than the total Btuh rating of all intended gas appliances.

Discussion - The absence of a gas supply connection identification tag was noted mostly on HUD Agnes units. It is possible that the tags were on the units when manufactured but were lost or removed later. However, this would be contrary to the intent of D5.1.11 which requires that the tag be "permanently affixed to the exterior skin." This would indicate that something more than a "paste-on" tag should be used. The change in the 1975 editions of the ANSI All9.1 as compared to 1974 is related to the wording on the tag and not the attachment method.

\section{Recommendations}

1. The enforcement program (plan review and in-plant inspection) should include the requirement that the manufacturer use permanently attached identification tags. The "paste-on" type which can be easily removed should not be accepted.

2. As a clarification, D5.1.11 (1975 edition) should be revised as follows (addition underlined) :

"D5.1.11 - Each mobile home shall have permanently affixed to the exterior skin with mechanical fasteners at or near each gas supply connection or the end of the pipe, a tag of 3 inches by $1-3 / 4$ inches minimum size, made of etched, metal stamped or embossed brass, stainless steel, anodized or alclad aluminum not less than 0.020 inch thick, or other approved material (e.g., 0.005 inch plastic laminates), which reads (as appropriate) in accordance with one of the following label designs depending upon the fuel used. The connector capacity indicated on this tag shall be equal to or greater than the total Btuh rating of all intended gas appliances."

\subsubsection{GAS PIPING - INADEQUATE HANGERS AND SUPPORTS (HGHS)}

Gas piping support was routinely checked in the field study. Mobile home occupants (HUD and Private Samples) would not generally recognize this as a problem.

\begin{tabular}{|l|c|}
\hline Sample & $\begin{array}{l}\% \text { of Mobile Homes in } \\
\text { Sample with Problem }\end{array}$ \\
HUD & - \\
Private & 2.2 \\
Field & 10.5 \\
\hline
\end{tabular}

Pertinent ANSI A119.1 Reference (1974 and 1975)

05.1.18 Hangers and Supports. All gas piping shall be adequately supported by galvanized or equivalently protected metal straps or hangers at intervals of not more than 4 feet, except where adequate support and protection is provided by structural members. Solid-ironpipe gas supply connections (s) shall be rigidly anchored to a structural member within 6 inches of the supply connections (s). 
Discussion - An inadequate number of hangers for gas piping is related to the enforcement process since D5.1.18 is quite specific as to minimum spacing requirements.

Recommendation - Improve plan and specification review and in-plant inspection to assure compliance with the requirements of D5.1.18.

\subsubsection{SUPPLY DUCT SYSTEM - SYSTEM NOT AIR TIGHT (HACS3.)}

\begin{tabular}{|l|c|}
\hline Sample & $\begin{array}{c}\text { \% of Mobile Homes in } \\
\text { Sample with Problem }\end{array}$ \\
\hline HUD & -- \\
Private & 4.1 \\
Field & 0.4 \\
\hline
\end{tabular}

Pertinent ANSI Al19.1 Reference (1974 and 1975)

D6.10.1.3 Airtightness of Supply Duct Systems. A supply duct system shall be considered substantially airtight when the static pressure in the duct system, with all registers sealed and with the furnace air circulator at high speed, is at least 80 percent of the static pressure measured in the furnace casing, with its outlets sealed and the furnace air circulator operating at high speed. For the purpose of this paragraph and 6.10.2 pressures shall be measured with a water manometer or equivalent device calibrated to read in increments not greater than $1 / 10$ inch water column.

Discussion - These problems were recorded from visual observations of enforcement officials investigating consumer complaints (Private Sample) and do not necessarily reflect the fallure of the supply air system to pass the test requirements of D6.10.1.3. Assuming the supply system was adequately sealed at the factory, it is possible that effects of transportation and site set-up could loosen the system causing excessive leakage.

$\underline{\text { Recommendations }}$

1. In-plant inspection should insure that testing according to D6.10.1.3 is conducted.

2. The airtightness of the supply duct system should be verified as part of a pre-occupancy inspection.

\subsubsection{APPLIANCES - INADEQUATE MARKINGS (HAMK)}

Required markings on appliances were routinely inspected in the field study. Mobile home occupants (HUD and Private Sample) would not generally recognize this as a problem.

\begin{tabular}{|l|c|}
\hline Sample & $\begin{array}{l}\text { \% of Mobile Homes in } \\
\text { Sample with Problem }\end{array}$ \\
\hline HUD & -- \\
Private & 0.2 \\
Field & 10.9 \\
\hline
\end{tabular}

Pertinent ANSI Al19.1 References (1974 and 1975)

D6.6 Marking

06.6.1 - Information on clearances, input rating, lighting and shutdown shall be attached to the appliances with the same permanence as the nameplate, and so located that it is easily readable when the appliance is properly installed.

D6.6.2 - Each fuel-burning appliance shall bear permanent marking designating the type(s) of fuel for which it is listed.

Discussion - The bulk of these data are related to the absence of required appliance markings. Possible explanations for the missing markings are (1) markings may not have been attached when manufactured, or (2) they may have been removed by occupants or maintenance personnel. 
Recommendation - While there can be little control over what happens to the mobile home after it is occupied, in-plant inspections must verify that required markings are permanently attached to the appliances.

\subsubsection{APPLIANCE CONNECTIONS - INADEQUATE FLEXIBLE GAS CONNECTOR APPLICATIONS (HGAC)}

Flexible gas connectors were inspected during the field study. Unless a malfunction occurred, mobile home occupants would not generally recognize this as a problem.

\begin{tabular}{|l|c|}
\hline Sample & $\begin{array}{l}\% \text { of Mobile Homes in } \\
\text { Sample with Problem }\end{array}$ \\
\hline HUD & -- \\
Private & 0.4 \\
Field & 4.3 \\
\hline
\end{tabular}

Pertinent ANSI A119.I References

1974

05.1.13 Appliance Connections. All gas-burning appliances shall be connected to the fuel piping with materials as provided in 5.1 .2 of this Part or with listed appliance connectors. Listed appliance connectors when used shall not run through walls, floors, ceilings or partitions. Connectors of aluminum shall not be used outdoors.

1975

05.1.13 Appliance Connections. All gas burning appliances shall be connected to the fuel piping. Materials as provided in Section 5.1 .2 of this Part or listed appliance connectors shall be used. Listed appliance connectors when used shall not run through walls, floors, ceilings or partitions. Connectors of aluminum shall not be used outdoors.

Discussion - The problems in this category consist of two types: (1) flexible gas connectors running through the floor to the underside of the mobile home in violation of D5.1.13, and (2) flexible connectors installed on appliances with excessively sharp bends. The second is an example of poor workmanship with the sharp bend being an area of potential gas leak. In many of the instances observed, it was not possible to determine whether they originated in the factory or were related to repair or replacement of the heating units after the mobile home was placed in service.

Recommendation - These examples of poor practice associated with flexible gas connectors which originate during the manufacturing process should be caught by in-plant inspection.

\subsubsection{VENTING SYSTEM - TERMINATION BENEATH THE MOBILE HOME (HAVE5.)}

\begin{tabular}{|l|c|}
\hline Sample & $\begin{array}{c}\text { \% of Mobile Homes in } \\
\text { Sample with Problem }\end{array}$ \\
\hline HUD & -- \\
Private & 1.2 \\
Field & 0.4 \\
\hline
\end{tabular}

Pertinent ANSI A119.I References (1974 and 1975)

06.2.3 The exhaust duct shall not terminate beneath the mobile home.

06.4.3 Venting Systems shall not terminate underneath a mobile home.

Discussion - Most of these problems involved the venting of dryers through the floor to the underside of the mobile home. It could not be determined if this was done by the manufacturer or the occupant; however, it is fair to assume that the occupants were responsible for a great deal of these violations of the ANSI Al19.I Standard. A space provided for a dryer was not always accompained by a venting system. If the manufacturer provides space for a clothes dryer, he should provide an approved venting system and not rely on the mobile home occupant to improvise. 
1. The enforcement process (plan review and in-plant inspection) should be improved to prevent dryer vent systems provided by the manufacturer from terminating under the mobile home.

2. Additiona11y, revise D6.2.3 as follows:

D6.2.3 - If space for a clothes dryer is provided, provision for an exhaust duct, whtch does not terminate beneath the mobile home, shall be installed.

4.4 ELECTRICAL SYSTEMS - The following problems are taken from the data presented in Appendices $B, C$ and D. The percentage of mobile home units in each data sample with the problem is listed along with the pertinent paragraphs of the 1974 and 1975 editions of the ANSI All9.1 Standard for Mobile Homes (NFPA 501B - 1973 and 1974 editions). A discussion of each problem is included with recommendations for changes in the enforcement process or other phases of the mobile home supply process as appropriate.

\subsubsection{RECEPTACLE OUTLETS - POOR INSTALLATION WORKMANSHIP AND DURABILITY (EFIN)}

\begin{tabular}{|l|c|}
\hline Sample & $\begin{array}{l}\text { \% of Mobile Homes in } \\
\text { Sample with Problem }\end{array}$ \\
\hline HUD & 2.5 \\
Private & 1.8 \\
Field & 1.2 \\
\hline
\end{tabular}

Pertinent ANSI A119.1 References

1974

E19.1 Receptacle outlets. All receptacle outlets shall be of the grounding type and shall be installed in accordance with Sections 210-7 and 210-21.6 of the National Electrical Code (ANSI C1-1971; NFPA No. 70-1971).

1975

E6.1 All receptacle outlets shall be:

(a) of grounding type;

(b) installed according to Section 210-7 of the National Electrical Code (NFPA No. 70-1974; ANSI C1-1974); and

(c) except when supplying specific appliances, be parallel-blade, 15 ampere, 125-volt, either single or duplex.

Note: For ground-fault circuit interrupter requirements, refer to Section 210-8(a) of the National Electrical Code (NFPA No. 70-1974; ANSI C1-1974).

Discussion - The problems associated with receptacle outlets can be classified into two categories: installation workmanship and durability. The substandard workmanship problems are related to inadequate electrical inspection during manufacturing. The Standard (E5.11974 Edition) simply states that devices "shall be listed by a nationally recognized testing agency" which does not necessarily insure long-term durability. This problem of inadequate durability is not unique to mobile homes within the housing area.

Recommendations

1. Improved in-plant inspection is required to reduce workmanship problems. 
2. A study of durability of electrical devices, including receptacle outlets, should be initiated for all types of housing.

\subsubsection{SERVICE GROUNDING - FAULTY INSTALLATION (EGSE)}

This problem occurred predominately in the HUD Agnes units (HUD and Field Samples). It can possibly be attributed to the emergency conditions encountered with these units.

\begin{tabular}{|l|c|}
\hline Sample & $\begin{array}{c}\text { \% of Mobile Homes in } \\
\text { Sample with Problem }\end{array}$ \\
\hline HuD & 1.7 \\
Private & 0.6 \\
Field & 0.8 \\
\hline
\end{tabular}

Pertinent ANSI A119.1 References

1974

E23.1 Service Grounding. Service grounding shall be accomplished as follows:

E23.1.1 - The green-colored grounding wire in the supply cord or permanent feeder wiring shall be connected to the grounding bus in the distribution panelboard or disconnecting means.

E23.1.2 - The distribution panelboard shall have a grounding bus, or approved grounding means for the various grounding connections.

E23.1.3 - The grounding bus shall have sufficient terminals for all grounding conductors.

1975

E9.1 General. Grounding of both electrical and nonelectrical metal parts in the mobile home shall be through connection to a grounding bus in the mobile home distribution panelboard. The grounding bus shall be grounded through the green-colored conductor in the supply cord or the feeder wiring to the service ground in the service-entrance equipment located adjacent to the mobile home location. Neither the frame of the mobile home nor the frame of any appliance shall be connected to the neutral conductor in the mobile home.

Discussion - Service grounding problems may be the result of improper initial installation of service wiring in mobile homes at the site. The possibility of loose connectors at the load center caused by vibration during transportation also exists. The ANSI A119.1 Standard appears to be adequate in this regard.

Recommendation - A pre-occupancy inspection of mobile homes should include a check of the load center to make sure that all electrical connections are properly made.

\subsubsection{RECEPTACLE OUTLETS - IMPROPER WALL LOCATION (ERLW)}

The location of wall receptacles was routinely inspected in the field study. Mobile home occupants (HUD and Private Sample) would not generally recognize this as a problem.

\begin{tabular}{|l|c|}
\hline Sample & $\begin{array}{l}\text { \% of Mobile Homes in } \\
\text { Sample with Problem }\end{array}$ \\
\hline HUD & -- \\
Private & 1.8 \\
Field & 10.9 \\
\hline
\end{tabular}

\section{Pertinent ANSI A119.1 References}

1974

E6.1 - Except in the bath and hall areas, receptacle outlets shall be installed at wall spaces 2 feet wide or more, so that no point along the floor line is more than 6 feet, measured horizontally, from an outlet in that space. Except as explained in the following, receptacle outlets are not required for wall spaces occupied by kitchen or wardrobe cabinets. In addition, a receptacle outlet shall be installed: 
(a) Over or adjacent to counter tops in the kitchen lat least one on each side of the sink if counter tops are on each side and 12 inches or over in width).

(b) Adjacent to the refrigerator and free-standing gas-range space.

(c) At counter top spaces for built-in vanities.

(d) At counter top spaces under wall-mounted cabinets.

1975

E6.3 - Same as E6.1 (1974).

Discussion - This problem concerns the location of receptacle outlets which do not conform to the requirements of the Standard. It is strictly enforcement related (plan review and in-plant inspection).

Recommendation - Improve plan review and in-plant inspection.

\subsubsection{BRANCH CIRCUITS REQUIRED - INADEQUATE CAPACITY FOR GENERAL APPLIANCES (EBCR3.)}

\begin{tabular}{|l|c|}
\hline Sample & $\begin{array}{c}\text { \% of Mobile Homes in } \\
\text { Sample with Problem }\end{array}$ \\
\hline HUD & - \\
Private & 5.3 \\
Field & - \\
\hline
\end{tabular}

Pertinent ANSI Al19.1 References

1974

E7.1.3 - General Appliances lincluding Furnace, water Heater, Range, and Central or Room Air conditioner, etc.). There shall be one or more circuits of adequate rating in accordance with the following:

(a) Ampere rating of fixed appliances not over 50 percent of circuit rating if lighting outlets (receptacles, other than kitchen, dining area, and laundry, considered as lighting outlets) are on same circuit;

(b) For fixed appliances on a circuit without lighting outlets, the sum of rated amperes shall not exceed the branch-circuit rating for other than motor loads or 80 percent of the branch-circuit rating for air conditioning or other motor loads;

(c) The rating of a single portable appliance on a circuit having no other outlets shall not exceed 80 percent of the circuit rating;

(d) The rating of range branch circuit shall be based on the range demand as specified for ranges in Section 8 of this Part;

(e) Where laundry facilities are provided in a mobile home, a 20 ampere branch circuit shall be provided with a 20 ampere outlet within six feet of the intended location of the appliance.

1975

E4.10 - A 15-ampere multiple receptacle shall be acceptable when connected to a 20-ampere laundry circuit.

E5.1.3 - Same as E7.1.3 (1974). 
Discussion - All reported problems in this category resulted from consumer complaints in the Private Sample. The majority of these problems are attributed to inadequate circuit ampere rating for general appliances. The problems with laundry facility circuitry was either that the circuit was nonexistent, was too low an amperage rating or the provided outlet was not within the specified distance from the laundry appliance. The ANSI Al19.1 Standard is clear in this regard and the problems can be attributed to inadequate electrical inspection during the manufacturing process or inadequate plan review prior to manufacturing.

Recommendation - The Standard should be enforced by improved plan review and in-plant inspection procedures.

4.4.5 WALL SIITTCHES - IMPROPER CONNECTION AND INADEQUATE DURABILITY (ESWL)

\begin{tabular}{|l|c|}
\hline Sample & $\begin{array}{c}\text { \% of Mobile Homes in } \\
\text { Sample with Problem }\end{array}$ \\
\hline HUD & 1.0 \\
Private & 1.3 \\
Field & 0.8 \\
\hline
\end{tabular}

Pertinent ANSI A119.1 References

1974

E5.1 - Electrical materials, devices, appliances, fittings and other equipment installed, intended for use in, or attached to the mobile home shall be listed by a nationally recognized testing agency and shall be connected in an approved manner when in service. Facilities shall be provided to securely fasten appliances when the mobile home is in transit. (See Section 23 for provisions on grounding.)

E18.1 - Switches shall be rated as follows:

(a) For lighting circuits, switches shall be rated not less than 10 amperes-125 volts and in no case less than the connected load.

(b) For motors or other loads, switches shall have ampere or horsepower ratings or both adequate for loads controlled (An "AC general use" snap switch may control a motor 2 horsepower or less with full-load current not over 80 percent of the switch ampere rating. I

1975

E7.1 - Electrical materials, devices, appliances, fittings, and other equipment installed, intended for use in, or attached to the mobile home shall be approved for the application and shall be connected in an approved manner when in service. Facilities shall be provided to securely fasten appliances when the mobile home is in transit. ISee Section 9 for provisions on grounding. I

E8.8 - Switches shall be rated as follows:

(a) For lighting circuits, switches shall have a 10-ampere, 120-125 volt rating; or higher if needed for the connected load.

(b) For motors or other loads, switches shall have ampere or horsepower ratings, or both, adequate for loads controlled. (An "AC general-use" snap switch shall be permitted to control a motor 2 horsepower or less with full-load current not over 80 percent of the switch ampere rating.) 
Discussion - Problems associated with switches can be classified into two categories, namely, workmanship (hook-up or connection) and durability. Workmanship problems can be attributed to Inadequate electrical inspection during the manufacturing process. As to durability, the ANSI Al19.1 Standard simply states that devices "shall be 11 sted by a nationally recognized testing laboratory" which does not necessarily assure durability.

\section{Recommendations}

1. The enforcement process (plan review and in-plant inspection) should be improved to insure that equipment is installed in a proper manner.

2. A study of durability of electrical devices, including switches, should be initiated for all types of housing.

\subsubsection{CABLE SUPPORT - INSUFFICIENT CABLE SUPPORT (EWSU)}

\begin{tabular}{|l|c|}
\hline Sample & $\begin{array}{l}\text { \% of Mobile Homes in } \\
\text { Sample with Problem }\end{array}$ \\
\hline HUD & -- \\
Private & 2.7 \\
Field & 5.8 \\
\hline
\end{tabular}

\section{Pertinent ANSI Al19.1 References}

1974

E11.9 - Cables shall be supported within 12 inches of outlet boxes, the service entrance box, and splice boxes on appliances. Supports are required every $4-1 / 2$ feet at other places.

1975

E8.1 - Except as specifically limited in this Part, the wiring methods and materials specified in the National Electrical Code (NFPA No. 10-1974; ANSI C1-1974) shall be used in mobile homes.

Discussion - These problems relate to cable support techniques which do not meet the requirements of E11.9 (1974 edition.) The reference to NEC in E8.1 (1975 edition) removes specific cable support requirements by calling for good workmanship.

A specific problem observed during the field study related to cable support was the passing of electrical wiring and water supply piping through the same small wall penetration without any attempt at isolation of the two.

\section{Recommendations}

1. Improved in-plant inspection of electrical wiring methods are needed.

2. The ANSI A119.1 Standard-1975 should be revised back to the same as 1 t was in ANSI A119.1-1974 which clearly defines support requirements for cables.

3. The following requirement should be added to Part C - Plumbing Systems:

"C5.2.6 Piping Location. Piping and electrical wiring shall not pass through the same holes in walls, floor or roof. Plastic piping shall not be exposed to excessive heat or radiation from the flame of hot water heaters." 


\subsubsection{ELECTRICAL MARKING - IPPROPER MARKING OF FUSES AT DISTRIBUTION CENTER (EMKE)}

Markings of distribution centers were not inspected during the field study or reported by occupants of units in the HUD Sample. Enforcement officials (Private Sample) did routinely inspect for proper marking.

\begin{tabular}{|l|c|}
\hline Sample & $\begin{array}{c}\% \text { of Mobile Homes in } \\
\text { Sample with Problem }\end{array}$ \\
\hline HUD & -- \\
Private & 3.6 \\
Field & -- \\
\hline
\end{tabular}

\section{Pertinent ANSI Al19.1 References}

1974

E25.1 The main circuit breakers or fuses shall be plainly marked "Main."

E25.2 If a fused distribution pane2 is used, the maximum fuse size for the mains shall be plainly marked as follows, with lettering at least 1/4 inch high where visible when fuses are changed: "Maximum Main Fuses 40 (or 50 ) amp."

1975

E4.1 The branch-circuit equipment shall be permitted to be combined with the disconnecting means as a single assembly. Such a combination shall be permitted to be designated as a distribution panelboard. If a fused distribution panelboard is used, the maximum fuse size for the mains shall be plainly marked with lettering at least 1/4-inch high and visible when fuses are changed.

Note: See Section 110-22 of the National Electrical Code (NFPA No. 10-1974;

ANSI (1-1974) concerning identification of each disconnecting means and each service, feeder, or branch circuit at the point where it originated and the type marking needed.

Discussion - This problem concerns inadequate marking of the maximum size of main fuses at the distribution center. These problems are an indication of inadequacies in the enforcement process (plan review or in-plant inspection) since the ANSI Al19.1 Standard is clear as to the type and size of markings required.

Recommendation - The enforcement process ( $\mathrm{plan}$ review and in-plant inspection) should be improved.

\subsubsection{DISCONNECTION MEANS AND BRANCH CIRCUITS - MALFUNCTIONS AND IMPROPER MARKINGS AND} INSTALLATION OF DISTRIBUTION PAVELBOARDS (EDIS)

\begin{tabular}{|l|c|}
\hline Sample & $\begin{array}{c}\text { \% of Mobile Homes in } \\
\text { Sample with Problem }\end{array}$ \\
\hline HUD & -- \\
Private & 3.4 \\
Field & 1.6 \\
\hline
\end{tabular}

Pertinent ANSI A119.1 References

1974

E9.1 Mobile homes shall contain a distribution panelboard having a main overcurrent protective device rated not in excess of the current carrying capacity of the feeder assembly, installed with supply cord and branch circuits wired at the factory. 
E9.2 - The distribution equipment, either circuit breaker or fuse type, shall be located a minimum of 24 inches from the floor level of the mobile, measured to the bottom of the equipment or shall be specifically approved for the purpose.

E9.5 - A distribution panelboard main circuit-breaker shall be rated 50 amperes and employ a 2-pole circuit breaker rated 40 amperes for a 40-ampere supply cord, or 50 amperes for a 50-ampere supply cord. A distribution panelboard employing a disconnect switch and fuses shall be rated 60 amperes and shall employ a single 2-pole, 60-ampere fuseholder with 40or 50-ampere main fuses for 40- or 50-ampere supply cords, respectively. The outside of the distribution panelboard shall be plainly marked with the fuse size. The main circuit breakers or fuses shall be plainly marked "Main."

E9.8 - Overcurrent protection shall be provided for branch circuits and feeders in accordance with Article 240 of the National Electrical Code (ANSI C1-1971; NFPA No. 10-1971) as applicable. The branch circuit overcurrent devices shall be rated:

(a) not more than the circuit conductors; and

(b) not more than 150 percent of the rating of a single appliance rated 10 amperes or more which is supplied by an individual branch circuit but

(c) not more than the fuse size marked on the air conditioner or other motoroperated appliance.

E 9.10 - When circuit breakers are provided for branch-circuit protection, 230-volt circuits shall be protected by 2-pole common or companion trip, or handle-tied paired circuit breakers.

1975

E4.1 - The branch-circuit equipment shall be permitted to be combined with the disconnecting means as a single assembly. Such a combination shall be permitted to be designated as a distribution panelboard. If a fused distribution panelboard is used, the maximum fuse size for the mains shall be plainly marked with lettering at least 1/4-inch high and visible when fuses are changed.

Note: See Section 110-22 of the National Electrical Code INFPA No. 70-1974; ANSI C1-1974) concerning identification of each disconnecting means and each service, feeder, or branch circuit at the point where it originated and the type marking needed.

E4.6 - A distribution panelboard main circuit breaker shall be rated 50 amperes and employ a 2-pole circuit breaker rated 40 amperes for a 40-ampere supply cord, or 50 amperes for a 50-ampere supply cond. A distribution panelboard employing a disconnect switch and fuses shall be rated 60 amperes and shall employ a single 2-pole, 60-ampere fuseholder with 40or 50-ampere main fuses for 40- or 50-ampere supply cords, respectively. The outside of the distribution panelboard shall be plainly marked with the fuse size.

E4.9 - The branch circuit overcurrent devices shall be rated:

(a) not more than the circuit conductors; and

(b) not more than 150 percent of the rating of a single appliance rated 10 amperes or more which is supplied by an individual branch circuit; but

(c) not more than the fuse size marked on the air conditioner or other motoroperated appliance.

E4.11 - When circuit breakers are provided for branch-circuit protection, 230-volt circuits shall be protected by 2-pole common or companion trip, or handle-tied paired circuit breakers. 
Discussion - The problems placed in this category were miscellaneous problems concerning the distribution panelboard, inadequately marked branch circuits and panelboards located too close to the floor. These are enforcement problems related to inadequate in-plant inspection since the ANSI A119.1 Standard is quite specific in these areas.

Recommendation - More stringent in-plant inspection procedures for electrical installations should be implemented.

\subsubsection{CABLE PROTECTION - INADEQUATE PROTECTION MEASURES (ENPR)}

Units in the field study were routinely inspected for adequate cable protection as were most units in the Private Sample. Mobile home occupants (HUD Sample) would not generally recognize this as a problem.

Pertinent ANSI A119.1 References

\begin{tabular}{|l|c|}
\hline Sample & $\begin{array}{l}\text { \% of Mobile Homes in } \\
\text { Sample with Problem }\end{array}$ \\
\hline HUD & -- \\
Private & 2.6 \\
Field & 1.6 \\
\hline
\end{tabular}

1974

E11.12 - Nonmetallic cable located 15 inches or less above the floor, if exposed, shall be protected from physical damage by covering boards, guard strips, or conduit. Cable likely to be damaged by stowage shall be so protected in all cases.

1975

E8.3 - Same as E11.12 (1974).

Discussion - Since the Standard clearly states that cables must be protected if located within 15 inches of the floor, this problem may be attributed to inadequate electrical inspection during manufacturing (enforcement process) or improper design.

Recommendation - The in-plant inspection program for evaluating wiring methods should be improved.

\subsubsection{PASSING OF CABLE THROUGH WALL STUDS - INADEQUATE PROTECTION (ENPS)}

This item was routinely inspected during the field study.

\begin{tabular}{|l|c|}
\hline Sample & $\begin{array}{c}\text { \% of Mobile Homes in } \\
\text { Sample with Problem }\end{array}$ \\
\hline HUD & -- \\
Private & 0.4 \\
Field & 9.7 \\
\hline
\end{tabular}

Pertinent ANSI A119.1 References

1974

E11.7 - Metal-clad and nonmetallic cables may be passed through the centers of the wide side of 2 by 4 studs. However, they shall be protected where they pass through 2 by 2 studs or at other studs or frames where the cable or armor would be less than 1-1/2 inches from the inside or outside surface. Steel plates on each side of the cable, or a tube, with not less than No. 16 manufacturer's standard gage wall thickness, are required to protect the cable. These plates or tubes shall be securely held in place. 
E8.4 - Metal-clad and nonmetallic cables shall be permitted to pass through the centers of the wide side of 2 -inch by 4 -inch studs. However, they shall be protected where they pass through 2 -inch by 2 -inch studs or at other studs or frames where the cable or armor would be less than 1-1/2 inches from the inside or outside surface. Steel plates on each side of the cable, or a tube, with not less than No. 16 MSG wall thickness shall be required to protect the cable. These plates or tubes shall be securely held in place.

Discussion - This problem involves inadequate protection of electrical cables passing through wall studs. The Standard is specific in this regard and the problem is a result of inadequate electrical inspection during manufacturing (enforcement process).

Recommendation - The in-plant inspection program for evaluating wiring methods should be improved.

\subsubsection{LISTED AND APPROVED DEVICES - LOOSE CONNECTIONS (ERXY1.)}

The tightness of electrical connections was routinely inspected in the field study.

\begin{tabular}{|l|c|}
\hline Sample & $\begin{array}{c}\text { \% of Mobile Homes in } \\
\text { Sample with Problem }\end{array}$ \\
\hline HUD & -- \\
Private & 0.2 \\
Field & 7.4 \\
\hline
\end{tabular}

Pertinent ANSI A119.1 References

1974

E5.1 - Electrical materials, devices, appliances, fittings, and other equipment installed, intended for use in, or attached to the mobile home shall be listed by a nationally recognized testing agency and shall be connected in an approved manner when in service. Facilities shall be provided to securely fasten appliances when the mobile home is in transit.

(See Section 23 for provisions on grounding.)

E17.1 - Connection of conductors to terminal parts shall ensure a thoroughly good connection without damaging the conductors and shall be made by means of pressure connectors lincluding set screw typel, solder lugs, or splices to flexible leads. No. 8 or smaller solid connectors and No. 10 or smaller stranded conductors may be connected by means of clamps or screws with terminal plates having upturned lugs, or by means of approved screwless terminals. Terminals for more than one conductor shall be of a type approved for the purpose.

\section{5}

E7.1 - Electrical materials, devices, appliances, fittings, and other equipment installed, intended for use in, or attached to the mobile home shall be approved for the application and shall be connected in an approved manner when in service. Facilities shall be provided to securely fasten appliances when the mobile home is in transit. (See Section 9 for provisions on grounding.)

E8.1 - Except as specifically limited in this Part, the wiring methods and materials specified in the National Electrical Code (NFPA No. 70-1974; ANSI C1-1974) shall be used in mobile homes.

Discussion - The loose connections occurred mainly at the wire connection to duplex outlets or switches that were made at the binding head screws. In some cases, it was obvious that little or no attempt was made to tighten the binding head screws on the devices which is not only poor workmanship, but also gross negligence. 
Recommendation - The in-plant inspection part of the enforcement process should be improved to ensure that good electrical wirlng practices are being used.

4.4.12 LISTED AND APPROVED - ALUMINUM/COPPER DEVICES USE WITH ALUMINU.1 WIRING (ERXY11.)

The compatibility of the electrical devices and wiring was routinely inspected in the field study.

\begin{tabular}{|l|c|}
\hline Sample & $\begin{array}{c}\% \text { of Mobile Homes in } \\
\text { Sample with Problem }\end{array}$ \\
\hline HUD & -- \\
Private & 0.1 \\
Field & 7.0 \\
\hline
\end{tabular}

\section{Pertinent ANSI A119.1 References}

\section{4}

E5.1 - Electrical materials, devices, appliances, fittings, and other equipment installed, intended for use in, or attached to the mobile home shall be listed by a nationally recognized testing agency and shall be connected in an approved manner when in service. Facilities shall be provided to securely fasten appliances when the mobile home is in transit.

(See Section 23 for provisions on grounding.)

\section{5}

E7.1 - Electrical materials, devices, appliances, fittings, and other equipment installed, intended for use in, or attached to the mobile home shall be approved for the application and shall be connected in an approved manner when in service. Facilities shall be provided to securely fasten appliances when the mobile home is in transit. ISee Section 9 for provisions on grounding.)

Discussion - This problem is concerned with the practice of using electrical devices which are not specifically approved for use with aluminum wire.

Recommendation - Follow the expected lead of the National Electrical Code concerning the use of special devices with aluminum wire when their position on the subject is clarified.

\subsubsection{WIRING PRACTICES - INADEQUATE CONTINUITY OF CABLE SIEATH (ENCS)}

\begin{tabular}{|l|c|}
\hline Sample & $\begin{array}{c}\text { \% of Mobile Homes in } \\
\text { Sample with Problem }\end{array}$ \\
\hline HUD & -- \\
Private & 0.4 \\
Field & 1.9 \\
\hline
\end{tabular}

Pertinent ANSI A119.1 References

1974

E11.6 - The sheath of nonmetallic cable or the armor of metal-enclosed cable shall be continuous between outlet boxes and other enclosures.

1975

E8.1 - Except as specifically limited in this Part, the wiring methods and materials specified in the National Electrical Code (NFPA No. 10-1974; ANSI C1-1974) shall be used in mobile homes. 
Discussion - The ANSI A119.1-1974 Standard clearly states that cable sheath "shall be continuous between outlet boxes and other enclosures." The ANSI A119.1-1975 is not as specific but refers to the National Electrical Code where the requirements are similar. The problem is related to the enforcement process (inadequate electrical inspection during manufacture). It is also an example of poor workmanship.

Recommendation - The in-plant inspection part of the enforcement process must be improved to ensure that good electrical wiring practices are being used.

\subsection{DURABILITY RELATED PROBLEMS}

Problems of a durability nature are quite prevalent in the mobile home performance data accumulated during this project. Many of these problems have already been discussed in Sections 3.0 and 4.0 since they are, in some cases, closely related to the four major problem subsections established to categorize the data (ANSI A119.1, Enforcement Process, Mechanical/Electrical Appliances and Routine Maintenance).

\subsection{WINDON (NCWD) AND DOOR HARDWARE (NCXH AND NCPH)}

\begin{tabular}{|l|c|c|r|}
\hline & \multicolumn{3}{|c|}{ \% of Mobile Homes in Sample with Problem } \\
\hline Sample & Exterior Door & Partition Door & Window \\
\hline HUD & 26.2 & 3.4 & 6.8 \\
Private & 8.3 & 7.9 & 12.2 \\
Field & 24.5 & 5.4 & 5.8 \\
\hline
\end{tabular}

Discussion - Data from the Routine Maintenance Subsection indicated that the most troublesome hardware problems were associated with exterjor doors. Window closing mechanisms and latches exhibited the most problems followed by partition door hardware.

ANSI A119.1-1975 does not include a reference specification for either exterior door locks or partition door hardware which may be a contributing factor to the poor performance indicated by the data. There is an existing specification for Locks and Lock Trim (ANSI Al56.21975) which could be referenced in ANSTI A119.1.

In the case of windows, ANSI A119.1-1975 does reference (B8.5.1) MHMA Specification No. 1-71Rev. 1973, "Window Specification for Utilization in Mobile and Factory Built Housing." This specification was developed primarily for energy conservation and weather resistance concerns. Performance requirements which would insure window hardware durability are not included. There is a proposed American National Standard, ANSI A134.5, "Specifications for Aluminum Mobile Home Windows" which does contain such performance requirements.

\section{Recommendations}

1. Reference ANSI A156.2-1975, "American National Standard for Locks and Lock Trim" in ANSI A119.1.

2. When approved as an American National Standard, reference ANSI A134.5, "Specification for Aluminum Mobile Home Windows," in ANSI A119.1. 


\subsection{FLOOR COVERING (FDUR1.)}

As mobile home owners, occupants of Private Sample units would be more concerned with floor covering durability than the occupants of HUD or Field Sample units which were rented.

\begin{tabular}{|l|c|}
\hline Sample & $\begin{array}{l}\text { \% of Mobile Homes in } \\
\text { Sample with Problem }\end{array}$ \\
\hline HUD & 1.0 \\
Private & 13.3 \\
Field & 3.5 \\
\hline
\end{tabular}

Discussion - Durability and workmanship problems were encountered with sheet vinyl floor coverings and carpeting. The sheet vinyl problems almost exclusively involved buckling of the floor covering at joints of the particle board decking. Carpeting problems, which comprised the greater percentage of the complaints, had to do with poor quality of materials. ANSI Al19.1 Standard does not include specifications which would insure minimum quality of floor coverings.

Recommendation - Floor covering specifications of HUD/FHA Minimum Property Stnadards (MPS) [8] should be incorporated into ANSI A119.1.

\subsection{EXTERIOR DOORS (DEDU)}

\begin{tabular}{|l|c|}
\hline Sample & $\begin{array}{c}\text { \% of Mobile Homes in } \\
\text { Sample with Problem }\end{array}$ \\
\hline HUD & 0.1 \\
Private & 3.6 \\
Field & 2.7 \\
\hline
\end{tabular}

Discussion - The durability problems encountered involved deterioration and delamination of facing materials; including aluminum, wood, hardboard and vinyl. The majority of these problems were encountered in the Private and Field Samples. As discussed in 3.1.6, ANSI Al19.11975 does not include a door specification. Proposed MHMA Spec. 3-74, "Exterior Passage Door Specification for Utilization in Mobile and Factory Built Housing," does not include performance tests which would evaluate durability. It is similar to the performance criteria in the HUD/FHA Minimum Property Standards for doors, windows and glazing, which covers only air leakage, water infiltration, and physical load testing.

Recommendation - Methods should be developed for evaluating durability characteristics of exterior doors which would be applicable to all types of housing.

\subsection{APPLIANCES AND MECHANICAL EQUIPIENT}

5.4.1 General. Durability of appliances (furnace, range, refrigerator, hot water heater, etc.) is covered only very generally in the ANSI Al19.1 Standard with the statement that appliances shall be "listed or certified by a nationally recognized testing agency for use in mobile homes." The definition of "listed," given in Parts D and E of the Standard is, "Equipment or materials included in a list published by a nationally recognized testing laboratory that maintains periodic inspection of production of listed equipment or materials and whose listing states either that the equipment or material meets nationally recognized standards or has been tested and found suitable for use in a specified manner."

An in-depth analysis of existing standards for appliances in regard to durability is beyond the scope of this study. As a comparison, standards for furnaces, hot water heaters, ranges, refrigerators and clothes dryers, as outlined in the HUD/FHA MPS and ANSI Al19.1, are presented in Table 22. The standards presented in ANSI A119.1 are more extensive than those in the MPS and no correlation between the two is evident for any of the appliances. This is understandable for furnaces since they are generally designed specifically for mobile homes and tend to differ considerable from those used in conventional housing. However, some correlation between MPS and ANSI Al19.1 could be expected for hot water heaters since similar appliances are used in both types of housing. 
The other major appliances found in mobile homes and conventional houses ( $r$ anges and refrigerators) are essentially not covered in either standard. ANSI Al19.1 does give a specification for commercial cooking equipment and refrigerators using gas fuel, but not for refrigerators. The MPS does not cover standards for ranges or refrigerators.

5.4.2 Problem Distribution. Problems associated with mechanical/electrical appliances and equipment accounted for 5,508 (17.2\%) of the total number of problems (31,982) categorized for all samples. The distribution of these 5,508 problems for the Private, Field and HUD Samples can be seen in Tables 11,16 and 19. Mechanical/electrical appliance and equipment problems were found in $52.8 \%$ of all mobile homes in the three samples.

Table 23 presents the rank ordering of problem occurrence for the combined sample by component as follows: furnace, hot water heater, range, exhaust fan, refrigerator, smoke detector, and electrical baseboard heating units. A further breakdown of problem occurrences associated with the three most troublesome components (furnaces, hot water heaters and ranges) are presented in Figures $5,6,7$ and 8 .

\subsection{SUMMARY COMMENTS AND RECOMMENDATIONS}

This project was undertaken by the National Bureau of Standards at the request and sponsorship of the Division of Energy, Building Technology and Standards of the Department of Housing and Urban Development with the objective of documenting mobile home performance problems and relating them to possible inadequacies in the ANSI Al19.I Standard for Mobile Homes and the mobile homes enforcement process. Additonally, the durability of mobile home components was a study objective for potential use in mortgage insurance evaluation.

The data presented in this report and in references [2], [3] and [4] represent a significant base of information from which the above objectives can be addressed. It should be pointed out that the number of mobile homes included in this study is small when compared to the total number of units now occupied in the United States. Also, the emphasis in this project, by design, was to concentrate on reported mobile home problems and does not reflect the large number of mobile home occupants who have been satisfied with the performance of their units. A problem oriented study of this type on conventional housing would probably be just as revealing.

Problem data were separated into five different categories, as described in Appendix A and presented in Appendices B, C and D, for the three data samples. These were related to (1) ANSI Al19.1 Standard for Mobile Homes, (2) Mobile. Home Enforcement Process, (3) Routine Maintenance, (4) Mechanical/Electrical Appliances, and (5) Miscellaneous. In many cases, a performance problem could be related to more than one of these categories. A judgment was made by the project staff as to which major category a problem should be placed. The problem discussions in Sections 3.0, 4.0 and 5.0 attempt to touch on the various reasons for the problem occurrence.

Problems placed in the ANSI A119.1 category indicated areas where the Standard was inadequate or where omissions were evident. The major problem areas in the Construction system were rain leaks, failure of interior paneling attachment, inadequate bottomboard durability, corrosion of exterior fasteners, and excessive metal roof membrance flexibility (roof rumble.) Plumbing problems included questionable quality of fixtures, loose fixture connections, watertightness of shower enclosures, and freezing of piping. Heating and electrical problems in the ANSI Al19.1 category consisted of questionable location of furnace thermostat and inadequate fastening of electrical boxes. 
The Mobile Home Enforcement category included problems which indicated deficiences in the mobile home regulatory process (plan and specification review, certification, and in-plant inspection.) In the Construction area, this included instances where thermal insulation in the walls and roof were found missing or improperly installed. Typical problems in the Plumbing area included piping water leaks, inadequate grade (slope) of drain pipe, water heater relief valve drain problems, and corrosion of piping. Heating system problems included use of unlisted or inadequately installed components, inadequate accessibility of appliances, joints of supply and vent systems not airtight, inadequate separation of combustion air system, inadequate marking of appliances and improper flexible gas connector usage. Electrical problems included lack of durability and long-term performance of devices, improper location of receptacles and devices, inadequate number of branch circuits, and problems related to workmanship such as insufficient cable support, inadequate cable protection, etc.

Problems related to durability of mobile home components are discussed in Section 5.0 . Most of the problems in the Mechanical/Electrical Appliance category are included in this discussion. While many of the problems in the Routine Maintenance category were of a normal wear and tear nature, of the types expected in all types of housing, some were related to durability and were also included in Section 5.0 .

The body of this report contains many specific recommendations on revisions to the ANSI A119.1 Standard for Mobile Homes and suggested improvements in the mobile home enforcement process. However, many of the identified problems point out that the state-of-the-art at this time will not permit a specific recommended solution. The following comments and recommendations are submitted in response to this obvious need for additional mobile home research:

1. The forces resulting from transportation and site set-up of the mobile home are not documented sufficiently to allow incorporation of specific design criteria into the ANSI A119.1 Standard for Mobile Homes. Throughout this report, the effect of these forces on the construction, plumbing, heating and electrical systems are implied but cannot be specifically substantiated. It is recommended that a research program be initiated to determine the effect of transportation and set-up on mobile home performance.

2. The effect of wind forces on mobile homes, both during transportation and on site, are unknown. The configuration of the mobile homes and siting conditions differ considerably from other structures making it difficult to apply results of available wind research. It is recommended that a research program be initiated to determine the magnitude and distribution of wind forces on mobile homes as well as the response of the structural system to expected wind forces. Available mobile home wind research data are quite limited.

3. Available data indicate that mobile homes are subjected to deteriorative forces after leaving the factory and prior to occupancy due to transportation and site set-up. It is recommended that a required inspection be considered for mobile homes after set-up and prior to occupancy to evaluate the adequacy of the construction, plumbing, heating and electrical systems. This could include an evaluation of the following which were documented in this study to be problem areas: tightness of the heating vent system; electrical system for shorts; plumbing system for gas, oil or water leaks; tie-down system; and the operation of plumbing fixtures and appliances. Since the enforcement process is generally accomplished at the state or local level, a handbook outlining this pre-occupancy inspection procedure should be developed for national use.

4. The problems related to the mobile home enforcement process were associated with inadequate plan/specification review or in-plant inspection. A uniform procedural guide for these phases of the process should be established for national use. 
5. The data presented in this report suggests that durability of mobile home components is a problem. However, there are few existing standards available within the housing industry which provide for evaluation of long-term durability performance of components such as door hardware, plumbing fixtures, and electrical devices. The development of such standards should be encouraged.

6. The ANSI A119.1 Standard for Mobile Homes consists of a combination of performance and prescriptive type requirements. Prescriptive requirements are generally written around systems, components or materials that are currently in use. This approach tends to Ereeze technology and discourage the use of innovative concepts. The further application of the performance approach to mobile home standards could allow the mobile home industry, which is quite competitive and receptive to cost effective innovations to produce a quality product which could be purchased by a larger segment of the population. 
[1] ANSI A119.1 (NFPA 501B) "Standard for Mobile Homes," National Fire Protection Association, Boston, Massachusetts.

[2] J.H. Pielert, W.E. Greene, L.F. Skoda, W.G. Street; Performance of Mobile Homes Data Acquisition and Analysis Methodology; National Bureau of Standards (U.S.) NBSIR 75-641, February 1975 (NTIS Accession No. COM-75-11209).

[3] W.G. Street, W.E. Greene, J.H. Pielert, L.F. Skoda; A Compilation of Problems Related to the Performance of Mobile Homes; National Bureau of Standards (U.S.) NBSIR 75-690, April 1975 (NTIS Accession No. COM-75-11207).

[4] L.F. Skoda, J.H. Pielert, W.E. Greene, W.G. Street; Performance of Mobile Homes A Field Inspection Study; National Bureau of Standards (U.S.) NBSIR 75-688, June 1975 (NTIS Accession No. COM-75-11222).

[5] ANSI A119.3 "Standard for Mobile Home Parks," National Fire Protection Association, Boston, Massachusetts.

[6] P.W. Cooke, L.P Zelenka, H.K. Tejuja; Mobile Home Construction Standards Adopted by State Regulatory Programs - An Analysis; National Bureau of Standards (U.S.) NBSIR 75-680, March 1975 (NTIS Accession No. COM-75-10423).

[7] P.W. Cooke, H.K. Tejuja, R.D. Dikkers, L.P. Zelenka; State Building Regulatory Programs for Mobile Homes and Manufactured Buildings - A Summary; National Bureau of Standards (U.S.) Technical Note 853, September 1974.

[8] HUD Minimum Property Standards - Volume 1 (One and Two Family Dwellings), U. S. Department of Housing and Urban Development Publication 4900.1, 1973 Edition. 
The authors are indebted to many persons for contributions and guidance that made this report possible. Special thanks are given to NBS staff members who participated in the regulatory and field inspection activities and provided invaluable assistance in the data reduction effort. Staff members from the Center for Building Technology included R. Beausoliel, T. Ray and W. Niessing. E. Budnick and J. Scott of the Center for Fire Research provided expertise in Fire Protection Engineering and J. Peebles of the Plant Division was responsible for the electrical discipline. M. Vogt of Technical Analysis Division prepared the computer programs used for data analysis. J. Finnan and T. Porter, working under outside contracts, provided valuable support to important project tasks.

The cooperation of the staff of the Office of Emergency Preparedness (OEP) of the Department of Housing and Urban Development, both in Washington, D.C. and at Wilkes-Barre, Pennsylvania, contributed significantly to the success of this project. Mr. James McCollom of HUD, Office of Policy Development and Research, provided liaison between NBS staff and OEP operations personnel, as well as valuable technical advise resulting from a previous HUD study of the Hurricane Agnes mobile homes.

The authors are particularly grateful to the many Federal, State and private organizations who cooperated with the NBS study team by making mobile homes available for field inspection, as well as providing mobile home performance data. 


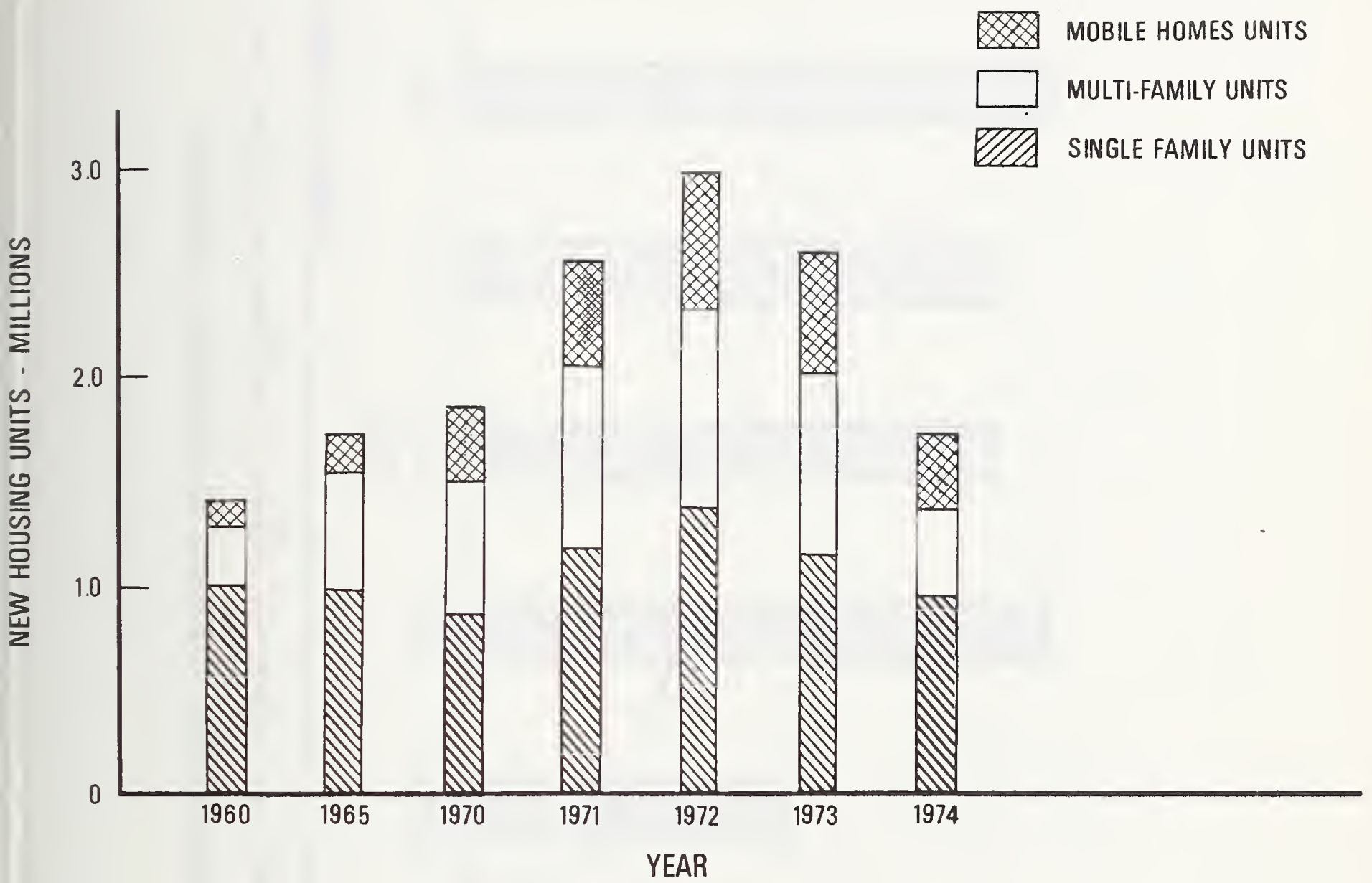

Figure 1 - New Housing Units Produced in U.S. Versus Year

Source: Bureau of the Census 


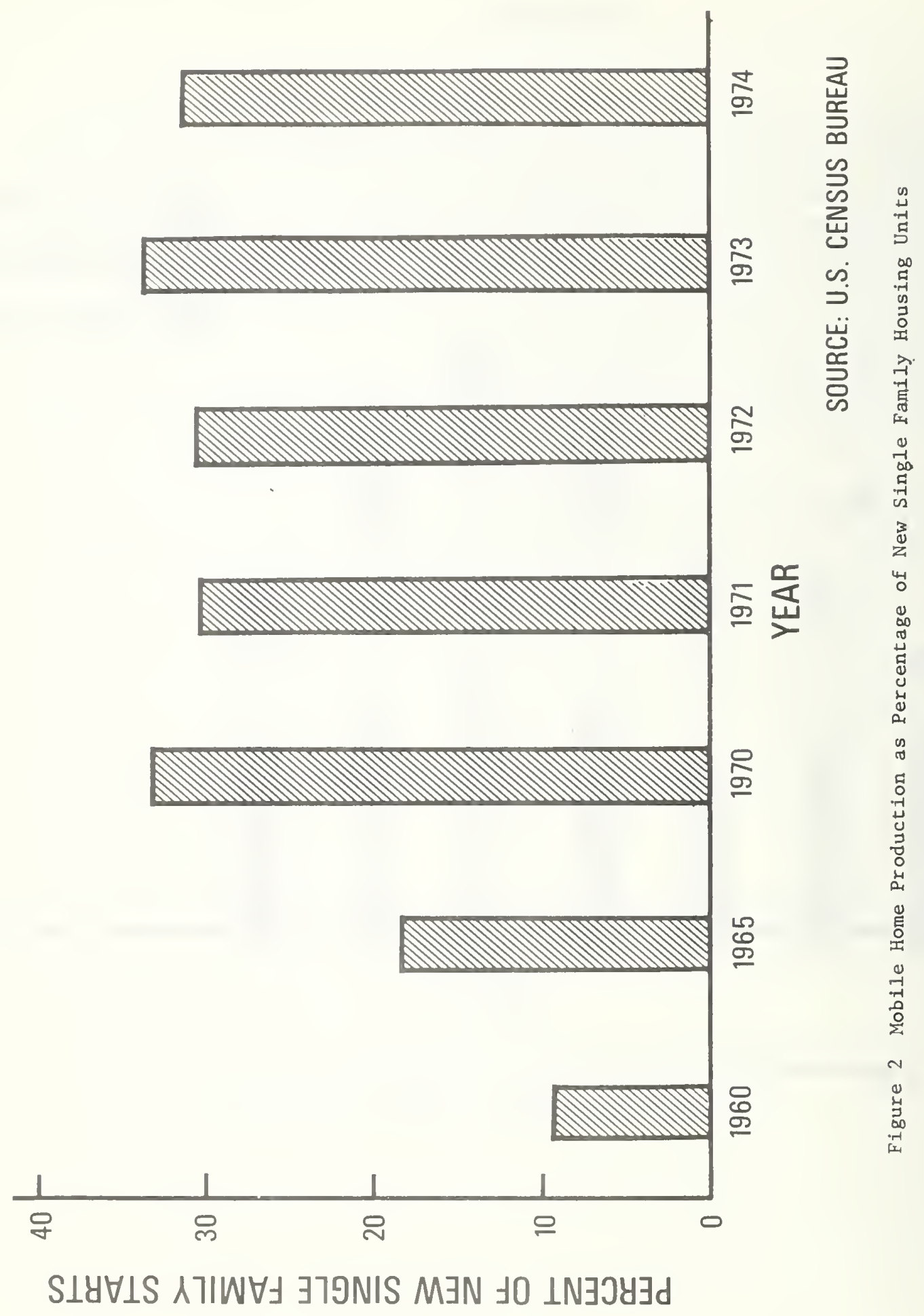




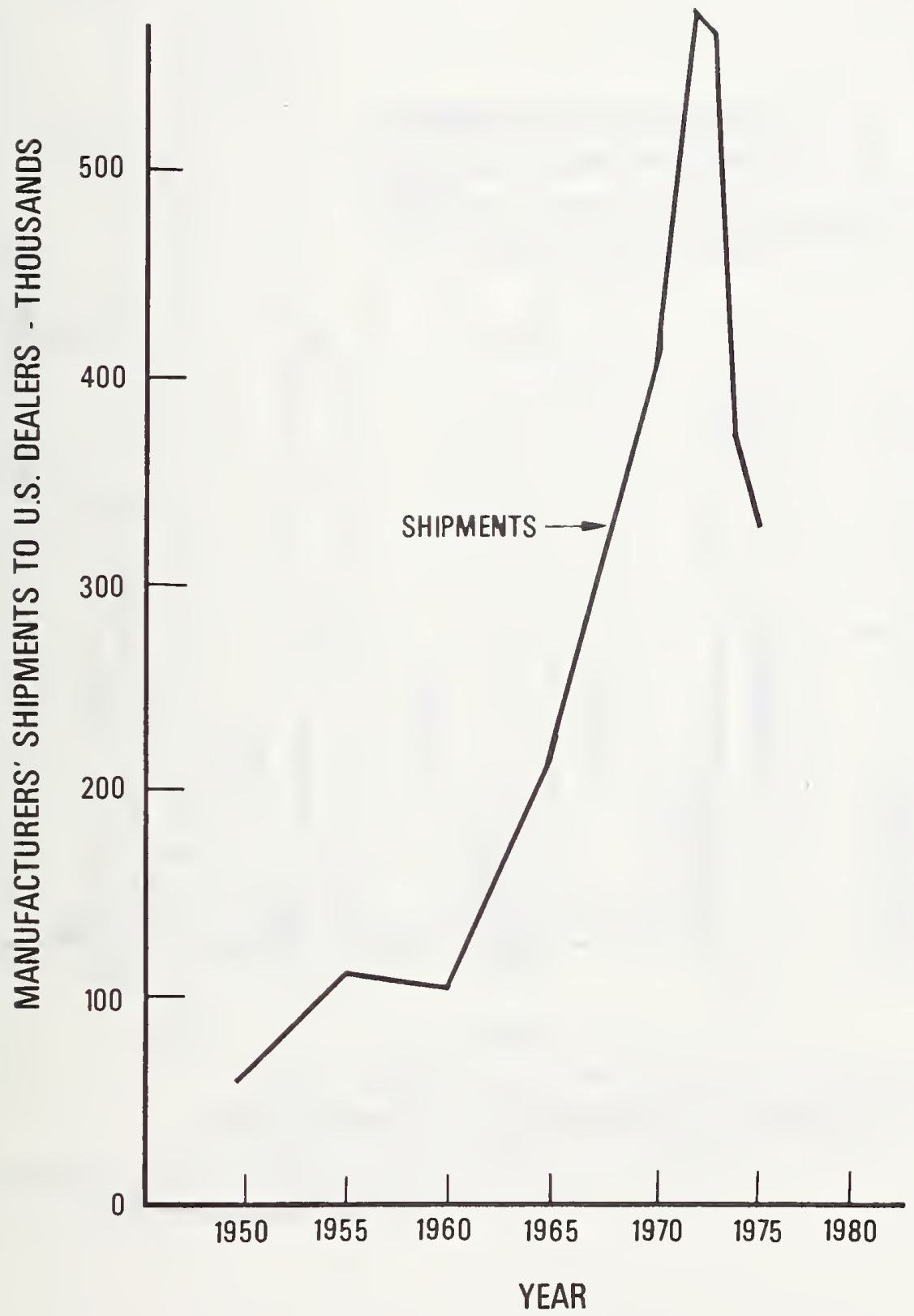

Figure 3 Mobile Home Shipments

Source: Manufactured Housing Institute

"Quick Facts" 1974 Data 


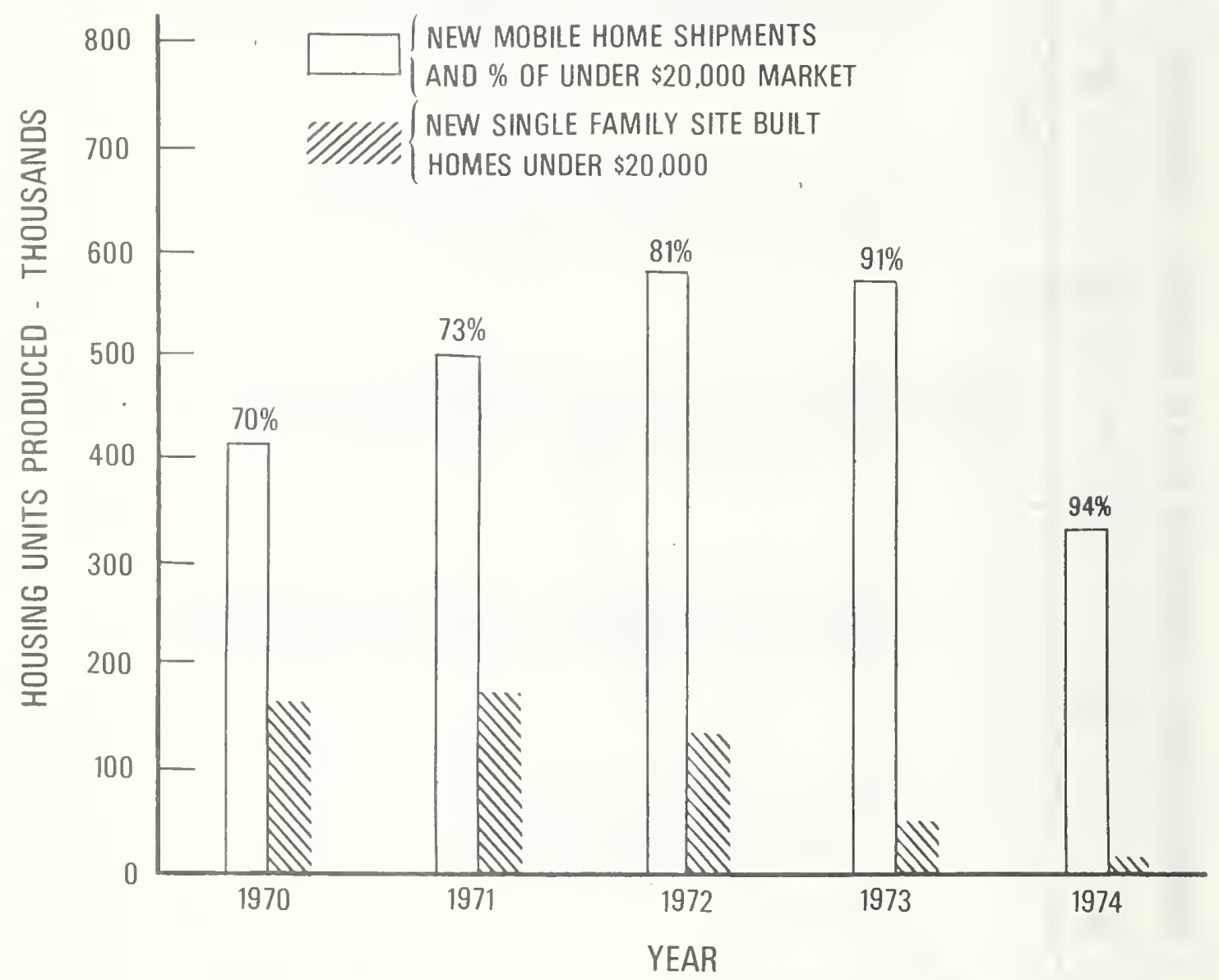

Figure 4 The Under $\$ 20,000$ New Home Market

Source: Manufactured Housing Institute "Quick Facts" 1974 Data 


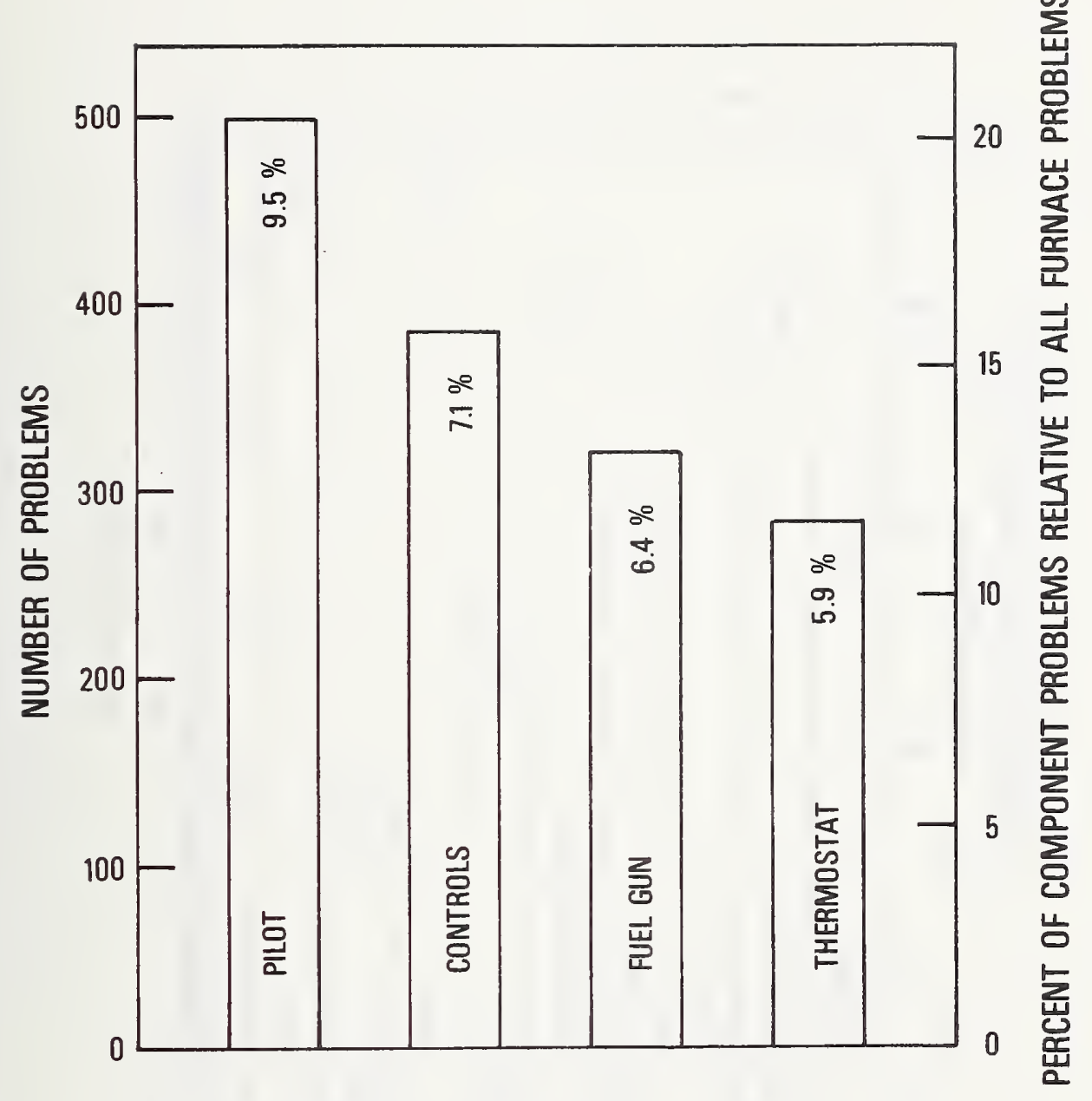

Figure 5 - Problem Distribution for Furnace Components (Total Sample)

Notes

1. Total sample includes HUD, Field, and Private Data

2. Percentages in bars indicate portion of mobile homes in total sample with component problem 


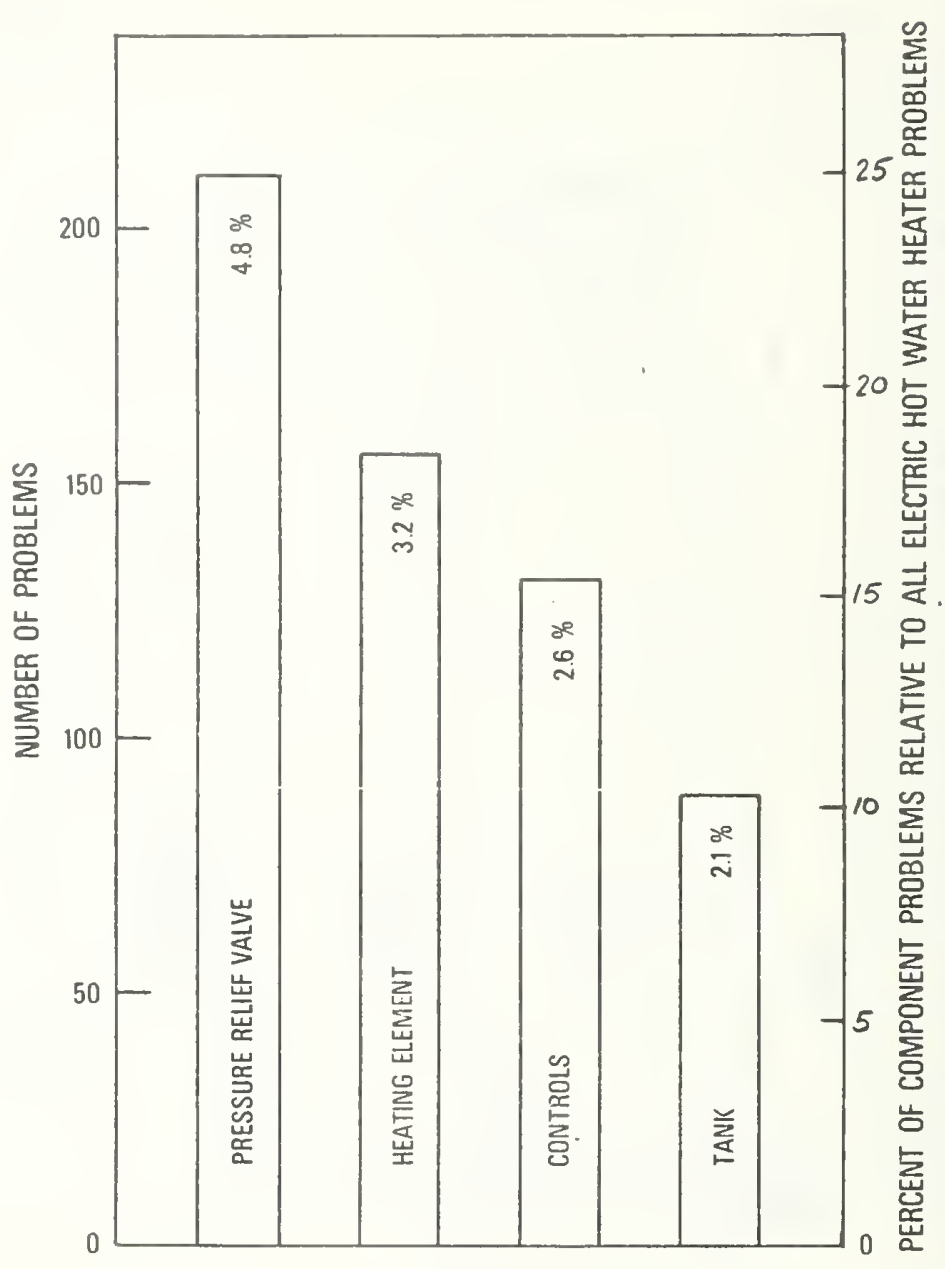

Figure 6 - Problem Distribution for Electric Water Heater Components (Total Sample)

Notes

1. Total sample includes HUD, Field, and Private Data

2. Percentages in bars Indicate portion of mobile homes in total sample with component problem 


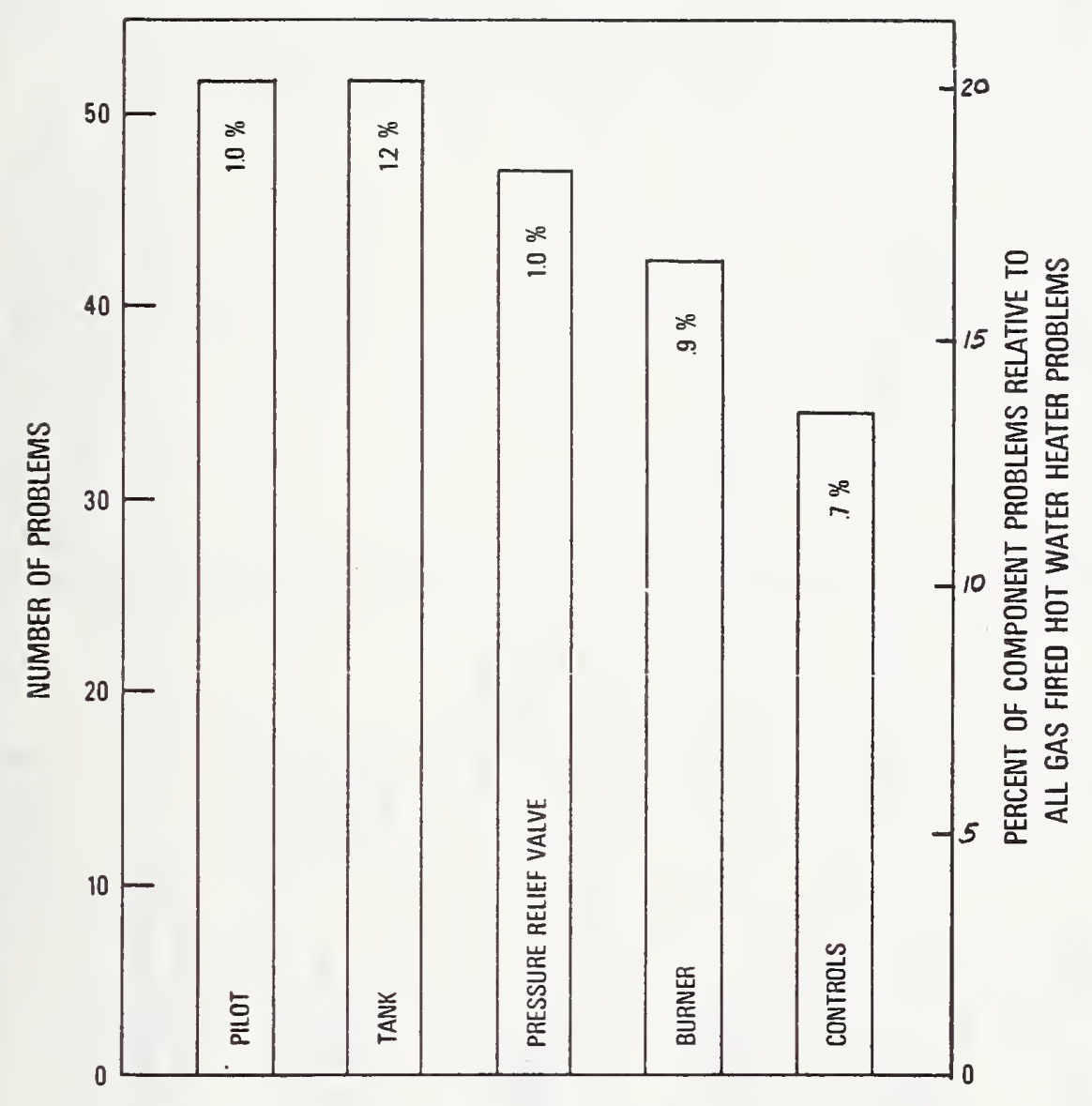

Figure 7 - Problem Distribution for Gas Fired

Water Heaters (Total Sample)

Notes

1. Total sample includes HUD, Field, and Private Data

2. Percentages in bars indicate portion of mobile

homes in total sample with component problem 


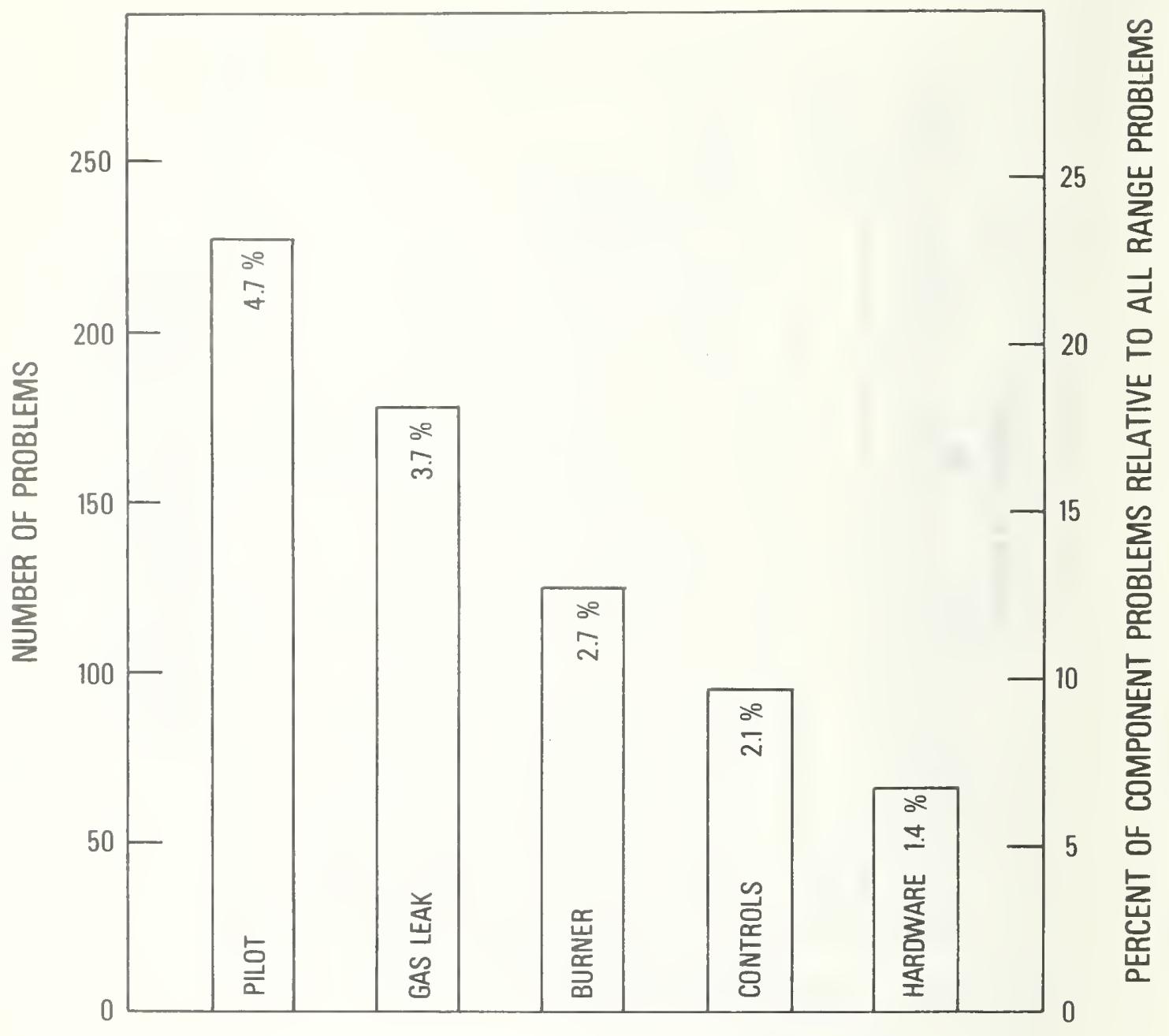

Figure 8 - Problem Distribution for Range Components (Total Sample)

Notes

1. Total sample includes HUD, Field, and Private Data

2. Percentages in bars indicate portion of mobile homes in total sample with component problem 


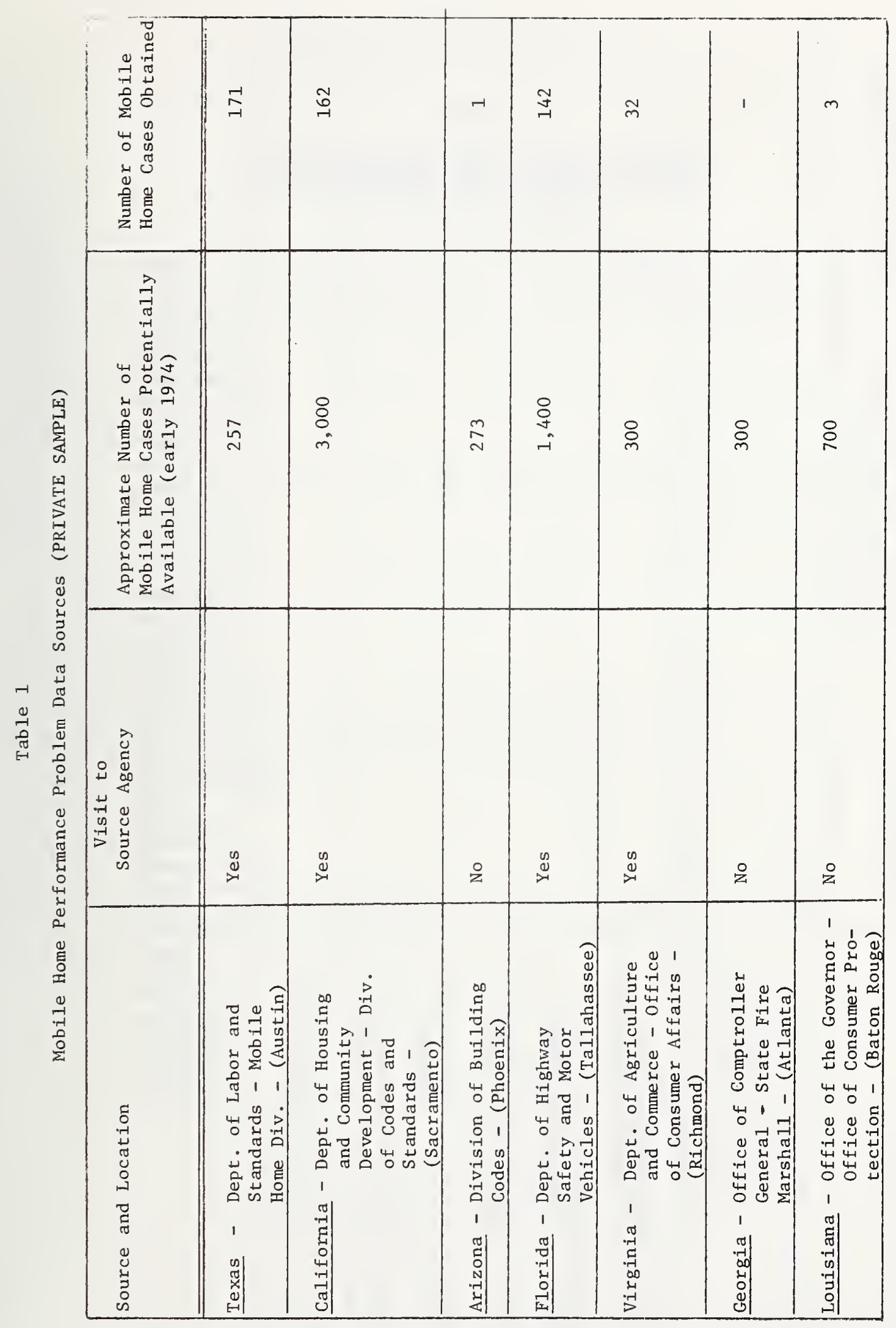




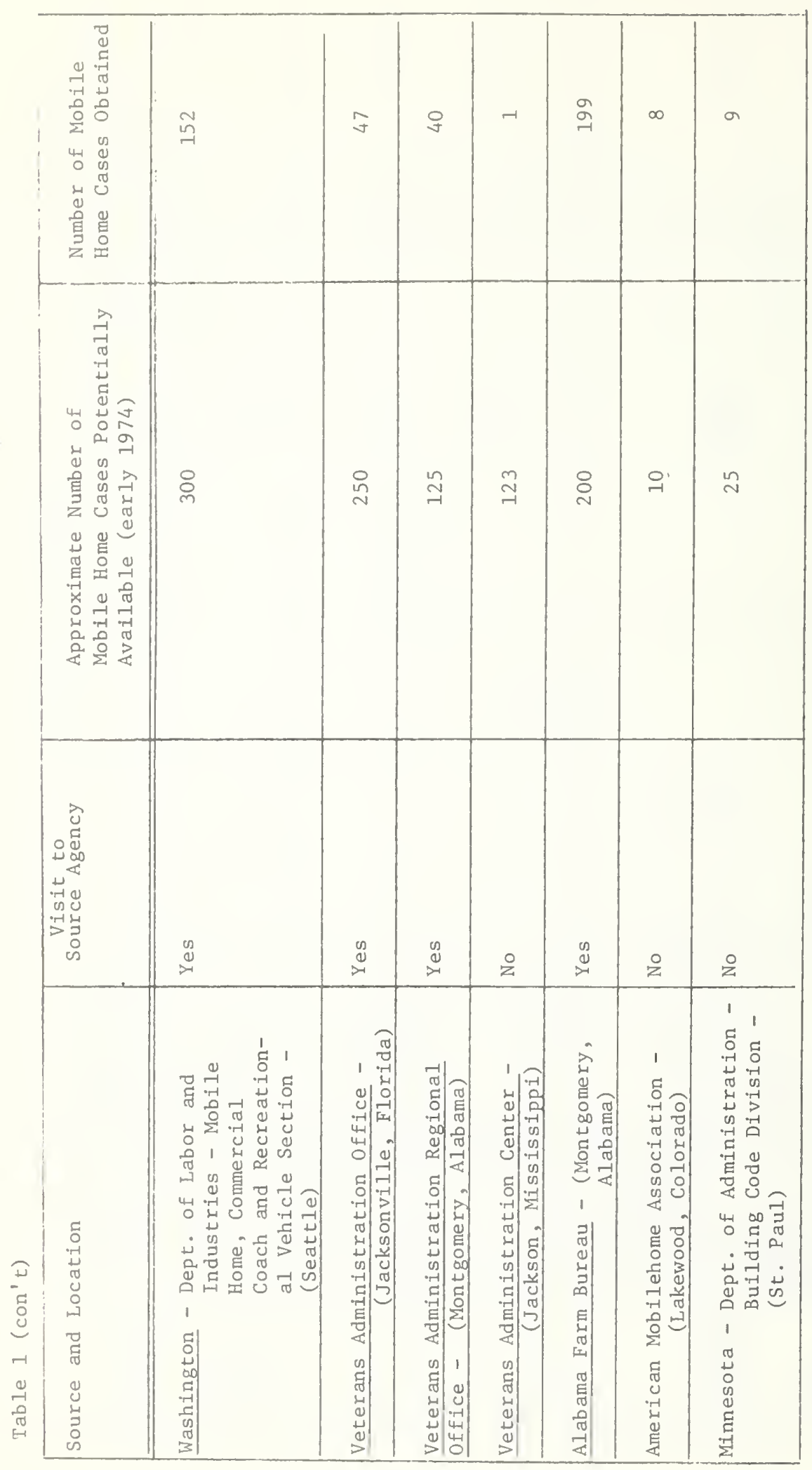




\section{Table 2}

State of Manufacture and Number of Units For the Combined (HUD, Field and Private)

\section{Mobile Home Sample}

State

Alabama

Alaska

Arizona

Arkansas

California

Colorado

Florida

Georgia

Idaho

Illinois

Indiana

Kansas

Kentucky

Louisiana

Maryland

Michigan

Minnesota

Mississippi

Miss ouri

New York

North Carolina

North Dakota

Ohio

Oklahoma

Oregon

Pennsylvania

South Carolina

South Dakota

Tennessee

Texas

Utah

Virginia

Washingt on

Wisconsin

Wyoming

Unknown
Number of Units

\begin{tabular}{rr}
272 \\
2 \\
1 \\
60 \\
160 \\
4 \\
168 \\
235 \\
31 \\
37 \\
329 \\
19 \\
15 \\
23 \\
4 \\
85 \\
38 \\
68 \\
6 \\
21 \\
131 \\
2 \\
65 \\
7 \\
61 \\
307 \\
52 \\
2 \\
40 \\
151 \\
2 \\
46 \\
58 \\
6 \\
1596 \\
\hline 4105
\end{tabular}

Total $\quad \frac{1596}{4105}$ 
Table 3

Year of Manufacture vs. Number of Units Combined HUD, PRIVATE and FIELD SAMPLE

Year

1974

1973

1972

1971

1970

1969

1968

1965

1962

Unknown

No. of Units

\begin{tabular}{cr} 
& 32 \\
& 382 \\
& 1791 \\
& 208 \\
& 18 \\
& 4 \\
& 1 \\
& 2 \\
& 2 \\
Tota1 & 1665 \\
\hline & 4105
\end{tabular}

Table 4

Width vs. Number of Units Combined HUD, PRIVATE and FIELD SAMPLE

Width

10.0 Feet

11.0 "

$12.0 "$

$13.0 "$

$14.0 "$

$16.0 "$

$20.0 "$

24.0 "

Unknown
No. of Units

\begin{tabular}{rr} 
& 2 \\
& 1 \\
& 2366 \\
& 2 \\
& 84 \\
& 1 \\
& 17 \\
Tota1 & 284 \\
& 1348 \\
\hline & 4105
\end{tabular}


Seals of Certifying Agency Combined HUD, PRIVATE and FIELD SAMPLE

Agency

Alabama

Arkansas

California

Colorado

Delaware

Florida

Georgia

Minnesota

Mississippi

Tennessee

Texas

Virginia

Washington
Type of Agency

State

11

11

11

11

11

11

11

II

11

II

"I

11
No. of Units with Seal

336

1

161

4

1

84

75

8

12

14

124

21

51

Pittsburgh Testing Lab. Third Party

National Consumer

Testing Lab.

11

22

Underwriters Lab.

11

46

MHMA/TCA 1 /

HUD Specification $2 /$

Trade Association

1326

Federal

449

Others (Misc.)

Manufacturers, etc.

14

\section{Total Other Seals}

1789

Total Seals

Units With No Seals Attached 4 /

Units With No Seal Information $5 /$

$2750 \underline{3 /}$

487

1126

1/ Trade Association - Mobile Home Manufacturers Association and Trailer Coach Association.

2/ HUD Purchase Contract required compliance with ANSI A119.1

3/ Exceeds 2492 mobile homes with seals because some units have more than one seal.

4/ Available data indicated that units had no attached seals.

5/ No information available to indicate if mobile homes had seals. 


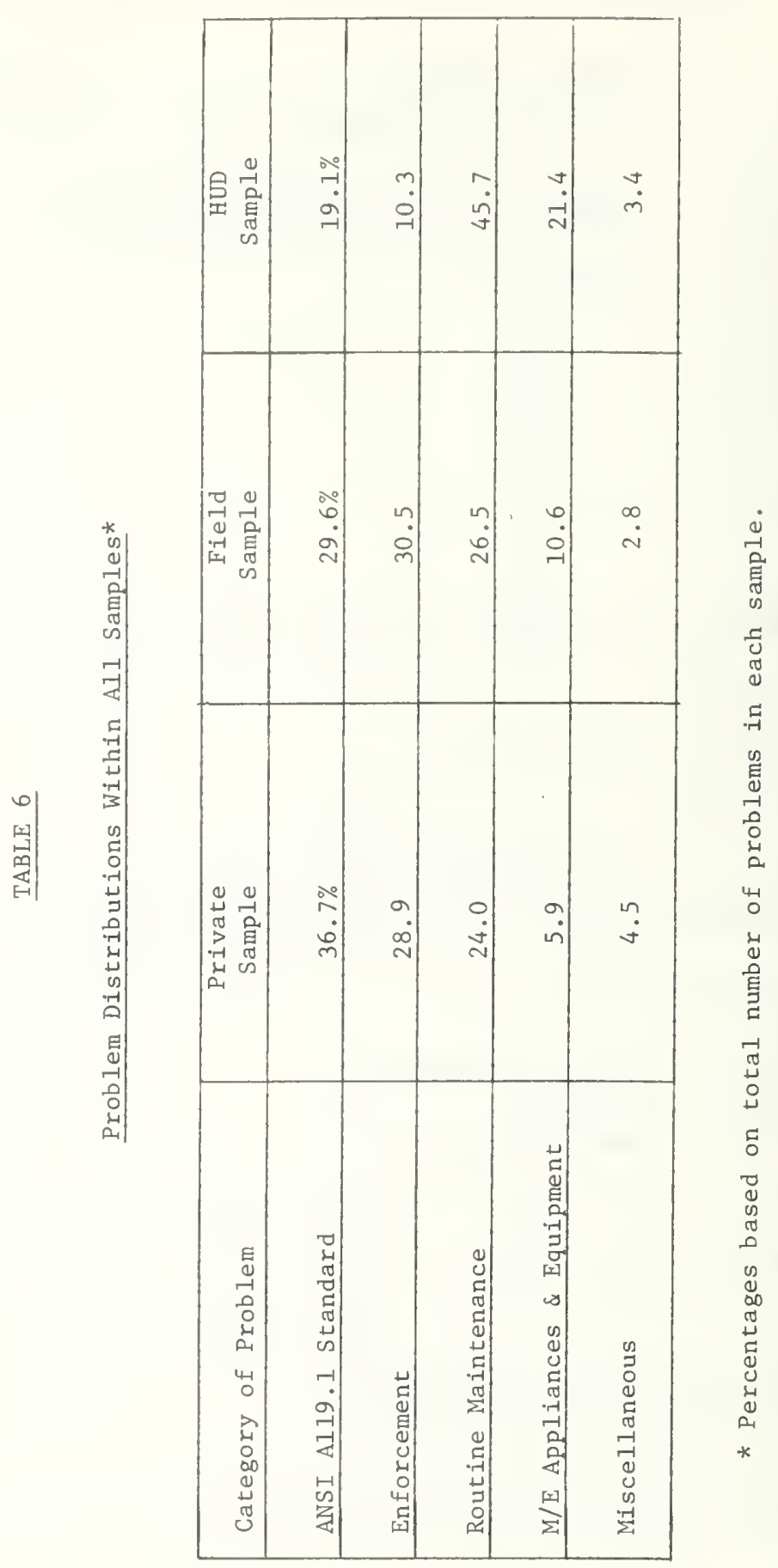




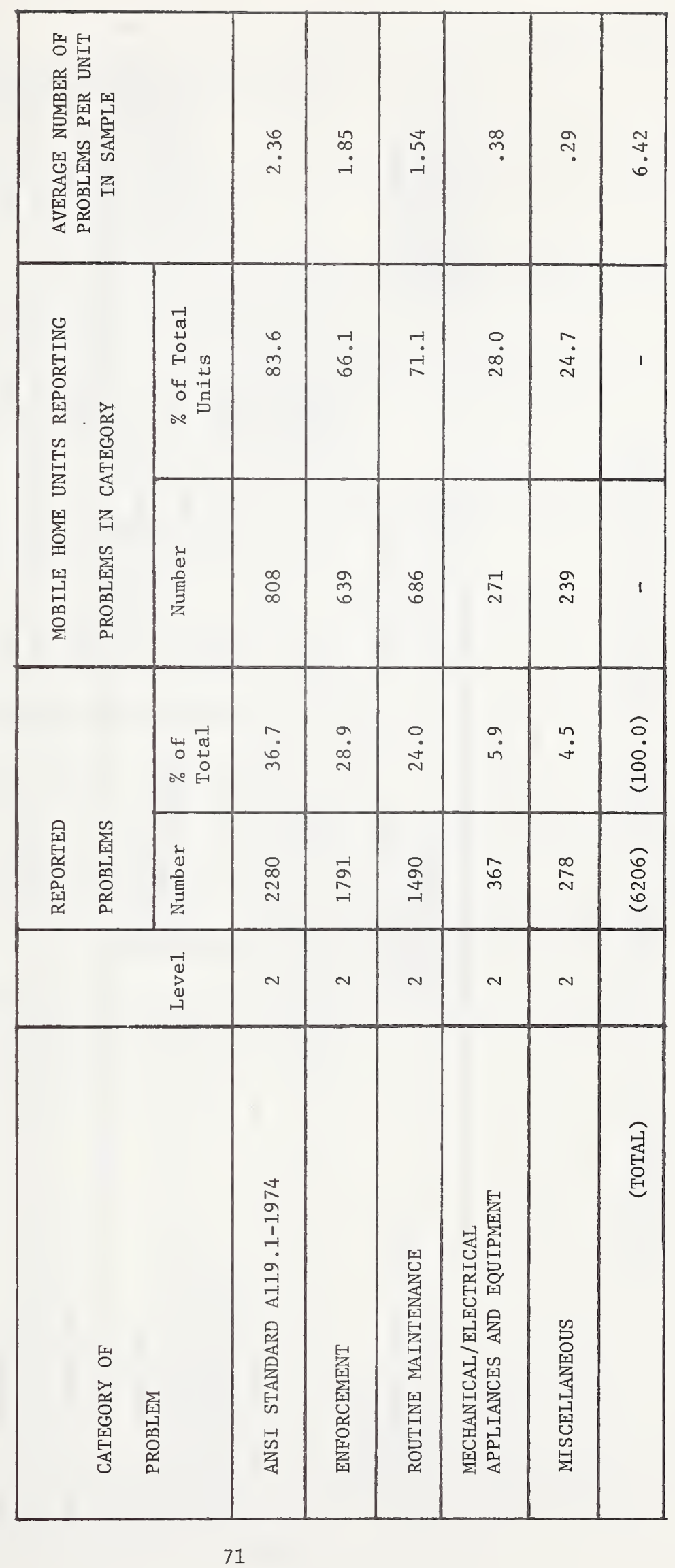




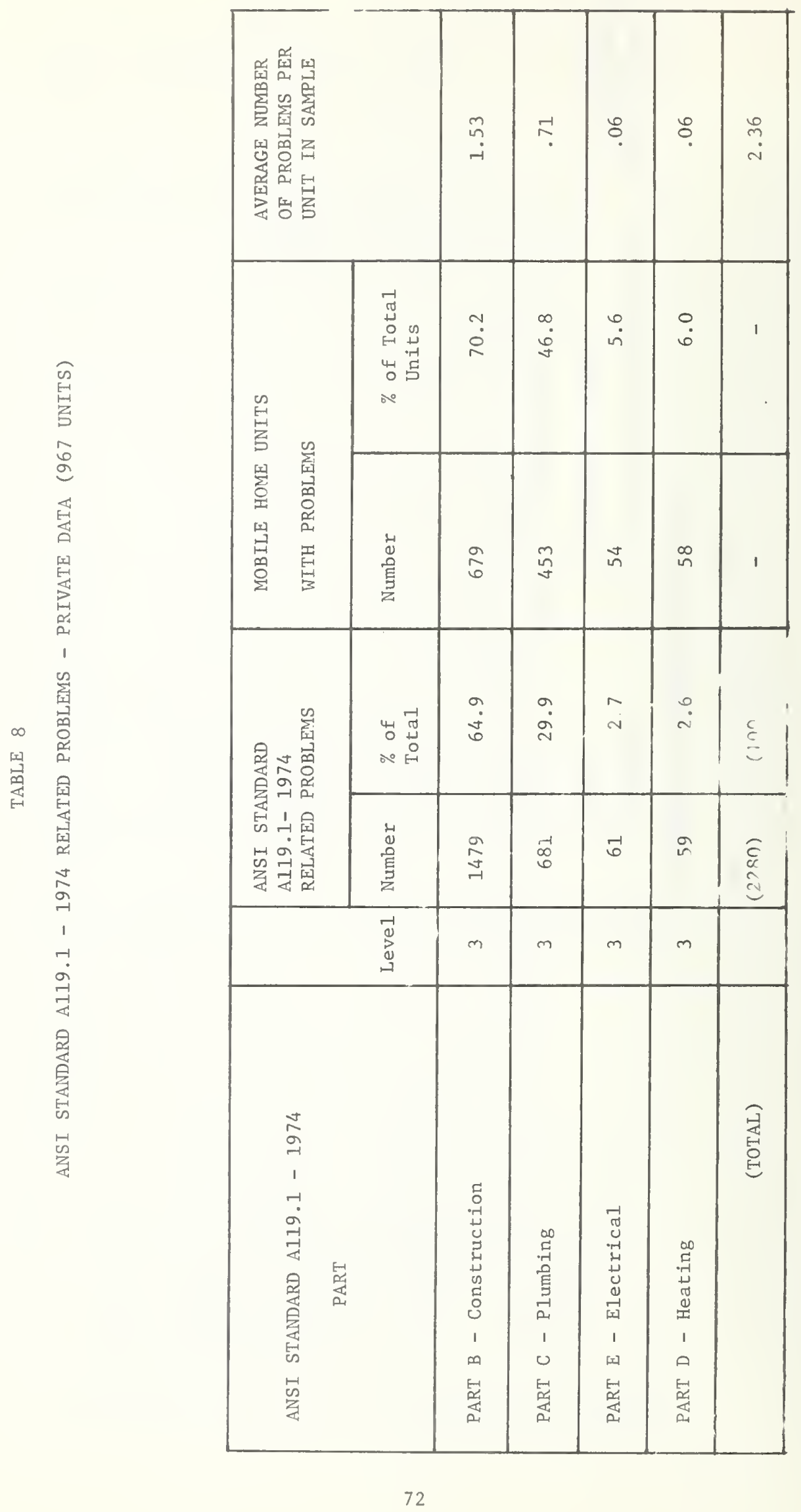




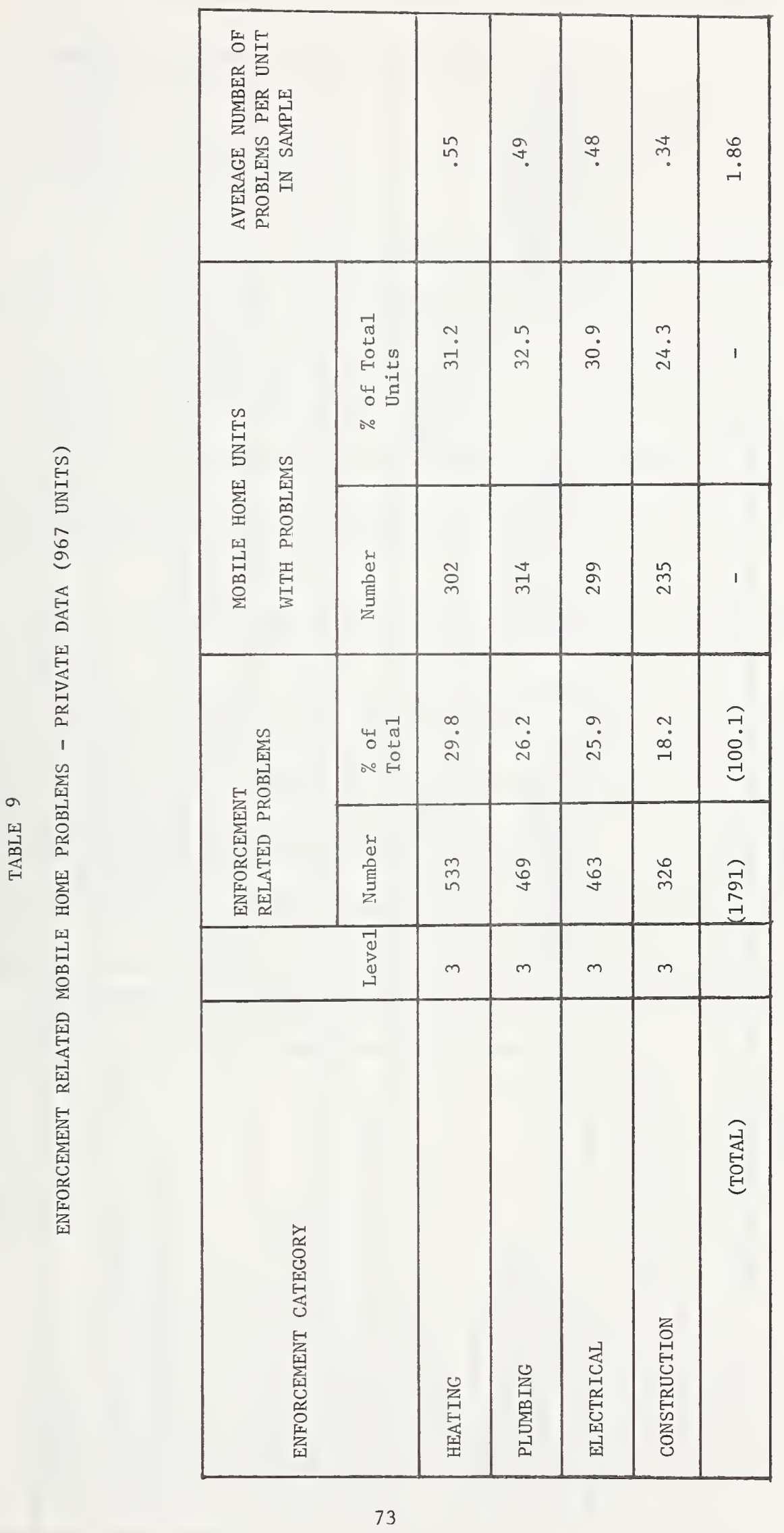




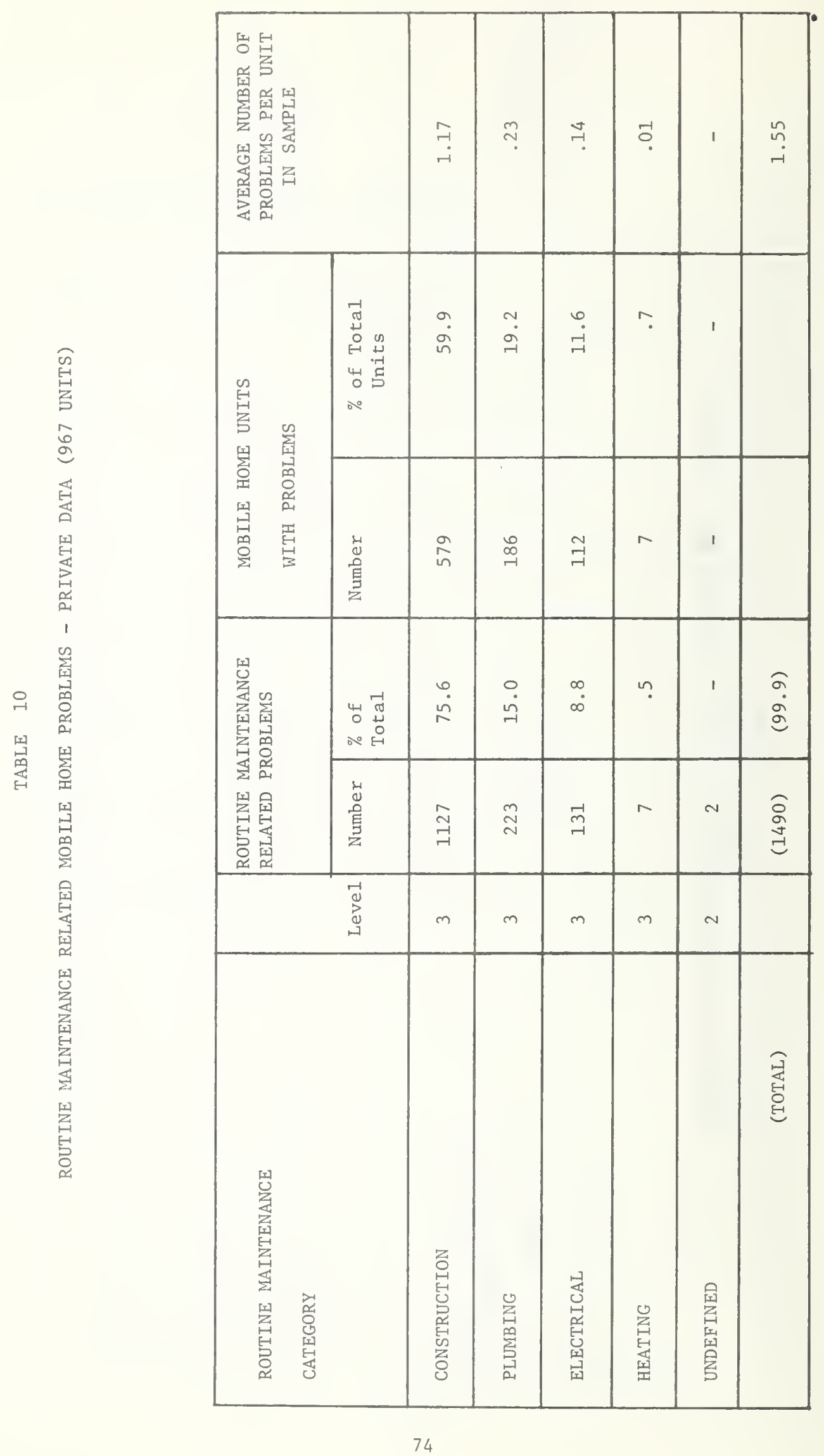




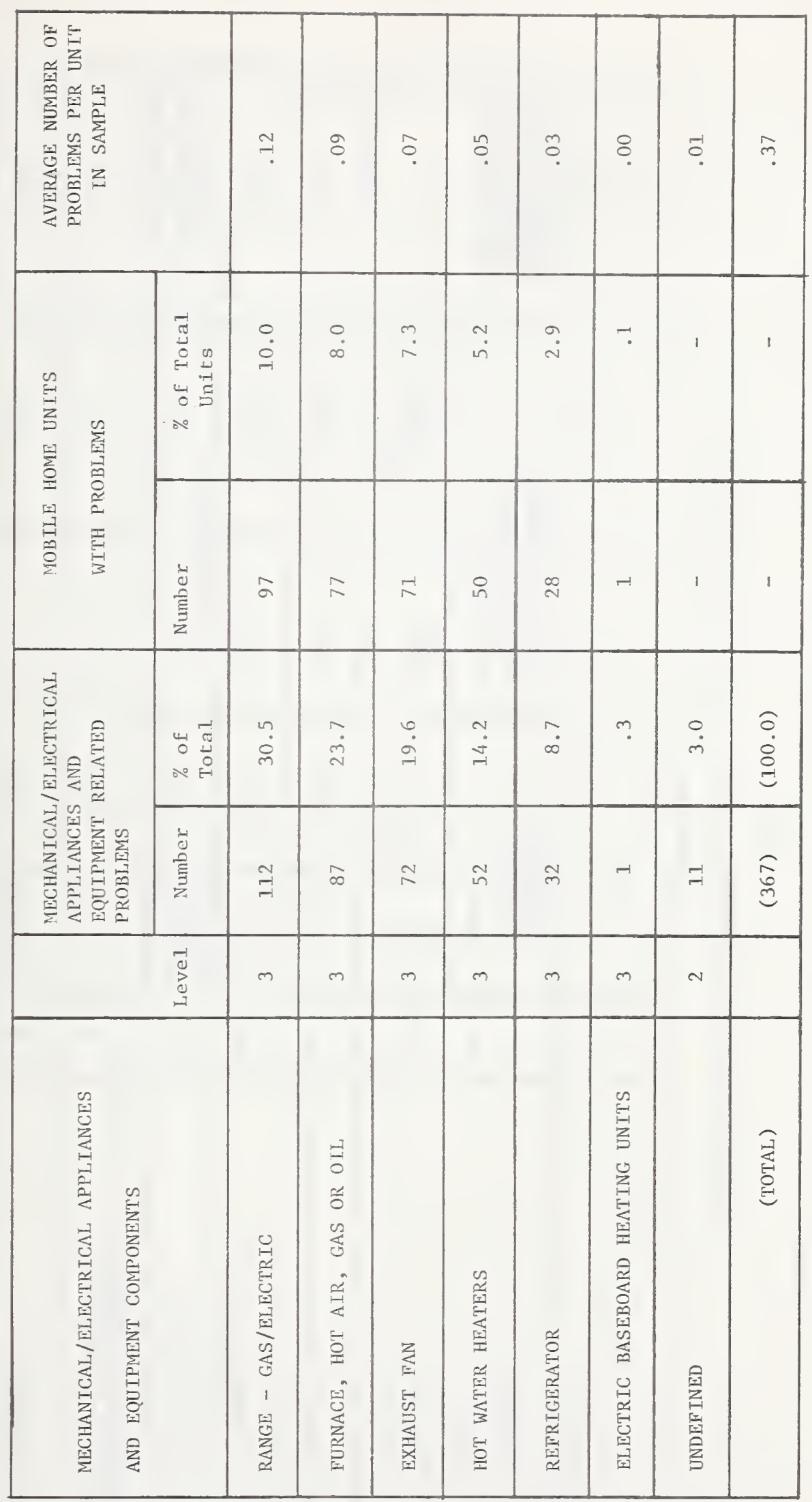




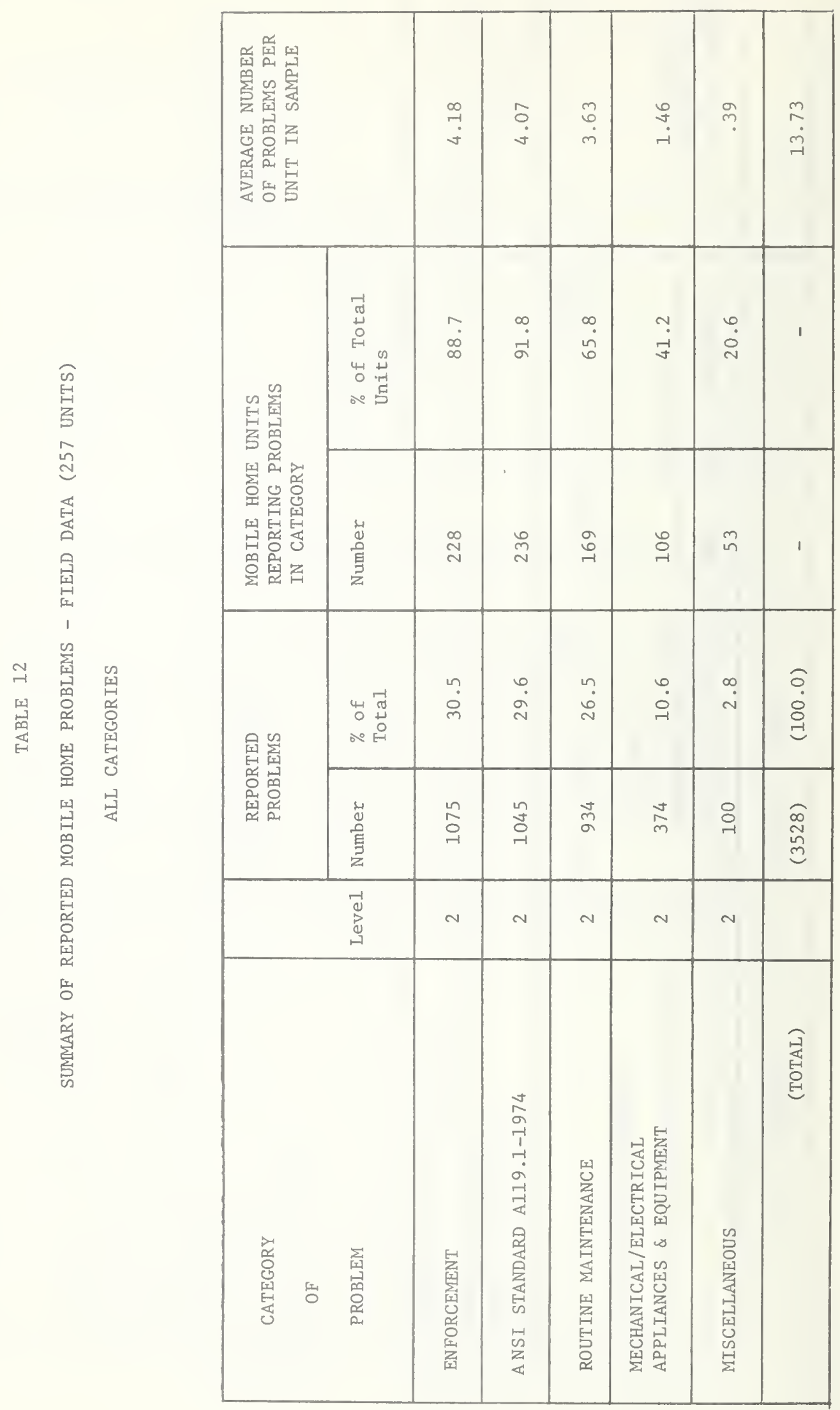




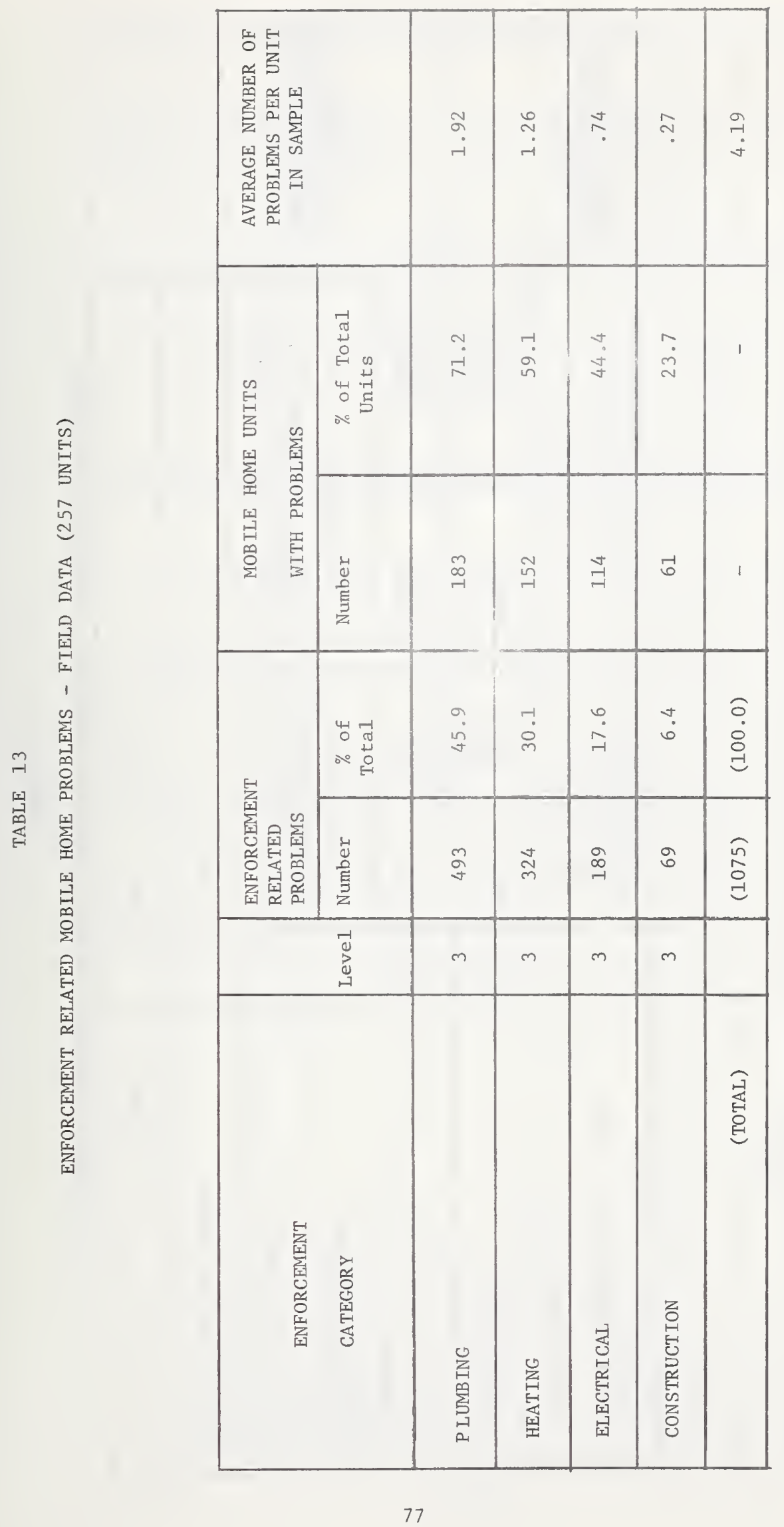




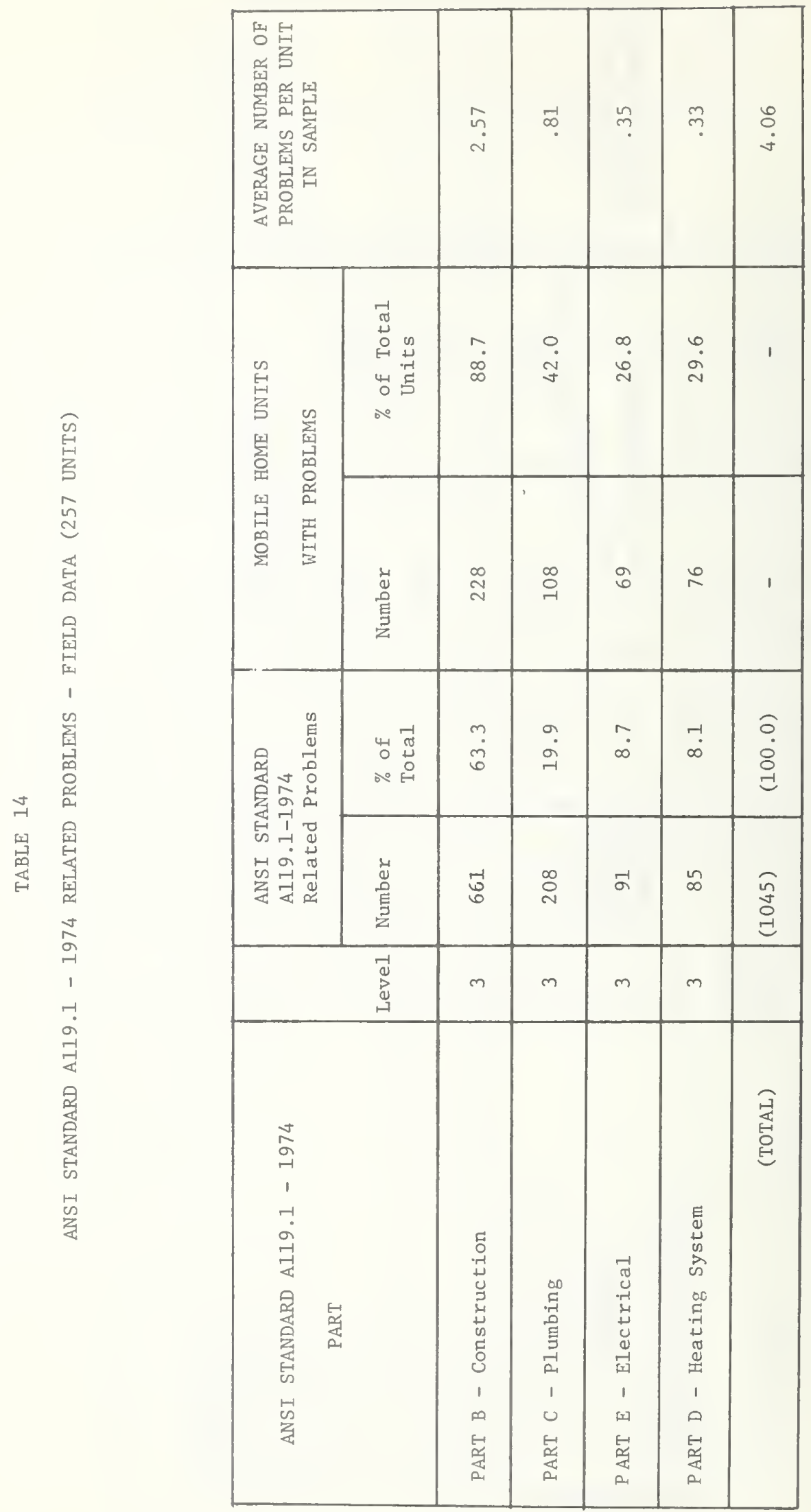




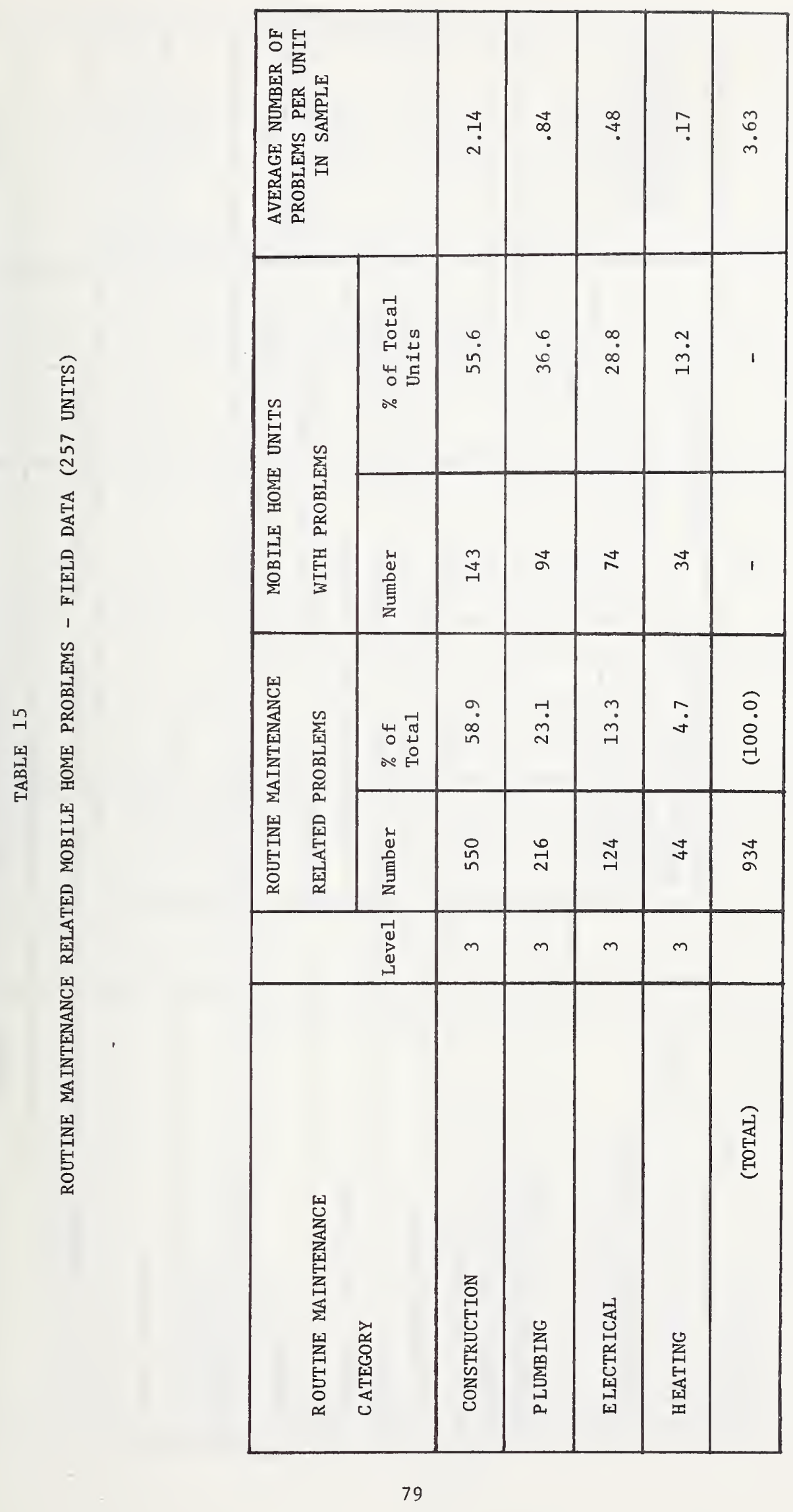




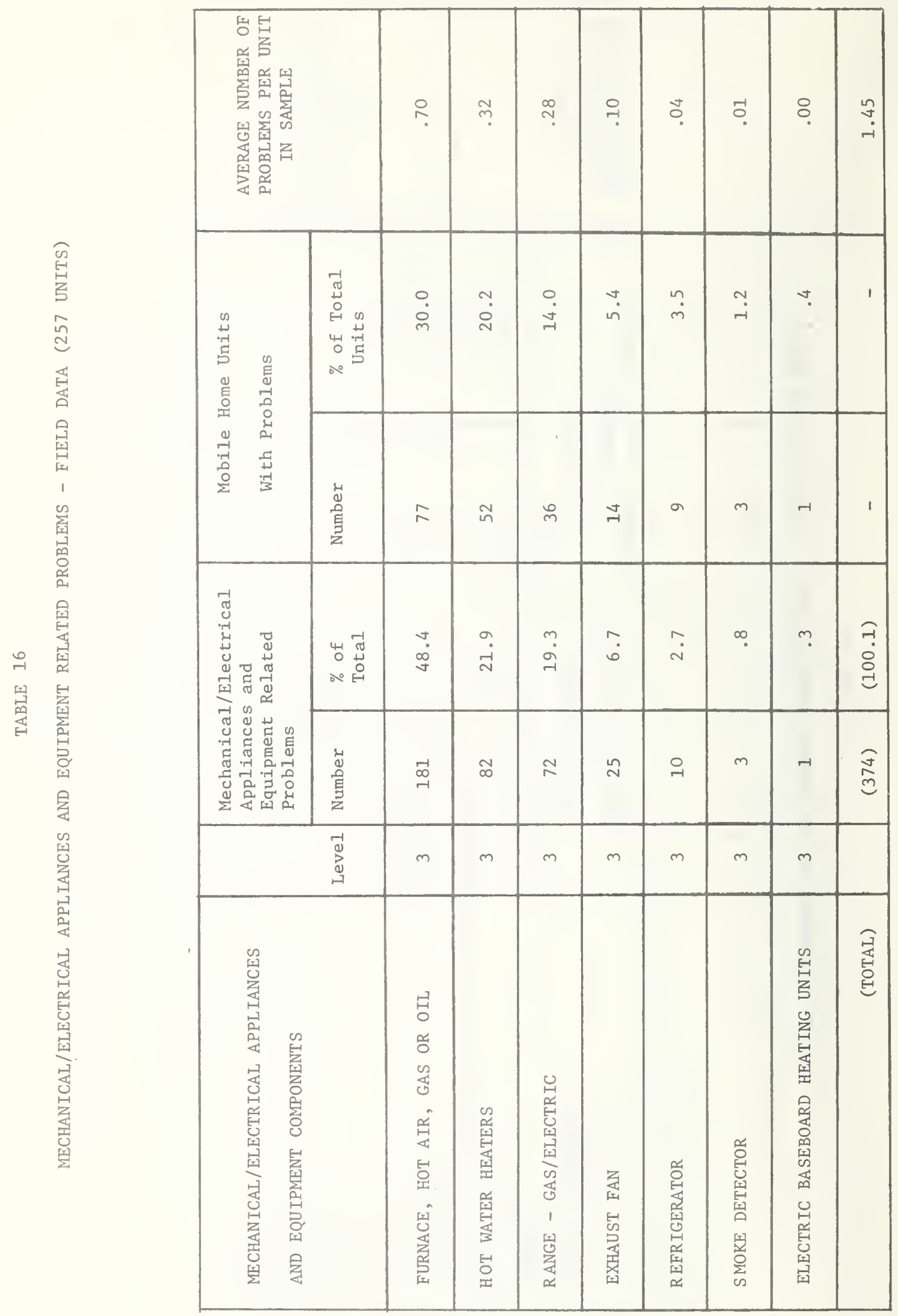




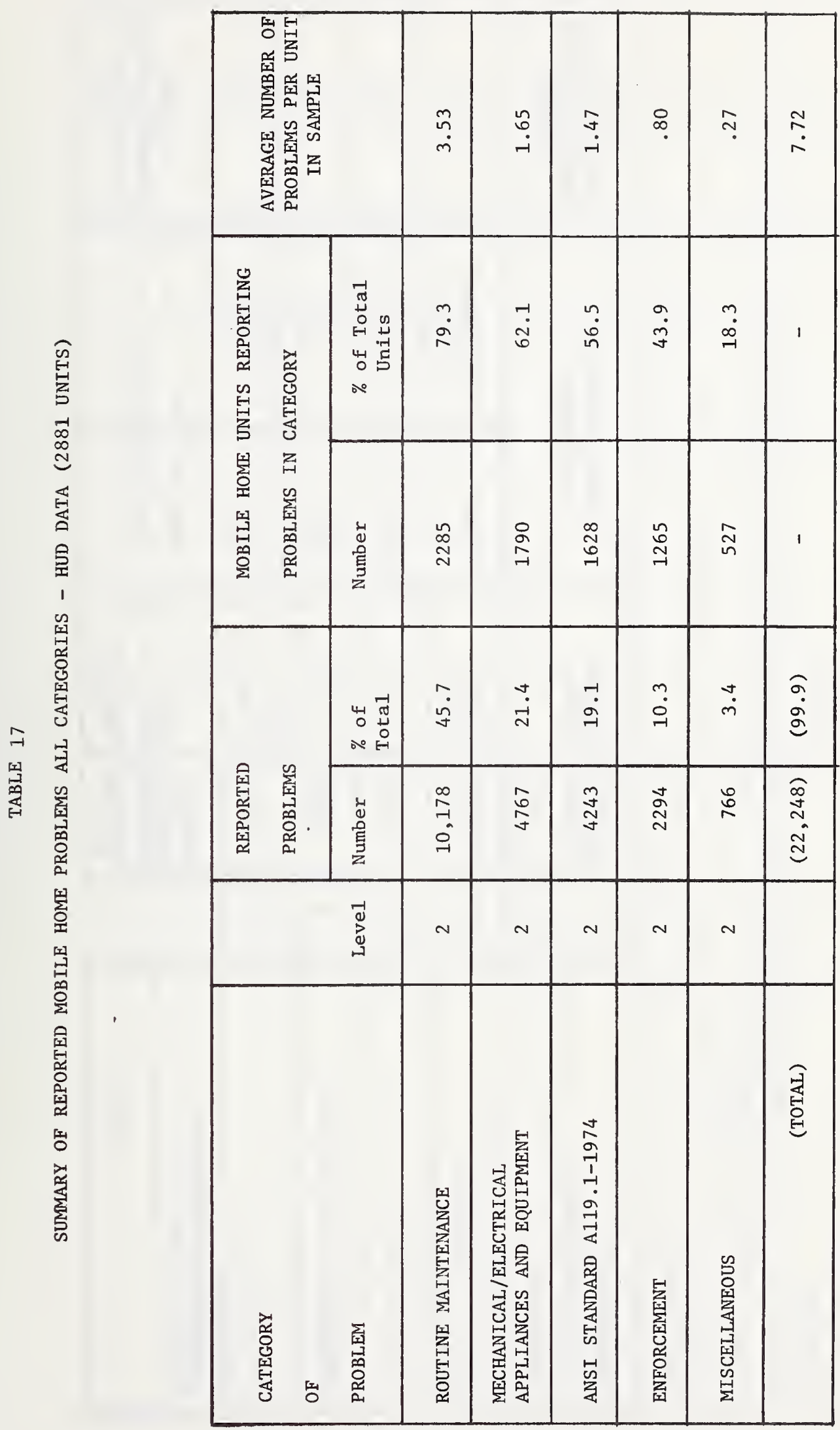




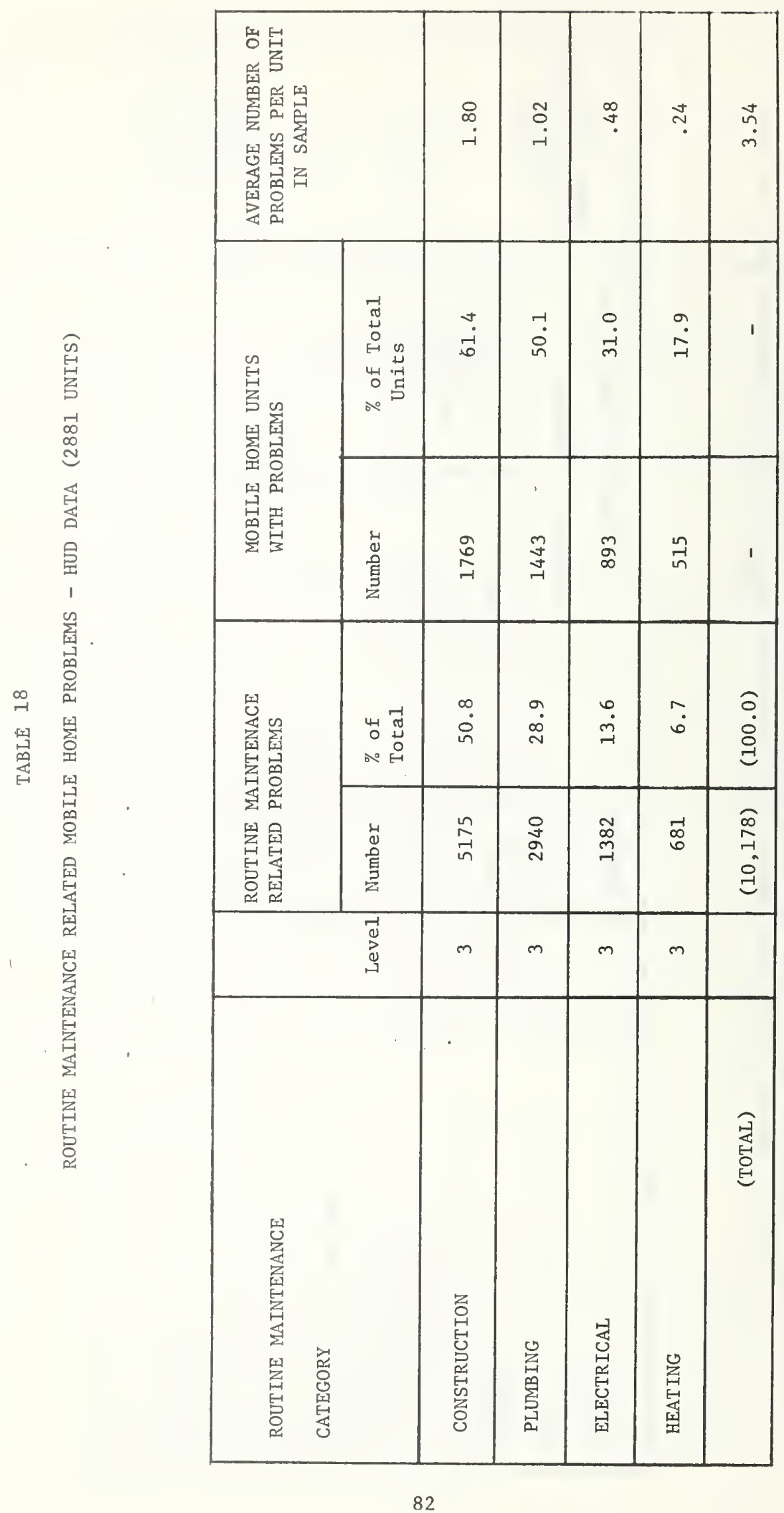




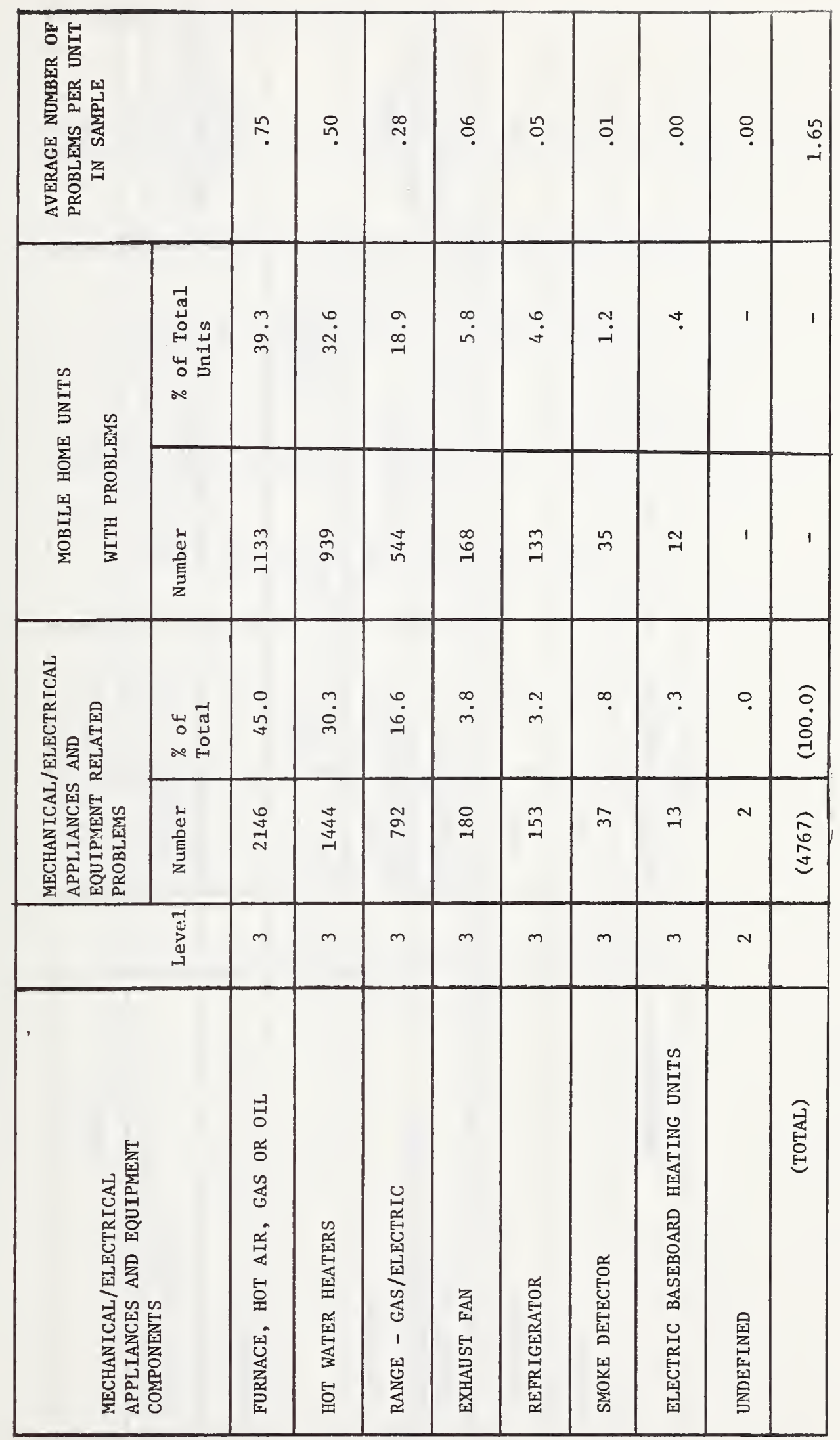




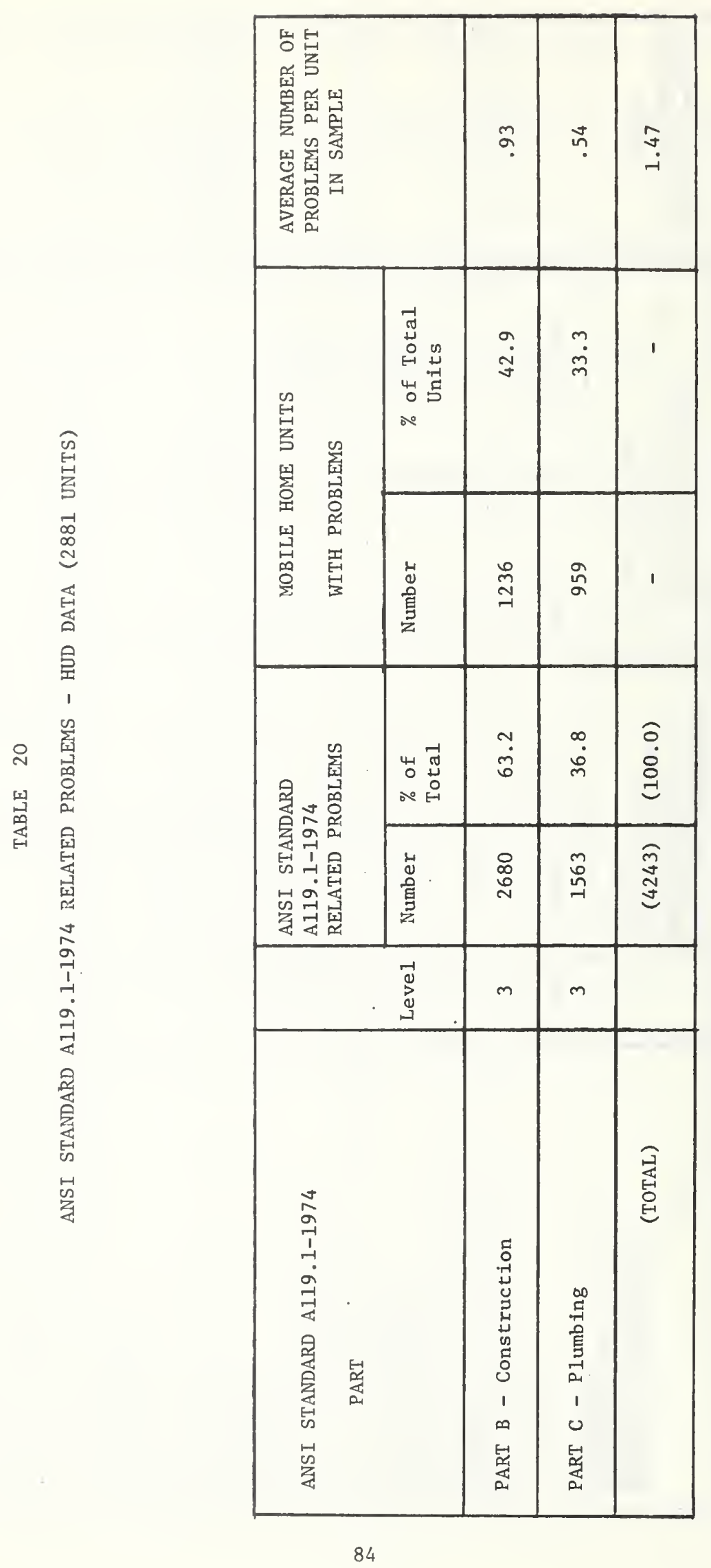




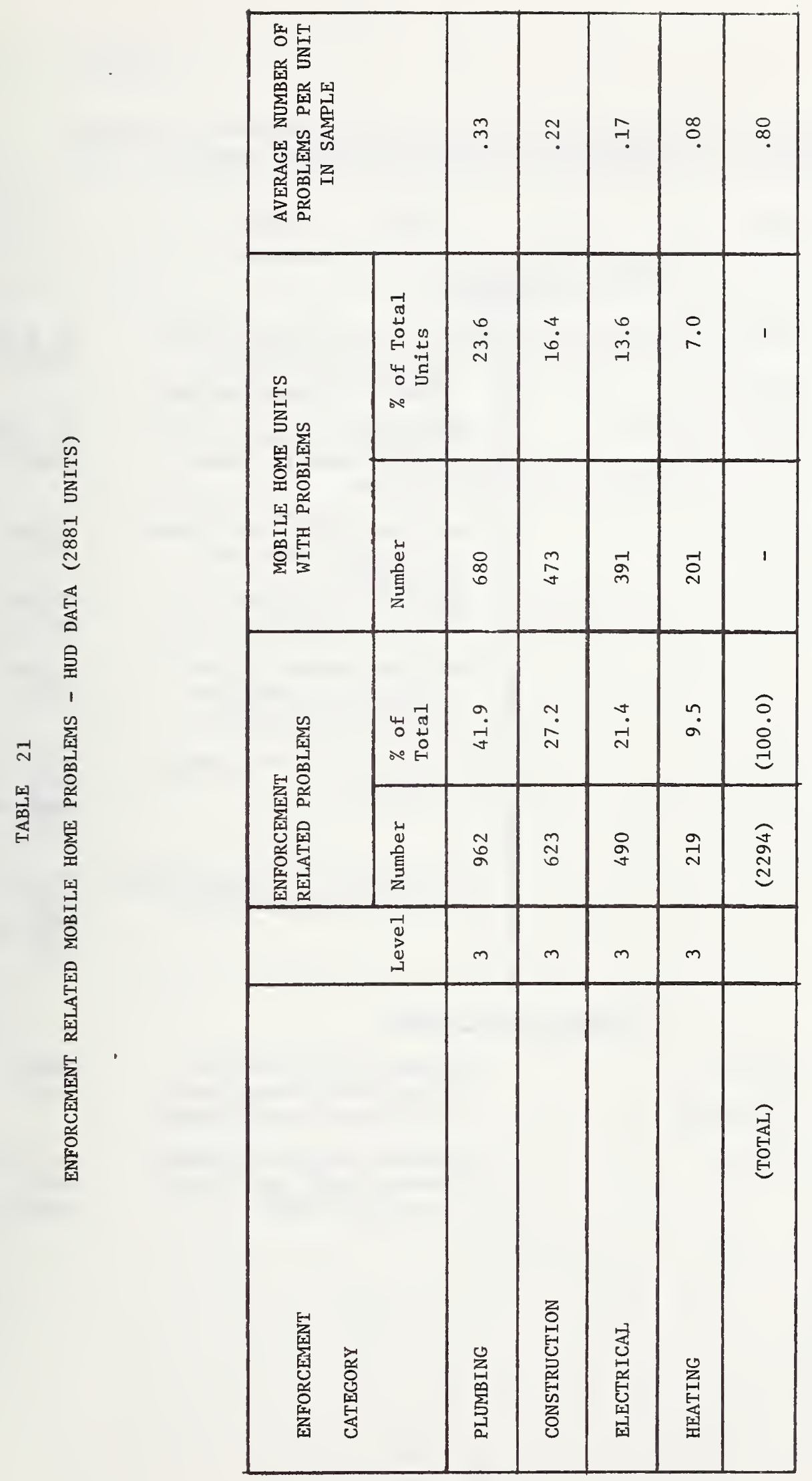


Table 22 - Comparison of Appliance Standards Included in the Minimum Property Standards [8] and ANSI Al19.1 Standard for Mobile Homes [1].

Al19. 1

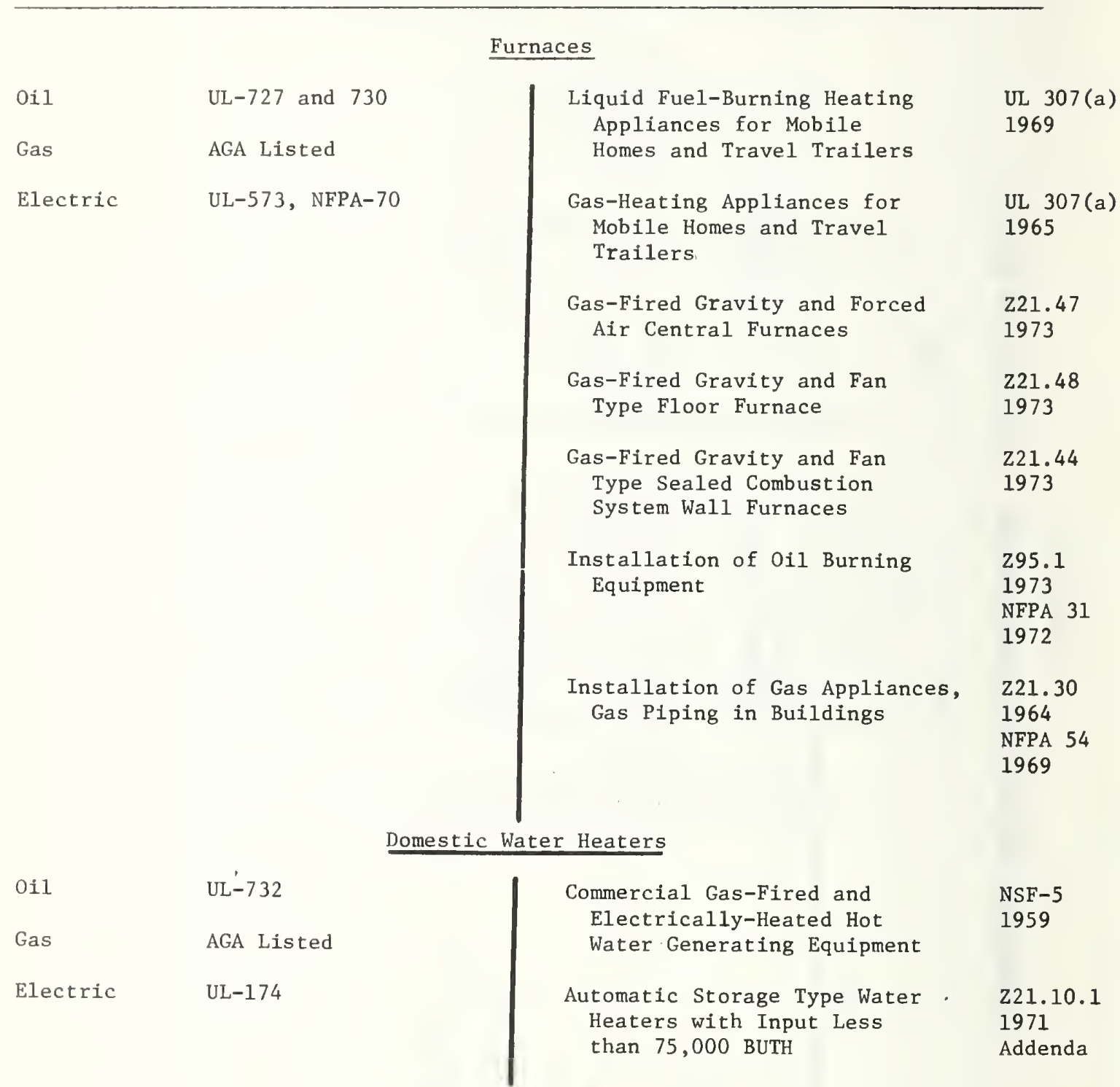


Table 22 - Continued

MPS

A119.1

\section{Ranges}

NONE

Commercial Cooking and Warming Equipment

NSF -4

Hous ehold Cooking Gas

221.1 Appliances

1972

\section{Refrigerators}

NONE

Refrigerators Using GasFue1

221.19

1971

\section{Clothes Dryers}

NONE

A21.5.I

1972 


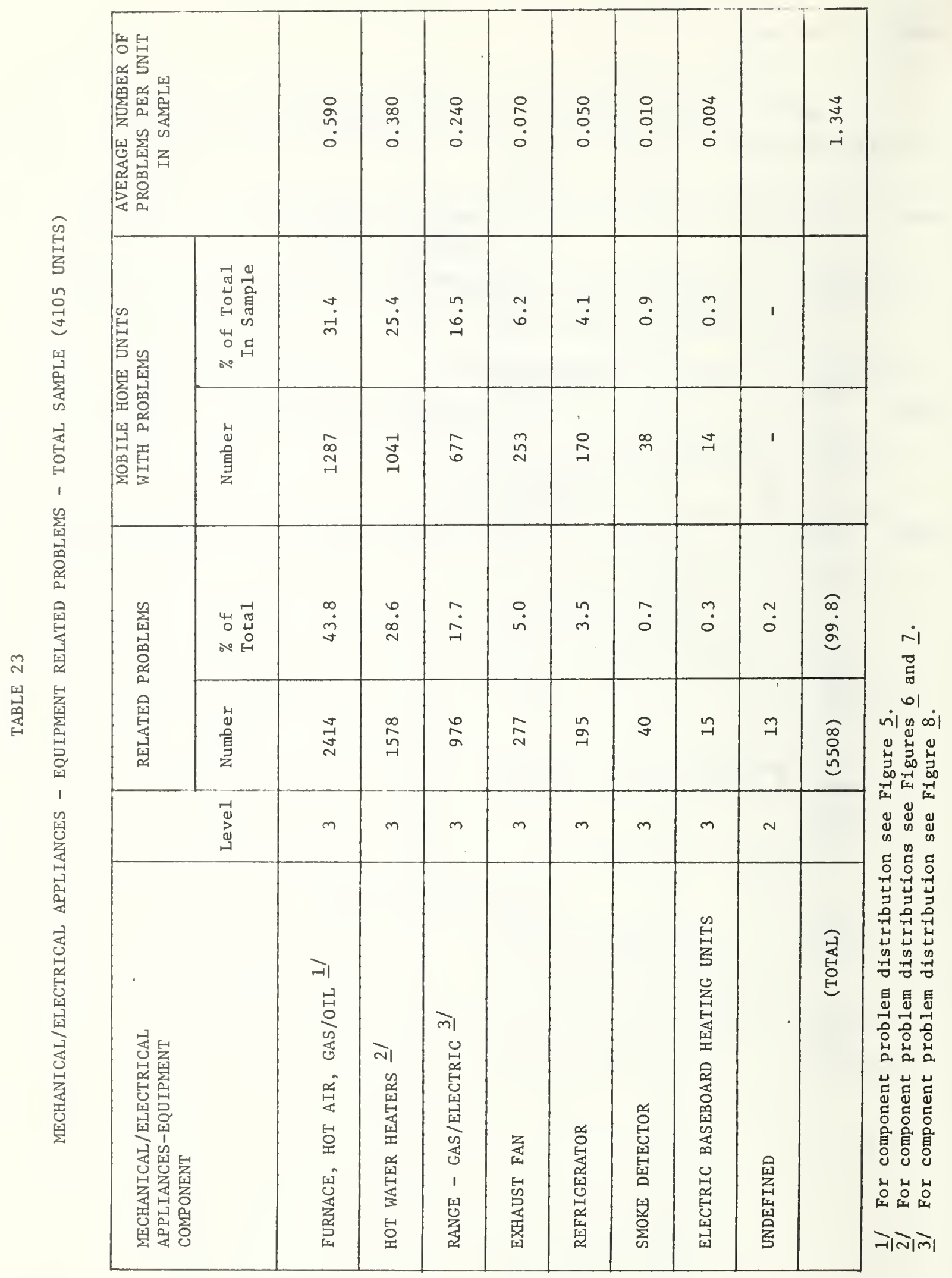


Appendix A

Organization and Use of the Problem Summation Tables 
It was necessary to develop a data handing system using computer techniques because of the large quantity of data collected. The system devised consisted of a 11 sting of performance problems, a coding technique to record the problems and computer programs to organize and present the data [2].

\title{
Organization of Problem Summation Tables
}

The Performance Problem List is organized around four major subsections and a mlscellaneous subsection. The mobile home performance problems significant to the project are categorized under one of the four major subsections listed below and indicated in figure Al.

\author{
A. Problems Related to ANSI A119.1 Standard for Mobile Homes \\ B. Problems Related to Mobile Home Enforcement Process \\ C. Routine Maintenance Problems \\ D. Mechanical/Electrical Appliance Problems
}

This categorization of problems allows documentation of all mobile home performance problems obtained from the various sources.

The ANSI A119.1 Standard for Mobile Homes subsection represents virtually the entire 1974 edition of the Standard [1], with coding symbols being assigned to appropriate paragraphs. In the case of the Plumbing (Part C), Heating (Part D) and Electrical (Part E) sections of the Standard, the paragraph numbers and key words appear just as they do in the Standard. Construction (Part B) differs in that it is organized around the major construction components such as roof, walls, doors, etc. Therefore, some Standard paragraph numbers which pertain to several components are repeated (example, weather resistance). The problems reported under the ANSI Standard A119.1 subsection are related to inadequacies or omissions in the Standard.

The Mobile Home Enforcement Process subsection is organized similar to the ANSI Al19.1 subsection to document problems related to deficiencies in the mobile home regulatory process.

The Routine Mainteriance subsection in the catalog is organized under the same general headings as the ANSI Al19.1 Enforcement Process subsections; i.e., construction, plumbing, heating and electrical.

The Mechanical/Electrical Appliance subsection of the catalog is grouped by appliance; i.e., furnace, range, hot water heater, refrigerator, exhaust fan and smoke detector. Since components of each appliance are listed, it was possible to pinpoint the component problem where the detail of the data permitted.

Use of Problem Summation Tables

A problem level concept is employed in the Performance Problem List to organize and assist in the evaluation of the data. Figure Al illustrates problem levels 1,2 and 3 and figure A2 isolates ANSI A119.1 (Construction) to illustrate levels 2 through 7 . The problem summation tables in Appendices B, C and D show the problem level for each item in the last column and in some cases the problem list has been extended to an 8 th 1 level. The problem level concept was established as a tool to order the data and does not impart any degree of importance or significance to the individual problems as they relate to one another.

Using Tables A1, A2 and A3 as references, the use of the Problem Summation Tables is illustrated as follows. 
Columns labeled (A), (B), (C), (D), (HOMES), (\% Homes), and (Leve1) defined below are the same for Tables $\mathrm{A} 1, \mathrm{~A} 2$ and $\mathrm{A} 3$.

Column (A) - The code assigned to identify a particular problem as recorded in the Performance Problem List.

Column (B) - A brief description of the problem or area of concern including the appropriate part of paragraph number in the ANSI Al19.1 Standard for Mobile Homes [1].

Column (C) - The number of problems that have been coded with the code identified on that line in Column A. Reported information on the problem has not allowed coding below the level of detail of the particular line (see column labeled "LEVEL.") For example, consider problem code NPLM on Table Al (Plumbing - Routine Maintenance); 395 of the 3,379 problems were recorded under the general plumbing category, while problem definition allowed the remaining 2,984 (3,379 - 395) problems to be recorded with greater detail.

Column (D) - The summation of all problems at a discrete level. For example, the total number of problems associated with Routine Maintenance is 12,602 (Table A1) which is made up of the following summation of leve1 3 problems.

\begin{tabular}{lr} 
Construction & 6,852 \\
Plumbing & 3,379 \\
Electrical & 1,637 \\
Heating & 732 \\
Undefined (Column C) & 2 \\
\hline \multicolumn{1}{c}{ Total } & 12,602
\end{tabular}

The number of problems at a given level is the summation of problems at the next lower level. As another example, the number of level 1 problems $(31,982)$ consists of the following level 2 problems: 12,602 Routine Maintenance problems; 7,568 ANSI A119.1 problems; 5,508 Mechanical/Electrical Appliance problems, 5,160 Enforcement problems, and 1,144 Miscellaneous problems.

Column (HOMES) - The values in this column indicate the number of mobile homes in the sample that had one or more of the problems identified on each 1ine ( 1,723 mobile homes with 3,379 Plumbing - Routine Maintenance problems in Table AI).

Column (\% Homes) - The entries in this column indicate the percentage of the total number of mobile homes reviewed in the sample which had the problem identified on each line. For example, under Plumbing - Routine Maintenance in Table Al.

$$
\frac{1,723 \text { homes with problems }}{4,105 \text { homes in sample }} \times 100=42.0 \%
$$

Column (Leve1) - These entries define the level of detail of the problem for each line.

Columns labeled (\% 2nd and \% 1st) in Table Al are defined below:

Consider the example of "Construction (CONS) - ANSI Standard A119.1" 
Column (\% 2nd) - The entries in this column are the percentage of 2 nd level problems that are contained at the third level of detail.

$$
\frac{\text { Leve1 } 3 \text { Problems }}{\text { Leve1 } 2 \text { Problems }}=\frac{4,820}{7,568} \times 100=63.7 \%
$$

Column (\% 1st) - The entries in this column are the percentages of 1st level problems that are contained at each lower level of detail.

$$
\frac{\text { Level } 3 \text { Problems }}{\text { Level } 1 \text { Problems }}=\frac{4,820}{31,982} \times 100=15.1 \%
$$

Columns labeled (\% 3rd), (\% 2nd), and (\% 1st) in Table A2 are defined below:

Consider the example of "Exterior Walls (EXTW) - Construction - ANSI Standard A119.1."

Column (\% 3rd) - The entries in this column are the percentages of $3 r d$ level problems which are contained at each 4 th level of detail.

$$
\frac{\text { Level } 4 \text { Problems }}{\text { Level } 3 \text { Problems }}=\frac{995}{4,820} \times 100=20.6 \%
$$

Column (\% 2nd) - Percentages relating 4th levels to the 2nd level of detail.

$$
\frac{\text { Leve1 } 4 \text { Problems }}{\text { Leve1 } 2 \text { Problems }}=\frac{995}{7,568} \times 100=13.1 \%
$$

Column (\% 1st) - Percentages relating 4 th level to the 1st level.

$$
\frac{\text { Level } 4 \text { Problems }}{\text { Level } 1 \text { Problems }}=\frac{995}{31,982} \times 100=3.1 \%
$$

Column labeled $(\% 7 \mathrm{th}),(\% 6 \mathrm{th}),(\% 5 \mathrm{th}),(\% 4 \mathrm{th})$, and $(\% 3 \mathrm{rd})$ on Table A3 are defined below:

Consider the example of "Faucet Assembly (NPKA) - Water Supply Piping-Plumbing Routine Maintenance."

Column (\% 7th and 6th) - Entries in these columns are percentages denoting the portions of the 7 th and 6 th level problems for each 8 th and 7 th level problem. These columns are blank on Table A3 since there are no 7 th and 8 th level problems shown on this page.

Column (\% 5th), (\% 4th), (\% 3rd) - Entries in these columns related the number of problems at a given level to preceeding levels (6, 5, 4 and 3 ).

$$
\begin{aligned}
& \frac{\text { Leve1 } 6}{\text { Leve1 } 5 \text { Problems }}=\frac{131}{478} \times 100=27.4 \% \text { (Column } \% 5 \text { th) } \\
& \frac{\text { Leve1 } 7 \text { Problems }}{\text { Leve1 } 4 \text { Problems }}=\frac{131}{1,196} \times 100=11.0 \% \text { (Column \% 4th) } \\
& \frac{\text { Leve1 } 7 \text { Problems }}{\text { Leve1 } 3 \text { Problems }}=\frac{131}{3,379} \times 100=3.9 \% \text { (Column \% 3rd) }
\end{aligned}
$$




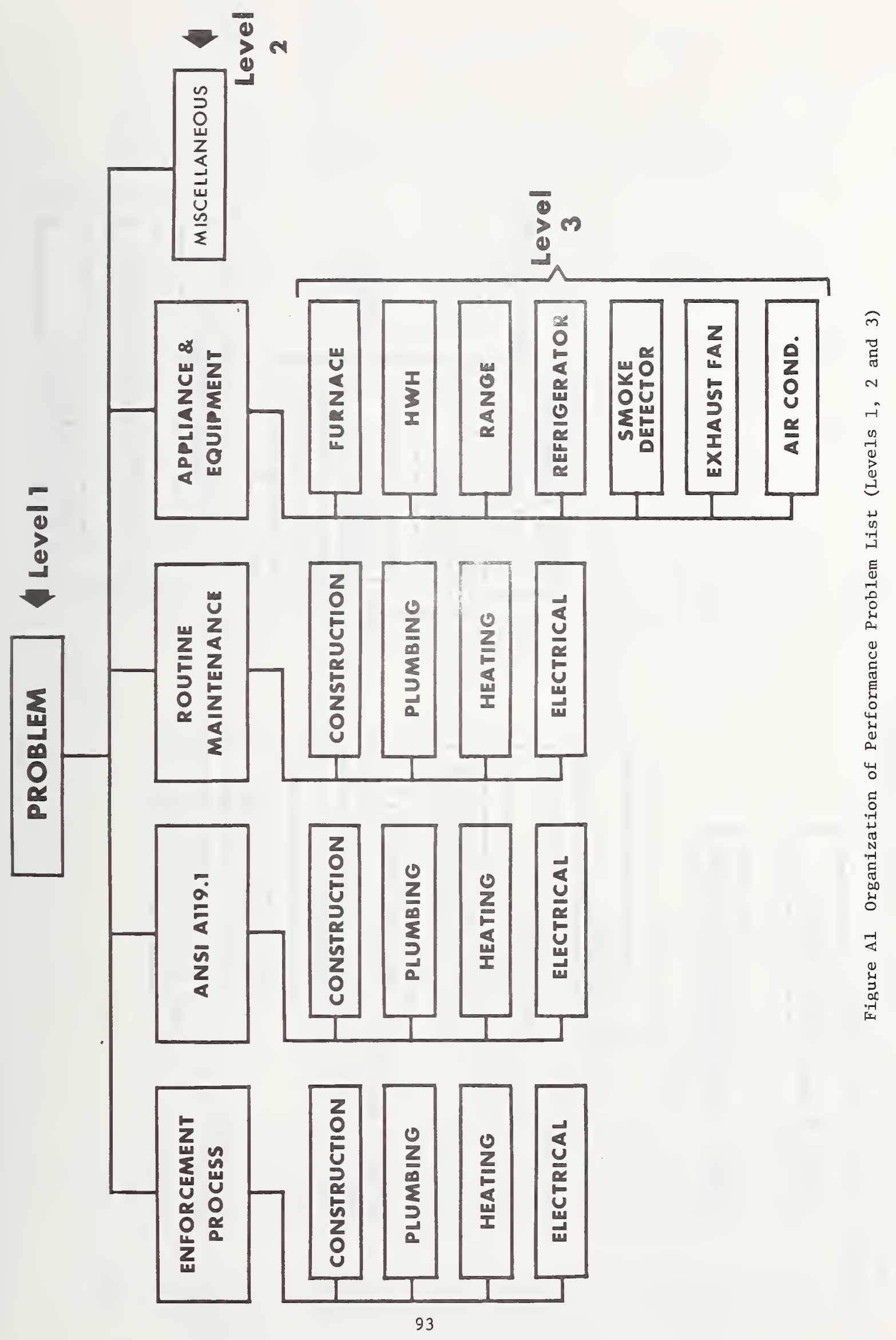




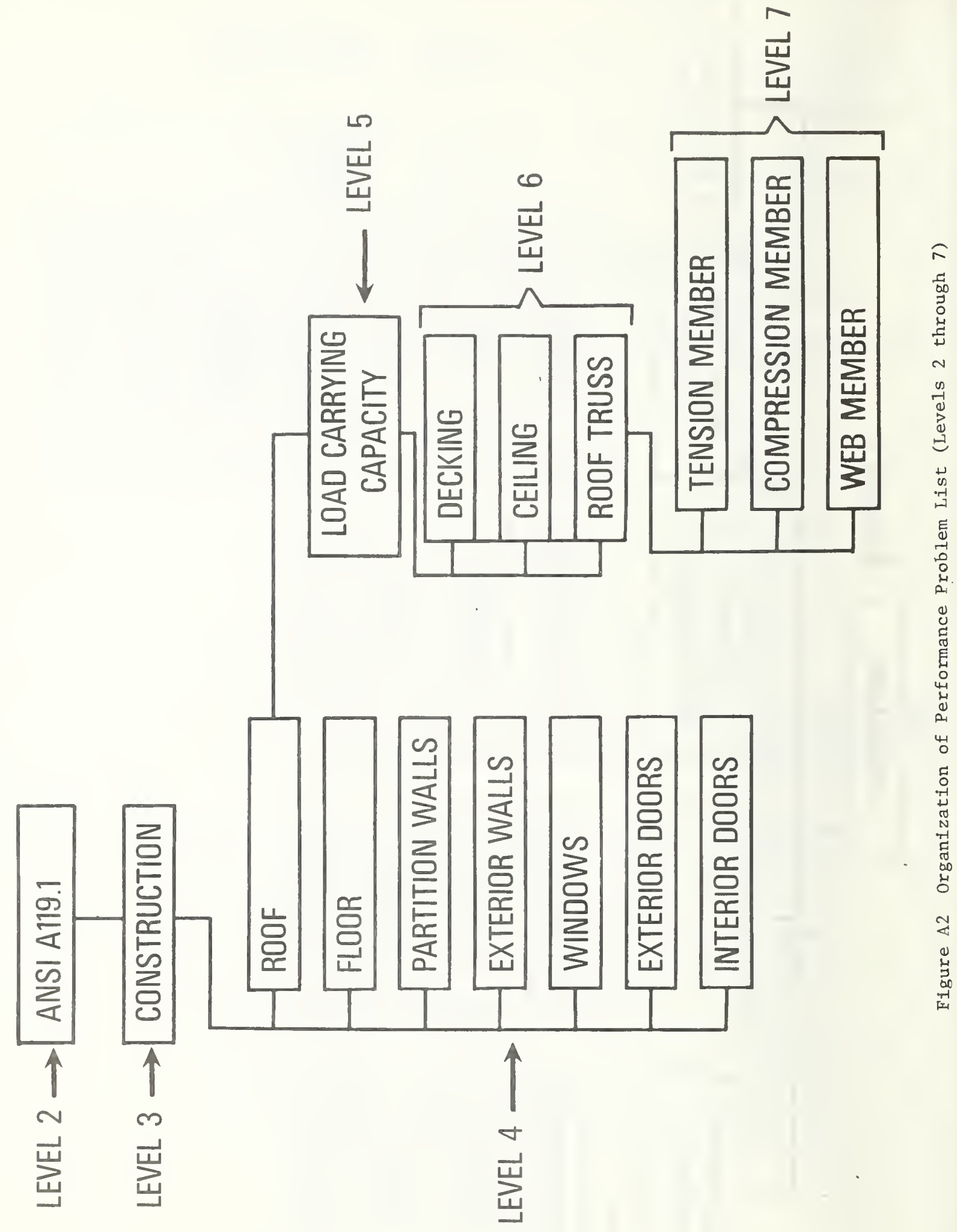



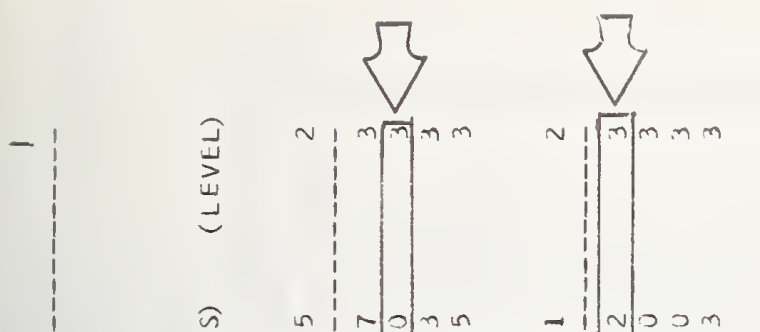

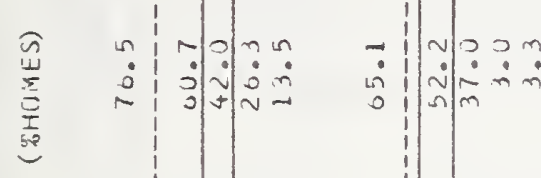

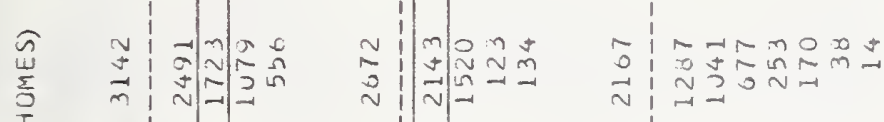

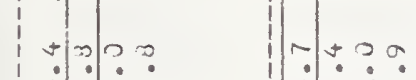
今an

min

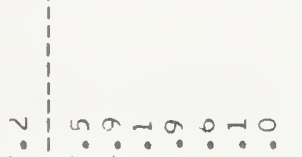

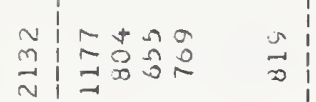
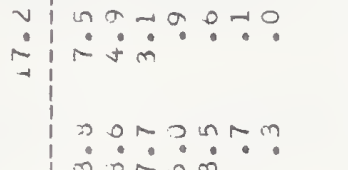

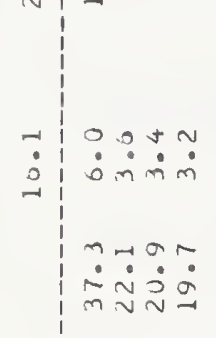
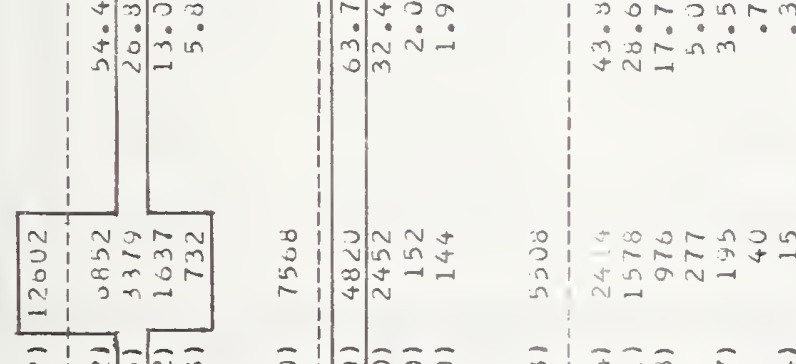

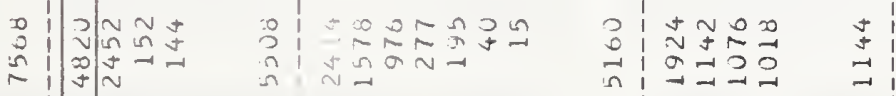

$0: 12 \sim 0 x$

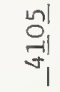

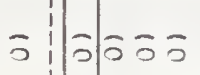

m:

$\sigma: 00 \underset{n}{0} 0$

(1)

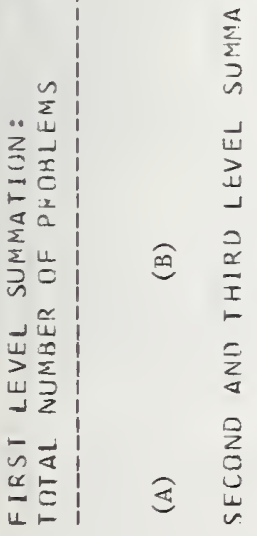
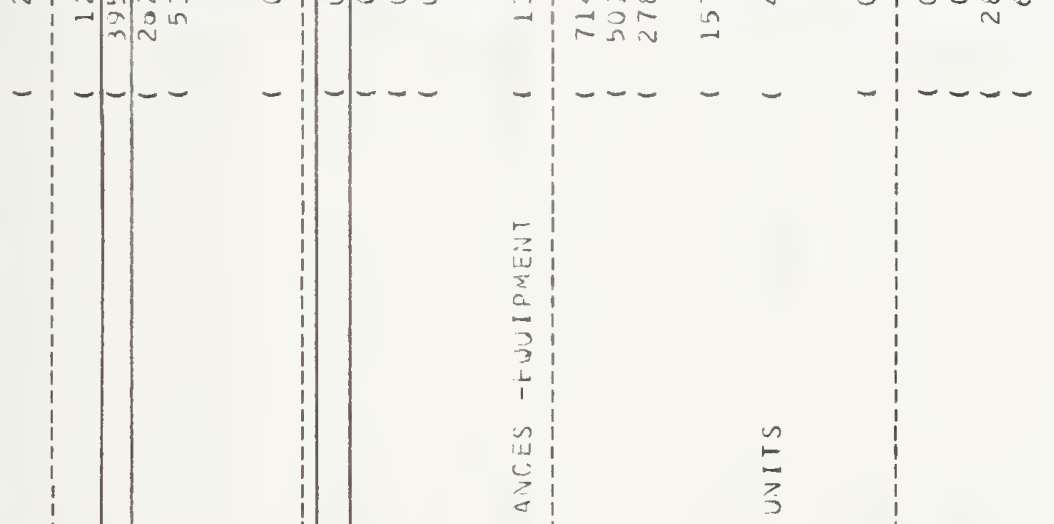

出

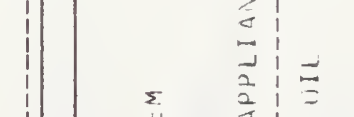

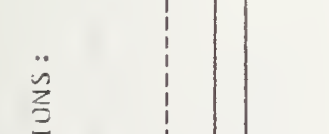

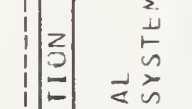

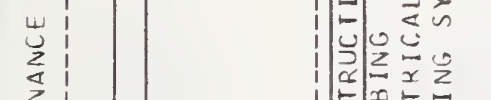

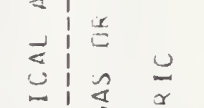

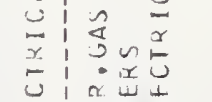

约它:

|

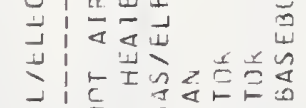

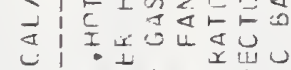

之

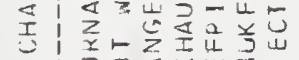

51 1020

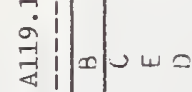

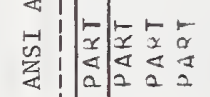

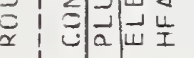

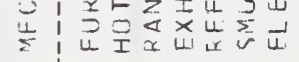

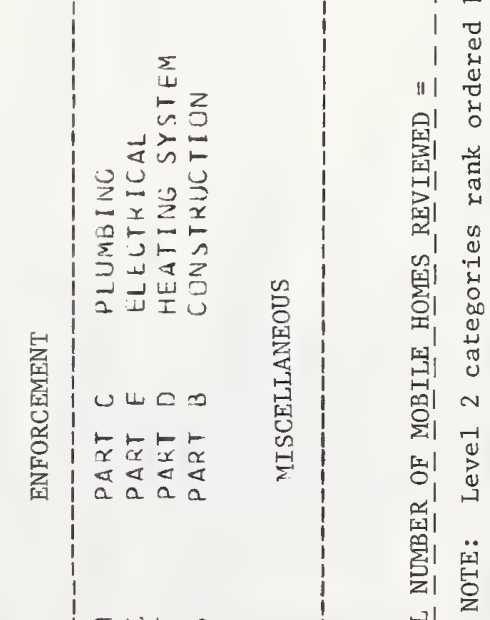

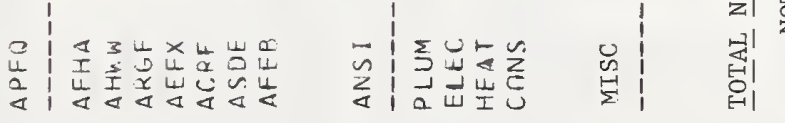




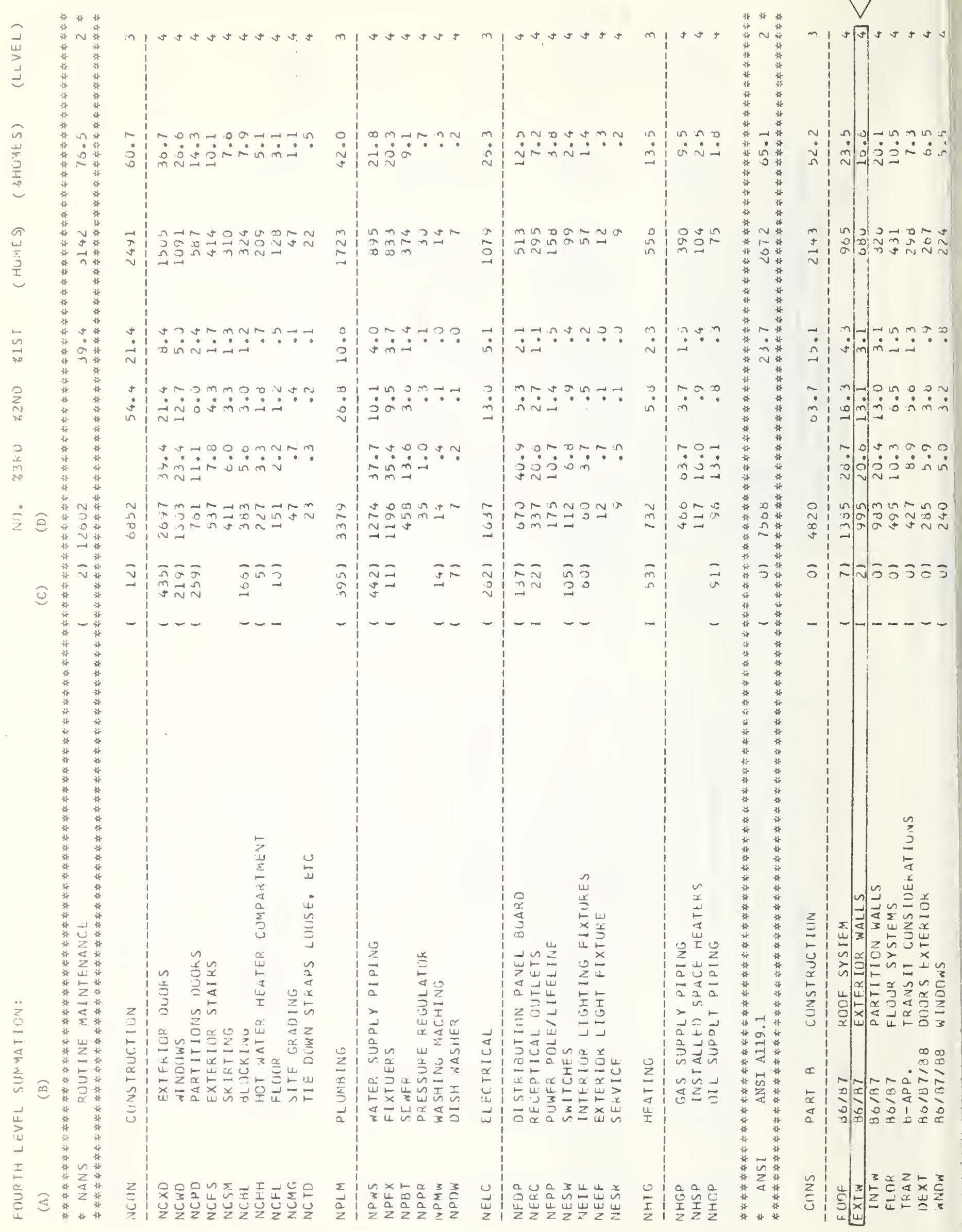




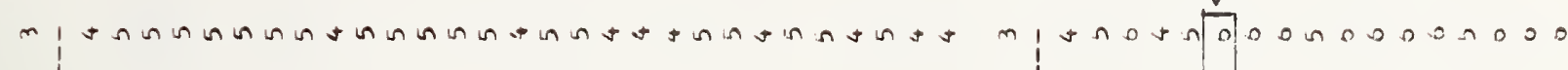
ก

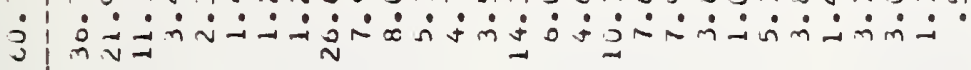

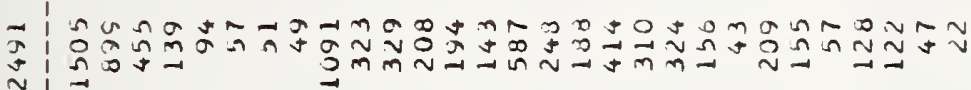

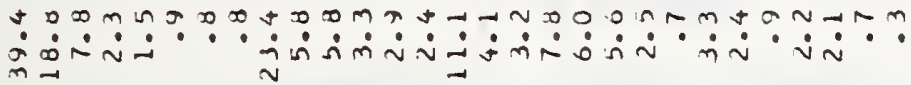

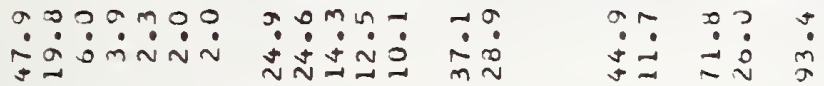

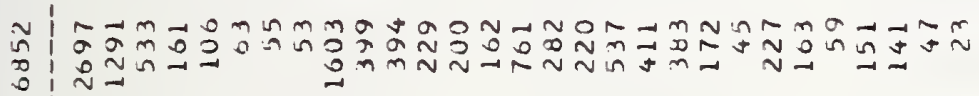
$\approx \mid \begin{array}{ll}n & a \\ 0 & a\end{array}$

$\vec{a}$

$\hat{\sigma}$

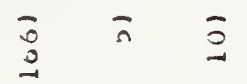<smiles>C=CC1CCCCC1</smiles>

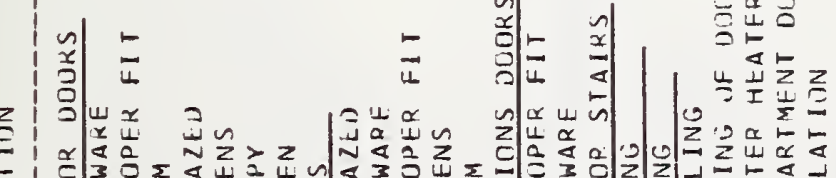

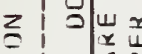

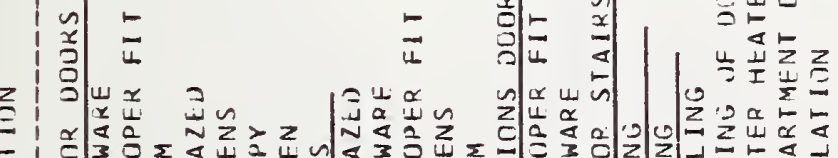

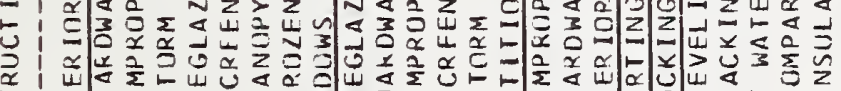

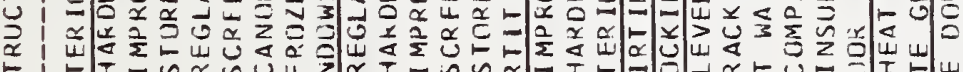

范

נلע

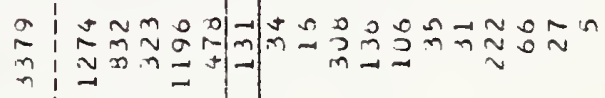

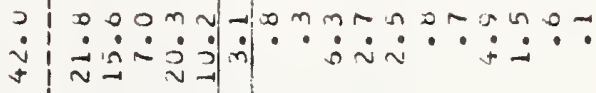

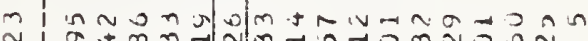

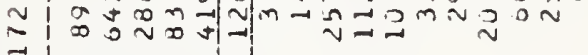

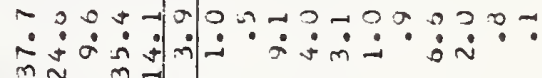
m.

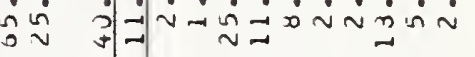

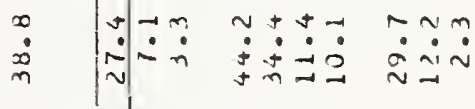

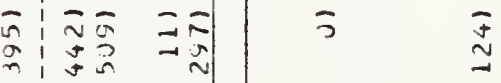

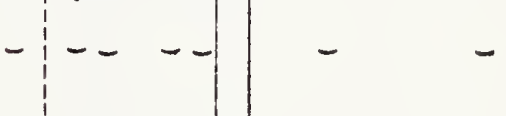




\section{Appendix B}

Problem Summation Tables - HUD Sample 


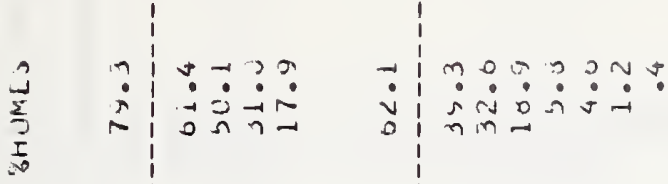

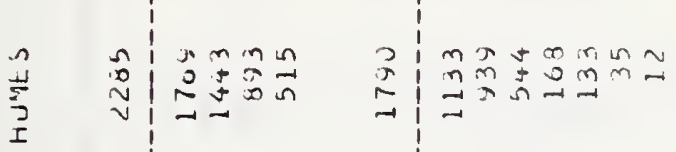

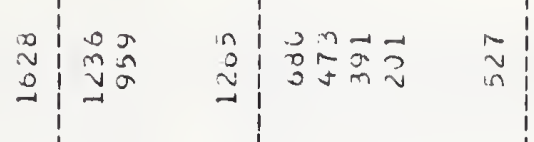

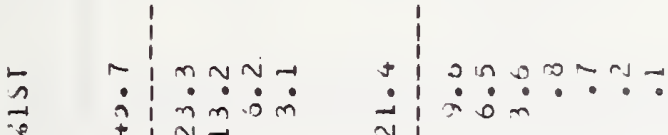

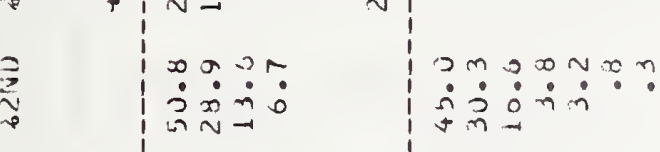

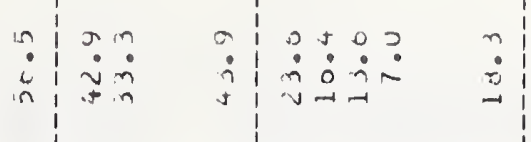
莎

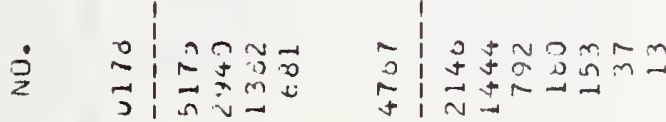

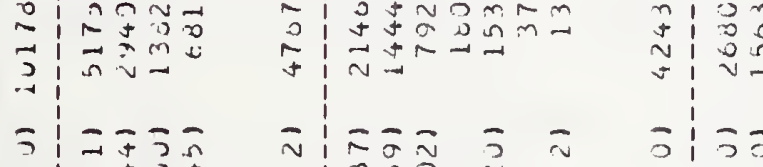

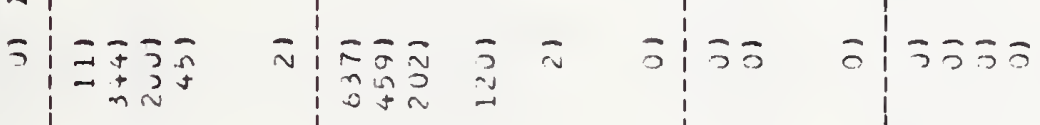

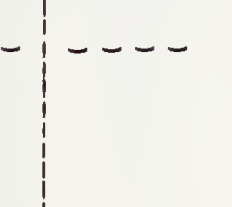

..

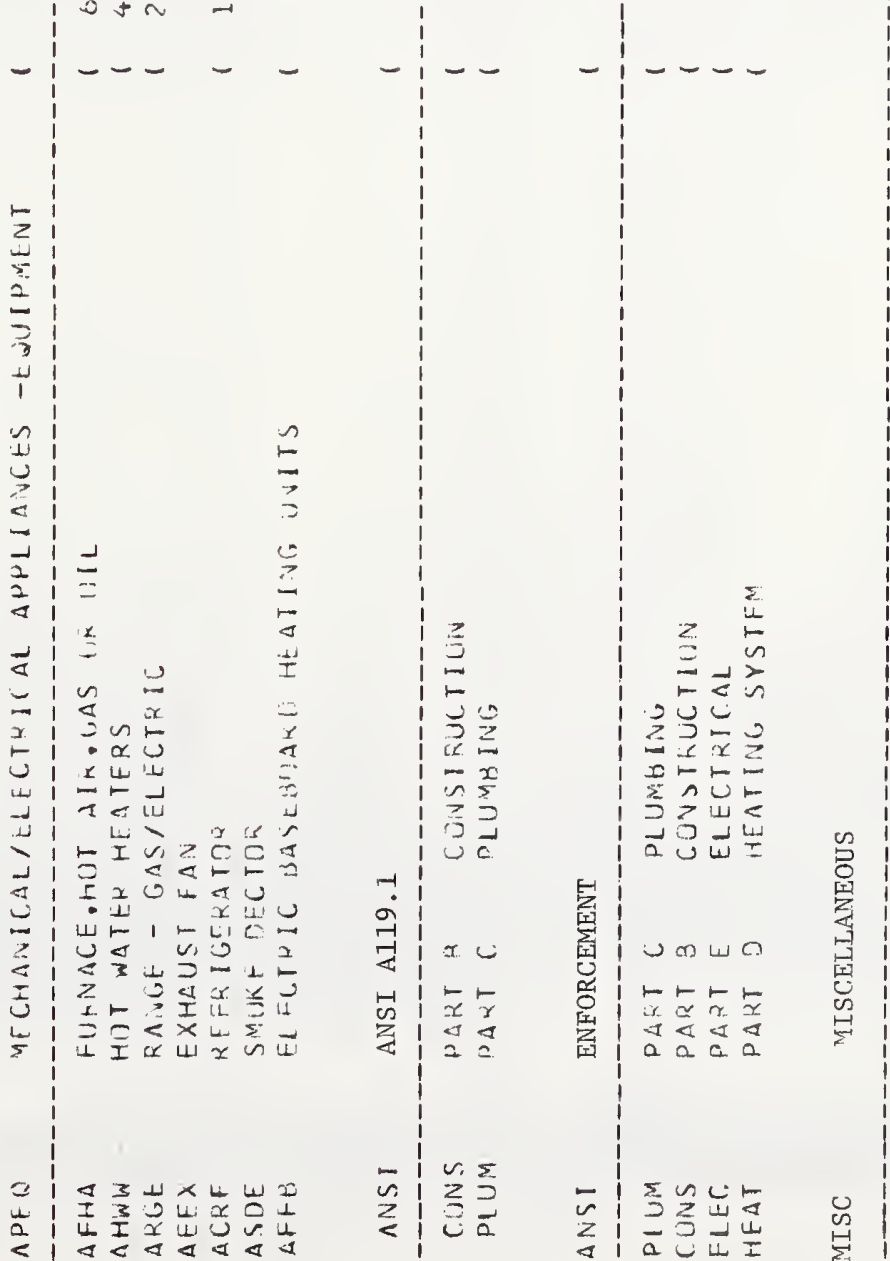









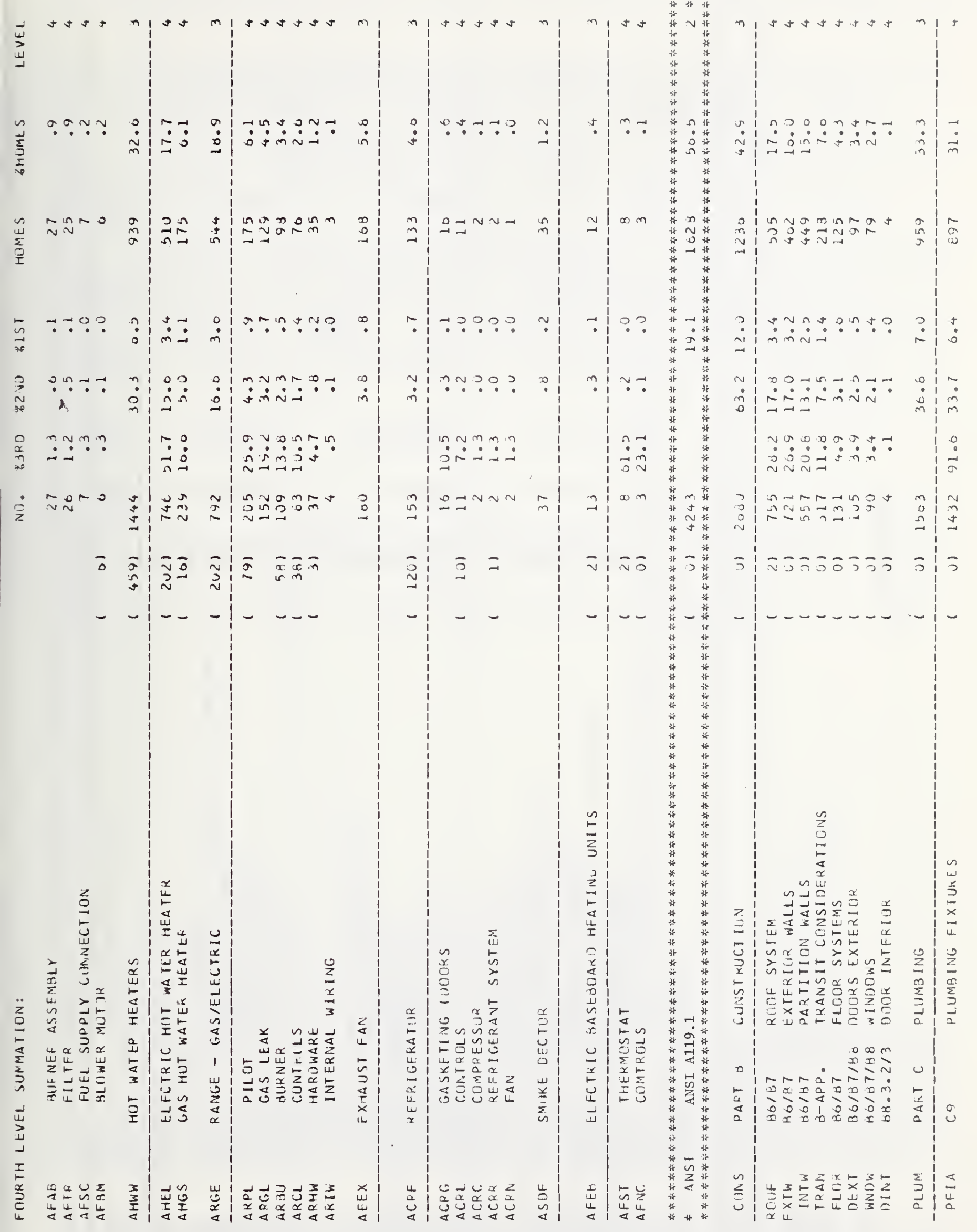




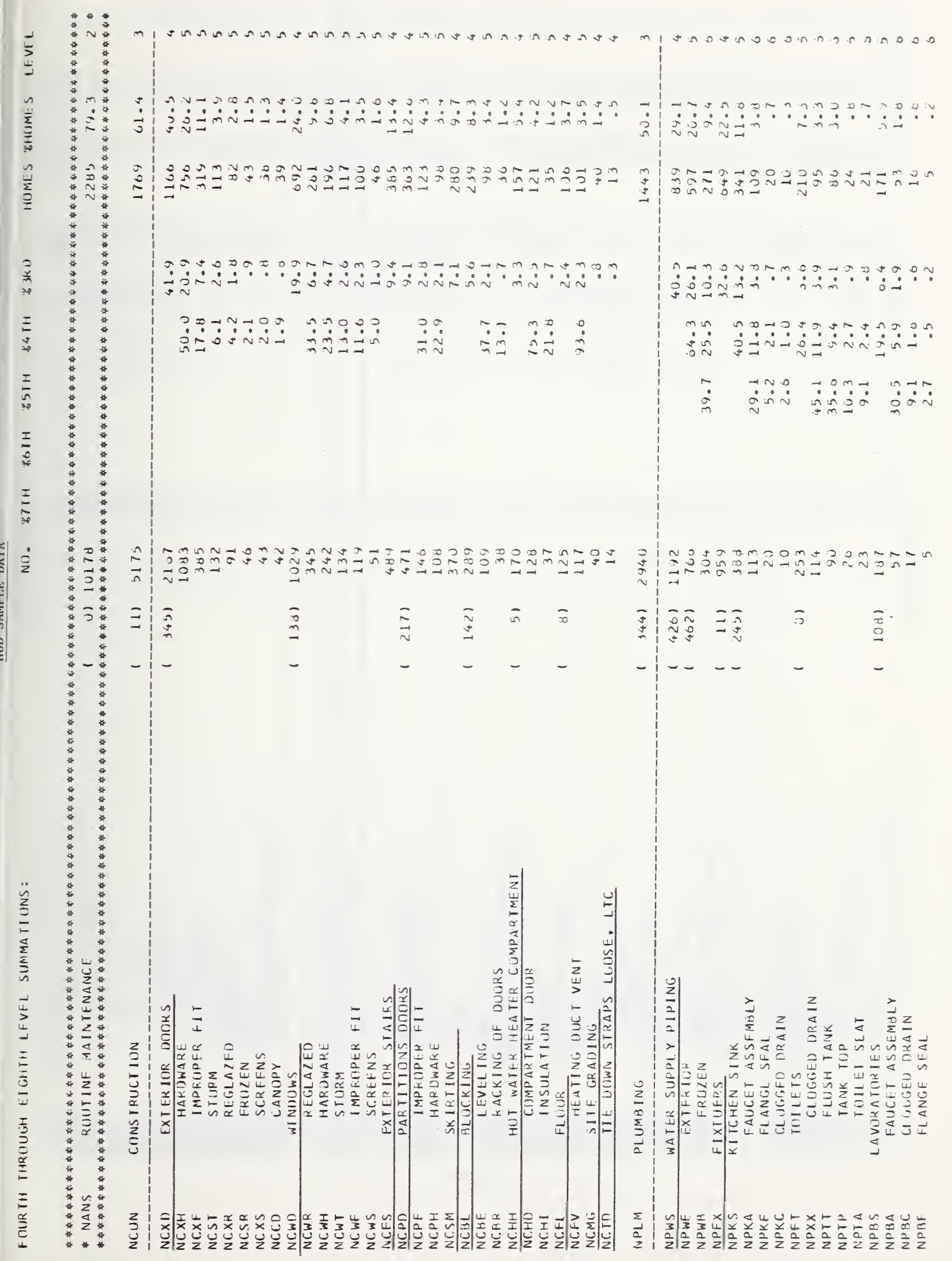




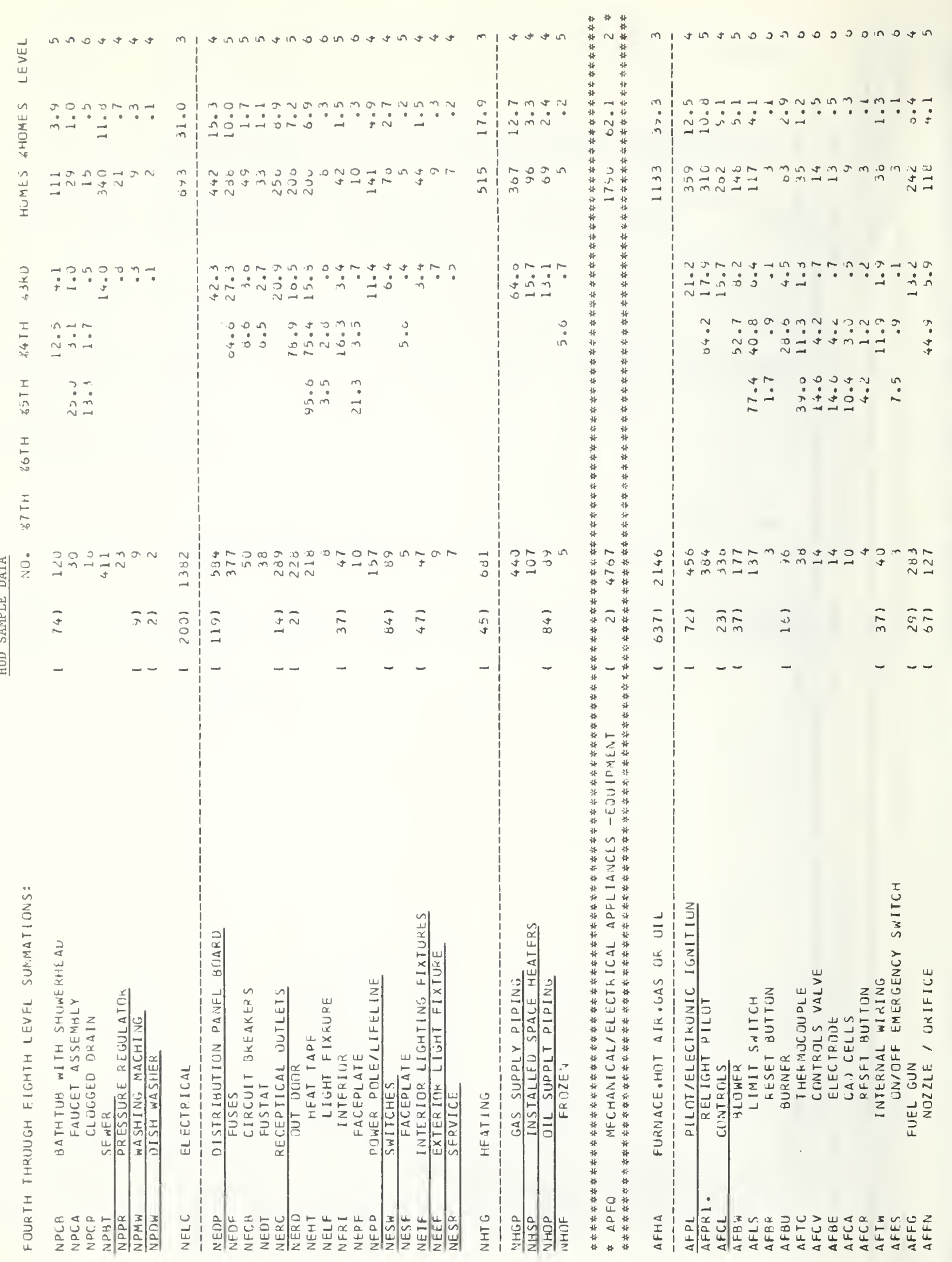




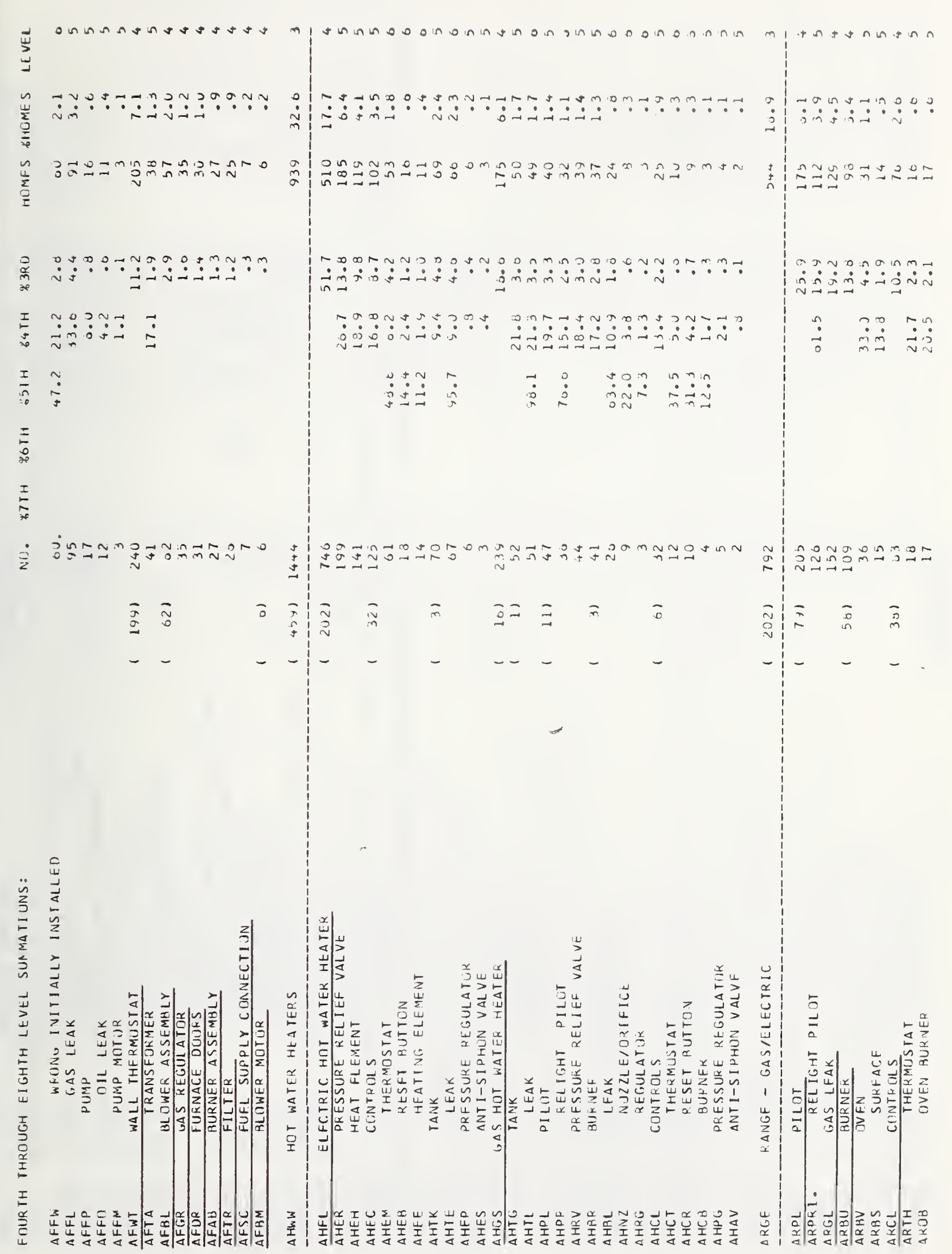




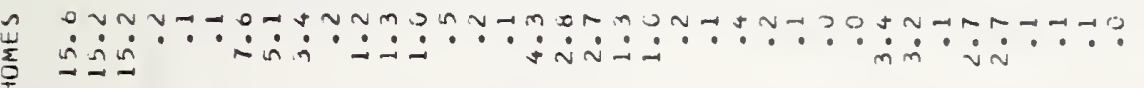

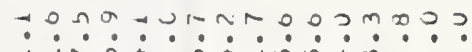

$\vec{n} \vec{v} \sim$

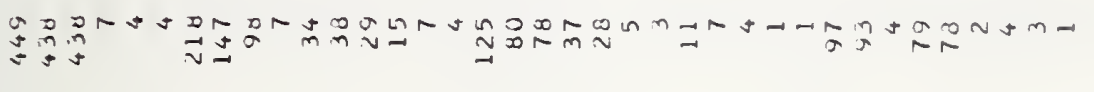

a)

ติ

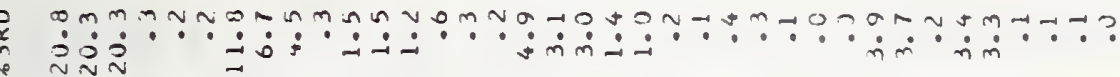

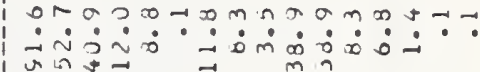

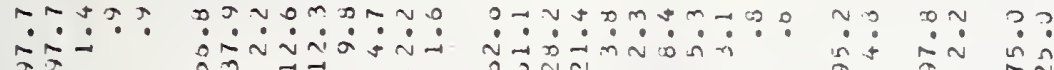

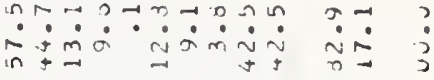

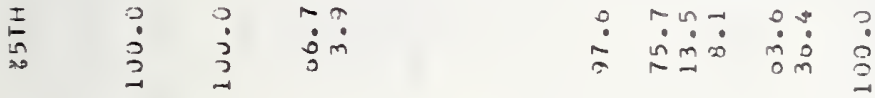

$\stackrel{I}{\circ}$

$\equiv$

5

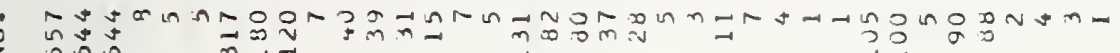

ก

$-1$

$\bar{j} \bar{n} \quad \hat{n}$

$\bar{\partial}=\overline{0} \bar{\jmath} \bar{b}$

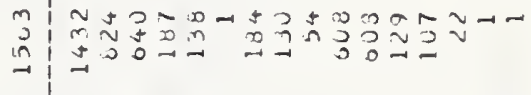

5

m

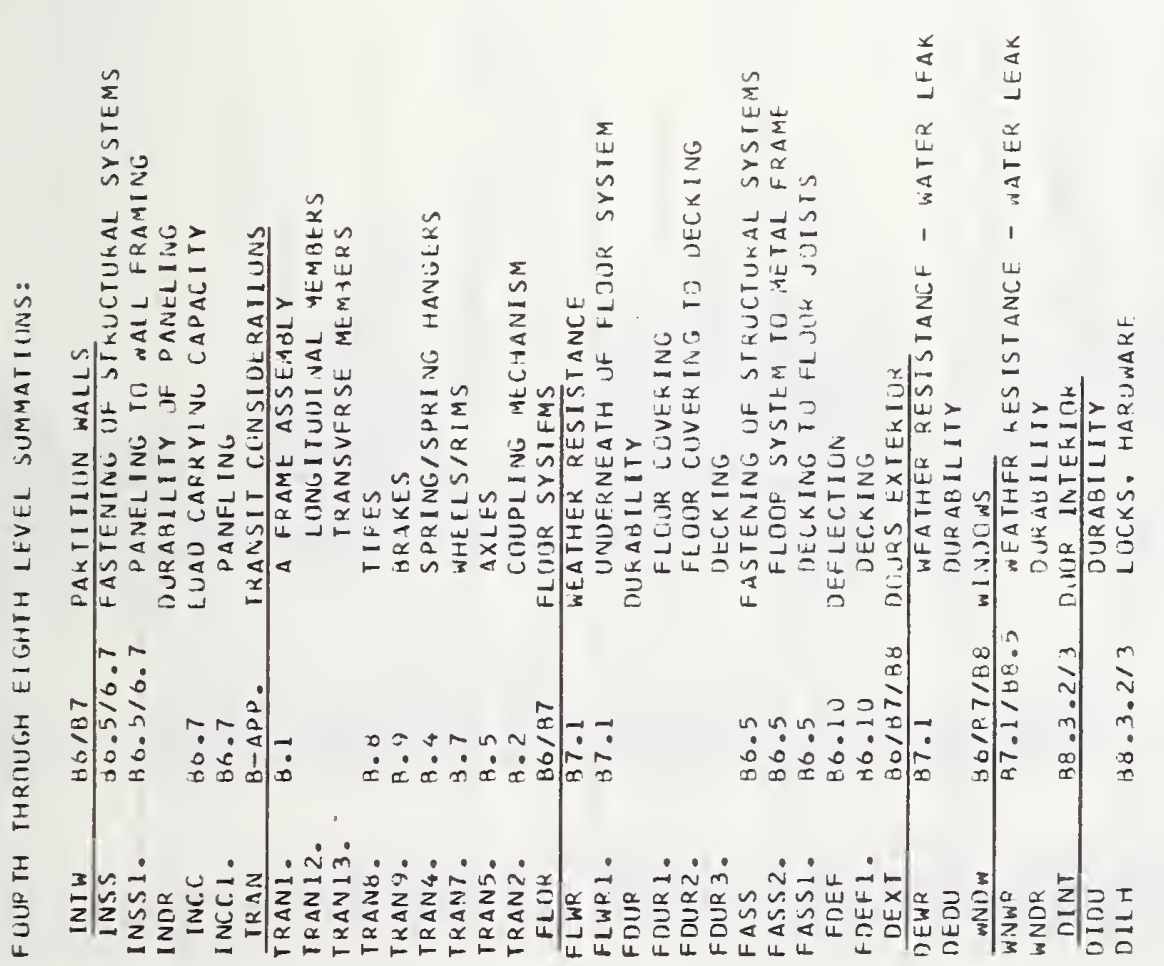

व:

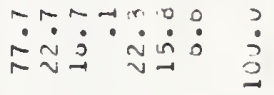

$\stackrel{\sim}{\dot{v} \vec{\sim}} \stackrel{\dot{2}}{\sim} \dot{v}$

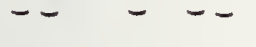




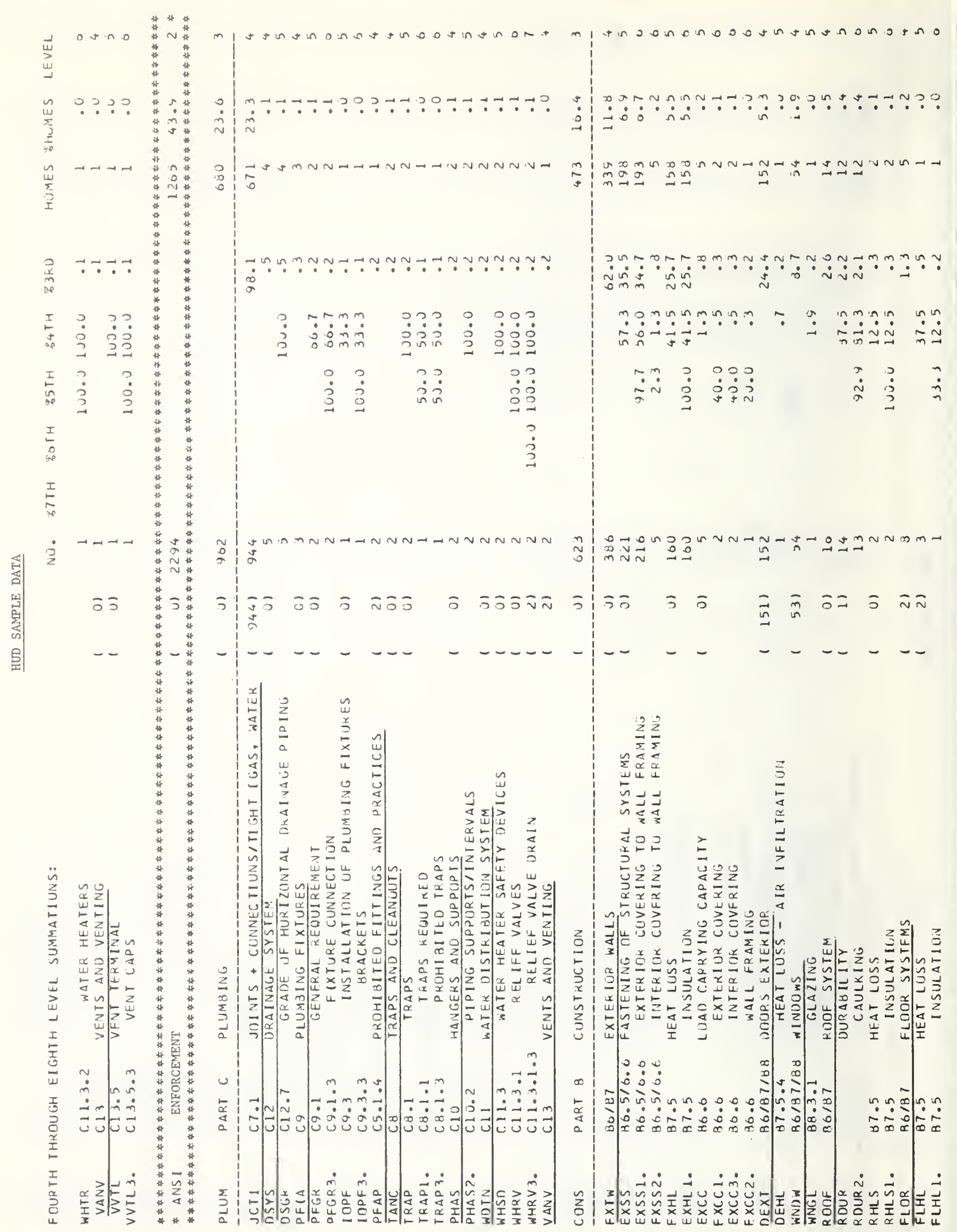


J h I

$\sum_{3}^{4}$

$00,30 \% \cos$

.....

เिं $\dot{m} \dot{\sim} \dot{\sim} \dot{\sim} \dot{m}$

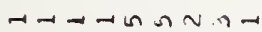

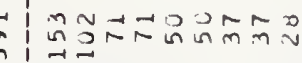

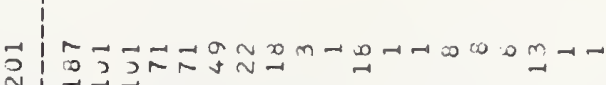

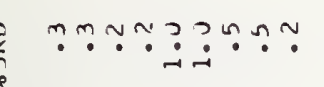

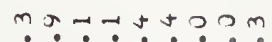

$\dot{m} \dot{\sim} \dot{\sim} \dot{0} \dot{0} \dot{0} \dot{0}$

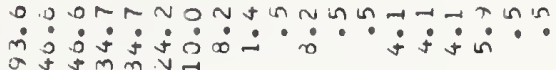

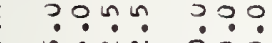
$\stackrel{\sim}{\sim} \dot{\sim} \sim \dot{0} \dot{0}$

$\begin{array}{llll}I & 0 & 0 & \dot{0} \\ \text { I } & 0 & 0 & 0\end{array}$

$\begin{array}{lll}0 & 7 & 0 \\ 0 & 3 & 0\end{array}$

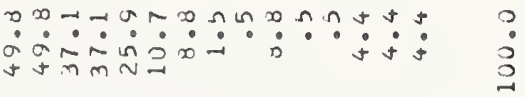

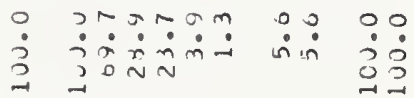

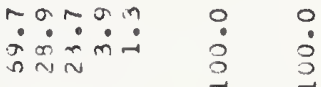

$\stackrel{n}{n} \dot{n}$

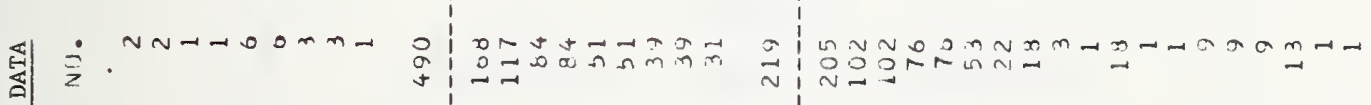

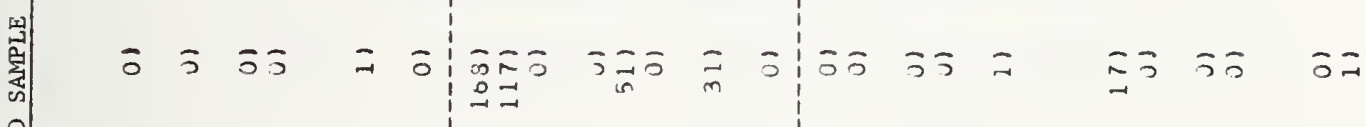

㝞
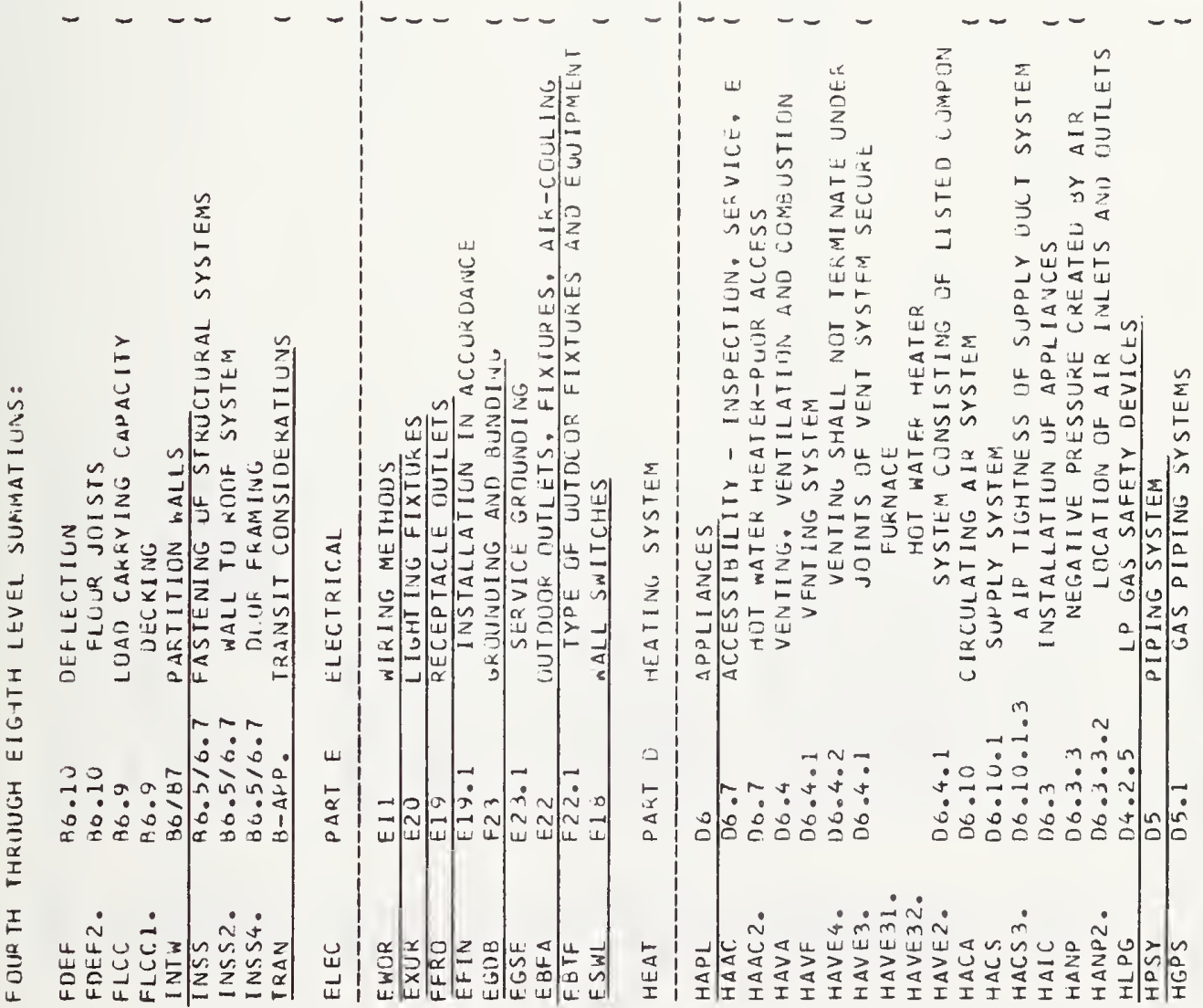
Appendix C

Problem Summation Tables - Private Sample 
ivinnn

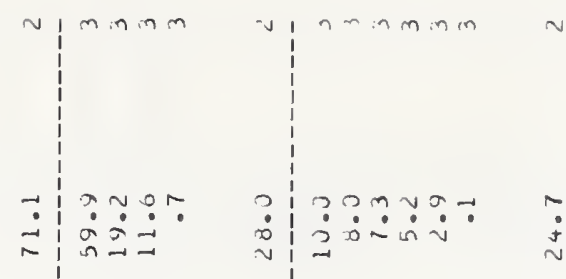

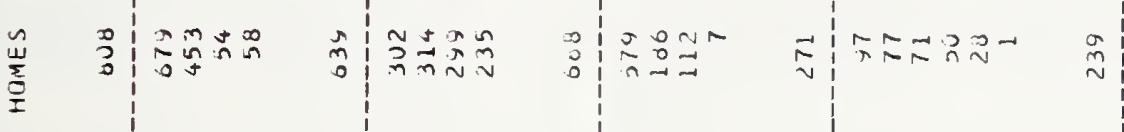

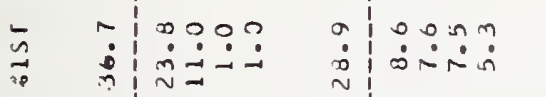

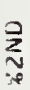

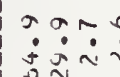

,

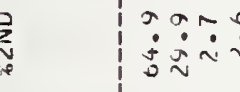

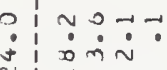

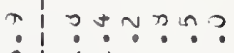

$\sim$

manan

$\therefore \quad \stackrel{2}{2} \approx \vec{D} \overrightarrow{0}$

a

ว

กาNำ

กิ:

$\dot{m} \dot{v} \dot{j} \dot{j} \dot{j}$

ว ร๐ธ

$-$

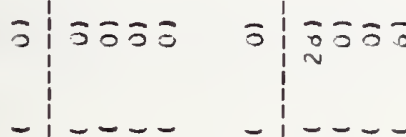

$\unlhd$

$\bar{\sim}$ テすす

再

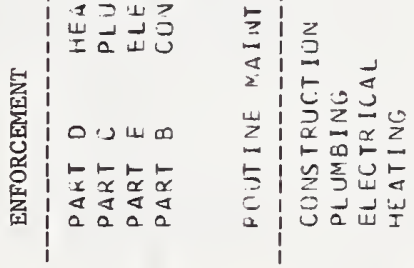

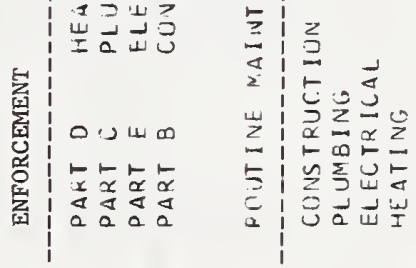

空

点专旁

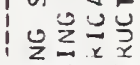

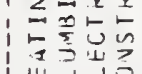

足

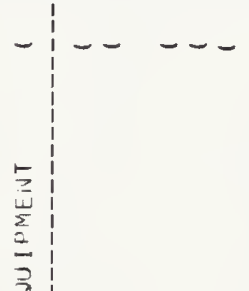

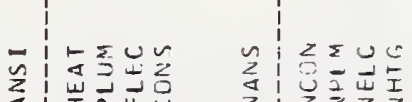

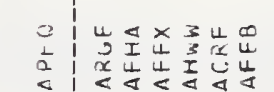

$\stackrel{n}{\underline{z}}$

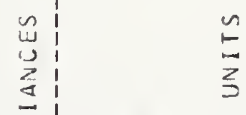

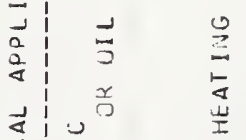

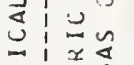

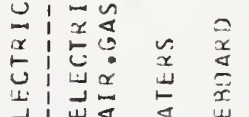

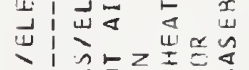

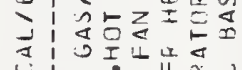

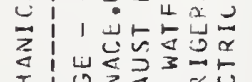

委

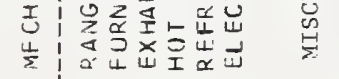




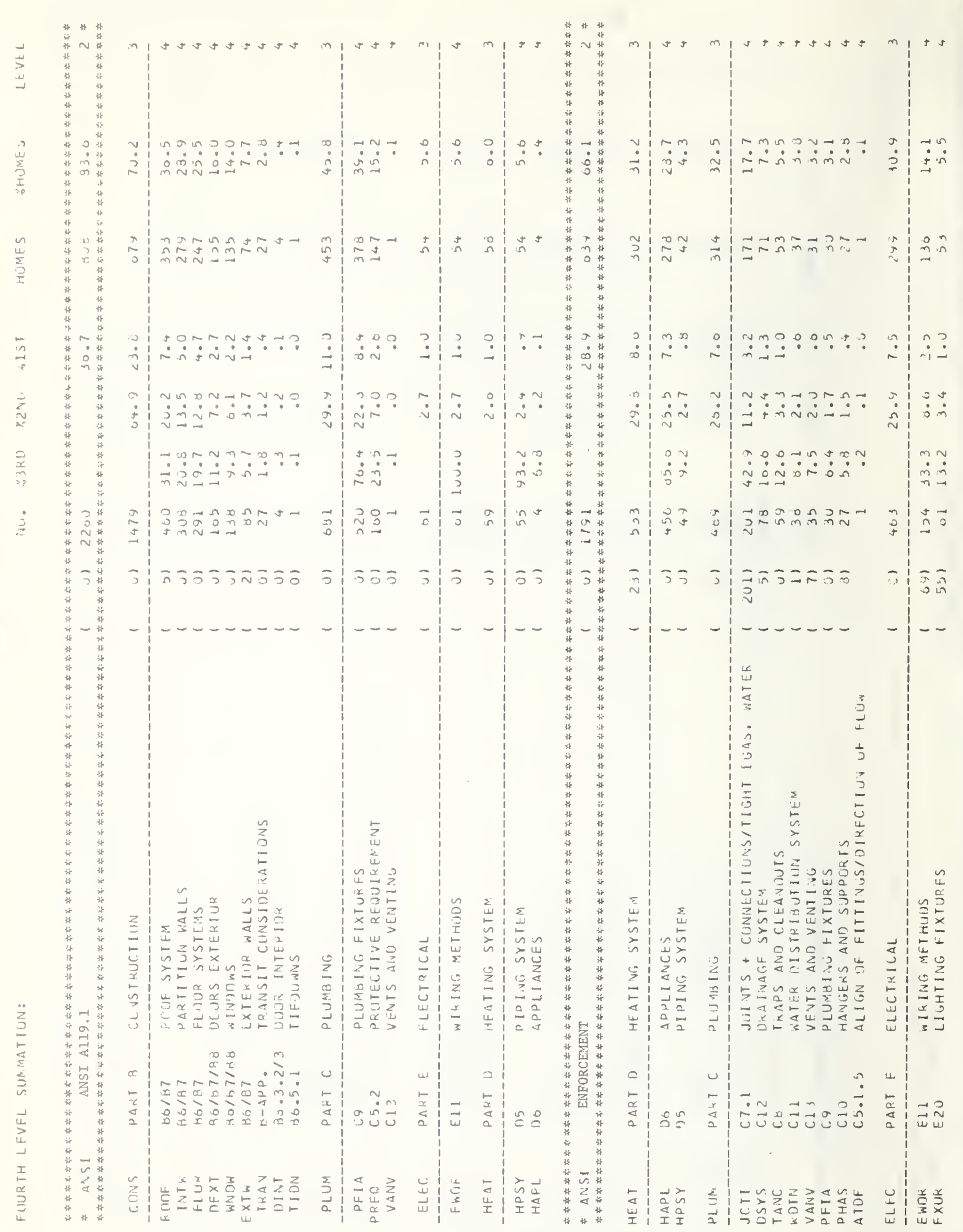




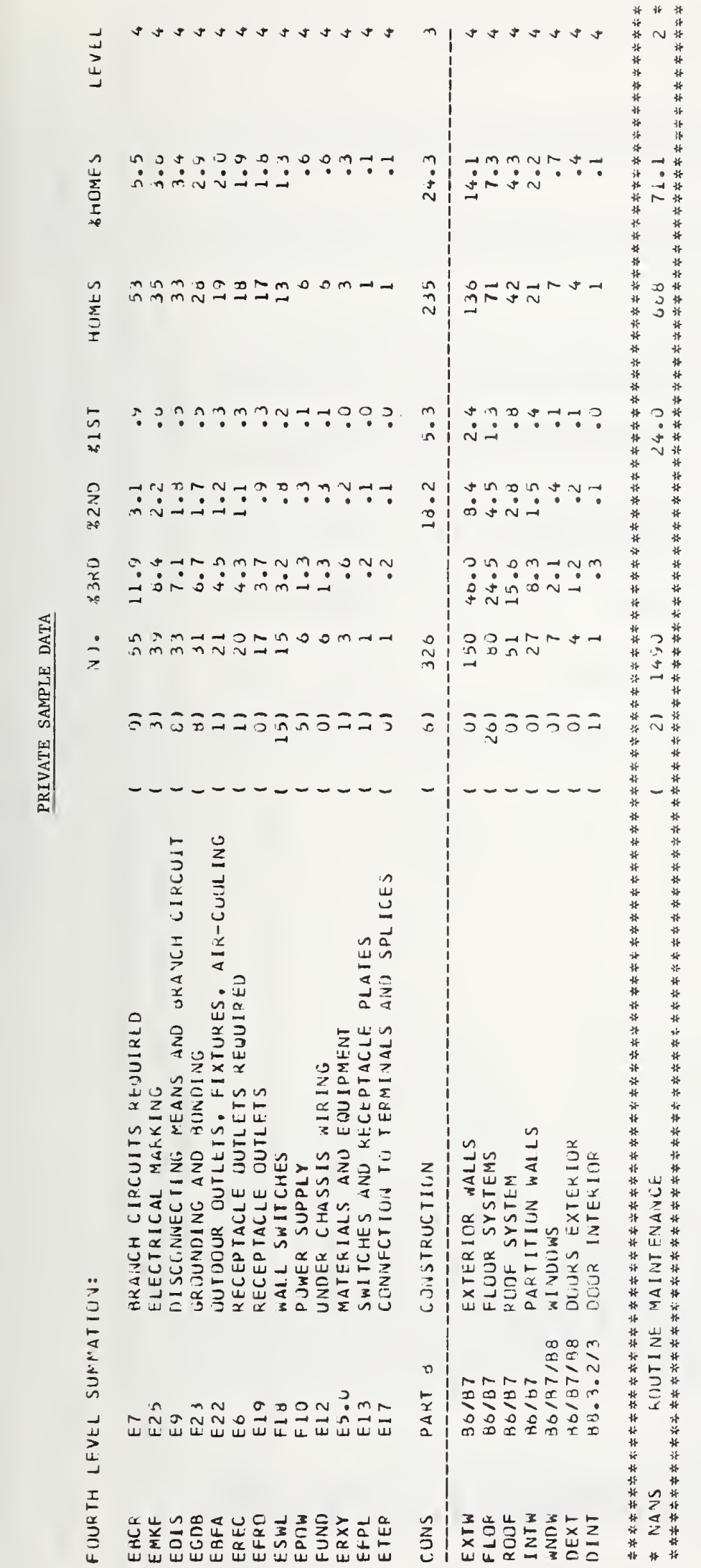

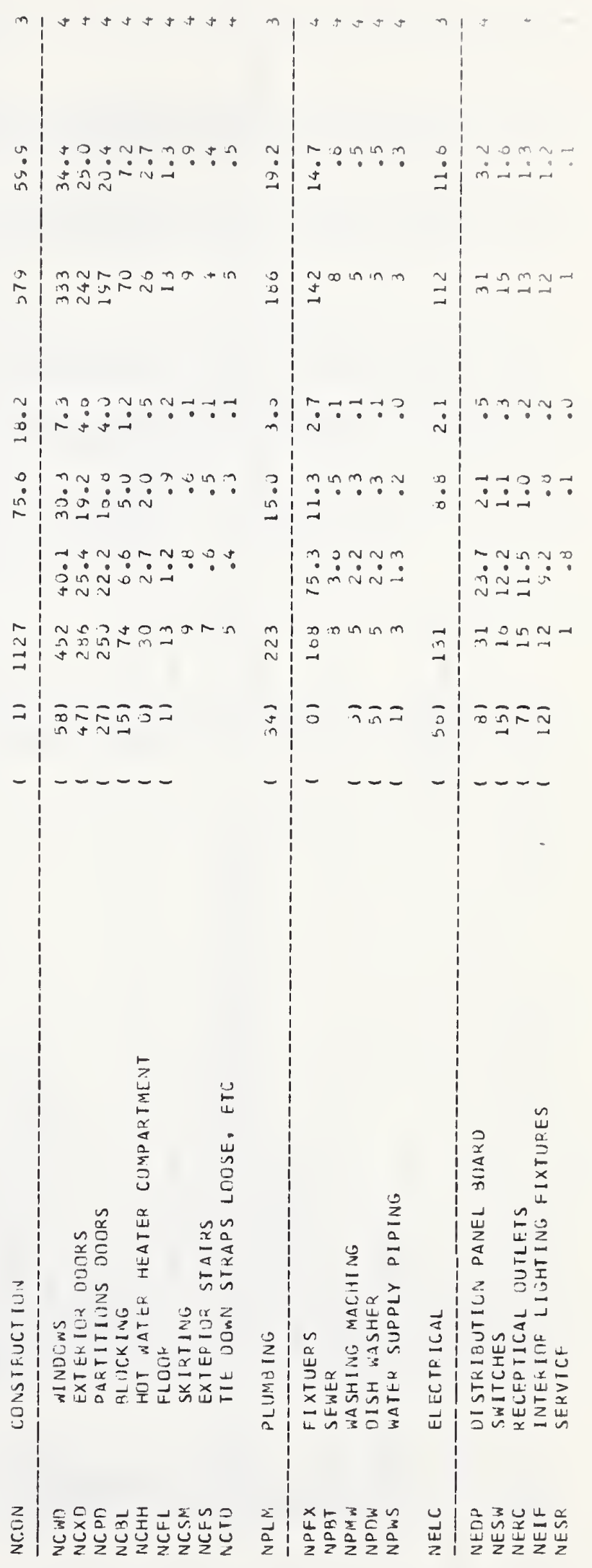




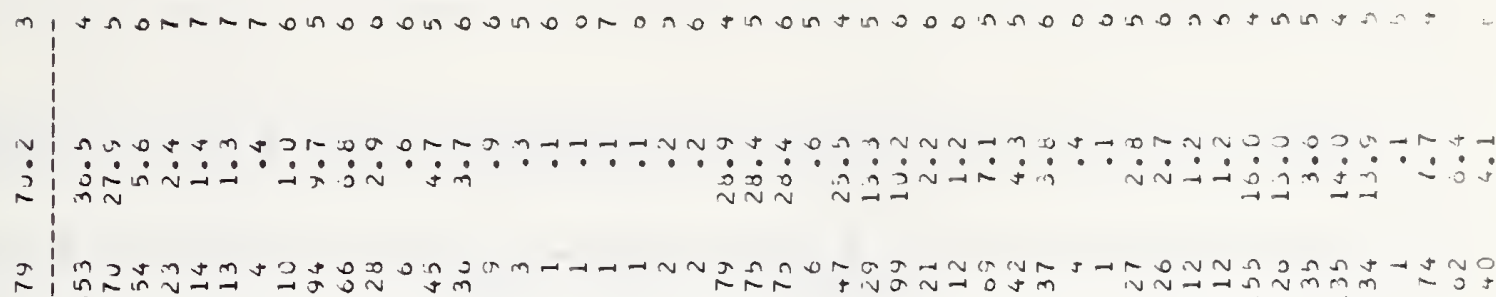

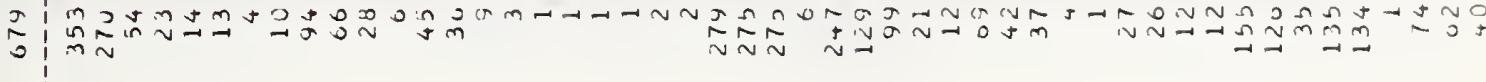

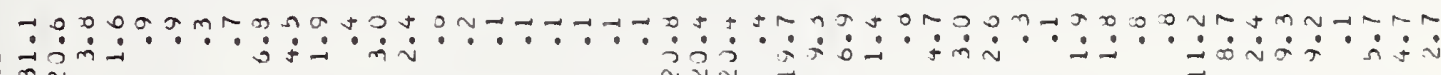

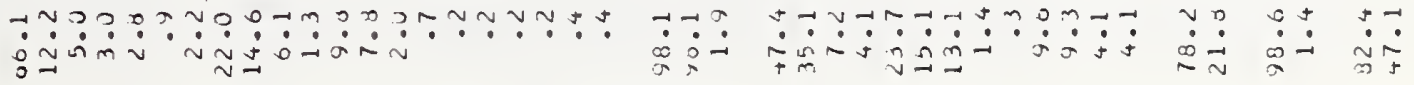

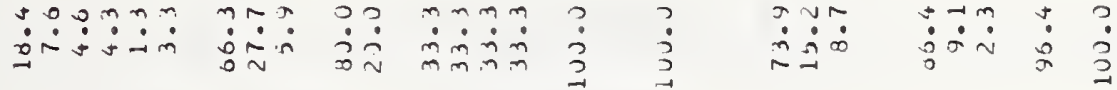

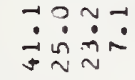

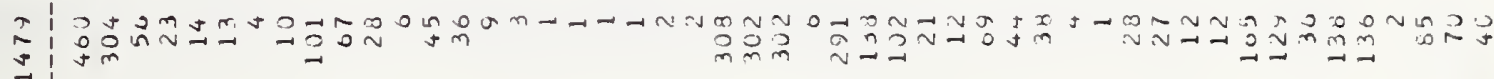

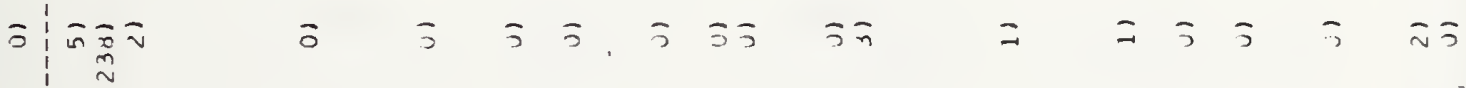
$-1 \ldots$<smiles>[CH]CCC</smiles>

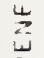

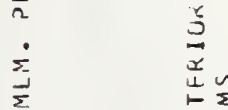

㟧- 可岕

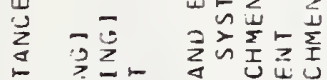

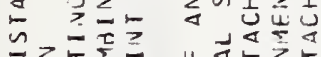

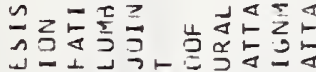

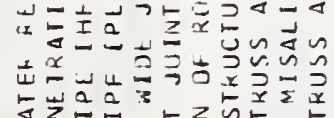

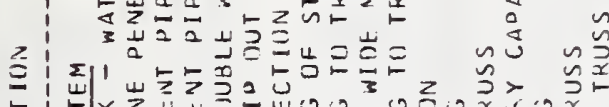

$\stackrel{3}{3}$ 


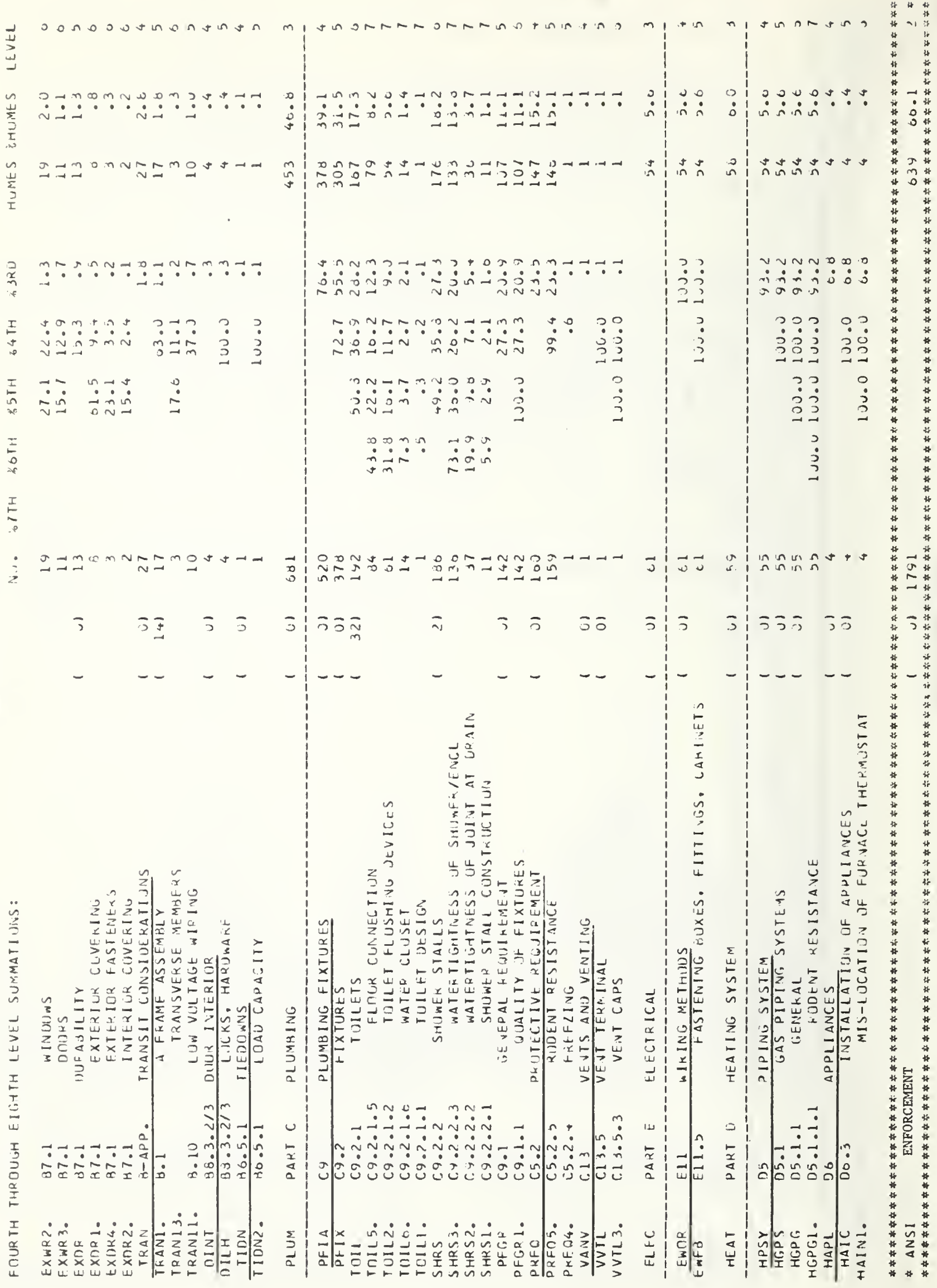




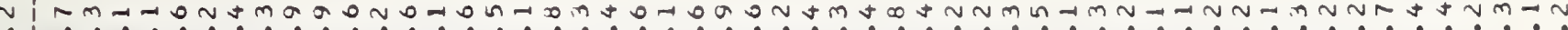

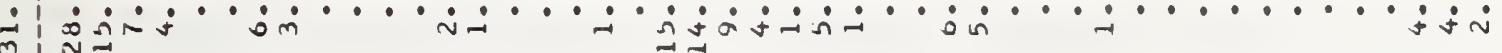

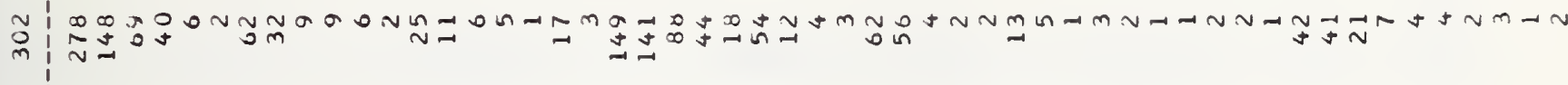

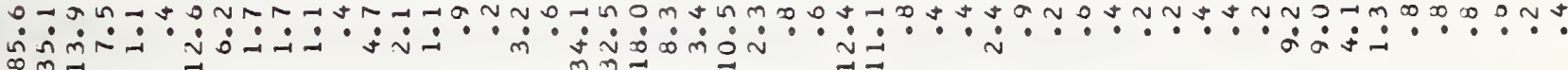

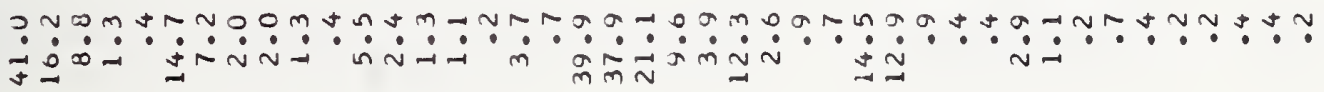

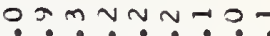

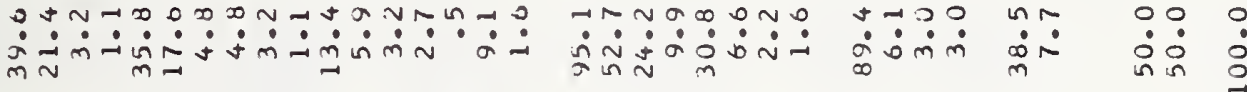

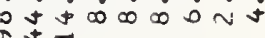

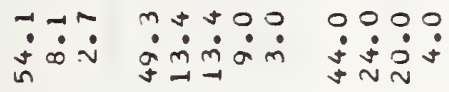

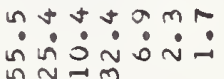

$\stackrel{0}{0}$

$\dot{j} \dot{0} \dot{0} \dot{\infty} \dot{\infty} \dot{\infty} \dot{\sim} \dot{j}$

$\stackrel{\infty}{i} \quad \stackrel{\infty}{i}$

m $\ln 1+$

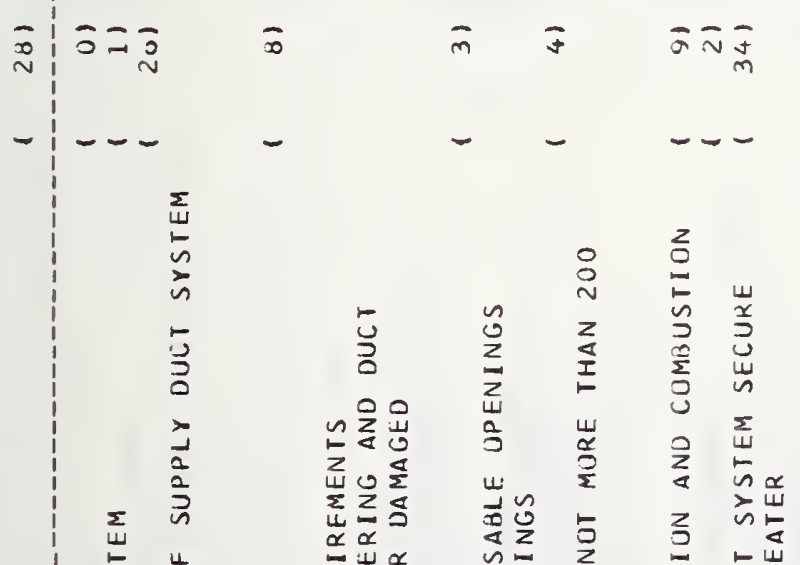

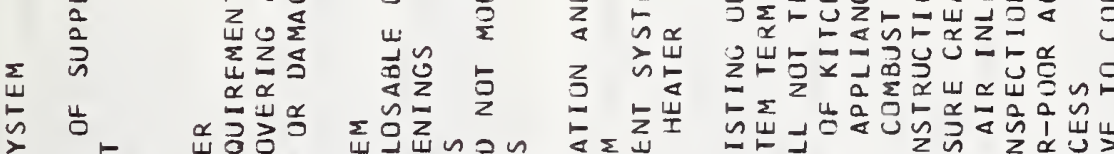

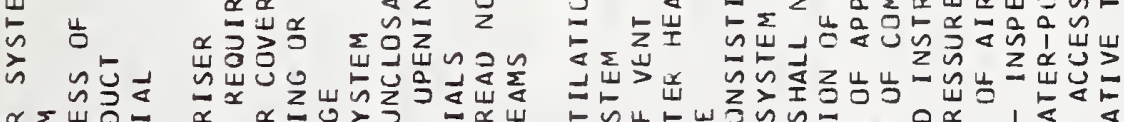
$\propto \sum \sum_{i}$

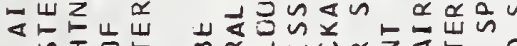

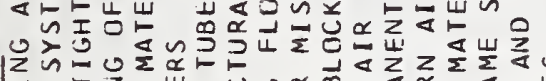

o

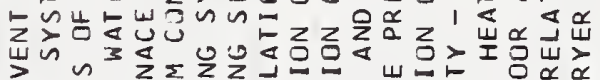

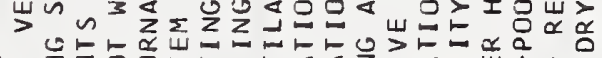

$\sum_{0}^{2} \begin{array}{ll}2 \\ 0\end{array}$

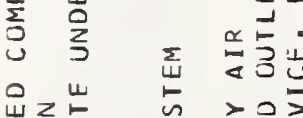

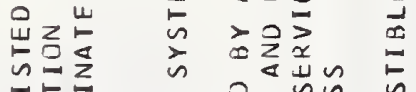

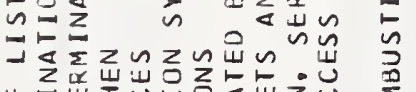

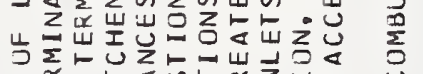

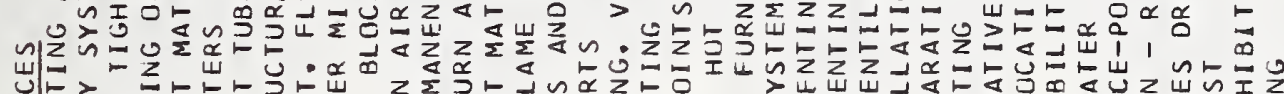

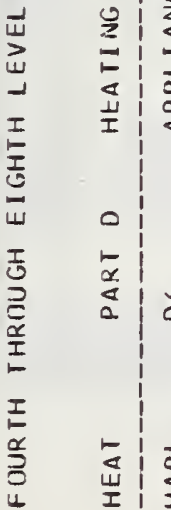

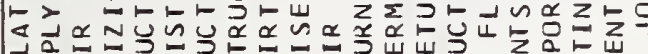

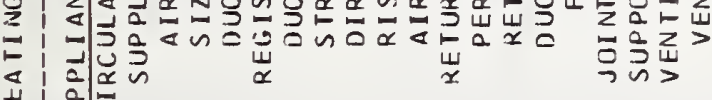

I

$m \div \because \quad \div \quad \div \dot{\sim}$

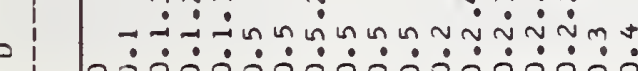

- $\quad \div 0000000000000000 \%$

a

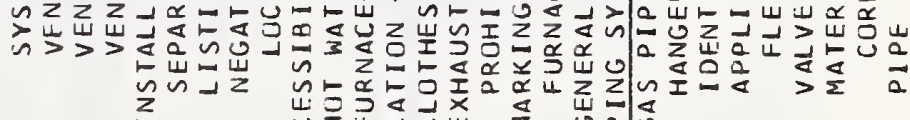
$\stackrel{n}{Z}$

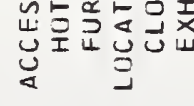

$\begin{array}{lll}4 & 0 \\ 0 & 0 & 0\end{array}$ 


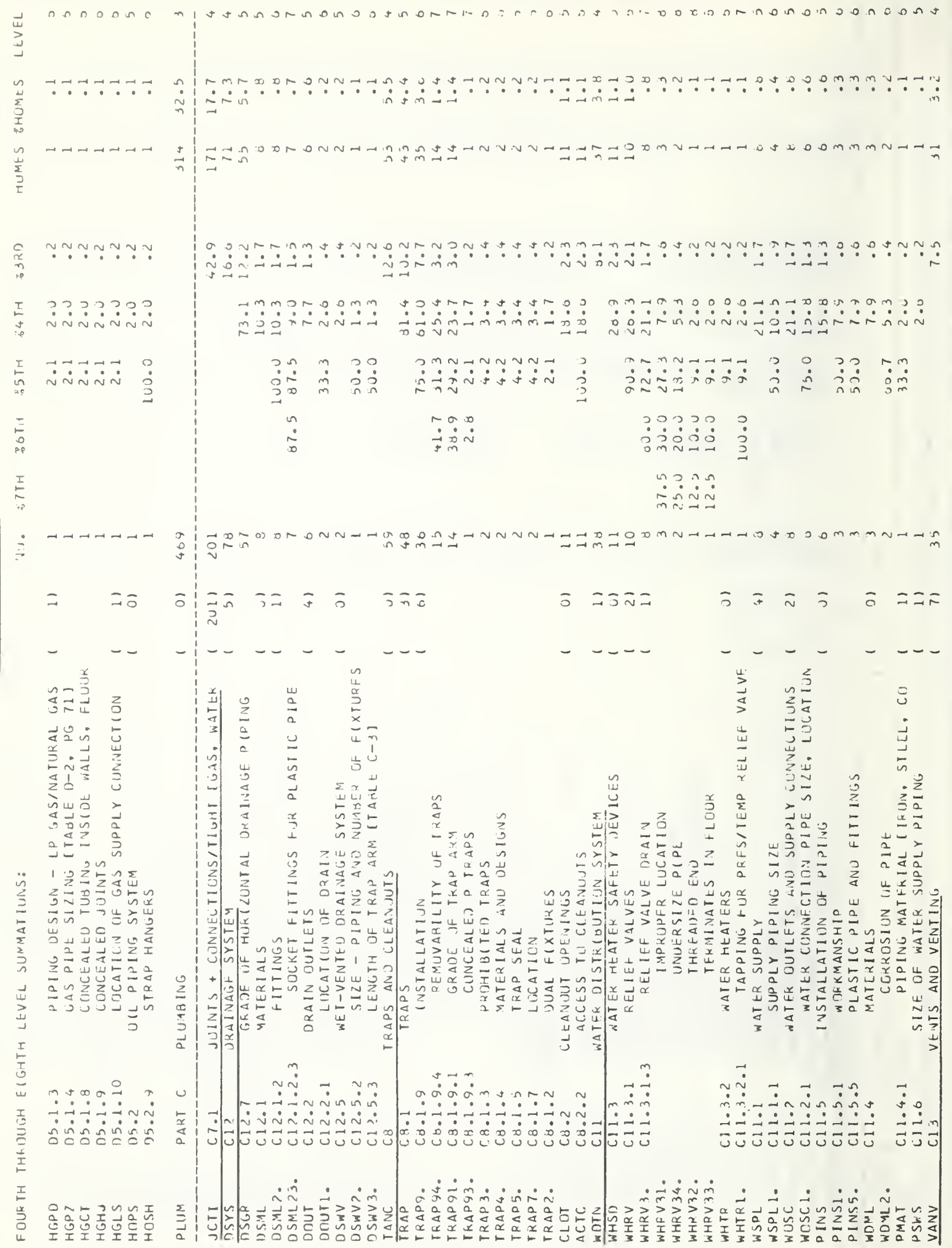




\section{.} $\stackrel{3}{\underline{s}}$

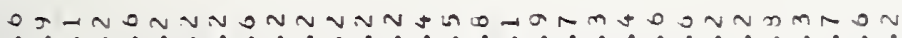

$\sqrt{3}$

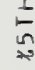

$\frac{1}{6}$

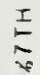

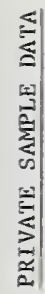

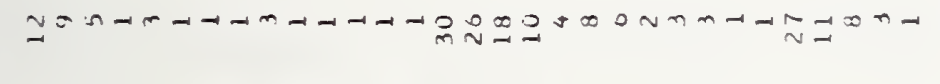

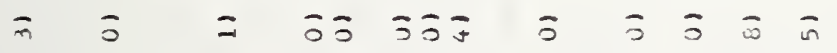

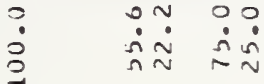

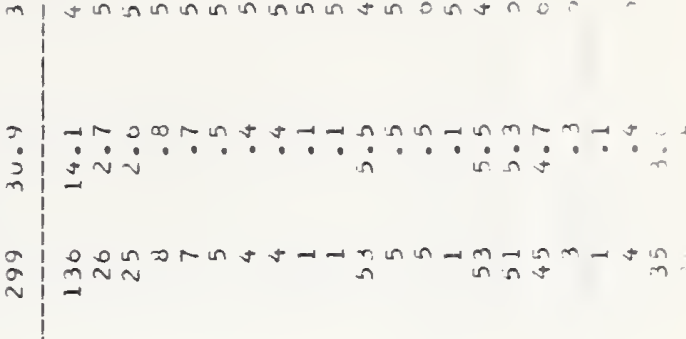

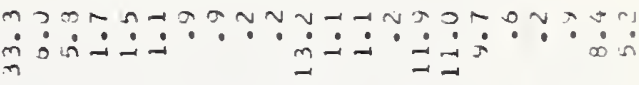

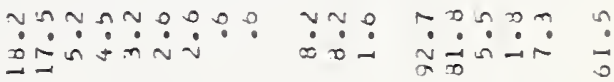

$$
\begin{array}{lll}
\dot{j} & \stackrel{v}{0} \dot{0} \dot{\sim}
\end{array}
$$

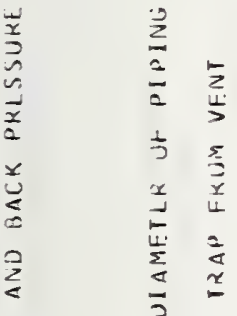

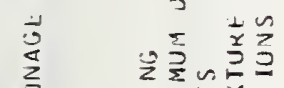

z

\section{a $2 \sum^{2} \leq \bar{z}$}

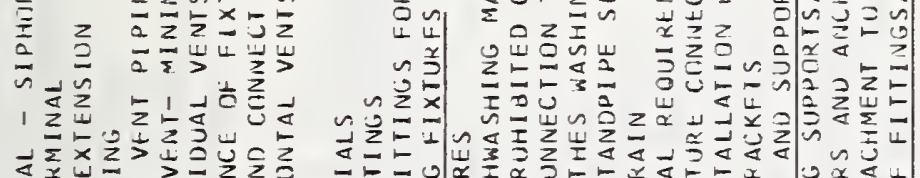

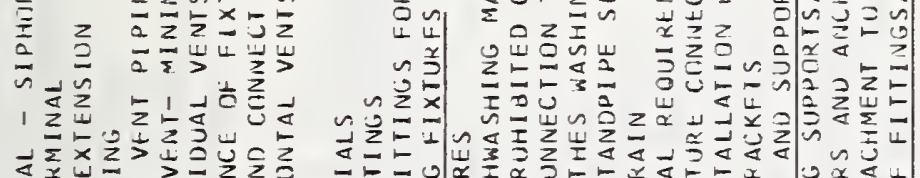

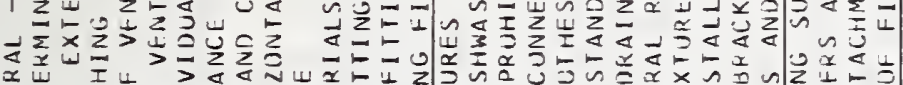

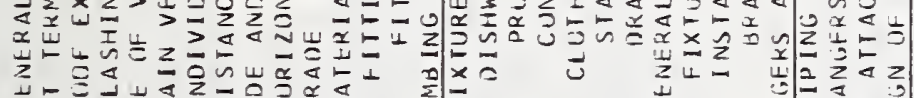

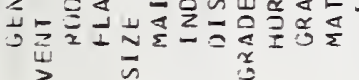

$>$

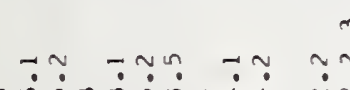

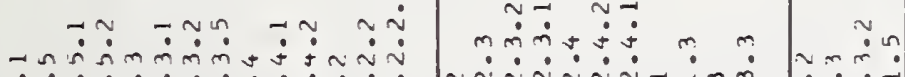

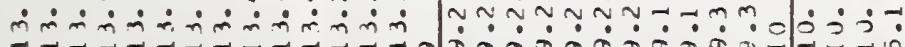

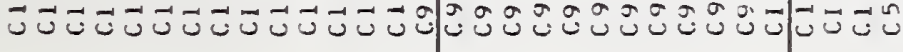

至

吾

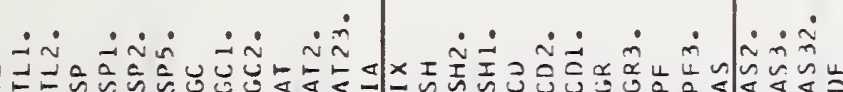

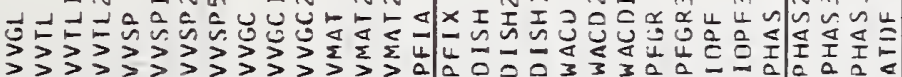

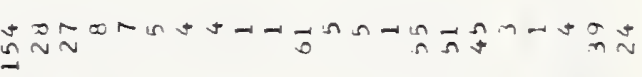

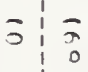

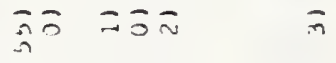

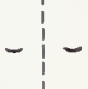

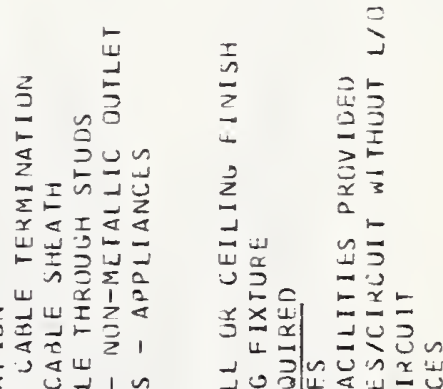

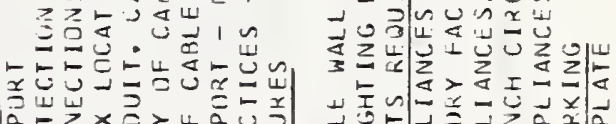

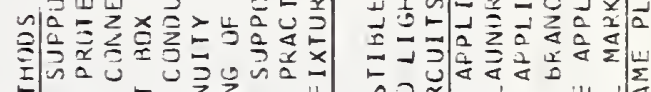
这|

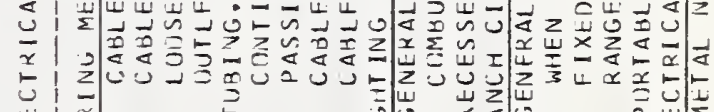
点

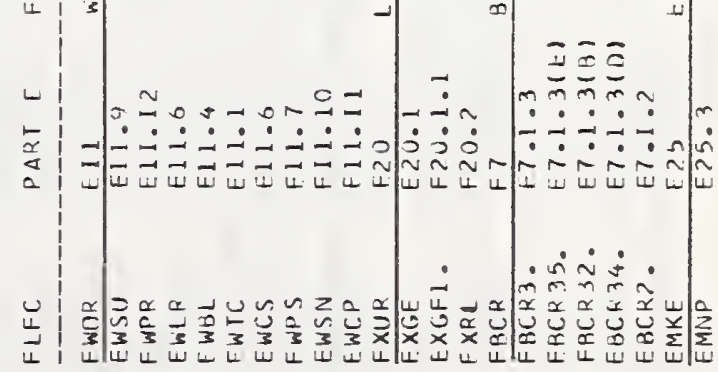



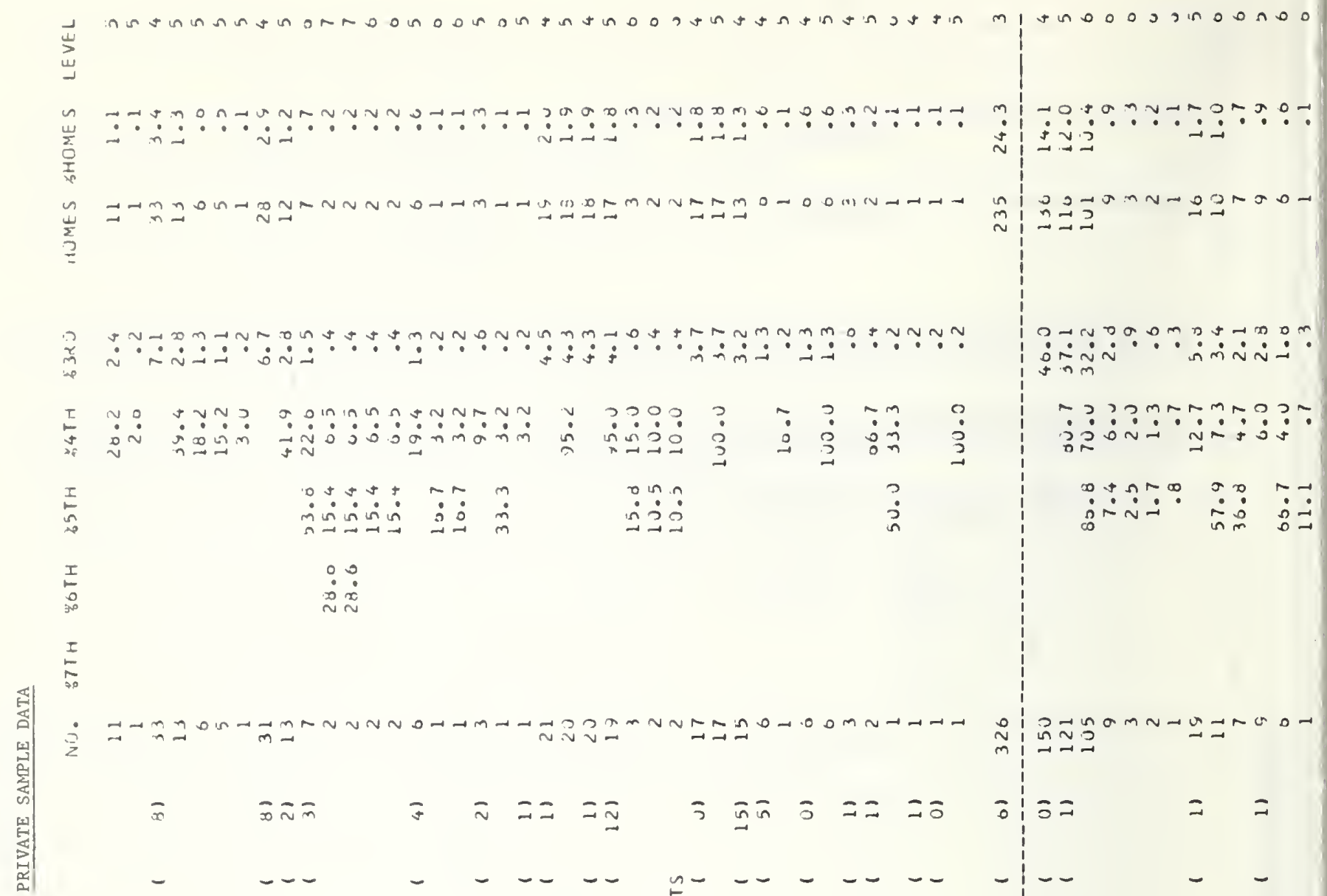

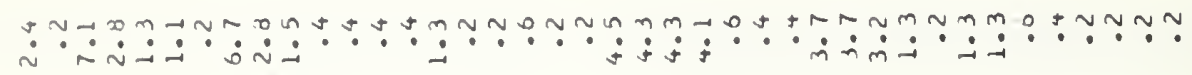

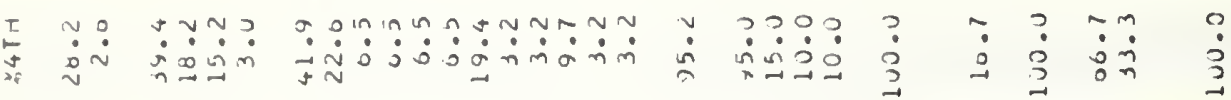

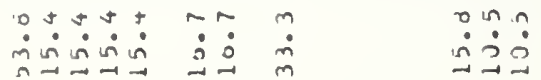

?

$\underset{1}{1}$

$\because 0$

$\underset{\leftarrow}{I}$

$\dot{z}$

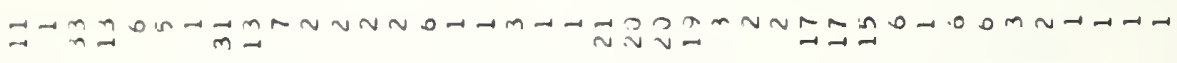

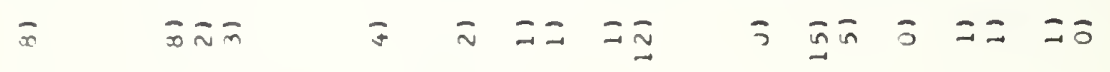

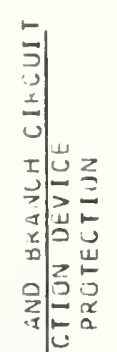

$--$

\section{当}

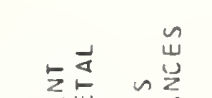

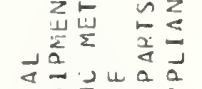

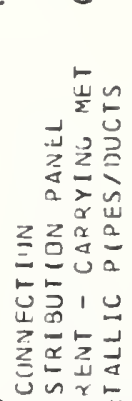

- - -

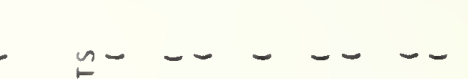

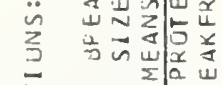

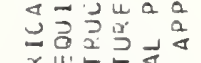

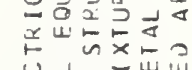

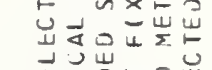

巨.

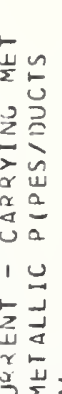

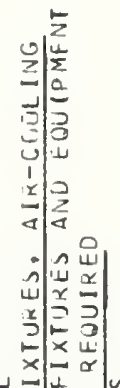

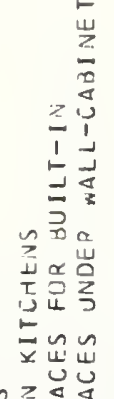

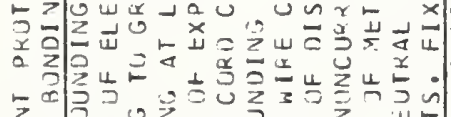

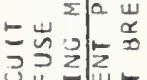

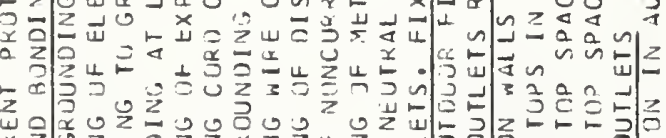

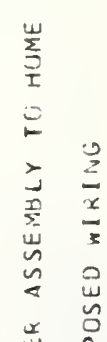

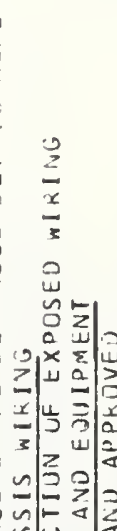

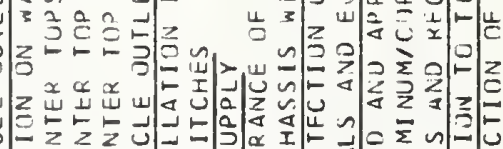

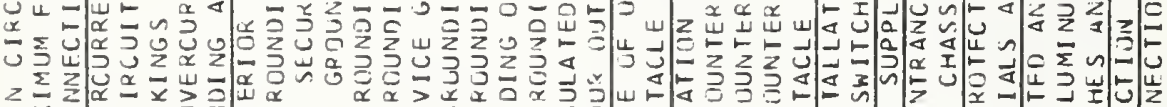

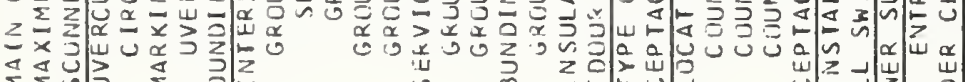

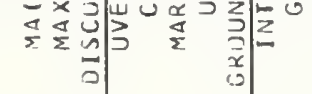

$$
\begin{aligned}
& \text { in } \\
& \text { 届 }
\end{aligned}
$$

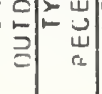

$\rightarrow \sim 2$ a

$\because$ :

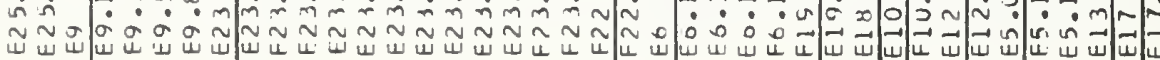

\section{(1)}

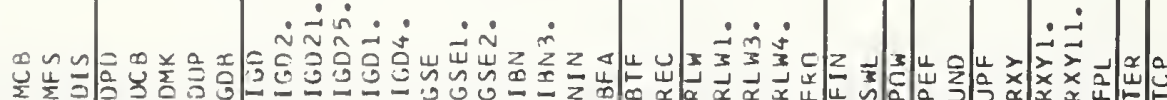

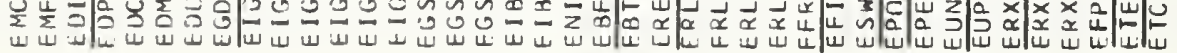




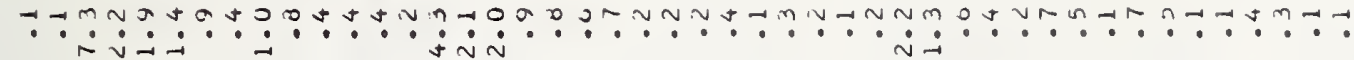

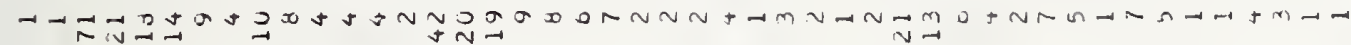

$\stackrel{I}{2}$

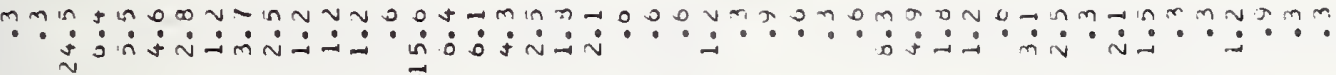

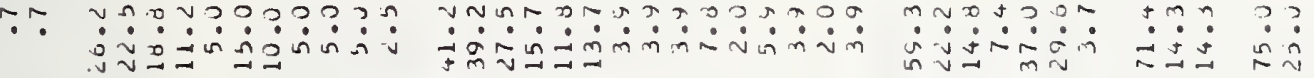

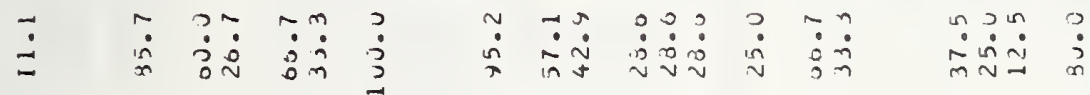

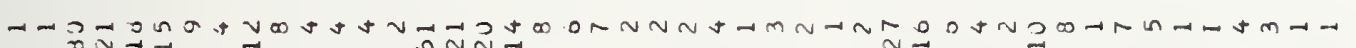

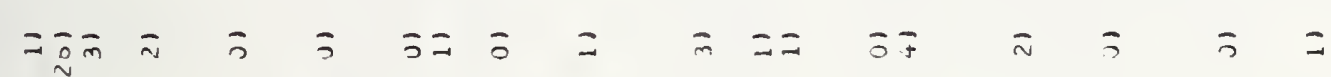
$\ldots \ldots \ldots \ldots \ldots \ldots \ldots \ldots \ldots \ldots$ 


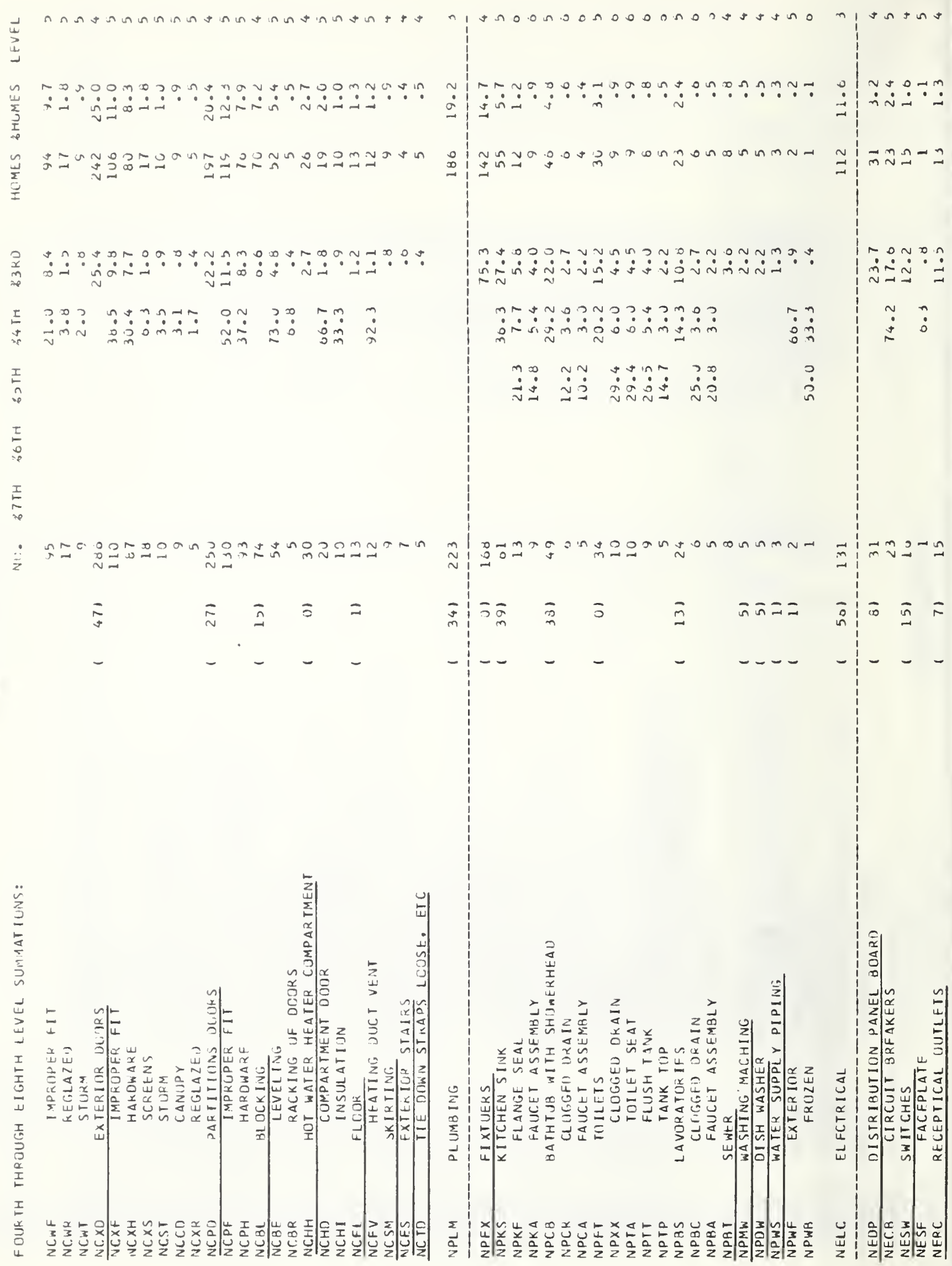




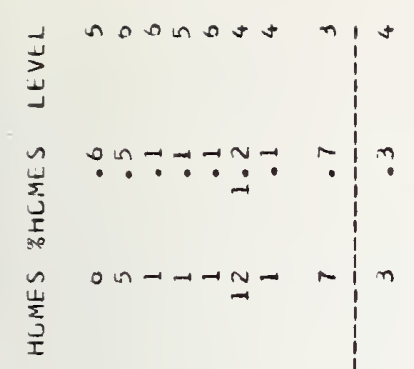

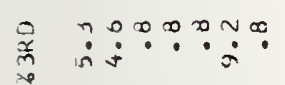

I

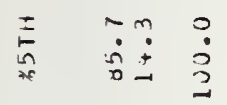

I

$\frac{5}{5}$

¿ำ-

$\overline{0} \bar{\beth} \overline{1}$

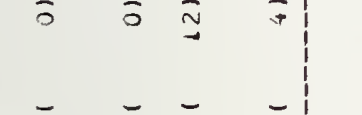

品

\#草

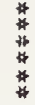

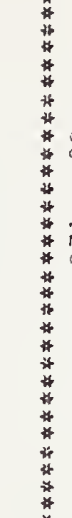
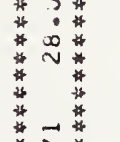

政

$$
\text { * }
$$$$
\text { * }
$$ 


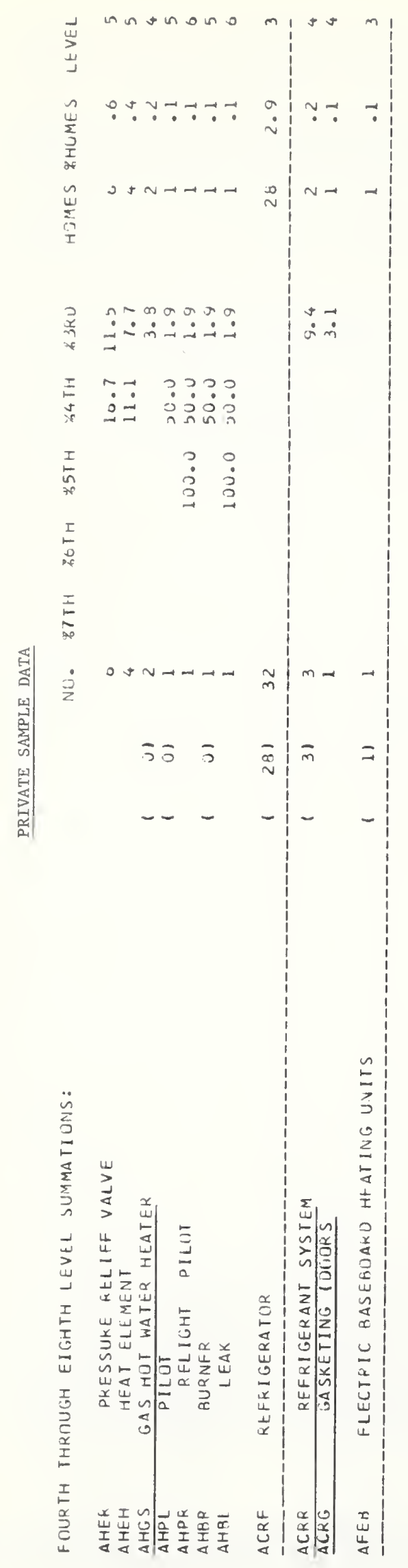


Appendix D

Problem Summation Tables - Field Sample 

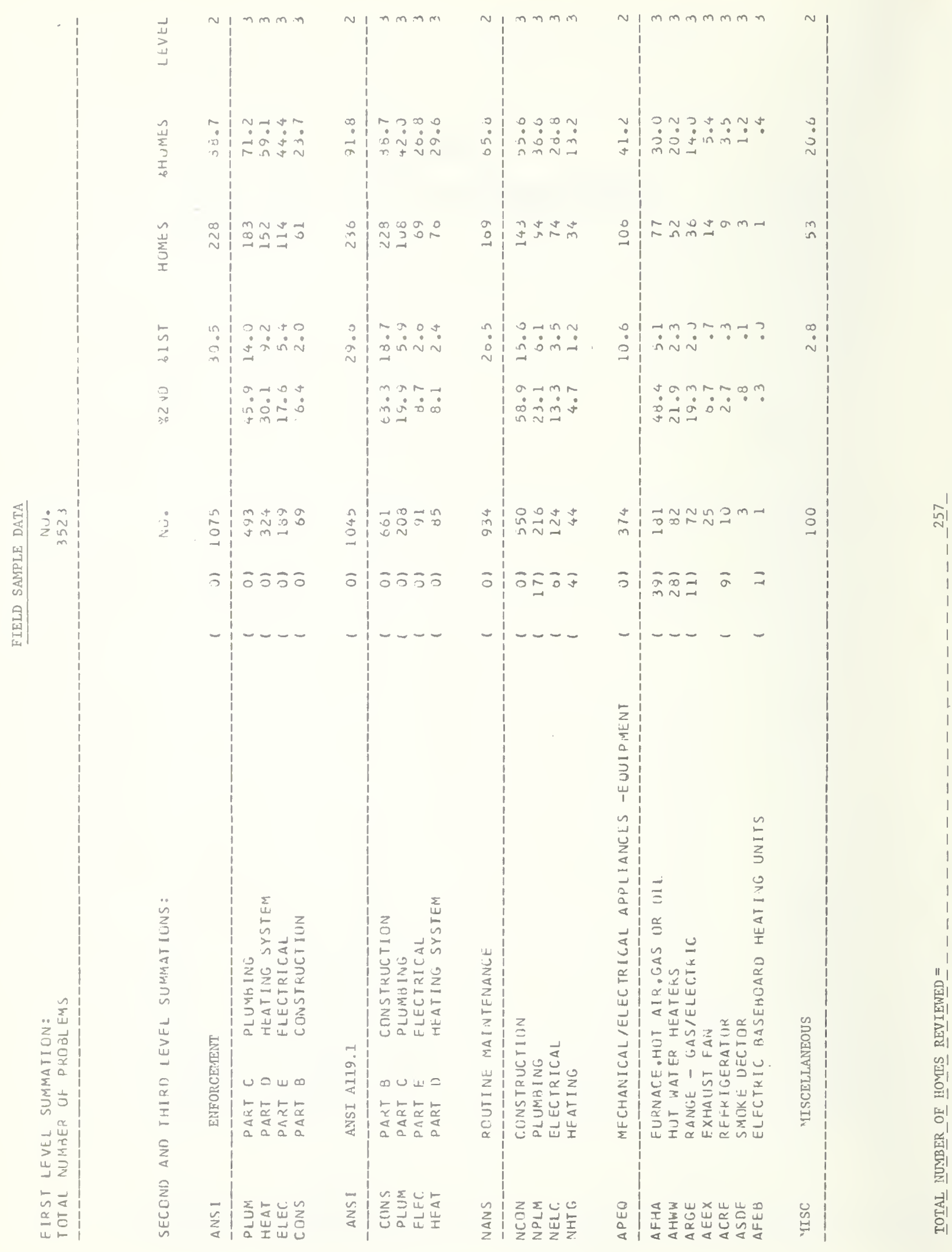


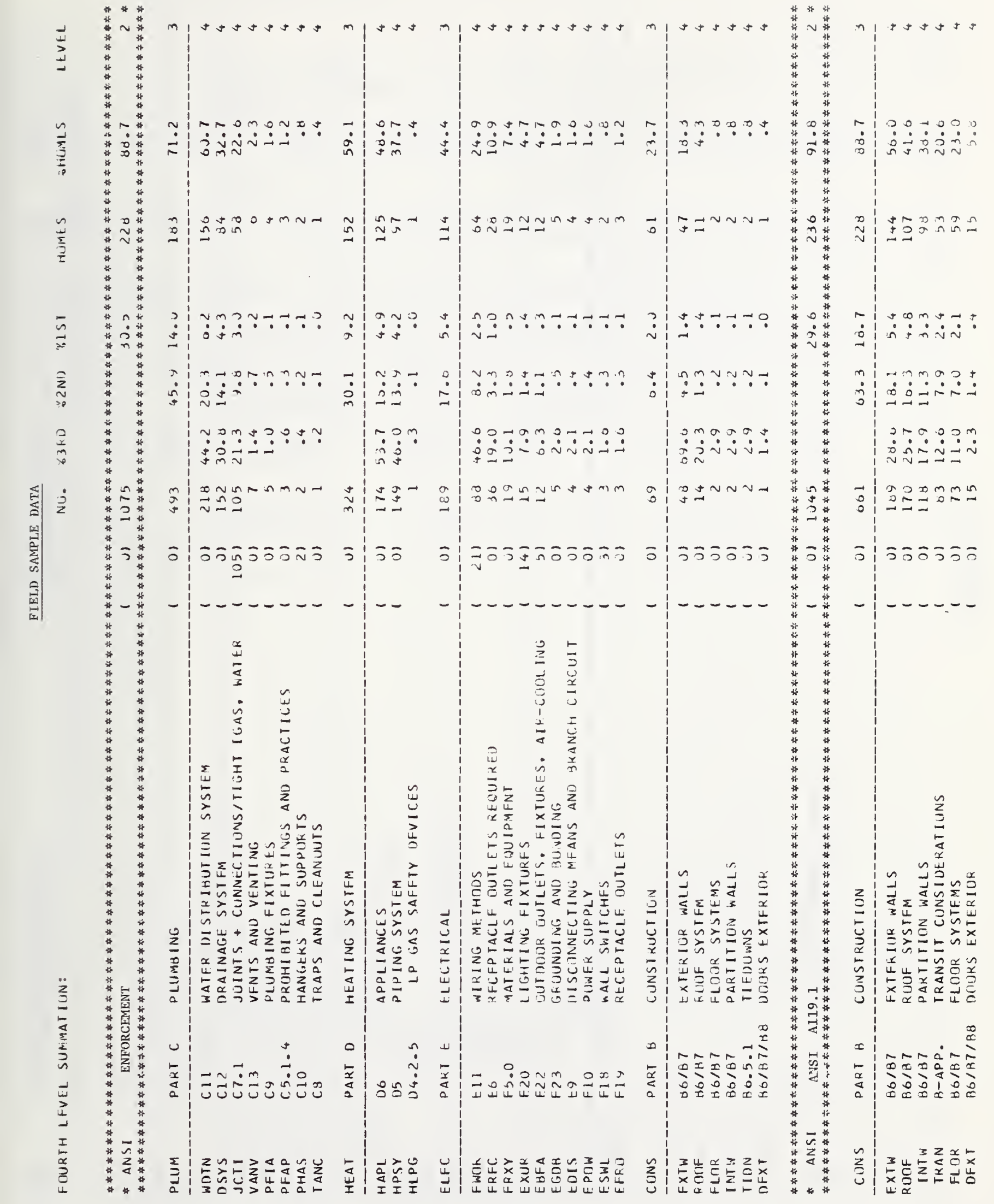




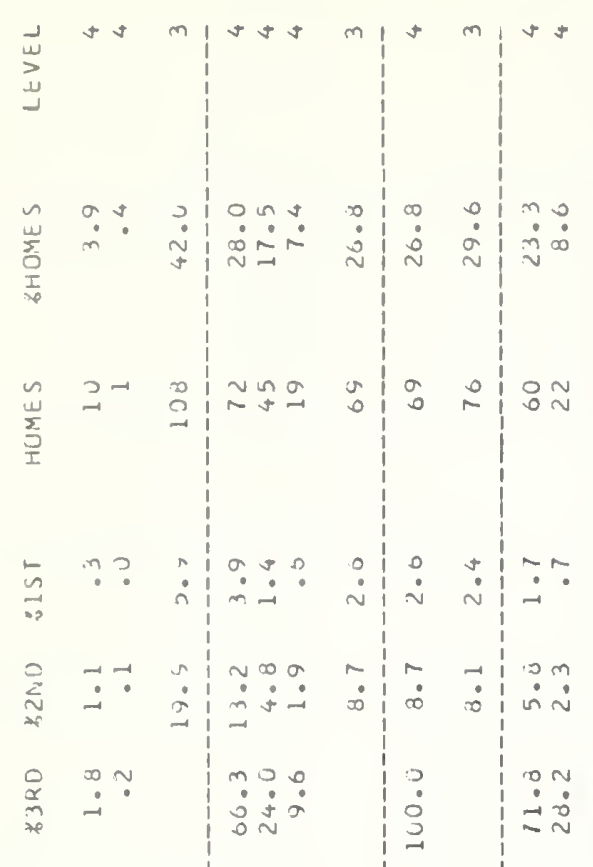

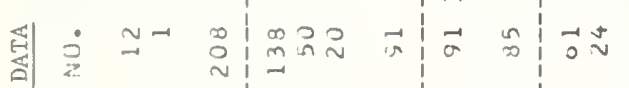

善

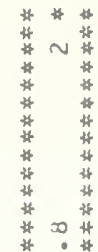

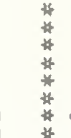
*

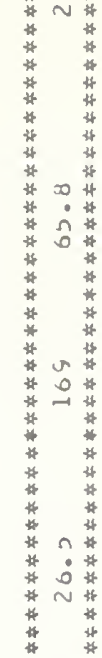

$$
\text { (1) }
$$

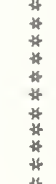

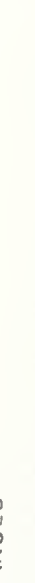

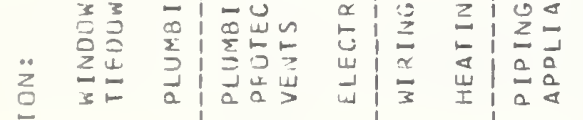

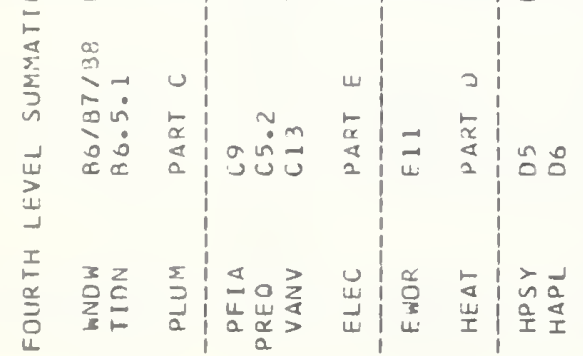

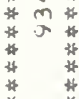

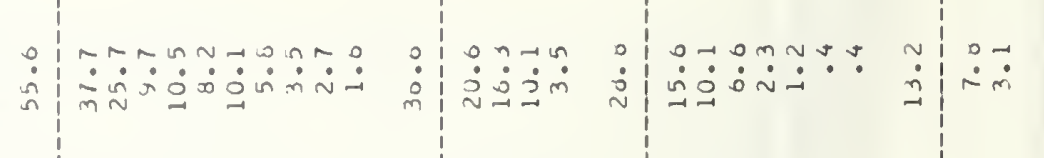

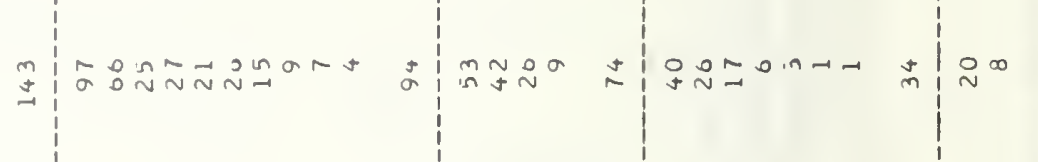
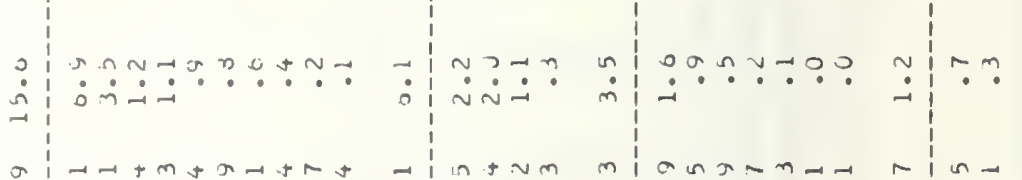

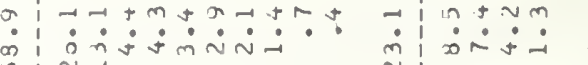

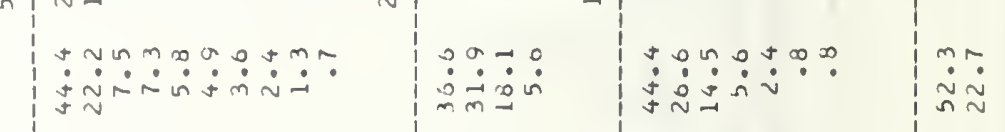

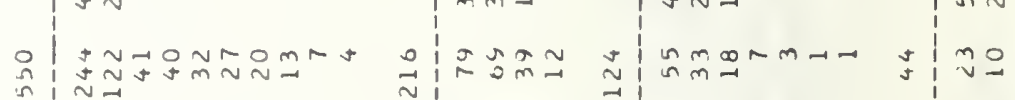

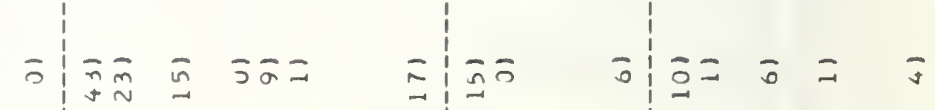

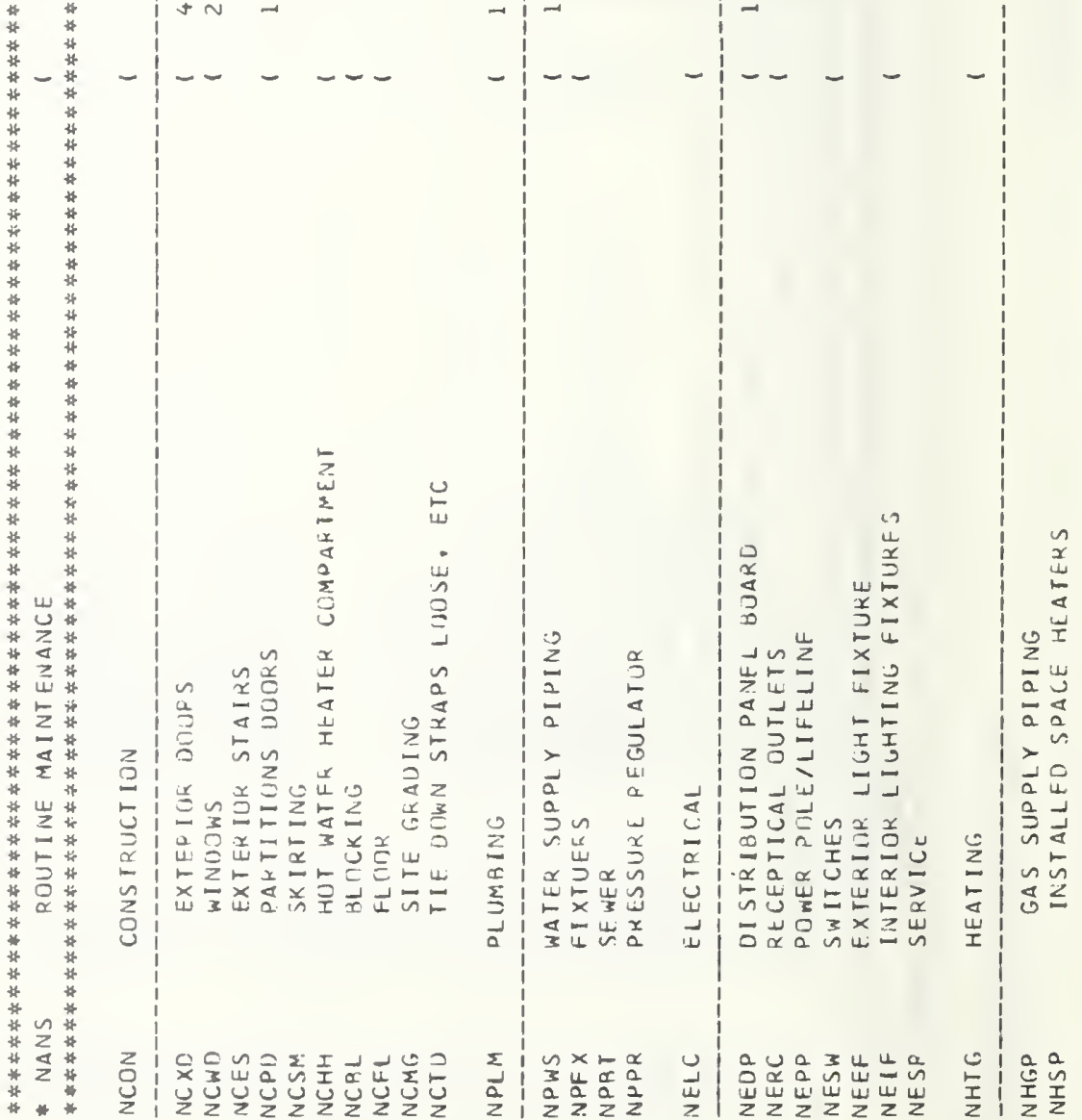




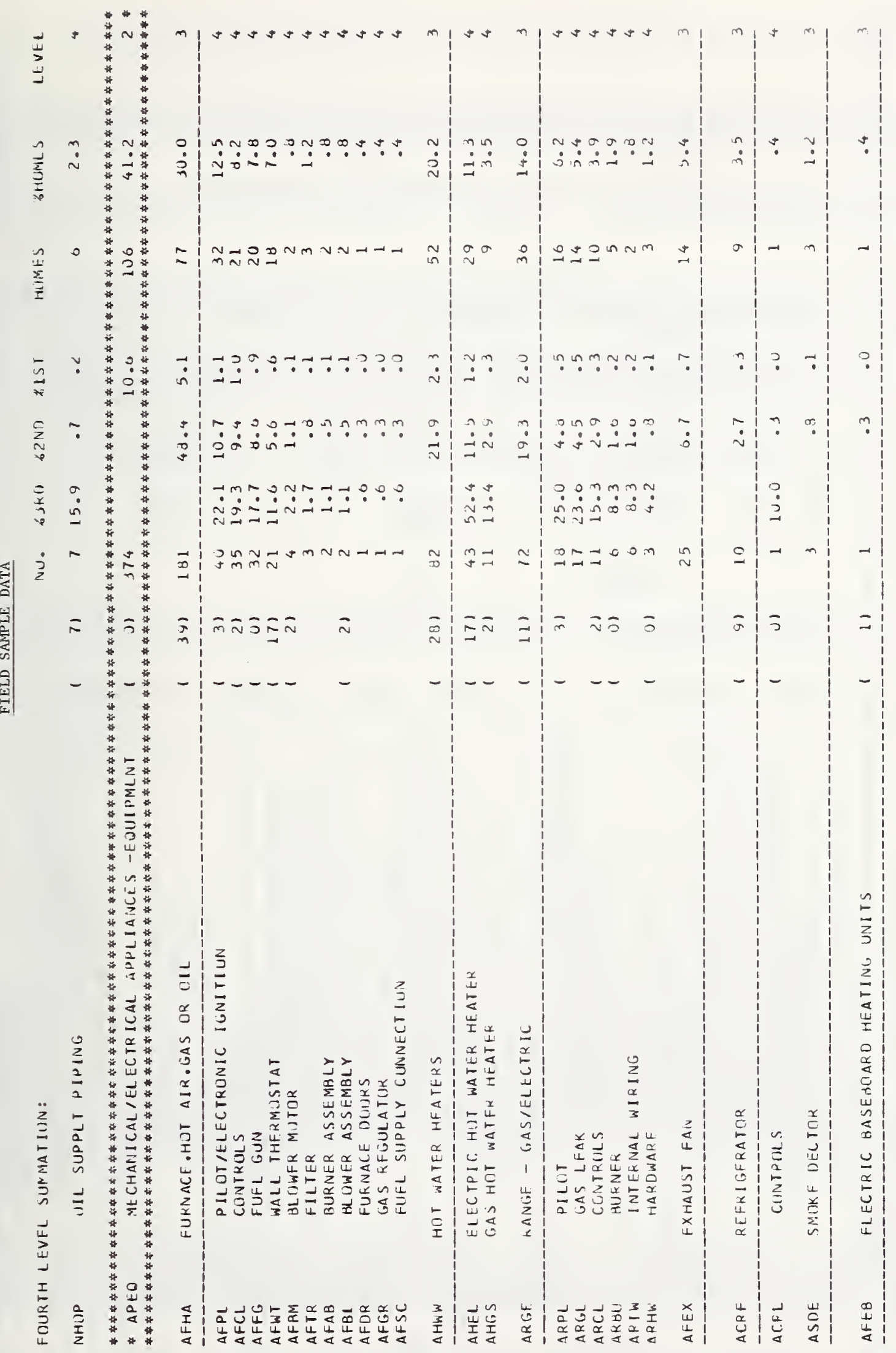




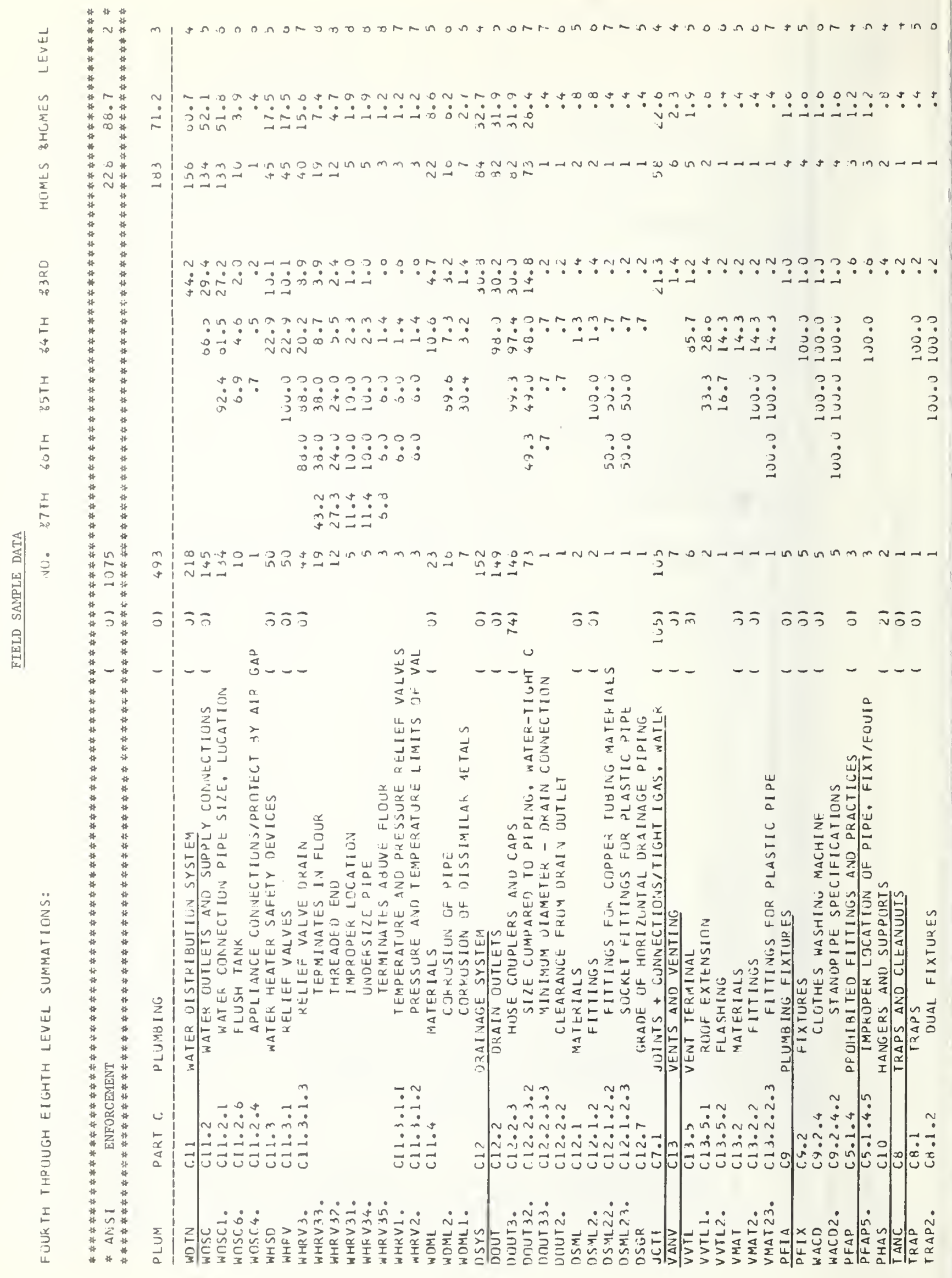




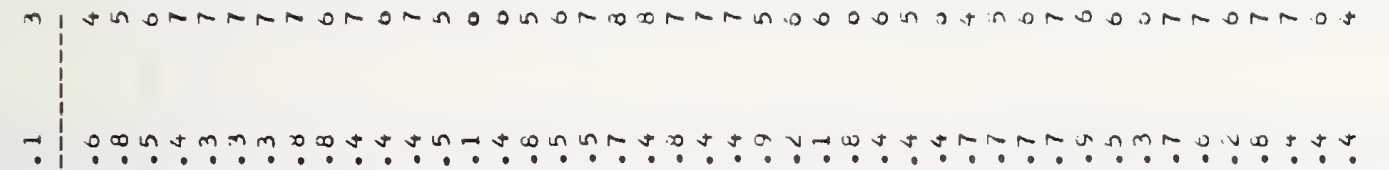

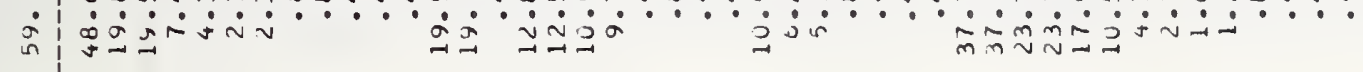

in

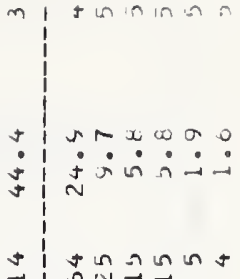

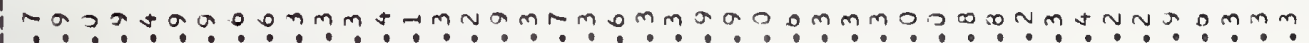

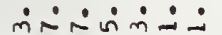
ining $\dot{0} \dot{0} \dot{0}$

$\dot{j} \dot{j}$

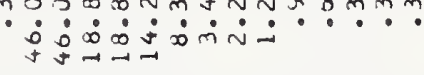

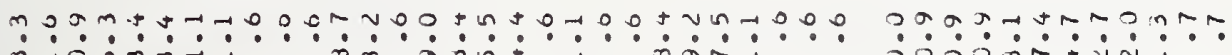

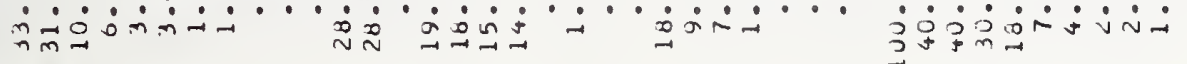

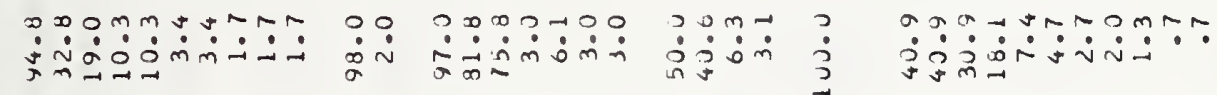

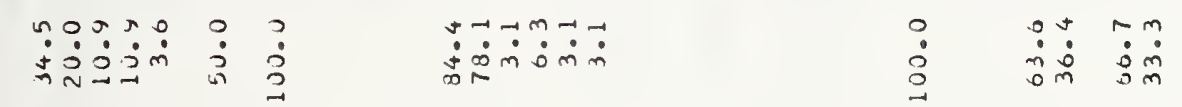

$\stackrel{0}{\dot{m}} \dot{m}$

赵|

(1)

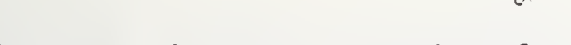

$\underset{m}{m}$

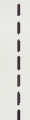

$\operatorname{lng} \rightarrow=$

5
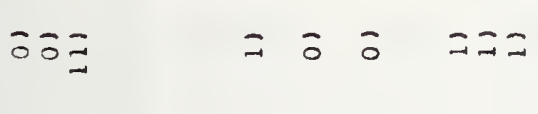

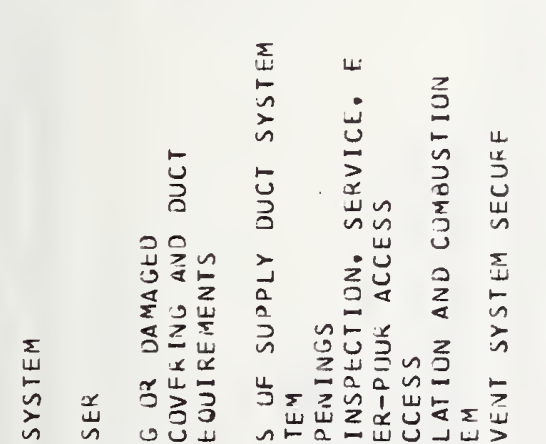

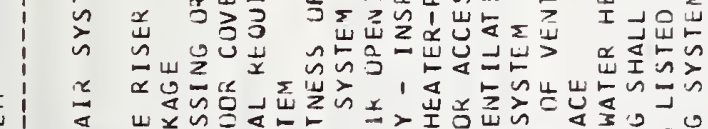

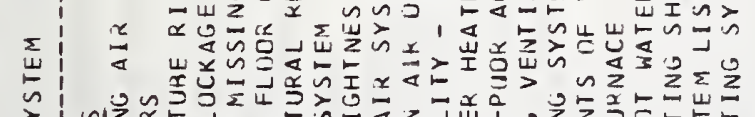

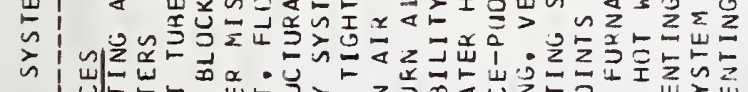

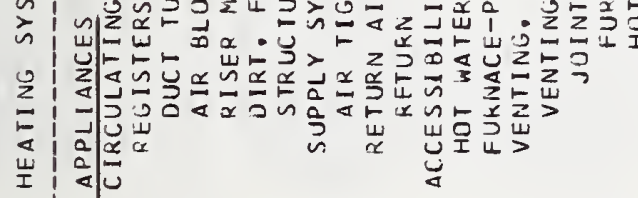

$=$

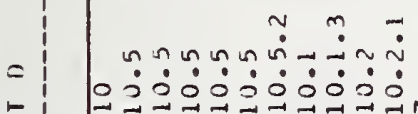

穷方焉

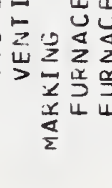

$+2$

ì:

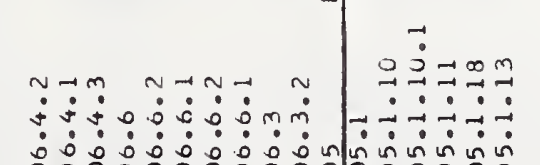

$\overline{0} 50 \overline{0}$

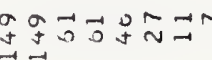

$0 \sin 20$.

$\dot{j}_{\dot{j} \rightarrow \dot{\sim} \dot{\sim}} \dot{\sim}$

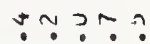

$\dot{\sim} \dot{0} \dot{0} \dot{0}$

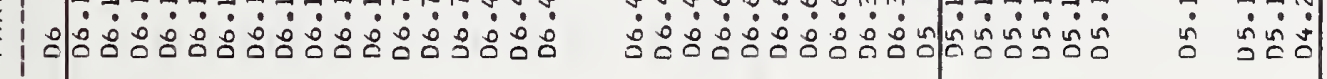

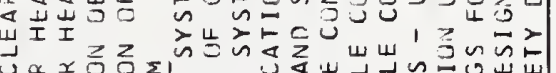

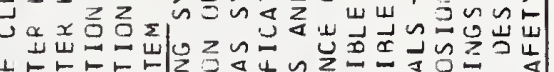

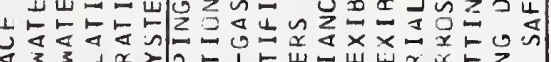
等

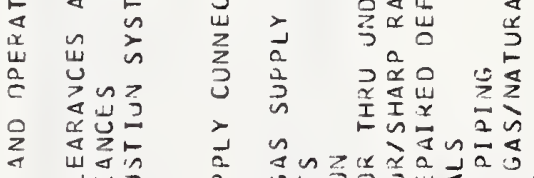

出

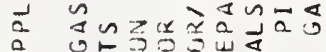

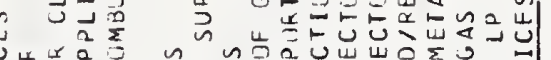

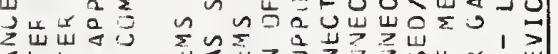

$\varangle$ 死 
t.

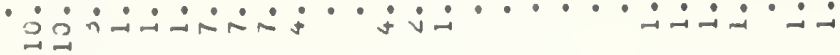

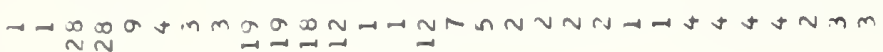

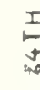

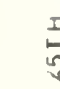$$
\frac{1}{9}
$$$$
\text { 言 }
$$$$
\text { I }
$$

赵

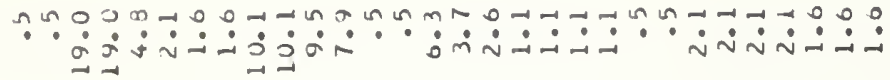

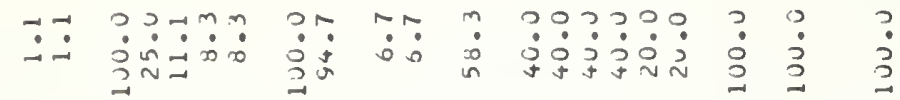

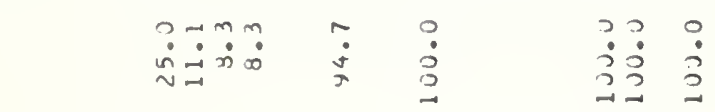

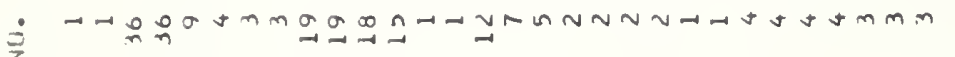

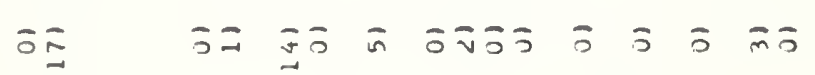

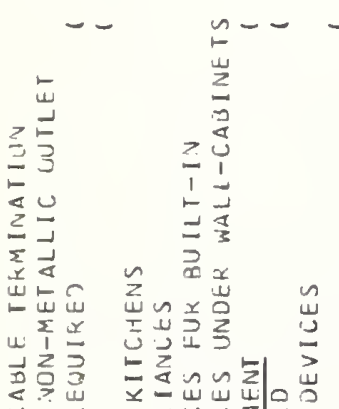

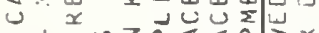

\section{$\therefore \sim \approx \backsim$ Za}

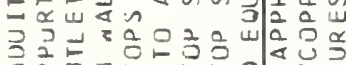
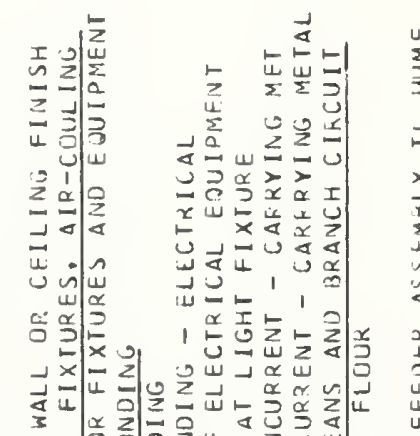

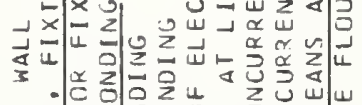

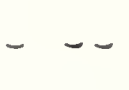

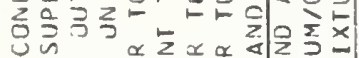

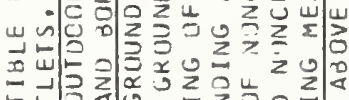

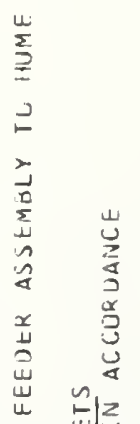

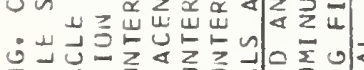

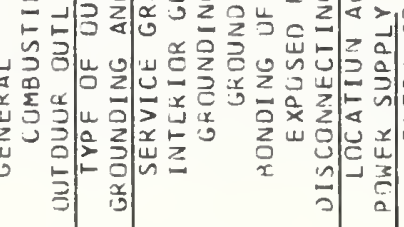

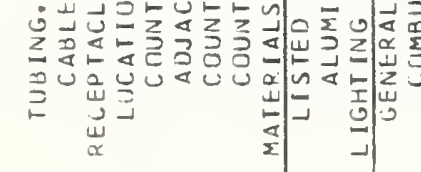

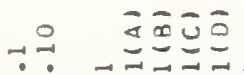

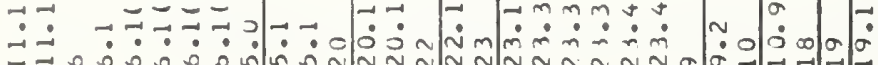

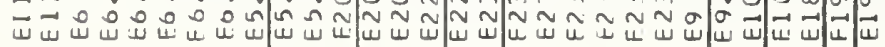
m|

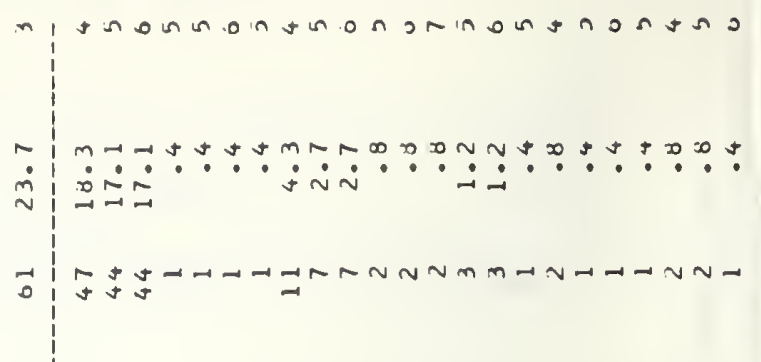

onntatam-7mmamma asta

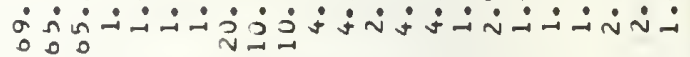

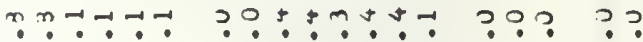

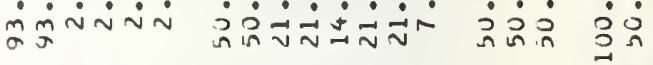

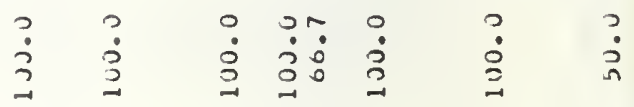

$$
\begin{aligned}
& \text {; }
\end{aligned}
$$

$0\left\{\begin{array}{l}0 \\ 0\end{array}\right.$

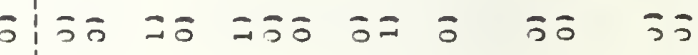

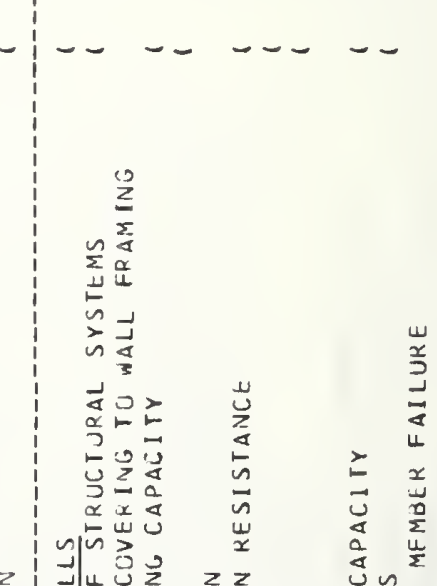

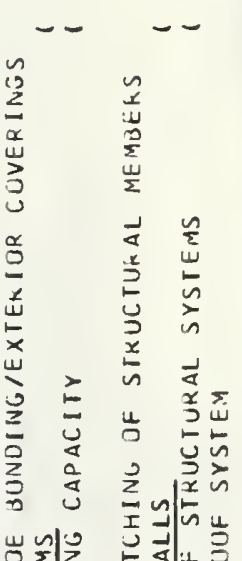

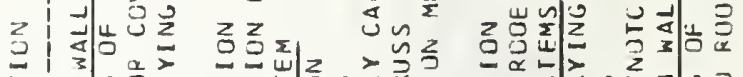
(1)

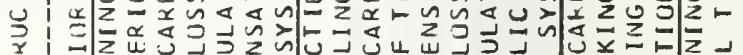
多

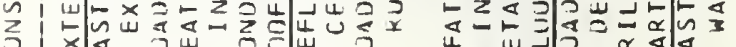

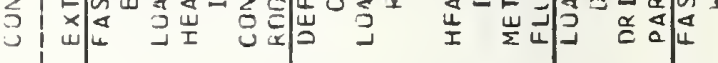
- N a 分| 


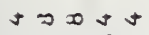

$\rightarrow \sim \sim \rightarrow$

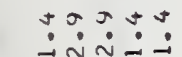

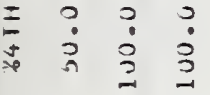

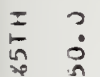

o. ?

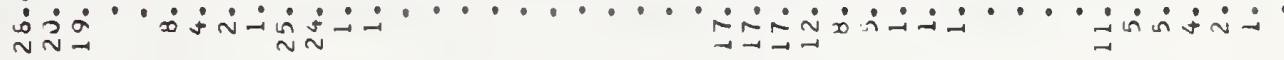

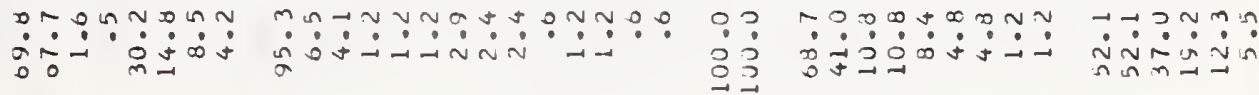

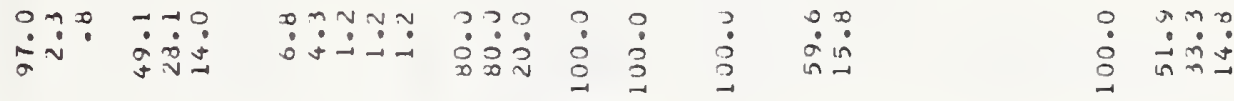

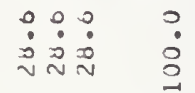

$\dot{2} \rightarrow \sim N \rightarrow-$

55

-

$\ddot{n}$

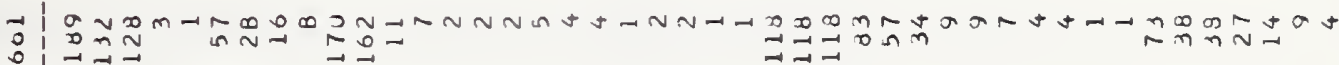

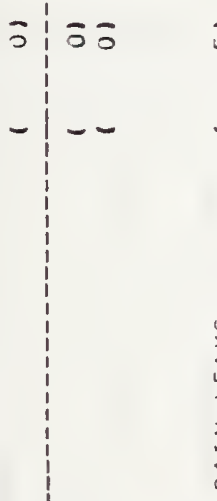

in $2 \overline{3}$

J

ニ๐う

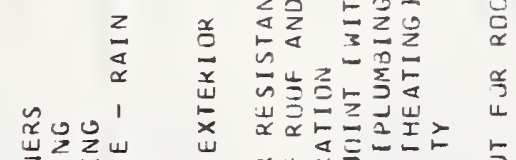

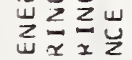

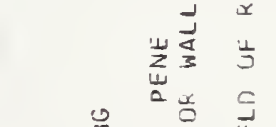

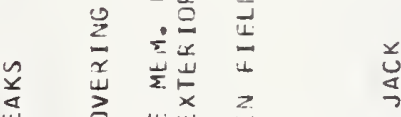

z

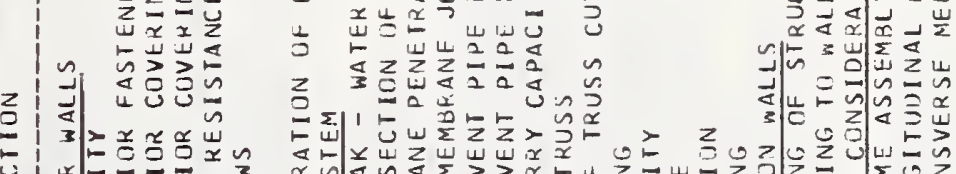

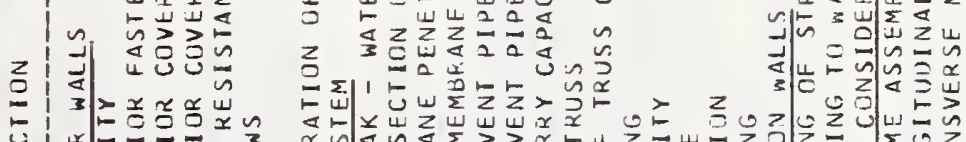

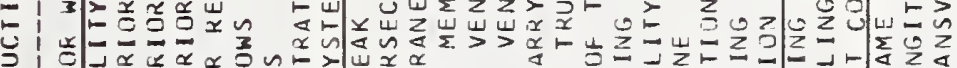
穸|

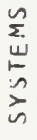

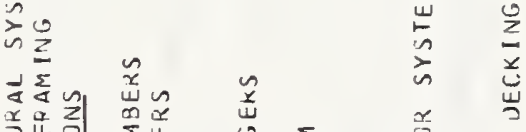

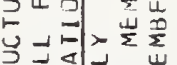




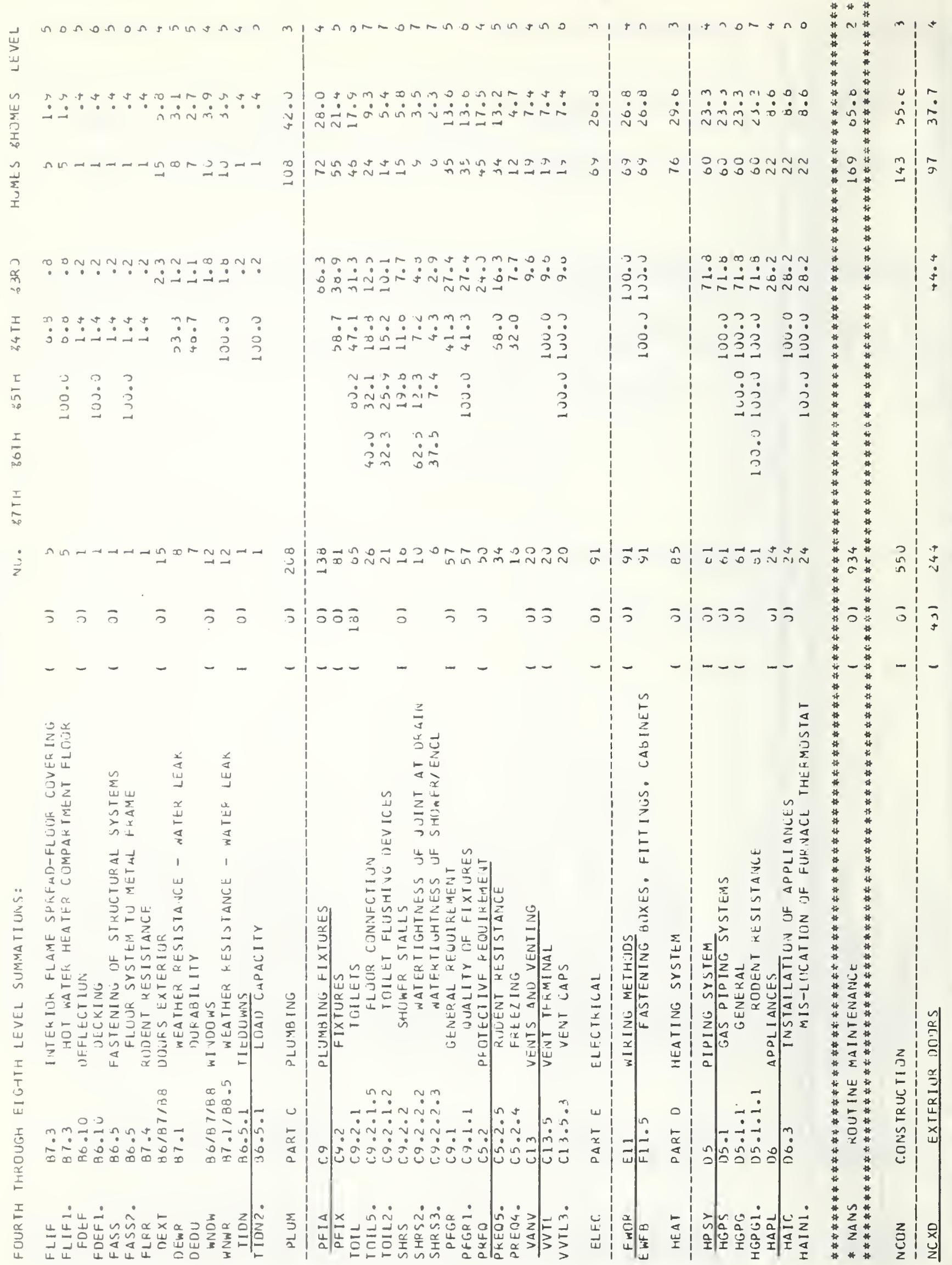


กำก ก พ

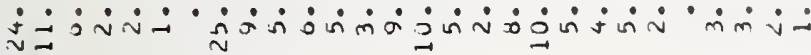

momarom

i

on

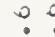

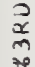

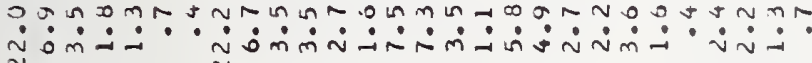

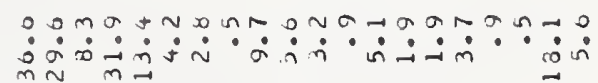

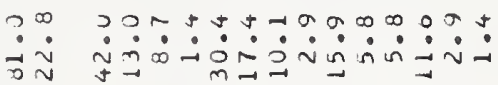

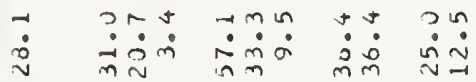

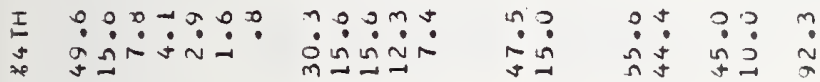

$\underset{\mathrm{I}}{\mathrm{I}}$

$\underset{I}{I}$

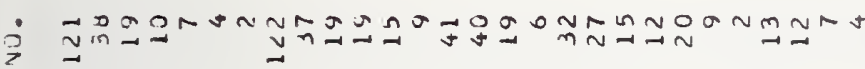

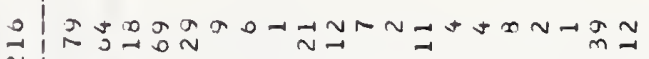

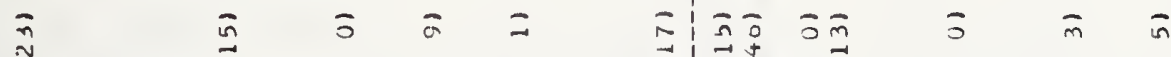

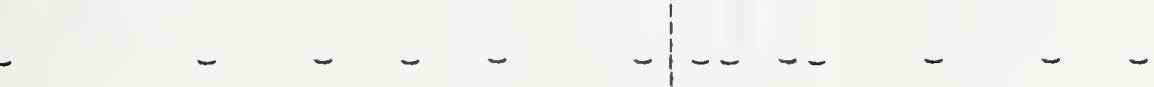

U

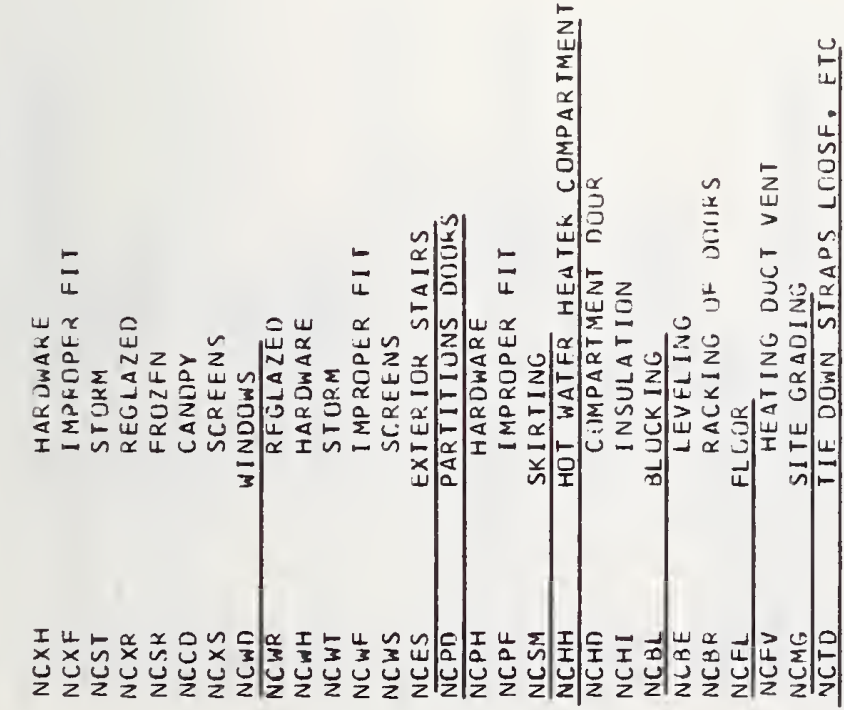

a

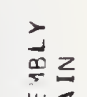

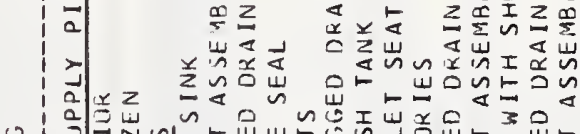

z|ที丶万人

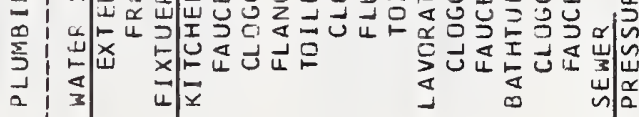



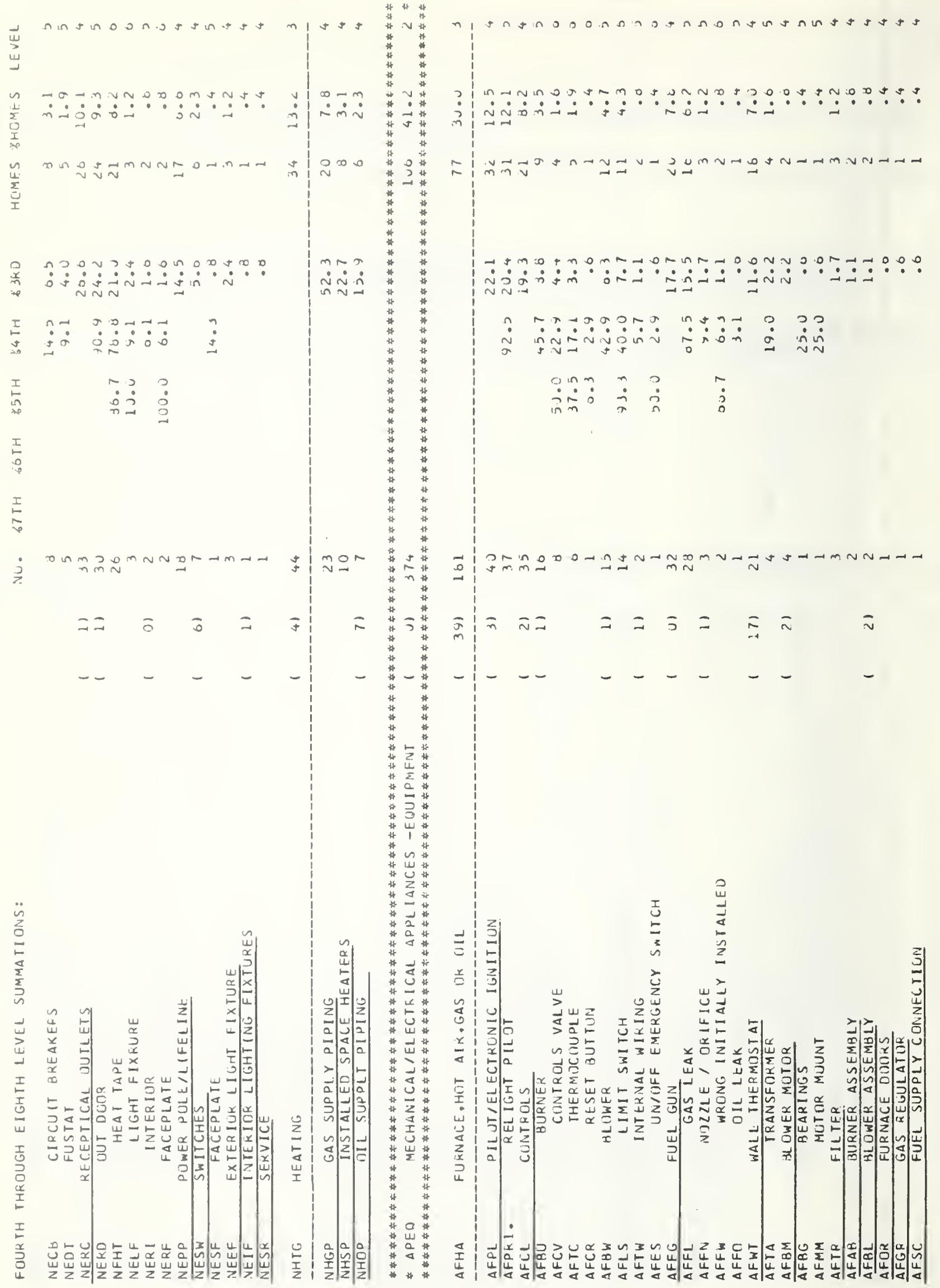


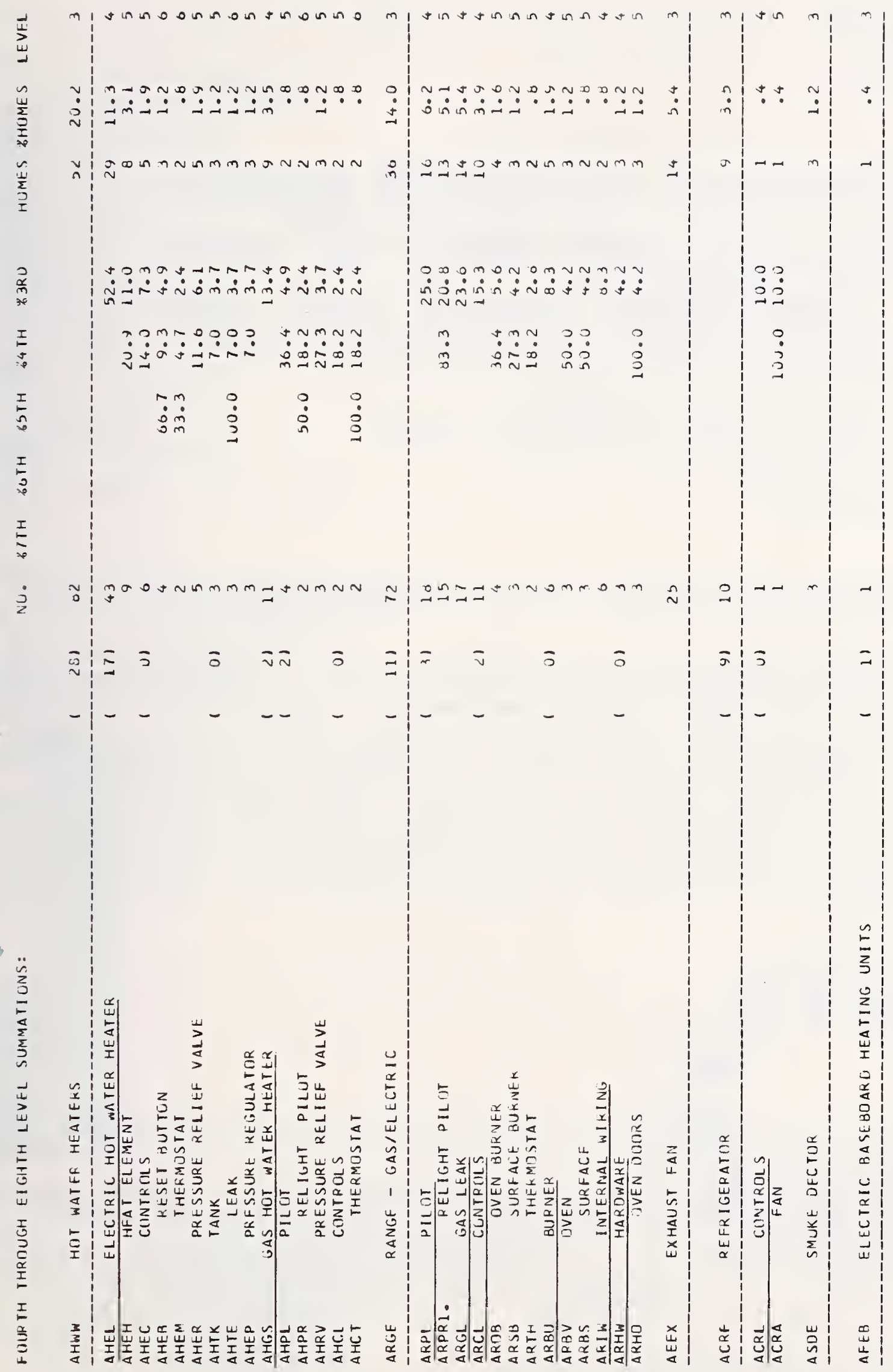


NBS-IIAA IREV. 7-73)

\begin{tabular}{|c|c|c|}
\hline $\begin{array}{l}\text { U.S. DEPT. OF COMM. } \\
\text { BIBLIOGRAPHIC DATA } \\
\text { SHEET }\end{array}$ & $\begin{array}{l}\text { 1. PUBLIC.ATION OR REIPORT NO. } \\
\text { NBSIR 76-1058 }\end{array}$ & 3. Recipient's Accession No. \\
\hline \multirow{2}{*}{\multicolumn{2}{|c|}{$\begin{array}{l}\text { 4. TITLE AND SUBTITLE } \\
\text { PERFORMANCE OF MOBILE HOMES - SUMMARY REPORT }\end{array}$}} & $\begin{array}{l}\text { 5. Publication Date } \\
\text { Apri1 } 1976\end{array}$ \\
\hline & & 6. Performing Organization Code \\
\hline $\begin{array}{l}\text { 7. AUTHOR(S) } \\
\text { J. H. Pielert, W. }\end{array}$ & Greene, Jr., L. F. Skoda, W. G. Street & 8. Performing Organ. Report No. \\
\hline \multicolumn{2}{|c|}{$\begin{array}{l}\text { 9. PERFORMING ORGANIZATION NAME AND ADDRESS } \\
\text { NATIONAL BUREAU OF STANDARDS } \\
\text { DEPARTMENT OF COMMERCE } \\
\text { WASHINGTON, D.C. } 20234\end{array}$} & 10. Project/Task/Work Unit No. \\
\hline \multirow{2}{*}{\multicolumn{2}{|c|}{$\begin{array}{l}\text { 12. Sponsoring Organization Name and Complete Address (Street, City, State, ZIP) } \\
\text { Office of Policy Development and Research } \\
\text { Division of Energy, Building Technology and Standards } \\
\text { Department of Housing and Urban Development } \\
\text { Washington, D.C. } 20410\end{array}$}} & $\begin{array}{l}\text { 13. Type of Report \& Period } \\
\text { Covered }\end{array}$ \\
\hline & & 14. Sponsoring Agency Code \\
\hline
\end{tabular}

15. SUPPLEMENTARY NOTES

16. ABSTRACT (A 200-word or less factual summary of most significant information. If document includes a significant bibliography or literature survey, mention it here.)

This project was funded at the National Bureau of Standard? $1, r$ the Department of Housing and Urban Development with the objective of documisi.!g mobile home performance problems and relating them to possible inadequacies in the ANSI Al19.1 Standard for Mobile Homes and the mobile home enforcement process. Additionally, the durability of mobile home components was a study objective for potential use in mortgage insurance evaluation. Mobile home performance data were obtained for 4,105 mobile homes, categorized and related to the project objectives. This summary report is the last of a series of four project reports. It documents the project approach, results of the various tasks, and presents conclusions and recommendations. This was a problem oriented study and did not attempt to document the many areas of satisfactory mobile home performance.

17. KEY WORDS (six to twelve entries; alphabetical order; capitalize only the first letter ol the first key word unless a proper name; separated by semicolons)

Computer Techniques; Construction; Enforcement Process; Housile; Hurricane Agnes; Mobile Homes; Mobile Home Parks; Performance Data; Regulatory I'rocess; Standards

18. AVAILABILITY $\square$ Unlimited

X. For Official Distribution. Do Not Release to NTIS

Order From Sup. of Doc., U.S. Government Printing Office Washington, D.C. 20402 , SD Cat. No. C13

Order From National Technical Information Service (NTIS) Springfield, Virginia 22151

\begin{tabular}{|l|c|}
\hline $\begin{array}{l}\text { 19. SECURITY CLASS } \\
\text { (THIS REPURT) }\end{array}$ & 21. NO. OF PAGES \\
UNCL ASSIFIED & 142 \\
\hline $\begin{array}{l}\text { 20. SECURITY CLASS } \\
\text { (THIS PAGE) } \\
\text { UNCLASSIFIED }\end{array}$ & 22. Price \\
\hline
\end{tabular}

